\title{
Robert Marzari
}

\section{Die Entwicklung}

\section{des historiographischen Stils}

im Vergleich zum literarischen

bei Lomonosov, Karamzin

und Puškin

Verlag Otto Sagner München · Berlin · Washington D.C.

Digitalisiert im Rahmen der Kooperation mit dem DFG-Projekt „Digi20“

der Bayerischen Staatsbibliothek, München. OCR-Bearbeitung und Erstellung des eBooks durch den Verlag Otto Sagner:

http://verlag.kubon-sagner.de

( $)$ bei Verlag Otto Sagner. Eine Verwertung oder Weitergabe der Texte und Abbildungen, insbesondere durch Vervielfältigung, ist ohne vorherige schriftliche Genehmigung des Verlages unzulässig. 


\title{
SLAVISTISCHE BEITRÄGE
}

\author{
Begründet von \\ Alois Schmaus \\ Herausgegeben von \\ Peter Rehder
}

\author{
Beirat: \\ Tilman Berger - Walter Breu - Johanna Renate Döring-Smirnov \\ Walter Koschmal · Ulrich Schweier · Milos Sedmidubský · Klaus Steinke
}

BAND 377

\section{VERLAG OTTO SAGNER \\ MÜNCHEN 1999}




\section{Robert Marzari}

\section{Die Entwicklung}

des historiographischen Stils im Vergleich zum literarischen bei Lomonosov, Karamzin und Puškin 
PVA

99.

\section{9}

\section{Bayerlsche} Staatsbibliethek München

ISBN 3-87690-728-4

(C) Verlag Otto Sagner, München 1999 Abteilung der Firma Kubon \& Sagner D-80328 München

Gedruckt auf alterungsbeständigem Papier 


\section{Vorwort}

Vorliegende Arbeit wurde im Sommersemester 1998 von der Neuphilologischen Fakultăt der Universităt Túbingen als Dissertation angenommen.

Mein Dank gilt Prof. Dr. Jochen Raecke, der die Arbeit betreut und gefordert hat. Als weiterem Gutachter der Arbeit habe ich Prof. Dr. Tilman Berger zu danken. Außerdem danke ich Prof. Dr. Sebastian Kempgen (Universităt Bamberg) und Prof. Dr. Reinhard Kohler (Universităt Trier) für nützliche Hinweise in bezug auf die statistischen Prufverfahren. Dank gebuhrt schließlich auch Prof. Dr. Rolf-Dieter Kluge und Prof. Dr. Vladimir B. Kataev (MGU - Moskau), durch deren Hilfe ein Forschungsaufenthat in Moskau im Herbst 1996 erfolgreich vonstatten gehen konnte.

Dem Herausgeber der Reihe 'Slavistische Linguistik', Prof. Dr. Peter Rehder, danke ich für die Aufnahme der Arbeit in die Reihe.

Tübingen, im Mărz 1999

Robert Marzari 


\section{INHALTSVERZEICHNIS}

\section{Teil A: Theoretischer Teil}

$\begin{array}{lll}1.0 & \text { Einleitung } & 13\end{array}$

$\begin{array}{lll}1.1 & \text { Untersuchungsgegenstand } & 13\end{array}$

$\begin{array}{ll}\text { 1.1.1 Untersuchungstexte } & 14\end{array}$

$\begin{array}{lll}1.2 & \text { Zum Begriff der Literatursprache } & 15\end{array}$

1.3 Abgrenzung des Untersuchungsgegenstandes 16

$\begin{array}{lll}1.4 & \text { Fragestellungen und These } & 16\end{array}$

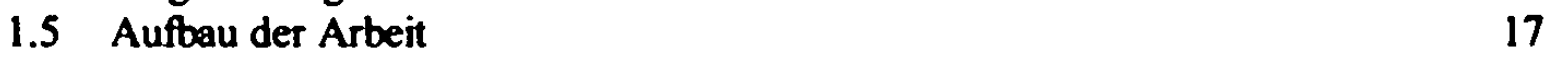

2.0 Geschichtsschreibung und Wissenschaftichkeit 20

2.1 Gliederung der Wissenschaften 20

2.2 Historische Entwicklung der Wissenschaften und der Wissenschaftssprache 20

$\begin{array}{ll}2.3 \text { Geisteswissenschaften } & 21\end{array}$

2.3.1 Differenzienung innerhalb der Geisteswissenschaften 22

2.3.2 Stellung der Geschichtswissenschaft innerhalb der Geisteswissenschaften $\quad 22$

2.4 Von der Geschichtsschreibung zur Geschichtswissenschaft 23

2.5 Die Problematik der Darstellung 25

2.5.1 Die narrative Darstellung 25

$\begin{array}{ll}2.5 .2 \text { Historie vs. Fiktion } & 26\end{array}$

2.6 Inhalt und Struktur der historischen Erzăhlung 27

2.6.1 Auswirkungen auf die Sprache der Geschichtswerke $\quad 28$

2.7 Die Funktion der Geschichtsschreibung 29

2.8 Die Sprache in der Geschichtsschreibung und der humanwissenschaftliche Stil 30

2.9 Zusammenfassung der Oberlegungen 31

3.0 Fachsprache, Funktionaktih, Stil 32

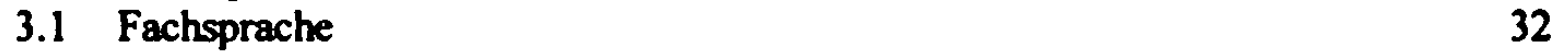

3.1.1 Zum Begriff 'Fachsprache' $\quad 32$

3.1.2 Definition(en) der Fachsprache 33

3.1.3 Phasen der Fachsprachenforschung $\quad 34$

$\begin{array}{lll}3.2 & \text { Funktionalstil } & 35\end{array}$

3.2.1 Das Funktionalitătsprinzip $\quad 36$

3.2.2 Anzahl der Funktionalstile $\quad 36$

3.2.3 Der wissenschaftiche Funktionalstil $\quad 36$

3.3 Wissenschafticher Funktionalstil und Fachsprache 37

3.4 Wissenschaftssprache $\quad 40$

3.4.1 Gibt es einen humanwissenschaftlichen Stil ?

3.4.2 Zum Konzept der Wissenschaftssprache

3.5 Genre, Textsorte $\quad 41$

$\begin{array}{ll}\text { 3.5.1 Textsorten } & 43\end{array}$

3.6 Die Problematik des Begriffs 'Stil'

3.7 Zusammenfassung der Überlegungen 46 
4.0 Zur Auswabl der Autoren und Werke 48

4.1 Zu Lomonosov 49

4.1.1 Lomonosovs Geschichtswerk Древняя Российская история 50

4.1.2 Edition 51

4.1.3 Editionsănderungen 51

4.1.4 Bedeutung des Geschichtswerkes $\quad 52$

4.2 Zu Karamzin $\quad 52$

4.2.1 Karamzins Geschichtswerk История zocydapcrвa Poccuйскоzo

4.2.2 Edition $\quad 55$

4.2.3 Editionsănderungen $\quad 55$

4.2.4 Bedeutung des Geschichtswerkes $\quad 56$

4.2.5 Karamzins literarisches Werk Бедная Лиза

4.2.6 Edition $\quad 56$

4.2.7 Editionsănderungen $\quad 57$

4.2.8 Bedeutung der Беднas Juзa

4.3 Zu Puskin 58

4.3.1 Puskins Geschichtswerk История Пугачева

4.3.2 Edition $\quad 59$

4.3.3 Editionsănderungen $\quad 59$

4.3.4 Bedeutung des Geschichtswerkes $\quad 60$

4.3.5 Puskins literarisches Werk Капитанская Дочка

$\begin{array}{ll}\text { 4.3.6 Edition } & 60\end{array}$

4.3.7 Editionsănderungen $\quad 60$

4.3.8 Bedeutung der Капитанская Дочка 61

4.4 Zusammenfassung der Oberlegungen $\quad 61$

5.0 Methodologische Voribberlegungen 63

5.1 Methodisches Konzept zur Satzbauanalyse 63

5.2 Methodisches Konzept zur statistischen Analyse 65

5.3 Eingrenzung des Untersuchungsgegenstandes 67

$\begin{array}{ll}\text { 5.3.1 Begrenzung der Untersuchungsebene } & 67\end{array}$

$\begin{array}{ll}\text { 5.3.2 Begrenzung der Parameter } & 68\end{array}$

5.3.3 Begrenzang der Untersuchungseinheit $\quad 71$

$\begin{array}{ll}\text { 5.3.4 Begrenzung auf narrative Prosa } & 72\end{array}$

5.3.5 Begrenzung des Stichprobenumfangs

5.3.6 Zur Auswahl der Untersuchungseinheiten $\quad 74$

5.4 Methodische Grundlagen des Vergleichs und Bedeutung der Zahlenwerte 75

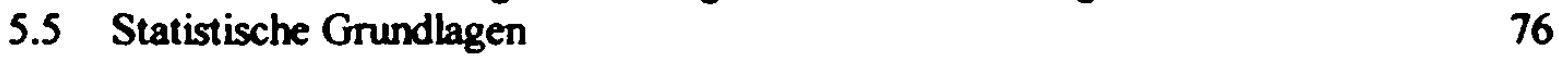

$\begin{array}{ll}\text { 5.5.1 Beschreibende Statistik } & 76\end{array}$

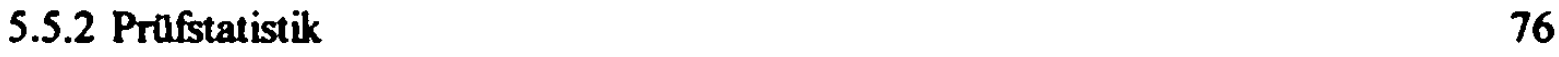

5.5.3 Zu den Vergleichswerten (Mittelwerten) 78

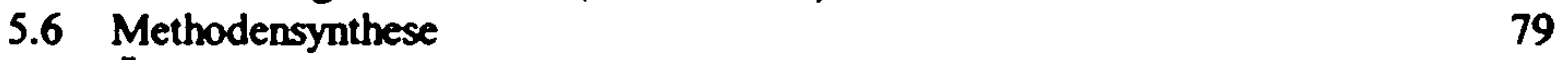

5.7 Obersicht Uber die Untersuchungseinheiten 80 


\section{Teil B: Untersuchung}

a) Parameter Satzlänge

Definitionen und Untersuchungsschritte

Darstellung der Untersuchungsergebnisse

Vergleichende Gegenuberstellung der Ergebnisse $\quad 101$

Bewertung des Parameters

b) Parameter Satzkomplexităt

Definitionen und Untersuchungsschritte

Darstellung der Untersuchungsergebnisse

$\begin{array}{ll}\text { Vergleichende Gegenaberstellung der Ergebnisse } & 124\end{array}$

Bewertung des Parameters

c) Parameter 'logische' Satzordnung

Definitionen und Untersuchungsschritte

Darstelhung der Untersuchungsergebnisse

130

Vergleichende Gegenaberstellung der Ergebnisse

134

Bewertung des Parameters

d) Parameter Prădikativităt

Definitionen und Untersuchungsschritte

Pradikativităt als Wortartenverteihung

Bewertung des Parameters

Beschreibende Darstellung

a) zu den wiederholten Satzbaustrukturen $\quad 145$

I Geschichtswerke

II Dichterische Werke

152

b) zu den vereinzelt vorkommenden Satzbaustrukturen $\quad 156$

$\begin{array}{ll}\text { 1) Spannungsbogen } & 156\end{array}$

2) Parallelismus $\quad 158$

3) Hăufung (Satzgliedreihe) 161

4) Rhetorische Konstruktionen bei Lomonosov 162

5) Langster Satz 162

6) Korzester Satz 165

Teil C: Engebnisse und Interpretation

Synopsis Parameter a

Synopsis Parameter b

Synopsis Parameter c

Synopsis Parameter d

Beantwortung der Fragestellungen und Interpretation 
Literaturverzeichnis

Primărliteratur (Untersuchungstexte)

Sekundarliteratur

\section{Aahang:}

zu Parameter a: Verteihung der Satzlängen nach geschlossenen und gleich großen Klassen

zu Parameter b: Art der Nebensätze

188

zu Parameter d: Wortartenanteil der Nomina

194 


\section{Teil A:}

\section{Theoretischer Teil}



at on (1)

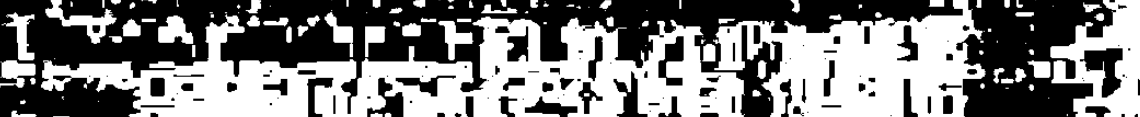
17 atis th. atris

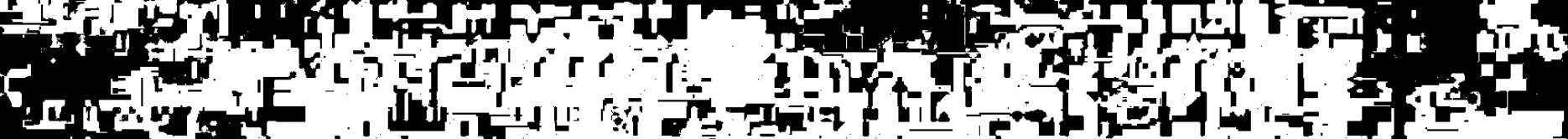

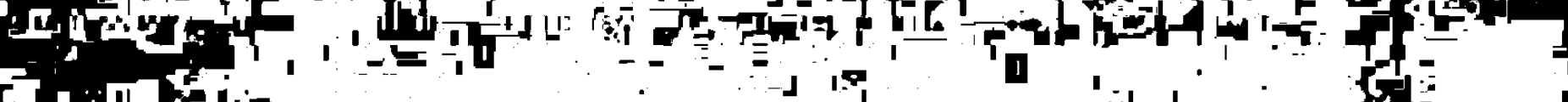

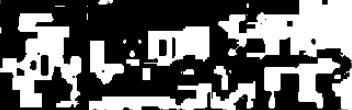
entrits

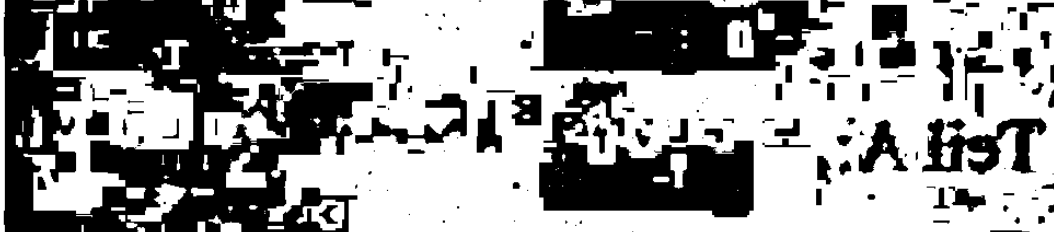
ind

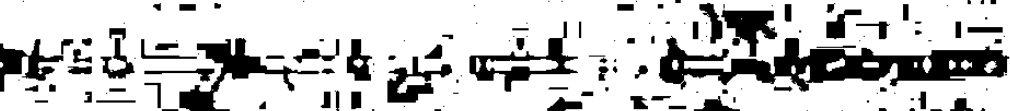
1) 它

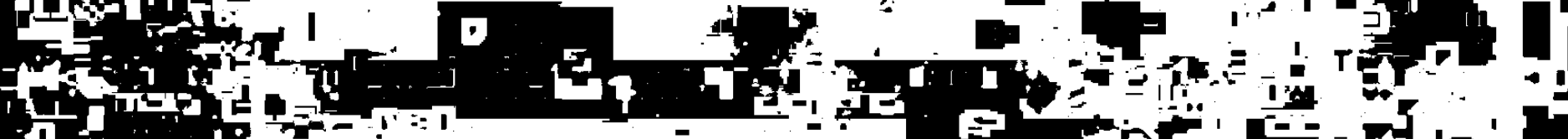

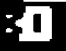
11 Po

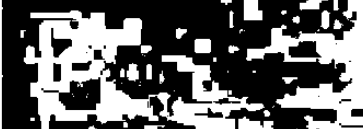

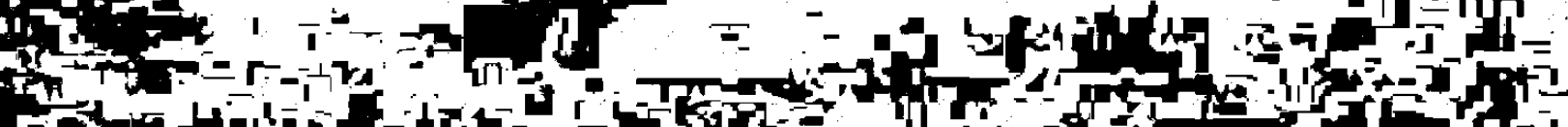
$2 y_{1}^{2}$

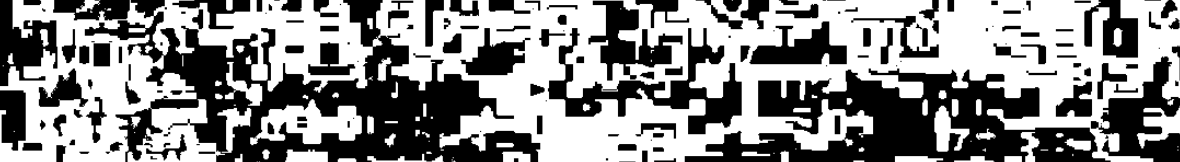
r

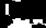

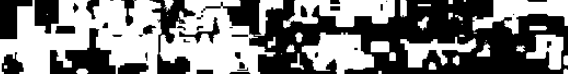

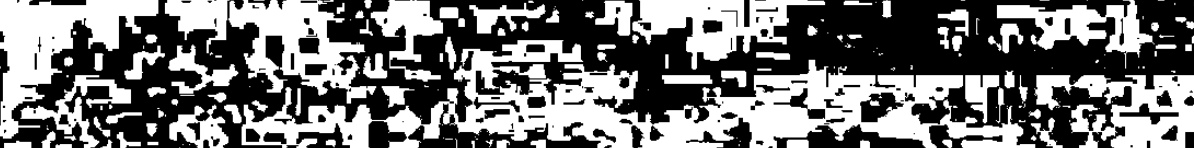

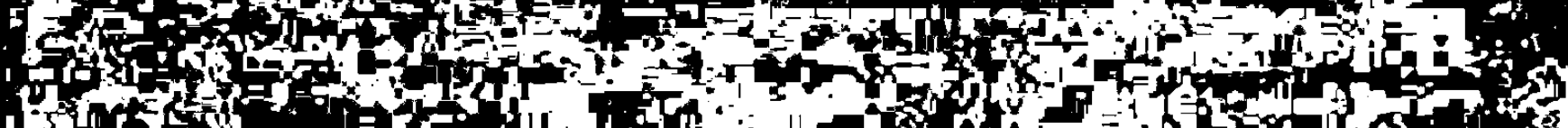

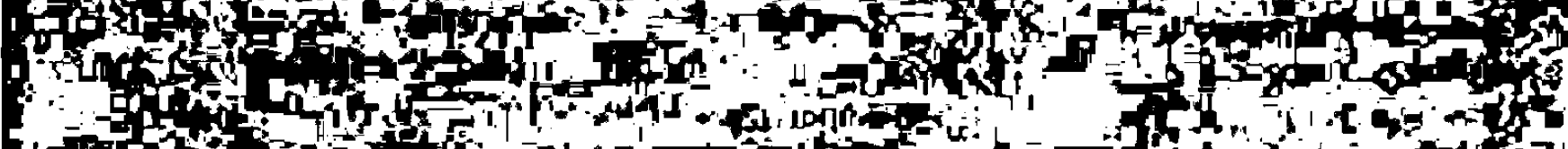
.

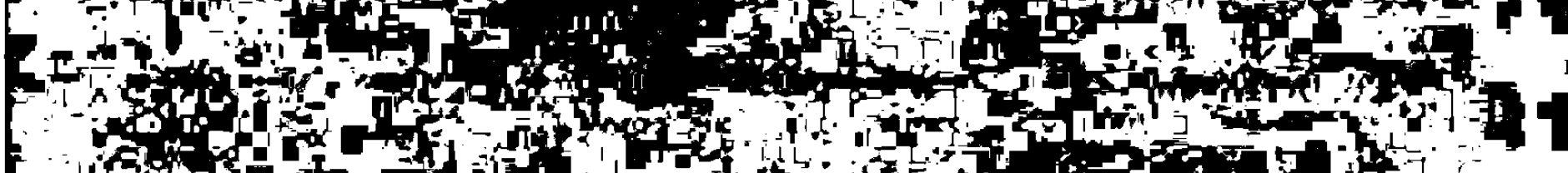

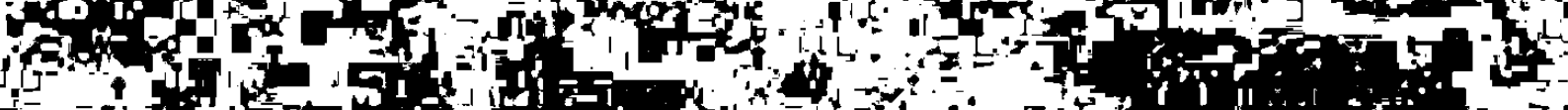

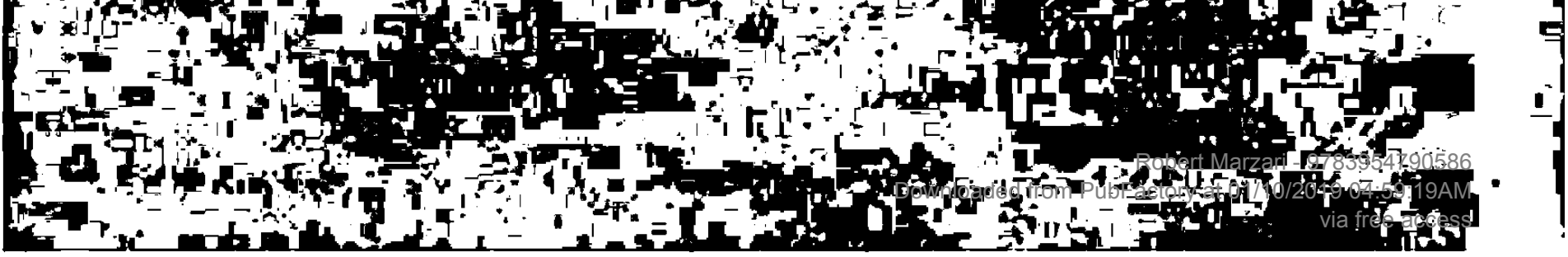




\subsection{Einleitung}

\subsection{Untersuchungsgegenstand}

Nach allgemeiner Auffassung spielt das 18. Jahrhundert eine wesentliche Rolle in der Entwicklung der russischen Literatursprache. Schon zu Anfang des 18. Jahrhunderts in der Petrinischen Zeit wurde die russische Sprache riesigen Verănderungen unterworfen. Vor allem der Wortschatz erfuhr eine explosionsartige Expansion. Ob es sich dabei um einen 'Bruch' mit dem vorherigen Sprachzustand handekt, ist wohl eher Interpretationssache; fest steht lediglich, daß aus dem Zusammenfließen von kirchenslavischem und russischem Wortmaterial (also Wurzeln und Ableitungsmustern) ein neues Amalgam entstand. Dieses Amalgam war um ein vielfaches umfangreicher und funktionsfahiger als der bisherige altkirchenslavische Wortschatz, der sich doch in erster Linie auf die Liturgie bezog, und als der bisherige russische volkssprachliche Wortschatz, der vor aliem die altăglichen Lebensbereiche abdeckte. Wesentlich bedingt wurde der Ausbau des Wortschatzes durch den riesigen Benennungsbedarf und die Erfordernisse der Fachsprachen. die aufgrund der sturmischen Entwicklung der Naturwissenschaften und durch die beginnende Industrialisierung im 17. und 18. Jahrhundert auch neue Ausdrucksmittel terminologischer Art erforderten. Auch die Syntax wurde in den naturwissenschaflichen Sprachen funktionsfahig ausgebaut, nicht zuletza deshalb, weil die Themen in der Technik und in den Naturwissenschaften klar und konkret faßbar waren '.

\footnotetext{
'Der Bereich des Wortschatzes ist sprachwissenschaftich gesehen sehr gut und umfassend beschrieben; als grundlegende Arbeiten sind BIRŽAKOVA (1972), HOTTLWORTH (1956), KIPARSKY (1975), KUTINA (1964) und (1966), OTTEN (1985), SOROKIN (1966) anzusehen. Das Gebiet der Syntax wird auch immer weiter ausgelotet; als Beispiel diene die neueste Veröffentlichung von HOTTL-FOLTER (1996), die sich besonders dadurch auszeichnet, daß sie versucht, die untersuchten Phănomene quantitativ zu erfassen und anschaulich in Tabellen darzustellen. Weniger dagegen wurden bisher die Verănderungen im Satzbau beschrieben, vor allem triff man hier meist auf intuitive und verallgemeinemde Aussagen.

Zu den Begriffen 'Syntax' und 'Satzbau': in der vorliegenden Arbeit sollen die beiden Begriffe voneinander geschieden werden. Gemeinhin schließt der Begriff 'Syntax' meist den Satzbau ein, ohne daß dies explizit erwăhnt wird. Wir folgen hier RAECKE (1994, 239 ff.), der den Begriff 'Syntax' streng auf die durch Kasusbeziehung erzeugte Abhăngigkeiten innerhalb des Satzes verstanden haben will; demzufolge kann die Syntax nicht von einzelnen Autoren verändert werden, weil sie das System betrifft. Der Begriff 'Satzbau' hingegen faßt dann die vom Autor individuell veränderlichen Relationen innerhalb des einzelnen Satzes wie auch zwischen den Sătzen (vgl. dazu SEITZ 1998, 56 ff.).
} 
In der Technik und in den Naturwissenschaften (also in der Sachprosa) war die russische Sprache bereits mit Lomonosov dem Stand der damaligen Zeit entsprechend funktionsfahig, wohingegen sie in der dichterischen Prosa gemeinhin erst mit Puskin als voll funktionsfahig angesehen wird. Die Entwicklung der Sachprosa ging der der dichterischen Prosa voraus. Die Prosa als Ganzes hatte lange mit ihrem 'proletarischen' Ursprung zu kămpfen. Wohl aufgrund dieses proletarischen Makels und der erst langsam einsetzenden Emanzipierung der dichterischen Prosa von der Verskunst, aber auch von der Sachprosa wurde in der Sprach- und Literaturwissenschaft vorwiegend die Entwicklung der dichterischen Prosa verfolgt. Laßt man sich aber nur von der Entwicklung der schonen Literatur einnehmen, ist man doch erstaunt, wenn Puskin am Anfang des 19. Jahrhunderts plotzlich eine 'metaphysische Sprache' fordert, denn allgemein gih Puskin doch als Vollender; wie kommt es, daß er nun einen Mangel konstatiert ? Grund fur dieses Erstaunen ist die allgemein verbreitete Fixierung auf die schone Literatur. Viel zu sehr wird allein sie als Maßstab fur die Entwicklung der Literatursprache angesehen, und viel zu wenig wird auf die Sachprosa geachtet. Deshalb tut eine Untersuchung not, in der die Sachprosa nicht nur neben der dichterischen Prosa betrachtet, sondern als Grundlage und Ausgangspunkt genommen wird. Erst gegen den Hintergrund der Sachprosa kann die dichterische Prosa in der richtigen Perspektive gesehen werden.

\subsubsection{Untersuchungstexte}

Wir wăhlen folgende Werke aus, um sowohl die Entwicklung der dichterischen Prosa als auch der Sachprosa bei den drei Autoren Lomonosov, Karamzin und Puskin verfolgen zu können. Als Vertreter der Sachprosa eignen sich am besten Geschichtswerke, da jeder der Autoren in dieser Gattung schrieb. Die dichterische Prosa fallt zwar bei Lomonosov aus, doch ist er der fruhestmögliche Kandidat für die Sachprosa:

Geschichtswerke

Lomonosov

"Древняя Российская история"

Karamzin

"Ксторня государства Российского"

Puskin

"Ксторня Путачева" dichterische Werke

\author{
Karamzin \\ "Бедная Лиза" \\ Puskin \\ "Капитанская Дочка"
}


Diese drei Autoren sind maßgeblich an der Ausarbeitung der russischen Prosa und damit der modernen russischen Literatursprache beteiligt, wenngleich das Verdienst Karamzins und Puskins oft nur auf dem Gebiet der dichterischen Prosa gesehen wird.

\subsection{Zum Begriff der Literatursprache}

Unter 1.1 wurde der Begriff 'Literatursprache' verwendet. Obwohl der Begriff seit geraumer Zeit verwendet wird, ist er im Grunde genommen doch nur recht vage bestimmt. Selbst die vier Kriterien von ISAČENKO $(1958,42)$ :
1) polyvalent
2) normient
3) allgemeinverbindlich
4) stilistisch differenziert

schaffen zwar eine bemerkenswerte Konkretisierung des Begriffs, doch die Kriterien selbst sind nicht genauer definiert ${ }^{2}$. Überhaupt herrscht hier, wie RAECKE in verschiedenen Aufsătzen $(1992,1993)$ aufgezeigt hat, viel zu sehr Intuition vor. Bei dem Versuch einer genaueren Definition fuhrt RAECKE $(1997,222)$ den Begriff der 'Literatursprachlichkeit' ein:

Wichtig in Bezug auf den Begriff Literatursprachlichkeit ist nun, daß er bislang ein weitgehend intuitives Wissen beinhahtet, dergestaht, daß zwar in den meisten Făllen ohne Schwierigkeiten gesagt werden kann, $o b$ resp. daß ein Text literatursprachliche Qualităt besitzt oder nicht, daß es aber erhebliche Schwierigkeiten bereitet, klar und bestimmt zu sagen, worin diese eigentlich ihren Ausdruck findet. $\mathrm{DaB}$ sie ihren Ausdruck allerdings auch wirklich im Text selber finden muß, ergibt sich daraus, daß sie ohne einen solchen Ausdruck uberhaupt nicht erkannt werden konnte.

${ }^{2}$ Vgl. hiera REHDER (1995, 355): „Eine genaue Untersuchung und allgemeine Definition dieser vier Begriffe fur sich ist uber die bekannten allgemeinen und grundlegenden Formulienungen hinaus $\mathrm{m}$. W. nicht versucht worden $[. . .]^{\text {s". }}$.

Außerdem sind die Kriterien nicht klar gegeneinander abgegrenzt: wie KEIPERT $(1984,451)$ richtig bemerkt, stellt die stilistische Differenziertheit das 'innersprachliche Korrelat' zu der Polyvalenz dar, d.h. stilistische Differenziertheit beschreibt die Art und Weise wie Polyvalenz erreicht wird; und auch die allgemeine Verbindlichkeit setzt zuerst einmal die Norm voraus. Die vier Kriterien lassen sich also auf zwei reduzieren, die als 'Norm' und 'Ausbau' bezeichnet werden konnten; oder als 'Stabilităt' und 'Flexibilităt', wie REHDER (1995, 355 f.) in seinem soziolinguistischen Strukturmodell vorschlagt:

\begin{tabular}{|l|l|l|}
\hline Sprachliche Seite & gesellschaftliche Seite & \\
\hline Normiertheit (N) & Obligatheit (O) & Stabilităt \\
\hline Differenziertheit (D) & Polyvalenz (P) & Flexibilităt \\
\hline
\end{tabular}


Dies ist vor allem deshalb so wichtig, weil - wie schon angedeutet - die Literatursprachlichkeit von Texten die notwendige Voraussetzung für eine Aussage Uber die mogliche Existenz einer Literatursprache ist.

Dementsprechend geht auch die vorliegende Untersuchung von konkreten Texten aus in der gleichen Erkenntnis, daß sich nur im Text etwaige Strukturen einer Literatursprachlichkeit manifestieren kơnnen. Anstelle eines Versuches, die Erfullung der vier Kriterien von ISAČENKO festzustellen, sollen also konkrete Strukturen anhand von genau festgestellten Verteilungen aufgezeigt werden. Da trotz dieses neuen Ansatzes eine endgaltige Definition der Kriterien der Literatursprache noch aussteht ${ }^{3}$, wird in der Arbeit weitgehend auf den Begriff 'Literatursprache' verzichtet und stattdessen mit dem Begriff 'Prosa' als Sammelbegriff für die bereits erwăhnte Sachprosa und dichterische Prosa (bezichungsweise als Sammelbegriff fur den historiographischen und literarischen Stil) gearbeitet.

\subsection{Abgrenzung des Untersuchungagegenstandes}

Beantwortet werden kann nicht, da es sich ausschlieBlich um geschriebene Texte handelt, das Verhăltnis von Mündlichkeit und Schriftichkeit ` . Anstelle dieser Einordnung mußte eine andere Einteilung innerhalb der Schriflichkeit gefunden werden. Hilfreich erschien die Einteilung in Fachsprachlichkeit und nicht-Fachsprachlichkeit, die der Einteilung in Sachprosa und dichterischer Prosa entspricht und die den Vorteil mit sich bringt, daB auf die Ansatze und Ergebnisse der Fachsprachenforschung zuruckgegriffen werden kann.

\subsection{Fragestelluagen und These}

Zunachst werden in der Untersuchung folgende zwei Fragestellungen bearbeitet:

I Wie verläuft die Entwicklung des "historiographischen Stils's bei den drei Autoren?

\footnotetext{
${ }^{3}$ Wir stimmen hier mit REHDER $(1995,356)$ aberein, der für jedes einzelne der vier Kriterien eine genaue Definition fordert.

"Hier sei auf die Untersuchungen von RAECKE (1989, 1990, 1997) hingewiesen, in der die Problematik von Mündlichkeit und Schriftlichkeit u.a. in Texten von Cochov, Suksin, Puskin, Avvakum erhelt wird.

${ }^{5}$ Unter 'historiographischer Stil' wird nur der Stil der drei historiographischen Werke zusammengefaßt, um umständliche Formulierungen wie 'der Stil in dem Geschichtswerk von Lomonosov/ Karamzin / Puskin' bzw. 'der Stil in den Geschichtswerken' zu vermeiden; das gleiche gitt fur die Bezeichnung 'literarischer Stil'. Nicht aber soll damit sprachliche Einheitlichkeit, weder in bezug auf unsere vier Parameter noch in bezug auf andere stilistische Phanomene, stillschweigend angenommen werden. (Vgl. hierzu die hypothetische Ansetzung einer 'Fachsprache der Historiographie' auf S.39.)
} 
II Gibt es eine Entwicklung des 'literarischen Stils' von Karamzin zu Puskin ?

Auf der Grundlage der Ergebnisse zu diesen Fragestellungen kann dann die zentrale These der Arbeit geprüft werden:

These: Erst Puškin war imstande, die Sachprosa und die dichterische Prosa mit einem gemeinsamen Stil zu bewaltigen.

(Die Gegenthese würde besagen, daß es bereits Karamzin gelang, die Sachprosa und die dichterische Prosa mit einem gemeinsamen Stil zu bewătigen.)

\subsection{Aufbau der Arbeit}

Die Arbeit ist in drei Teile gegliedert: in den theoretischen Teil, den Untersuchungsteil und den Interpretationsteil. Der theoretische Teil weist vier Kapitel auf: in den ersten drei werden die Untersuchungstexte unter verschiedenen Gesichtspunkten eingeordnet; im letzten Kapitel des theoretischen Teils wird versucht, die Methodik der Untersuchung vorzustellen und zu begründen.

Die zu untersuchenden Texte werden tentativ zwei Textsorten zugeordnet: der Textsorte 'historiographische Texte' und der Textsorte 'literarische Texte'. Um sich über die moglichen Eigenschaften und Charakteristik dieser Textsorten klar zu werden, wird in Kapitel 2 die Problematik der Historiographie und in Kapitel 3 das Konzept der Fachsprache skizziert, denn es steht zu vermuten, daß der Inhalt bzw. die Thematik der Textsorte Einfluß nimmt auf deren sprachliche Strukturienung. Wichtig fur die theoretische Einbettung der historiographischen Texte scheint auch die Heranziehung des Konzepts des Funktionalstils. Mit der Einführung dieses Konzepts soll der Brückenschlag von den konkreten Texten zu dem Begriff des 'Stils' gemacht werden, wobei auch versucht wird, den Stilbegriff so einzugrenzen, daß er für die Untersuchung arbeitsfahig wird.

Nach dieser Einordnung der Texte werden sie in Kapitel 4 noch den Autoren zageordnet; dabei soll nicht nur die Entstehung der Werke beleuchtet, sondern auch etwaige programmatische Vorhaben der Autoren erwăhnt werden, die Einfluß auf die sprachliche Gestaltung nehmen konnten. Diese programmatischen Äußerungen konnen zugegebenermaßen vorerst nur intuitiv erfaßt werden, in der Untersuchung soll aber anschließend versucht werden, die Umsetzung dieser Programme konkret in quantitativen Verteilungen aufzuspüren. 
In Kapitel 5 wird neben anderen methodologischen Voraberlegungen der Stilbegriff genau definiert, und zwar anhand von zăhlbaren Parametern. (Als Parameter bieten sich, wie spăter noch begründet wird, Satzlänge, Satzkomplexităt, 'logische' Satzordnung und Prădikativităt an.) Da die Parameter auf alle Texte gleichermaßen angewendet werden konnen, erhalten wir fur jedes Werk klare quantitative Großenordnungen ${ }^{6}$.

Im Untersuchungsteil werden die Texte der Reihe nach auf die einzelnen Parameter untersucht. Es erschien dabei wichtig, die Ergebnisse fur jeden Text getrennt aufzufuthren, da ketztlich doch nur der einzelne Text Ausgangspunkt einer Analyse sein kann. Auf diese Weise kann aber auch die Arbeitshypothese uberpruft werden, ob und inwieweit die von uns definierten Stilparameter eine Regelmaßigkeit von Text zu Text und damit eine meßbare Struktur aufweisen. Nachdem die Ergebnisse dem Gang der Untersuchung entsprechend sukzessiv dargestellt worden sind, werden die Mittelwerte symoptisch aufgezeigt. Durch den gegenüberstellenden Vergleich kann schließlich festgestelt werden, ob, wann und wie eine Entwicklung in den entsprechenden stilistischen Parametern stattgefunden hat. Auf diese Weise soll in unserer Untersuchung der „Impressionismus" (Racke) vieler Stiluntersuchungen durch einen Stilbegriff, der durch wenige dafur aber genau festgelegte Parameter bestimmt wird, ersetzt werden. Wichtiger als absolute Zahlen bzw. relative Haufigkeiten sind dabei die quantitativen Großenordnungen, die die einzelnen Parameter aufweisen.

Im Interpretationsteil schließlich werden die Ergebnisse in bezug auf die Fragestellungen und die These betrachtet.

Der Grundgedanke und das Vorbild für die Anordnung und die Systematik der Arbeit war die Prăsentation naturwissenschaftlicher Forschungsergebnisse: in dieser Hinsicht wurde im theoretischen Teil nur das herangezogen, was für die 'Versuchsdurchfuhrung' notwendig erschien, und all das ausgeschlossen, was störend auf die Untersuchung hătte einwirken kơnnen. Der konkreten Untersuchung selbst wurde eine große Autonomie zugestanden und die Methodik moglichst zielstrebig für die Fragestellung der Arbeit entwickeht. Bewußt wurde dabei auf einen sogenannten 'Forschungsbericht' verzichtet, weil er erstens viel zu sehr methodologisch den Blick verengt und weil es zweitens wichtiger erschien, das theoretische Instrumentarium für die Untersuchung bereitzu-

\footnotetext{
${ }^{6}$ Überhaupt kann jeder zusammenhängend geschriebene Text auf diese vier Parameter untersucht werden, so daß sie durchaus als universale Parameter für 'Stil' angesetzt werden kơnten.
} 
stellen. Jedoch wurden Ergebnisse anderer Untersuchungen, die direkten Bezug zu
unserer Untersuchung aufwiesen (sei es einer der vier Parameter oder sei es eines der
untersuchten Werke), zum Vergleich an der entsprechenden Stelle der Untersuchung
herangezogen. Weniger sinnvoll ware auch hier ein blockartiger und der Untersuchung
vorgeschalteter Forschungsbericht gewesen. stellen. Jedoch wurden Ergebnisse anderer Untersuchungen, die direkten Bezug zu
unserer Untersuchung aufwiesen (sei es einer der vier Parameter oder sei es eines der
untersuchten Werke), zum Vergleich an der entsprechenden Stelle der Untersuchung
herangezogen. Weniger sinnvoll ware auch hier ein blockartiger und der Untersuchung
vorgeschalteter Forschungsbericht gewesen. stellen. Jedoch wurden Ergebnisse anderer Untersuchungen, die direkten Bezug zu
unserer Untersuchung aufwiesen (sei es einer der vier Parameter oder sei es eines der
untersuchten Werke), zum Vergleich an der entsprechenden Stelle der Untersuchung
herangezogen. Weniger sinnvoll wăre auch hier ein blockartiger und der Untersuchung
vorgeschalteter Forschungsbericht gewesen. stellen. Jedoch wurden Ergebnisse anderer Untersuchungen, die direkten Bezug zu
unserer Untersuchung aufwiesen (sei es einer der vier Parameter oder sei es eines der
untersuchten Werke), zum Vergleich an der entsprechenden Stelle der Untersuchung
herangezogen. Weniger sinnvoll wăre auch hier ein blockartiger und der Untersuchung
vorgeschalteter Forschungsbericht gewesen. stellen. Jedoch wurden Ergebnisse anderer Untersuchungen, die direkten Bezug zu
unserer Untersuchung aufwiesen (sei es einer der vier Parameter oder sei es eines der
untersuchten Werke), zum Vergleich an der entsprechenden Stelle der Untersuchung
herangezogen. Weniger sinnvoll ware auch hier ein blockartiger und der Untersuchung
vorgeschalteter Forschungsbericht gewesen. vorgeschalteter Forschungsericht gewesen

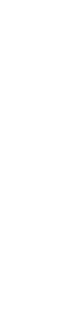

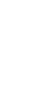




\subsection{Geschichtsschreibung und Wissenschaftlichkeit}

\subsection{Gliederung der Wissenschaften}

Die Naturwissenschaften unterscheiden sich von den Humanwissenschaften' sowohl im Untersuchungsgegenstand als auch in der Darstellung der Untersuchungsergebnisse. Augenscheinlich wird dies daran, daß die 'Sprache der Naturwissenschaft' durch außersprachliche Zeichensysteme unterstutzt wird: durch die Mathematik, die Formeln der Chemie und sonstige Symbole. Somit wird die hohere Präzision und Wissenschaftlichkeit der Naturwissenschaften nicht durch die Sprache allein geschaffen ${ }^{2}$. Anders verhăht es sich in den Humanwissenschaften: hier kann nur mit sprachlichen Mitteln gearbeitet werden; außersprachliche Zeichensysteme kðnnen kaum herangezogen werden.

\subsection{Historische Entwicklung der Wissenschaften und der Wissenschaftssprache}

Seit dem 17. Jahrhundert kann von den Naturwissenschaften im heutigen Sinne gesprochen werden, weil von dieser Zeit an Beobachtung und Erklănung präzise einander zugeordnet werden. Sprachlich bedeutet das, daß Termini immer mehr mathematisch, physikalisch, chemisch oder technisch begrifflich erfaßt und definiert wurden. Die naturwissenschaftlichen Făcher losten sich aus dem Kanon der 'alten' Wissenschaften. Neben der methodischen Emanzipation wurde auch die Forderung nach einer sprachlichen Emanzipation laut. Und standen die Wissenschaften bislang unter der Herrschaft der thetorischen Făcher des Triviums. deren Führungsanspruch sich auch auf die sprachliche Gestaltung erstreckte, so suchte man nun, eine 'unrhetorische Wissenschaftssprache' zu entwickeln. Letzlich waren die neuen Methoden, die sich klar von den atten unterschieden, ein offensichtlicher Beweis dafür, daß ein Bruch mit der Antike stattgefunden hatte: vor allem Aristoteles war es gewesen, gegen dessen ubermăchtige Autorităt keiner anzugehen gewagt hatte. Nun waren eine Vielzahl seiner Thesen und Theorien widerlegt

\footnotetext{
'Unter 'Humanwissenschaften' werden hier und im folgenden sowohl Geistes- wie auch Gesellschaftswissenschaften verstanden.

${ }^{2}$ Vgl. KUTSCHMANN (1986): „Wahrend noch bei Galiei und Kepler die Sprache der Mathematik wesentlich aus den Idealformen der Geometrie bestand, vollzog sich in der Folgezeit eine Verschiebung zur Algebra und Arithmetik, zur verallgemeinerten Zahl als Symbol einer RechengroBe uberhaupt. [...] In der Folge wurden symbolisierte Formeln zu einem selbstverstandlichen methodischen Stilmittel der Naturwissenschaft." (S.105 f.) Und weiter spricht KUTSCHMANN auch von der ,mathematische[n] Sprache der modermen Physik". (S.110)
} 
worden, kein Wunder, daß auch sein Stil desavouiert war. Gleichwohl ist die Forderung nach einer unrhetorischen Wissenschaftssprache differenziert zu sehen. Denn die Rhetorik der Attvorderen war so vielseitig, daß sich doch wieder eine vorbildliche Form fur die neuen Bedürfnisse fand: der Dialog. So bestimmte der forensische Stil des Dialogs, der zu Erkenntnissen schrittweise und anschaulich fuhrte, anstatt sie apodiktisch zu verkünden, viele wissenschaftiche Werke wie z.B. den 'Dialogo' GALILEIs oder den 'Discours' von DESCARTES ${ }^{3}$. Allerdings war die Sprache, wie sie in den neuen Abhandlungen verwendet wurde, viel präziser und sachlicher als die der (antiken) Vorgănger (KUTSCHMANN 1986, 101).

Der Wissenszuwachs in den Naturwissenschaften war im 18. Jahrhundert ungeheuer und setzte sich bis heute nicht nur unvermindert fort, sondern nahm geradezu exponential zu. Im 19. Jahrhundert begannen sich auch die Geisteswissenschaften zu konsolidieren bzw. neu zu konstituieren; sie sind nach BODAMMER $(1987,27)$ „Kinder des 19. Jahrhunderts". Die Sprache in der Naturwissenschaft folgte weiter dem 'unrhetorischen' Ideal: angestrebt wurde Kürze und Prăzision. Aufgrund der beeindruckenden Forschungsergebnisse übernahmen sie innerhalb der Wissenschaften den Führungsanspruch, was nicht ohne Auswirkung auf die Sprache in den Geisteswissenschaften bleiben konnte.

Im Zuge der Verselbständigung der Geisteswissenschaften war es erforderlich, neue Grundlagen zu schaffen. Herausragend war dabei DILTHEY, der den Geisteswissenschaften eine den Naturwissenschaften vergleichbare methodologische Sicherheit geben wolte: er versuchte. die „.Objektivităt der Geisteswissenschaften immer voraussetzungsloser, kritischer, strenger herauszuarbeiten“" (DILTHEY VII, 138).

\subsection{Geisteswissenschaften}

Nach HABERMAS entwicketten sich die geisteswissenschaftlichen Disziplinen nicht aus den handwerklichen Disziplinen und jenen Berufsarten, die technisches Wissen verlangten. sondern aus den Handlungsbereichen, die praktische Klugheit erforderten. Somit steht ,praktisches Erkenntnisinteresse“ bei der Entstehung der Geisteswissenschaften im Vordergrund (HABERMAS 1968, 223).

\footnotetext{
${ }^{3}$ GALILEI: Dialogo di Galileo Galilei sopra i due massimi sistemi del mondo tolemaico e copernicano. Florenz 1632. DESCARTES: Discours de la méthode. Leiden 1637.
} 
Vorrangig bemerkbar macht sich ein solches Erkenntnisinteresse in den Philologien und in der Geschichtsschreibung nicht zuletzt auch deshalb, weil sie die kulturelle Oberlieferung und damit das Selbstbewußtsein der bürgerlichen Gesellschaft des 19. Jahrhunderts garantierte. HABERMAS spricht in diesem Zusammenhang vom ,praktischen Lebensbezug der Geisteswissenschaften“, „der sowohl ihre historische Entstehung als auch ihren faktischen Verwendungszusammenhang bestimmt [...]“" (ebd.).

\subsubsection{Differenzierung innerhalb der Geisteswissenschaften}

DILTHEY unterscheidet zwischen systematischen und historischen Geisteswissenschaften. Letzaere reichen von der Biographie bis zur Universalgeschichte (DILTHEY VII, 120 ff.). Am Beispiel der Ókonomie macht DILTHEY den Unterschied fest: systematische Geisteswissenschaften entwickeln ,allgemeine Theorien von Ausschnitten des gesellschaftlichen Lebens, die durch gleichbleibende Strukturzusammenhănge ausgezeichnet sind und selber Systeme darstellen“" (HABERMAS 1968, 231).

\subsubsection{Stellung der Geschichtswissenschaft in nerhalb der Geisteswissenschaften}

Unter den neu sich formierenden Geisteswissenschaften ragte besonders die Geschichtswissenschaft heraus: sie hatte in der ersten Hälfte des 19. Jahrhunderts durch Niebuhr und Ranke eine neue methodische Grundlage erhaten, wobei weniger Rankes geschichts-theologisches als vielmehr Droysens historisch-hermeneutisches Deutungskonzept zur Konstituierung der neuen Geschichtswissenschaft beitrug (BODAMMER 1987, 27). Eine wichtige Abgrenzung war die zur Philosophie: die Geschichtswissenschaft vollzog damit eine Emanzipation, die die Mathematik schon unter Pythagoras vollzogen hatte. Historisches Wissen wurde auf empirisch öberlieferte menschliche Vergangenheit bezogen. Eine strenge Methodik fitterte schlieBlich weitgehend subjektiv gefarbte Überlieferung ab; „[die Geschichtswissenschaft] ist deshalb zu intersubjektiv uberprufbaren Aussagen über Vergangenes făhig" (RÜSEN 1976, 17).

Es wurde bereits DILTHEYs Unterscheidung zwischen systematischen und historischen Geisteswissenschaften erwăhnt. Im Grunde genommen zeigt Droysen, wie innerhalb der Geisteswissenschaften der Wunsch nach Annăherung an die Naturwissenschaften virulent bleibr. So verwundert es keineswegs, daß sich die Geschichtswissen- 
schaft immer wieder und immer mehr an den systematischen Geisteswissenschaften, d.h. vor allem den Sozialwissenschaften orientiert:

$\mathrm{Daß}$ sozialwissenschaftliche Techniken in die historische Methode integriert werden müssen und können, daran besteht kaum ernst zu nehmender Zweifel. Das "Wie" dieser Integration ist aber nicht nur als methodologisches, sondern auch als Problem konkreter Forschung so lange offen, wie die Geschichtswissenschaft sich noch auf Grund ihrer Methode von den systematischen Sozialwissenschaften als eine besondere wissenschaftliche Disziplin unterscheidet. (RÜSEN 1976, 116 f.)

Das großte Hindernis, das einer erfolgreichen Annăherung an die Sozialwissenschaften im Wege steht, ist die Notwendigkeit der narrativen Darstellung (vgl. auch 2.5). Zwar können quantifizierende und kausal-analytische Methoden durchaus integriert werden, doch $\mathrm{LaBt}$ sich eine Oberwindung der traditionellen narrativen Darstellungsweise, die naturgemaß großen individuellen Schwankungen unterworfen ist, kaum verwirklichen. Jedoch ist grundsătzlich zu fragen, ob die narrative Darstellung denn wirklich unwissenschaftlich sei. Sie mag aus naturwissenschafticher Sicht veraltet erscheinen, doch ist mit FRICKE festzuhatten, daß die primăre Aufgabe der Humanwissenschatten die Aufklărung im ursprünglichen Sinne des Begriffs ist, und daraus folgt, daß auch die Art der Darstellung moglichst breiten Schichten von Nicht-Fachleuten zugänglich sein soll, was durch die narrative Darstellung sicher gewăhrleistet wird (FRICKE 1986, 65).

\subsection{Von der Geschichtsschreibung zur Geschichtswissenschaft}

Geschichtsschreibung beginnt damit, daß einzelne Personlichkeiten sich die Aufgabe stellen, sei es Selbsterlebtes oder Oberliefertes planmäBig literarisch aufzuzeichnen [...] (SCHMID-STÄHLIN 1959, 683)

Dabei muß hier angemerkt werden, daß die Geschichtsschreibung auch zusammenhängt mit der Problematik 'Mündlichkeit/ Schriftlichkeit'. Im vor-schriftlichen Alter, d.h. in der schriftlosen Zeit waien die Mythen und Sagen sozusagen das Behălinis für die Geschichte. Die Ereignisse der Geschichte konnten nicht wie spăter mit Hilfe der Schrift auf Jahreszahlen genau festgehaten werden. Vielmehr geschah das Erinnem auf recht grobem und ungenauem Wege, ja oft sogar verfalschend

\footnotetext{
`Vgl. hierzu ONG $(1987,52)$ uber die nachtrăgliche Korrektur von Ahnenstammbaumen: „Die im Verlauf von Rechtsstreitigkeiten im nigerianischen Tiv-Stamm münlich wiedergegebenen Genealogien wichen in jüngerer Zeit betrăchtlich von denjenigen ab, welche die Briten vierzig Jahre vorher mit großer Sorgfalt niedergeschrieben hatten."
} 
Lange war der Mythos die einzige Quelle der Geschichte; erst mit der schriftlichen Aufzeichnung konnte Geschichte soweit objektiviert werden, daß sie sich rein auf die Konstatierung von Fakten beschränken konnte und damit den ganzen Ballast der mnemotechnischen Gedăchtnisstützen, wie ihn die mündliche Überlieferung erforderte, nicht mehr benotigte. Aufgrund ihrer oralen Vergangenheit und weil sie eine wesentliche Frage des Menschen, nămlich die Frage nach dem 'woher ?', beantworten sollte, konnte sich die Geschichtsschreibung lange nicht dem Zauber des Erzăhlens (und Hinzudichtens) entziehen. Die Nahe zum Mythos, der öffentlich und laut vorgetragen wurde, beeinflußte schon von Anfang an die Form der Geschichtsschreibung. Geschichtsschreibung war daher lange Zeit Literatur. Davon abgesehen wurde in der Antike die Literatur noch nicht so funktional verstanden wie heute, wo streng unterschieden wird zwischen schöngeistiger Literatur, d.h. Literatur zum Vergnügen, und Fachliteratur, d.h. Literatur die 'nüzlich' ist, und wo deren Wirklichkeitsbezogenheit als wertvoll angesehen wird.

Im Altertum war die Geschichtsschreibung noch der Kunst zugehörig. Wie bei Herodot beobachtbar, mischten sich noch Fabeln, die der damalige Hörer/ Leser sicher als solche erkannt hat (man hüte sich davor, zuviel Naivităt in jene Zeit zu projizieren), in den sonst nüchternen Geschichtsbericht. Die Rezeption jener ersten Geschichtswerke war darauf angelegt zu gefallen; genaue Information und wissenschaftiche Wahrheit war wohl weniger gefragt. In dieser Hinsicht enthielt die Geschichtsschreibung der damaligen Zeit viele fiktionale Elemente, was noch belastend für die Geschichtswissenschaft werden sollte. In der Renaissance wurde der Gedanke der Kunsthaftigkeit der Geschichtsschreibung verstårkt wiederaufgenommen, nachdem das Mittelalter hindurch die Geschichte .hypotaktisch“ (WHITE 1990, 19) der Erklărungswelt des Christentum untergeordnet gewesen war. Auch in der Renaissance war nicht so sehr die trockene Faktizităt der Geschichte das Maßgebende als vielmehr die hörer-/ leserfreundliche Darstellung ausschlaggebend. Kein Wunder also, daß die Rhetorik eine entscheidende Rolle spielte und die Texte of mehr nach rhetorischen Gesichtspunkten als nach heutigen wissenschaftlichen Kriterien aufgebaut wurden. Eine entscheidende Veränderung erfuhr die Haltung zur Geschichtsschreibung im Zeitalter der Aufklärung: nun stand weniger die äußere Form als die inhaltliche Genauigkeit im Vordergrund.

Die Geschichtswissenschaft knüpte an das „vorwissenschaftliche Geschichtsbewußtsein“ an (BODAMMER 1987, 83). Überhaupt beginnt jede Wissenschaft nicht mit plan- 
maßigem Nachdenken über Inhaht und Methode, sondern mit der Untersuchung einzelner Erscheinungen und Vorgănge. Im Gegensatz zu dem schlagartigen Paradigmenwechsel ${ }^{3}$ in den Naturwissenschaften zog sich die 'Verwissenschaftlichung' der Geschichtsschreibung aber Jahrhunderte hinweg. Deutliche Ansătze konnen im 15. Jahrhundert gesehen werden; die wissenschaftiche 'Weihe' wird erst im 19. Jahrhundert mit Ranke und Niebuhr verliehen. Wăhrend dieser Zeit mußte sich die Geschichtsschreibung /wissenschaft schrittweise von der traditionellen Zuordnung zur Rhetorik und dem uralten Verdacht des 'Geschichtenerzăhlens' befreien. Dabei war der innere Wandel ăußerlich kaum bemerkbar, denn grundlegend blieb die narrative Darstellung; der Paradigmenwechsel in den Naturwissenschaften war dagegen åußerlich klar erkennbar durch die Verwendung der mathematischen außersprachlichen Symbole und Erklärungsmodelle.

\subsection{Die Problematik der Darstellung}

Nach STIERLE ist die Darstellungsproblematik ,so etwas wie der blinde Fleck der Historiographie" (1979, 108). Er meint weiter, daB die narrative und somit literarische Form der Historiographie eine Funktion erfulle. die nicht Restbestand eines 'vorwissenschaftichen' Umgangs mit der Vergangenheit sei, sondem daß sie ihr unauthebbares Eigenrecht behaupte. Jedoch ist es eben die Narrativităt, die manchem den Eindruck einer fehlenden Objektivităt vermittett. Die Frage nach der Mðglichkeit von Objektivităt narrativer Strukturen ist indes positiv zu beantworten. Die Tătigkeit des Erzăhlens in der Geschichtsschreibung bestimmt den historischen Gegenstand, wobei vielfaltige temporale Strukturen und mannigfache Erkenntnisinteressen und Stellungnahmen vom Erzăhler/ Geschichtsschreiber verwendet werden. Die Freiheit, die der Geschichtsschreiber bei der Darstellung hat, ist dabei nicht zu verwechseln mit Subjektivităt. Somit kann in der Geschichtsschreibung nur Objektivităt erzieht werden, wenn nicht gegen die Strukturen der Erzăhlung verstoßen wird (BAUMGARTNER 1975, 59).

\subsubsection{Die narrative Darstellung}

Es wurde bereits auf die orale Vergangenheit verwiesen: dem Mythos lag die Narration zugrunde. Überhaupt sind die Formen der Narration, soweit unser kulturelles Gedăchtnis reicht, grundlegend für die Organisation. Transformation und Kommunikation von

\footnotetext{
s Im Sinne von KUHN (1967): Die Struktur wissenschaftlicher Revolutionen.
} 
Erfahrung" (STIERLE 1979, 92). Gleichwohl scheint die narrative Darstellung in letzter Zeit eine Krise durchlaufen zu haben, was im Zusammenhang mit der Entwicklung der anderen Wissenschaften, insbesondere der Naturwissenschaften, steht. Letztere weisen einen beachtlichen Abbau narrativer Darstellungsformen bei der Beschreibung ihrer spezifischen Forschungsinhalte auf. Dadurch entstand bei einigen Historikern der Eindruck, daß die Verwendung der narrativen Darstellung ein Anzeichen fur ein methodisches wie auch theoretisches Versagen sei:

Eine Disziplin, die uber ihren Gegenstand narrative Schilderungen produziert, erscheint methodisch unsolide; eine Disziplin, die ihre Daten untersucht, um daruber eine Geschichte zu erzahlen, erscheint theoretisch defizient.

(WHITE 1990, 40)

KRETZENBACHER (1994) spricht gar von einem 'Erzähltabu' '. Diese Ansicht ist jedoch eine fremdbestimmte und dem Wesen der Geschichtsschreibung und -wissenschaft nicht angemessen. Man darf nicht Methode und Darstellung gleichsetzen:

[...] le problème n'est pas de savoir comment on écrit l'histoire (question de méthode), mais au contraire comment il n'y a d'histoire qu'écrite (question du discours). (MAIRET 1974, 18)

Die Erzăhlung in der Geschichtsforschung ist demnach als Form des wissenschaftlichen Diskurses zu verstehen. Und wie CROCE sagt, gibt es keine Geschichte, wo es keine Erzăhlung gibt (S.36).

\subsubsection{Historie vs. Fiktion}

Die fiktiven Elemente, die in den Mythen und Sagen noch auftraten, wurden im Laufe der Zeit zurluckgedrăngt. In der Neuzeit wurden sie gănzlich ausgeschlossen, da sie dem Anspruch der Wissenschaftlichkeit klar zuwiderliefen. Mit der steigenden Verwissenschaflichung verengte sich jedoch der Kreis der Leser von Geschichtswerken, so daß die Ausbildung des historischen Romans (vor allem ab der zweiten Hălfte des 19. Jahrhunderts) auf großes Interesse derjenigen stieß, die zwar an Geschichte interessiert waren, doch an der 'trockenen' wissenschaftichen Form keinen Gefallen fanden.

Gleichzeitig entstanden mit der Erscheinung dieses unwissenschaftlichen Pendants der Geschichtsschreibung die erwăhnten Zweifel bezäglich der narrativen Darstellung. Tat-

${ }^{6}$.Ein Tabu, das in einigen Geistes- und Sozialwissenschaften in letzter Zett etwas an Striktheit zu verlieren scheint, aber in den Naturwissenschaften nach wie vor unverandert besteht, ist das Erzähltabu. Wissenschaftler sollen nicht erzăhlen. " (KRETZENBACHER 1994, 30) 
sache ist, daß sich historische von fiktionalen Geschichten in erster Linie durch ihren Inhalt unterscheiden, weniger durch ihre Form; oder weiter präzisiert: der fundamentale Inhal, nămlich die Strukturen der menschlichen Zeit, ist gleich, nur die unmittelbaren Inhalte, d.h. reale bzw. imaginäre Ereignisse, sind verschieden. Jedenfalls ist die Erzăhlung die gemeinsame Form, die als Darstellung der Strukturen der (menschlichen) Zeit notwendig ist. Die Erzăhlung als besondere Art des Diskurses fügt dem Inhalt nichts hinzu, sie versucht lediglich ein Abbild der Struktur und der Prozesse der realen Ereignisse zu sein (WHITE 1990, 41).

Die Fiktion dagegen ist, unabhängig vom Wahrheitsgehalt ihres Inhalts, eine Setzung. Die gebrăuchlichsten Formen der (schriftsprachlichen) Narration sind Romane, Novellen. Fabeln und Erzăhlungen. Der fiktionale Anteil kann innerhalb der einzelnen Werke große Schwankungen aufweisen; dabei ist es oft schwer, fiktionale Narration von nichtfiktionaler zu unterscheiden, da die Wahrscheinlichkeit der geschilderten Ereignisse dem einzelnen Leser unterschiedlich plausibel erscheint; andererseits gibr es auch fiktionale Erzăhlungen, über deren Fiktionalităt von Anfang an Klarheit herrscht. Letzalich konnen wir aber nur aufgrund unseres Wissens vorab entscheiden, inwieweit eine Geschichte fiktional ist. Dieses Wissen ist nicht auf historisches Wissen beschrănkt, sondern es umfaßt das 'Wissen von der Welt' an sich '. Geschichtsschreibung selbst ist dem historischen Wissen zugewandt:

In der referentiellen Bezogenheit auf ein Wissen liegt der wesentliche Unterschied zur narrativen Fiktion, deren Thema phänomenologisch gesehen die Erfahrung selbst ist, losgelठst von einem konkreten AnstoB dieser Erfahrung. (STIERLE 1979, 99)

Folglich werden in der Fiktion Äquivalente von Erfahrungsschemata organisiert (ders., S.98).

\subsection{Inhalt und Struktur der bistorischen Erablung}

Nach SCHLIEBEN-LANGE ist der Gegenstand der Historiographie „die wahre Erzăhlung auf der Zeitachse linear ablaufender Ereignisse" $(1983,148)$. Die Ereignisse werden ausgewahht und organisiert, wobei die Auswahl dem Ermessen des einzelnen Historikers anheimgestelt ist: einerseits kann ein Jahrhundert auf einer Seite Platz finden, andererseits kann ein einziger Tag ein ganzes Kapitel fullen. VEYNE spricht in diesem

\footnotetext{
${ }^{7}$ Vgl. COSERIU (1988): Sprachkompetenz.
} 
Zusammenhang von einem unterschiedlichen Tempo des Historikers (1990, 22); folglich arbeitet die Historiographie nicht streng linear ${ }^{8}$. HARDTWIG sieht die Strukturierung der temporalen Sukzession als grundlegendes Prinzip der Geschichtsschreibung, doch schränkt er ein:

Die Herstellung einer temporalen Struktur geht uber die bloße 'und - dann'Aneinanderreihung nur hinaus, wenn Selektionsprinzipien, Sinnentwürfe, Vermutungen uber Kausalverhăltnisse vorliegen, die in der verwissenschaftlichten Geschichtsschreibung immer schon theoriegeleitet sind. (HARDTWIG 1979, 294)

Er spricht dabei die Achillesferse der Geschichtsschreibung an, die ironischerweise nicht nur vorwissenschaftichen Ursprungs ist, sondern auch aus dem Versuch den Naturwissenschaften gleichzukommen entstand, indem Gesetzmäßigkeiten in den Ereignissen der Vergangenheit gesucht wurden. Demgegenuber bleibt das sicherste Vorgehen in der Geschichtsschreibung das mðglichst objektive Beschreiben; anstelle der Postulierung von Gesetzmaßigkeiten soltten nur Kausalbezüge hergestelt werden.

Eine solchermaßen verstandene Geschichtsschreibung laßt vor allem folgende drei Elemente der historischen Erzahlung vorfinden:

(1) Aussagen über vergangene Ereignisse nach Ort und Zeit, d.h. Tatsachenbehauptungen. deren deskriptive Pradikatoren im allgemeinen der Umgangssprache entstammen und jedenfalls nicht durch wissenschaftiche Theorien festgelegt sind.

(2) Aussagen ubber die Verknüpfung von zeitdifferenten Ereignissen sowohl nach Wirkungs- wie nach Sinnzusammenhängen, d.h. Erklärungen und Interpretationen geschichtlicher Tatsachen; und

(3) historische Urteile im engeren Sinne: Bewertungen und Beurteilungen von einzelnen Ereignissen bzw. Ereigniszusammenhangen in bezug auf Wertskalen, die es erlauben. Negatives von Positivem, Angemessenes von Unangemessenem [...] zu unterscheiden.

(BAUMGARTNER 1975, 49)

\subsubsection{Auswirkungen auf die Sprache der Geschichtswerke}

HARDTWIG behauptet, die temporale Struktur gehe uber die bloße Aneinanderreihung von 'und - dann' hinaus; damit hat er die grundlegende sprachliche Umsetzung erwăhnt: die Parataxe. Auch WHITE weist der temporalen Sukzession den Begriff 'Parataxe' zu: .Diese Zeit hat keine Hohepunkte oder Tiefpunkte; man kơnnte sagen, sie ist para-

\footnotetext{
${ }^{8}$ Auch bei simultanen Ereignissen kann die Zeit nicht mehr das alleinige Prinzip sein, das den Aufbau der Erzăhlung bestimmt. Es muß dann das Nebeneinander in ein Nacheinander aufgel̋st werden, was zwangslăufig zur Verletzung der Linearităt fuhrt (HARTMANN 1979, 39).
} 
taktisch und endlos."(1990, 19); wobei er den Begriff nicht linguistisch verwendet, sondem in der ursprünglichen Bedeutung als 'Aneinanderreihung' und im Gegensatz zur 'hypotaktischen Ordnung' der christlichen Geschichtsauffassung.

Im Grunde genommen ist die temporale Anordnung von Sătzen bereits kausal begrundet: dargestellt werden sollen Kausalketten. Und die (historische) Erzăhlung braucht nicht immer explizit durch Konjunktionen und sonstige sprachliche Markierungen den Grund zu kennzeichnen, vielmehr kommt der Leser/ Rezipient schon mit seinem Textsortenwissen' dem Erzăhler entgegen und ist sich der kausalen Zusammenhănge von Ereignissen allein schon wegen seines 'Wissens von der Welt' bewußt und braucht nicht immer explizit auf Kausalbezüge hingewiesen werden. Die sprachliche Parataxe, die in den (historischen) Erzahlungen verwendet wird, ist demnach nicht als ein Zeichen von fehlender Kausalităt zu sehen. Man könnte hier auch von der ,linearen Kausalitătsvermutung" sprechen, aufgrund welcher der Mensch auch dort noch Kausalităt erwartet, wo er dem Zufall begegnet (ROTHERMUND 1994, 44) ${ }^{10}$. Der Historiker, der diese Kausalitătsvermutungen ausnútzt, kann einen sehr flussigen Stil schreiben. Schwierig wird es allerdings, wenn komplexe Zusammenhănge (wie z.B. simultane Ereignisse) dargestelt werden sollen; dann verhăt es sich in der Historiographie wie in naturwissenschaftlichen Texten: Kausalitătsbezuge müssen explizit dargestelt werden, weil diese Kausalitătsbezage nicht mit dem allgemeinen Wissen erkannt werden können.

\subsection{Die Funktion der Geschichtsschreibung}

Nach SCHLIEBEN-LANGE ist die Funktion der Geschichtsschreibung ,der Menschheit das Gedăchtnis zu bewahren, sie durch die Erhaltung des Vergangenen von der Herrschaft des Gegenwărtigen zu befreien" $(1983,148)$. Man kann diese Funktion auch einer allgemein 'aufklärerischen Funktion' unterordnen und würde das Ziel der Geschichtsschreibung und -wissenschaft unter das Ziel der Humanwissenschaften stellen, welches nach FRICKE $(1986,65)$ ebenfalls die Aufklarung aller ist; nicht nur die der Fachgemeinschaft.

\footnotetext{
${ }^{9}$ Bei COSERIU das ..expressive Wissen“; vgl. vor allem $(1988,158-186)$

${ }^{10}$ ROTHERMUND erwähnt hier Humes Annahme, daß Kausalitătsvermutungen als menschliche 'Vor-Urteile' anzusehen sind (ebd.).
} 
Allerdings muß festgestellt werden, daß das Ziel von Autor zu Autor und vor allem von Epoche zu Epoche durchaus variieren mag. Aufgrund der untrennbaren Verbindung der Vergangenheit mit dem Selbstbild/ der Identităt des einzelnen Menschen wie auch des einzelnen Volkes erwachsen oft Finalităten, die dementsprechend die Auswahl der darzustellenden Ereignisse und ihre Interpretation beeinflussen, ohne daß die Objektivităt offensichtlich verletzt wïde. Dabei ist nicht nur der Inhalt betroffen, sondern auch die sprachliche Form. Und obgleich die Varianz der sprachlichen Gestaltung mit dem Kriterium der Wissenschaftlichkeit teilweise noch in Ubereinstimmung gebracht werden kann verbleibt doch ein gewisser Freiraum für den Autor, seinen Text zu gestalten, um andere Funktionen als die der gedăchtnisstutzenden einzubringen.

\subsection{Die Sprache in der Geschichtsechreibung und der bumanwissenschaftiche Stil}

Geht man davon aus, daß Geschichte keine Wissenschaft sei (wie z.B. VEYNE 1990, 126), so erubrigt sich die Frage nach der Existenz und den Eigenheiten eines wissenschaftichen Geschichtsstils. Uns erscheint diese Position jedoch falsch, denn die Geschichtswissenschaft hat sehr wohl den Rang einer Wissenschaft erreicht.

Es muß eingestanden werden, daß sich die Humanwissenschaften von den Naturwissenschaften dadurch grundlegend unterscheiden. daB sie keine umfangreichen Terminologien aufzuweisen haben. Zwar mögen wohl Termini oder Fachausdrücke existieren, doch ist erstens deren Zahl recht gering, und zweitens kann die Fachbedeutung oft viel leichter erschlossen werden, als dies in den Naturwissenschaften der Fall ist. Was den Diskurs in den Humanwissenschaften anbelangt, so gehen fur ihn die gleichen Regeln wie in den Naturwissenschaften: Aussagen dürfen weder in sich noch untereinander Widersprulche enthaten; auch der logische Aufbau der Sătze ist der gleiche. Dies zum allgemeinen, nun zum besonderen: in der Historiographie herrscht die narrative Darstellung vor. Die Trennlinie zur dichterischen Erzăhlung erscheint recht schmal. Trotzdem hatten wir daran fest, in der vorliegenden Untersuchung von einem 'historiographischen Stil' $2 \mathrm{~d}$ sprechen, wobei wir uns auch von praktischen Gesichtspunkten keiten lassen: 'historiographischer Stil' ist in erster Linie ein Arbeitsbegriff, der den Stil der drei untersuchten Geschichtswerke bezeichnet ".

\footnotetext{
${ }^{11} \mathrm{Vgl}$. Anm. 5, S.16
} 


\subsection{Zusammenfassung der Uberlegungen}

Die Dichotomie Natur-/ Humanwissenschaften wurde vor dem historischen Hintergrund beleuchtet, um zu zeigen, daß die Naturwissenschaften einen Vorsprung in der Ausbildung ihrer 'Fachsprache' hatten und daß sich die Humanwissenschaften nicht durch ein außersprachliches System wie die Mathematik entlasten konnen. Danach wurde versucht, die Stellung der Geschichtswissenschaft innerhalb der Humanwissenschaften ausfindig zu machen: zwar hat sich die Geschichtswissenschaft erst seit dem 19. Jahrhundert methodologisch etabliert, doch besaß auch die vorhergehende Geschichtsschreibung zumindest sachlichen Charakter und wies bereits soweit einen wissenschaftlichen Ansatz auf, daß wir im nächsten Kapitel die Aspekte, die die Wissenschaftlichkeit der Geschichtsschreibung mit sich bringt, beleuchten können; auf jeden Fall kann aber der historiographische Stil als sachlicher Stil festgemacht werden.

Weiter wurde festgestelt, daB die Geschichtsschreibung auf das Erzahlen als Diskursform angewiesen ist. Den Geschichtswerken liegt demnach die gleiche Diskursform wie den dichterischen Werken zugrunde, was einem Vergleich zwischen dem historiographischen und literarischen Stil entgegenkommt, weil somit ein tertium comparationis vorhanden ist, uber welches die Geschichtswerke mit den dichterischen Werken sinnvoll verglichen werden können.

Zuletzt wurde noch auf die Funktionen der Geschichtsschreibung verwiesen; diese können sich im Laufe der Zeit wandeln und sind jedenfalls auch von dem einzelnen Autor abhăngig. Ob und wie sich diese Funktionsănderungen konkret im historiographischen Stil bemerkbar machen, wird die Untersuchung zeigen. 


\subsection{Fachsprache, Funktionalstil, Stil}

Entsprechend der Erorterung im vorigen Kapitel kann im folgenden vom sachlichen Charakter der Historiographie ausgegangen werden. Die Untersuchungstexte werden dadurch inhaltlich genauer eingegrenzt. Aus linguistischer Sicht wurde allenfalls die semantische Ebene betrachtet, doch weitere sprachliche Ebenen wurden noch nicht in Augenschein genommen, abgesehen von einigen konkreten Konjunktionen wie ,und dann".

In diesem Kapitel sollen die Texte aus eigentlich linguistischer Sicht năher bestimmt werden: dazu soll vor allem das theoretische Konzept der Fachsprache und das des Funktionalstils herangezogen werden. Sowohl vor diesem theoretischen Hintergrund als auch im Hinblick auf allgemeine Stildefinitionen wird abschließend eine fur die Untersuchung nützliche Arbeitsdefinition des Begriffs 'Stil' erarbeitet.

\subsection{Fachsprache}

Eine wissenschaftiche Disziplin wie die Geschichtswissenschaft' trăgt unzweifelhaft Fachcharakter. Es liegt daher nahe zu uberprufen, ob und inwieweit das Konzept der Fachsprache fü die Untersuchung nutzbar gemacht werden kann. Im folgenden sollen kurz der Erkenntnisstand der Fachsprachenforschung und ihre methodologischen Ansătze skizziert werden.

\subsubsection{Zum Begriff 'Fachsprache'}

Unsere heutige Vorstellung von 'Fach' im Sinne von "Wissens-, Sach-, Arbeitsgebiet" (...) ist historisch gesehen verhältnismäßig jung und sprachlich erst fur das 19. Jahrhundert belegt. Demnach könnte man den Standpunkt vertreten, daß das, was wir heute mit 'Fach' bezeichnen, ein historisch junges Phănomen darstelt, Făcher also erst seit dem 18./ 19. Jahrhundert, seit ihrer sprachlichen Erfassung mit dem Ausdruck Fach bestehen.

(MÖHN 1984, 30)

KALVERKÄMPFER kritisiert, daB in der Fachsprachenforschung zu wenig das Fachkriterium untersucht oder năher definient wird. Stattdessen werde die Fachlichkeit

\footnotetext{
'Im folgenden legen wir die Geschichtswissenschaft und nicht mehr nur die Historiographie/ Geschichtsschreibung den Überlegungen zugrunde. Dabei umfaBt 'Geschichtswissenschaft' die Historiographie, theoretische Diskurse uber die Methodik und Aufgaben der Geschichtsschreibung sowie aber Methoden und Aufgaben der Geschichtswissenschaft innerhalb der geisteswissenschaftichen Disziplinen.
} 
geradezu einem Axiom gleich ohne weitere Hinterfragung akzeptiert ( er nennt dies das „Axiom einer intuitiv einleuchtenden Fachlichkeit irgendeines Bereichs“ (1979, 54)). Nach HAHN gibt es zwei Moglichkeiten: entweder man geht von den in einem Fach verwendeten Texten aus oder von einem wie auch immer definierten Fach aus und nimmt an, daß das Fach die Fachsprache beeinflußt.

Beim ersten Verfahren besteht die Gefahr, daß nicht die Fachlichkeit das Wichtigste ist, sondem daß textsortenspezifische, semantische und sonstige Kriterien in den Vordergrund treten. Beim zweiten Verfahren besteht die Problematik darin, daß man nicht weiß, was eigentlich Fächer konstituiert; ob z.B. als Fach die gesamte Naturwissenschaft anzusetzen ist oder ob man sich beschränken mußte auf die Chemie oder gar nur auf die organische Chemie usw. (HAHN 1983, 63). Aus letzterem Grund mag es deshalb unangebracht erscheinen, uberhaupt eine abstrakte, allumfassende Fachsprache zu konstruieren, da doch jedes Fach seine eigene Fachsprache besitzen mochte. Um dieses Dilemma zu losen, wird oft auf die eine Gemeinsamkeit der Fachsprachen verwiesen; nămlich daß sie alle fachbezogen und daher speziell seien.

Allgemein kann festgestellt werden, daß die Fachsprachenforschung durch ein Pendeln zwischen diesen beiden Polen gekennzeichnet ist, und es ist fraglich, ob es uberhaupt eine eindeutige Lossung geben wird. Man muß deshalb mit BUNGARTEN befinden:

Auch heute ist der Begriff Fachsprache nicht eindeutig geklart und einverständlich festgelegt, und eine konsistente Theorie der Fachsprache laßt immer noch auf sich warten. (BUNGARTEN 1992.11)

\subsubsection{Definition(en) der Fachsprache}

Es gibt eine Vielzahl von Definitionsversuchen der Fachsprache. Zwar stutzen sie sich meist nur auf bestimmte Aspekte der Fachsprache oder enthalten gar problematische Festlegungen, doch dienen sie einer Annaherung an das zu untersuchende Phănomen der Fachsprache. Vorab mag man SCHRŌDER zuzustimmen, der die Meinung vertritt, daß eine theoretische Bestimmung des „Wesens der Fachsprache“ eigentlich gar nicht møglich sei (SCHRÖDER 1987, 48).

Im folgenden seien die verschiedenen Definitionsversuche, wie sie SCHRODER zusammenfaßt, wiedergegeben:

1.Fachsprachen sind 'typische Funktionssprachen' und keine Sondersprachen. Fachsprachen zielen eher auf Präzision, wăhrend Sondersprachen Absonderung bedeuten konnen. 
2.Es gibt nicht eine Fachsprache, sondern eine Vielzahl von Fachsprachen, die sich auch untereinander unterscheiden. Man geht von ungefăhr 300 Fachsprachen aus.

3.Es gibt nicht nur Fachsprachen einzelner Făcher, sondern auch eine Differenzierung innerhalb eines Faches (Textsorten, Inhalte, kommunikative Situationen, Zwecke, usw.)

4.Fachsprachen unterliegen einem zeitlichen Wandel, so daß der Begriff 'Fachsprache' immer auf einen bestimmten Zeitpunkt bezogen werden soltte.

5.Fachsprachen seien weder als stilistische Variante noch allein als terminologisches Subsystem hinreichend erfaßt, so daß nur eine 'ganzheitliche Betrachtung' Aufschluß uber das Wesen der Fachsprache geben kann.

(SCHRŐDER 1987, 48 f.)

Es sei noch die geradezu klassische Definition von HOFFMANN erwăhnt, die umfassend und konzise besagt:

Fachsprache - das ist die Gesamtheit allet sprachlichen Mittel, die in einem fachlich begrenzbaren Kommunikationsbereich verwendet werden. um die Verstăndigung zwischen den in diesem Bereich tătigen Menschen zu gewăhroleisten ( HOFFMANN 1976, 170)

Die Vielzahl der Definitionen zeigt deutlich den problematischen Stand der theoretischen Diskussion in der Fachsprachenforschung. Dies hat seinen Grund wohl darin, daß die theoretische Diskussion erst allmahlich in Gang kam, nachdem die Fachsprachen bereits praxisbezogen untersucht worden waren. So sind es denn auch eher die praxisbezogenen Untersuchungsmethoden, die die Fachsprachenforschung auszeichnen, als die (sprach-)theoretischen Erkenntnisse.

\subsubsection{Phasen der Fachsprachenerforschung}

Die Fachsprachenforschung blickt auf eine etwa 30-jăhrige Geschichte zuruck. Nach SCHRÖDER (1987) werden ublicherweise in der Fachsprachenforschung drei Phasen unterschieden ${ }^{2}$ :

1. Die Lexik-Phase: man beschrănkte sich auf die Erforschung des Fachwortschatzes.

Die Untersuchung und Zusammenstellung der Terminologie eines Faches wurde als vorrangig betrachtet. Methodische Untermauerung war durch die Gleichsetzung von Fachwortschatz und Fachsprache gegeben; stellvertretend sei JUMPELT genannt, der meinte, das Wesentliche der fachlichen Aussage liege in den Fachworten, nicht in der Syntax ( JUMPELT 1960, 71).

\footnotetext{
${ }^{2}$ Die Periodisierung darf nicht zu streng aufgefaßt werden: BENES (1966) hat sich schon in den 60er Jahren der Syntax zugewandt. Auch in der Text-Phase gab es Vorreiter wie SCHILLING (1973) und KAMPRAD (1975).
} 
2. Die Syntax-Phase, in der Syntax und Stilistik der Fachsprachen untersucht wurde, wobei der Impuls der Funktionalstilistik wesentlich war.

3. Die Text-Phase, in der eine ganzheitliche Betrachtung angestrebt wurde. Der Impuls ging von der sich etablierenden Textlinguistik aus.

Folgerungen für die Untersuchung:

Man konnte die erste Phase auch umschreiben mit 'lexikologischer Ansatz'. Der lexikologische Ansatz war zwar eng, trotzdem sehr ergiebig und vor allem praktisch verwertbar. Man denke an all die technischen Worterbulcher und die nicht zu verleugbare Bedeutung, die diese lexikologische Arbeit auch für das Fach /die Făcher selbst brachte. Auch in unserer Untersuchung werden wir die Ergebnisse lexikalischer Untersuchungen heranzichen, wenn es gilt, einen lexikalisch orientierten Parameter zu definieren, mit dem die Entwicklung des historiographischen Stils unter Berucksichtigung seines Fachsprachencharakters verfolgt werden kann. Die zweite und dritte Phase der Fachsprachenforschung ist wesentlich von außen beeinflußt worden, es erscheint daher angebracht, die Ausłőser, nămlich die Funktionalstilistik und die relevanten Aspekte der Textlinguistik, zu erörtern.

Bevor wir uns der Überlegung zuwenden, inwieweit das Konzept der Fachsprache auf den historiographischen Stil anwendbar ist, soll zuerst noch das Konzept des Funktionalstils vorgestelt werden.

\subsection{Funktionalstil}

Wenn die Historiographie als wissenschaftliche Disziplin ${ }^{3}$ eingestuft wird, ist es auch nỏtig, das Konzept des Funktionalstils auf seine Brauchbarkeit zu uberprufen; dazu soll nun der historiographische Stil unter den 'wissenschaflichen Stil' der Funktionalstilistik subsumiert werden.

\footnotetext{
${ }^{3}$ Dies bedeutet nicht die Gleichsetzung der Historiographie mit der Geschichtswissenschaft als Ganzes. Ausgangspunkt für diesen Schritt ist die Oberlegung aus 2.9, daß die Historiographie im untersuchten Zeitraum das Kriterium der Wissenschaftichkeit ausreichend erfullte, um als wissenschaftliche Disziplin angesehen werden zu können. Dabei darf der hypothetische Charakter einer solchen Postulierung nicht übersehen werden.
} 


\subsubsection{Das Funktionalitatsprinzip}

Das Funktionalitătsprinzip, welches durch die Arbeiten der Prager Schule an Bedeutung gewann, erbrachte beachtliche wissenschaftliche Erkenntnise und bewies seine theoretische Tragfăhigkeit. Wichtig für die Formulierung des Begriffs war die Übernahme des theoretischen Konzepts der funktionalen Differenzierung der Literatursprache durch SČERBA (1957, 119): fulr ihn hatte jede Variante der Literatursprache eine bestimmte Aufgabe zu erfullen; Motivation der Differenzierung war ,funktionale Zweckmaßigkeit" (функциональная целесообразность). In derselben Reihe steht auch VINOGRADOV $(1963,5)$, wenn er die Funktionalstile aus ..Sprachfunktionen“ (функции языка) ableitet.

\subsubsection{Anzahl der Funktionalstile}

Ober die Anzahl der Funktionalstile herrscht keine einheitliche Meinung. Die Anzahl der Stile schwankt bei den Autoren zwischen vier und sieben ${ }^{4}$. Weit ist auch die Klassifikation verbreitet, die funf Stile aufweist (LINGVO- 1979, 4).

So z.B. bei ROZENTAL' (1976, 11):

1) разговорный стиль;

2) научный стиль;

3) официально-деловой стиль;

4) публицистический стиль;

5) литературно-художественный стиль.

Das Modell von GLÄSER (1983) weist sechs 'Fachstile' auf. Interessant dabei ist, $\mathrm{da}$ sie am einen Ende das Auftreten fachlicher Inhalte in der Belletristik ansiedelt. Die daraus resultierende Schnittmenge von fachlichem Inhalt und belletristischem Funktionalstil nennt sie den 'ästhetischen Fachstil'. Durch dieses Modell stell GLÄSER einen Zusammenhang zwischen Funktionalstil und Fachsprache her, was sich auch schon in dem von ihr verwendeten Terminus 'Fachstil' widerspiegelt (S.7 ff.).

\subsubsection{Der wissenscbaftliche Funktionalstil}

Dem wissenschaftlichen Funktionalstil liegt nach HAVRÁNEK $(1976,127)$ die 'theoretisch-fachliche Mitteilungsfunktion' zugrunde. Einstweilen herrscht keine einhellige Meinung dariber, ob nun ein einziger monolither wissenschaftlicher Stil existiert

\footnotetext{
'HAVRÁNEK (1932, 127) spricht von vier; MURAT von sieben Funktionalstilen (1957, 20 ff.).
} 
oder ob in seinen Grenzen eine große Anzahl von 'Substilen' der einzelnen Wissenschaftszweige Platz findet sowie ob sich im gegenwärtigen Augenblick eine Divergenz oder eine Konvergenz dieser Substile abzeichnet ${ }^{5}$.

Nach Meinung der russischen ( sowjetischen) Forscher ragt unter den Funktionalstilen derjenige der allgemein-wissenschaftichen Sprache ausreichend deutlich hervor: "Среди функциональных стилей достаточно отчетливо выделяется функцио нальный стиль общенаучного языка." (FUNKCIO- 1974, 7). Als Beweis dafur wird von den russischen Forschern auf die Ergebnisse zahlreicher linguistischer Untersuchungen verwiesen, wobei die erste von OLSCHKI stammte, welche in den 20-er Jahren veroffentlicht wurde ${ }^{6}$. Zuzustimmen ist der Beobachtung, daß der wissenschaftliche Stil determiniert wird durch

a) die Entwicklung des wissenschaftlichen Denkens des betreffenden Landes;

b) den Ausbaugrad der nationalen Literatursprache des betreffenden Landes;

c) das wissenschaftlich-künstlerische Niveau des Autors;

d) und das intellektuelle Niveau der Leser, für welche die Arbeit bestimmt ist (FUNKCIO- 1974, 8).

Auch SENKEVIČ folgert, daß die regelmäßig wiederkehrenden sprachlichen Elemente, die der wissenschaftlichen Arbeit aller Wissenszweige eigen sind, es erlauben, uber den einheitlichen Stil der wissenschaftichen Darstellung als einen funktionalen Stil zu reden (SENKEVIĆ 1976, 42). BUDAGOV schrănkt ein, daß wohl Unterschiede zwischen einem technisch-wissenschaftlichen und einem mathematisch-wissenschaftichen sowie auf der anderen Seite zwischen einem strengen wissenschaftlichen Stil und einem popularrwissenschaftichen Stil existierten, doch basierten sie eher auf quantitativen Kriterien. Sie würden daher nicht einem allgemeinen Begriff eines wissenschaftlichen Stils widersprechen (BUDAGOV 1967, 220).

\subsection{Wissenschaftlicher Funktionabtil und Fachsprache}

Wie hăngen wissenschafticher Funktionalstil und Fachsprache zusammen ? Diese Frage beinhałtet bereits eine Prămisse, nămlich daß die beiden Phănomene etwas gemeinsam haben oder in Relation zueinander stehen.

\footnotetext{
${ }^{5}$ Zum Postulat der Divergenz vgl. AVRASIN (1973, 4); zu dem der Konvergenz vgl. BUDAGOV $(1965,461)$ und KOŻINA $(1972,81)$.

${ }^{6}$ OLSCHKI (1922): Geschichte der neusprachlichen wissenschaftichen Literatur.
} 
Vorab muß konstatiert werden, daß beide Begriffe unabhăngig voneinander entwickett wurden. Der Begriff 'Funktionalstil' wurzelt in der funktionalen Auffassung der Sprache aberhaupt; der Begriff 'Fachsprache' dagegen geht vom Fach aus. Die Frage nach dem Zusammenhang spiegeh also eher das Bestreben wider, einen solchen heraustellen, um eben beide Konzepte, von denen jedes allein schon recht fruchtbar ist, in einen noch ergiebigeren Rahmen zu stellen, der wiederum neue methodische Erkenntnisse bringen solte.

HOFFMANN $(1976,69)$ versucht, das aufgezeigte Problem zu losen, indem er feststelt, daß „die Aussagen der Vertreter der funktionalen Stilistik, was ihre Einzelbeobachtungen angeht, fast ausnahmslos zutreffen". Auch hăh er die Beschreibung eines 'wissenschaflichen Stils' vor dem Hintergrund anderer Funktionalstile, insbesondere dem 'Stil der schðnen Literatur', fur einen Fortschritt (ebd.). Andererseits hat er eine Reihe von Argumenten gegen die Funktionalstilistik vorzubringen, deren wichtigste u.E. folgende sind:

- die Stilistik neige dazu, den Stil und besonders den Funktionalstil der Wissenschaft als geschlossenes System zu betrachten, wăhrend die Fachsprachen als ausgesprochen offene Systeme oder einfacher als sich stăndig entwickelnde und vervollkommnende Gesamheiten sprachlicher Mittel angesehen werden solten;

- die Stilistik habe es auf Grund ihrer bisherigen Einteilung in Funktionalstile schwer, alle fachsprachlichen Bereiche zu einer Einheit zusammenzufassen:

- die konkreten Gemeinsamkeiten der einzelnen Fachsprachen seien zu wenig. als daß man diese zu einem Funktionalstil zusammenfassen und sie selbst als 'Abarten' oder 'Gattungsstile' behandeln könne (ders., 71 f.).

Polemisch beschreibt HOFFMANN die Position der Funktionalstilistik folgendermaßen:

Die [Funktional] Stilistik ist, auch wenn sie es nicht immer eindeutig so formuliert. der Auffassung: Fachsprache ist (ein) Funktionalstil oder es gibt keine. (HOFFMANN 1976, 72)

Diese extreme Position konnte als Deckungsgleichheit bezeichnet werden:

Fachsprache $=$ Funktionalstil. 
Demgegenüber differenziert HOFFMANN genauer: nach seiner Meinung haben Fachsprachen einen Stil, aber keinen einheitlichen. Gemeinsam seien ihm nur sehr allgemeine Zuge und eine Reihe von Einzelmerkmalen (ders., 73).

Die Frage nach dem Zusammenhang zwischen Fachsprache und wissenschaftichem Funktionalstil muß im geschichtlichen Kontext der Fachsprachenforschung gesehen werden: der lexikologische Ansatz war insofern berechtigt, als ohnehin fast ausschließlich die technische(n) und naturwissenschaftliche(n) Fachsprache(n) untersucht wurde(n), in denen bekanntlich die Terminologie eine maßgebliche Rolle spielt. Die Frage nach dem Zusammenhang der beiden Konzepte drückt demnach auch das Bedürfnis aus, die Untersuchung methodisch ganzheitlich auf die Humanwissenschaften auszudehnen. die bisher weitgehend vernachlassigt worden waren' .

Folgerungen für die Untersuchung:

Das Konzept der Fachsprache soll folgendermaßen herangezogen werden: ausgehend von der Existenz des Faches Geschichte bzw. Historiographie setzen wir hypothetisch eine 'Fachsprache der Historiographie' an. In der Untersuchung wird festzustellen sein, ob zumindest in bezug auf die vier Parameter eine Einheitlichkeit innerhalb der historiographischen Werke auftritt. Wenn eine solche auftritt, so wäre in bezug auf unsere Parameter die Existenz einer Fachsprache bewiesen ${ }^{8}$. Weiterhin ist fur die Untersuchung nützlich, sowohl Ergebnisse als auch einige Methoden der Fachsprachenforschung heranzuziehen (siehe dazu die Überlegungen zur Wahl des Parameters Prådikativităt bzw. Kapitel 5: Methodologische Vorüberlegungen).

Unter Einbeziehung der im zweiten Kapitel gemachten Prämisse, daß die Historiographie zu den Wissenschaften gezăhlt werden kann. wurde der historiographische Stil unter den wissenschaftichen Funktionalstil subsumiert, jedoch wird noch im Verlauf der Untersuchung festzustellen sein, welche konkreten Funktionen der historiographische Stil erfullen muß und inwieweit diese in der 'theoretisch-fachlichen Mitteilungsfunktion'

\footnotetext{
${ }^{7}$ Eine Ausnahme mag die Philosophie darstellen, die sich unter den Humanwissenschaften am meisten durch eine eigene Terminologie auszeichnet, was der lexikologisch orientierten Fachsprachenforschung entgegen kam.

${ }^{8}$ Dabei ist zu betonen, daß der Begriff 'historiographischer Stil' nicht den Anspruch auf Einheitlichkeit erhebt; der Begriff 'historiographischer Stil' ist ein Arbeitsbegriff und bezeichnet die tatsächlich vorkommenden sprachlichen Erscheinungen in den untersuchten Werken. (Vgl. auch Anm. 5, S.16)
} 
bereits erfaBt werden. Damit soll auch versucht werden, letztere am Beispiel des historiographischen Stils konkret festzumachen.

\subsection{Wissenschaftssprache}

Der Begriff 'Wissenschaftssprache' zeichnet sich durch eine größere Hinwendung zu den Wissenschaften als Ganzes (insbesondere der Einbeziehung der Humanwissenschaften) aus und distanziert sich damit gewissermaßen von der Fachsprache, die neben ihrer Fixierung auf die Naturwissenschaften noch die technischen Făcher einschloB. Zwar gab es durchaus Ansătze. auch die Humanwissenschaften in fachsprachliche Untersuchungen einzubeziehen. doch ánderte dies wenig an der grundsătzlichen Ausrichtung. Oberhaupt orientien sich der Begriff der Wissenschaftssprache weit eher am Begriff des wissenschaftichen Stils aus der Funktionalstilistik als an dem Begriff der Fachsprache.

\subsubsection{Gibt es einen humanwissenschaftlichen Stil ?}

Wir sprachen bisher immer nur von dem einen 'wissenschaftlichen Stil', als ob dieser alle Wissenschaften umfassen wüde, denn da es keine Dichotomie des Begriffs in einen 'naturwissenschaftlichen Stil' und einen 'humanwissenschaftlichen Stil' gab, muBte davon ausgegangen werden, daß sich auch die Humanwissenschaften des allgemein postulierten 'wissenschaftichen Stils' bedienten. Es gibt jedoch Ansătze, diese Ungenauigkeit zu beheben; so z.B. von SENKEVIC (1976, 43), der neben dem маучнотехнический und dem маучно-естестөенный auch den маучно-zуманитарный Stil unterscheidet, und es zeichnet sich allgemein das Bestreben ab, die u.E. durchaus notwendige Unterscheidung zwischen naturwissenschaftlichem und humanwissenschaftlichem Stil voraunehmen.

Năher mit der Problematik des Sprachstils in den Humanwissenschaften hat sich FRICKE (1986) befaßt. Er beschrănkt seine Überlegungen auf die Humanwissenschaften, d.h. auf die „uberwiegend nicht experimentell arbeitenden Geistes- und Sozialwissenschaften“ (S.63). Nach seiner Meinung könne in den humanwissenschaftlichen Disziplinen keine Rede sein von einer Fachsprache oder gar einer Wissenschaftssprache. Der entscheidende Mangel liege in der fehlenden Einheitlichkeit innerhalb einer Disziplin:

Wăhrend man auch von zwei auf ganz verschiedene Sachgebiete spezialisierten Chemikem immer noch sagen kann. daß sie Sprachteilhaber derselben 'Fachsprache der Chemie' sind, wird man beispielsweise bei einer Diskussion 
zwischen drei Stadtsoziologen mindestens drei verschiedene sprachliche Schulzugehörigkeiten bemerken können; und etwa von einer einheitlichen 'Fachsprache der Geschichtswissenschaft' uberhaupt sprechen zu wollen, wäre ebenso unüblich wie unberechtigt. (FRICKE 1986, 63)

Im Gegensatz zu HAHN, der bereits Bedenken hat, eine Fachsprache der Chemie zu postulieren $(1983,63)$, gibt es fulr FRICKE anscheinend eine solche. Zwar kann man FRICKE schwerlich widersprechen, wenn er die Einheitlichkeit der 'Fachsprache der Geschichtswissenschaft' in Frage stelt (wie in der Untersuchung noch zu sehen), doch wird von ihm die Einheitlichkeit der 'Fachsprache der Chemie' zu sehr idealisiert.

Allerdings schneidet er als wichtigen Punkt den Adressaten an: es tue der Arbeit des Naturwissenschaftlers keinen Abbruch, wenn er sich nur im engsten Kreis der Fachkollegen verstăndlich machen kơnne, eher im Gegenteil. Dem Humanwissenschafter dagegen müsse an der möglichst weitgehenden Verbreitung seiner Forschungsergebnisse gelegen sein. denn ihr offentlicher Nutzen könne nur bestehen in einem Beitrag zur 'Aufklarung' und in einem Anstoß zur Selbstreflexion bei møglichst vielen durch die Anwendung der wissenschaftlichen Einsichten auf sich selbst (FRICKE 1986, 65).

\subsubsection{Zum Konzept der Wissenschaftssprache}

Das Konzept der Wissenschaftssprache fallt in theoretischer Hinsicht hinter das Konzept des Funktionalstils zurück. Die Trennung zwischen human- und naturwissenschaftlichem Stil würde das Konzept der Wissenschaftssprache heuristisch und praktisch ergiebiger machen; sie wird aber nicht durchgefürt, so daß die theoretische Abstraktion eines 'wissenschaftichen Funktionalstils' einer nicht năher definierten 'Wissenschaftssprache' vorzuziehen ist.

\subsection{Geare, Textsorte?}

Nachdem bisher Abstraktionen hoheren Grades angenommen wurden ('Fachsprache', 'wissenschaftlicher Funktionalstil', 'Wissenschaftssprache'), soll jetzt konkret von den Texten ausgegangen werden. Wichtig erscheint uns hier der Begriff des Genres, mit dessen Hilfe Texte eingeordnet wurden.

\footnotetext{
'Die Begriffe 'Genre' und 'Textsorte' sind nicht vollig identisch. Die Textsortenproblematik ist in der russischen Forschung noch mehr ein neues Gebiet als in der deutschen.
} 
Die Verwendung des Genre als Grundlage für die Textklassifikation hat in der russischen Sprachwissenschaft eine lange und feste Tradition ${ }^{10}$. Nach EFIMOV fuhrte Lomonosov das Genre-Prinzip fur das Russische ein: "[...] Ломоносов дифференцировал стили языка в соответствин с жанрами литературы."(EFIMOV 1969, 11). Der Inhaht sprachlicher Äußerungen sei somit ausschlaggebend; er allein regle die Auswahl der sprachlichen Mittel und bestimme die Normen ihrer Verwendung, weshalb man bei jeder Stilklassifikation vom Genre ausgehen musse. Man muß hier jedoch eine Oberinterpretation EFIMOVs sehen. denn bei Lomonosov findet sich keine klar umrissene und ausgearbeitete Definition eines Genre-Stils " .

Nach VOMPERSKIJ feht der Begriff eines Genre-Stils aberhaupt bei Lomonosov. Grund dafur sei die zweiseitige Abhangigkeit des Genres in der stilistischen Theorie von Lomonosov:

- einerserts hănge bei Lomonosov die Wahl der sprachlichen Mittel nicht vom Genre ab, sondern vom Thema, d.h. bevor der Schriftsteller an seine Arbeit geht, mulsse er feststellen, welchen Grad der Wichtigkeit der Gegenstand und das Thema besaßen, und erst dann das entsprechende Genre auswăhlen.

- andererseits gebe es bei Lomonosov keinen konkreten Hinweis darauf, daß das Genre eine Komponente des Stils darstelle. Komponenten des Stils sehe Lomonosov nur in der Lexik. der Phraseologie, der Phonetik und der Grammatik (VOMPERSKIJ 1970, 152). Folglich betrafen die grundlegenden Aufgaben, die Lomonosov in seiner Theorie losen wolte, nahezu ausschlieBlich die lexikalische Charakteristik der sprachlichen Stile und den Versuch der Festlegung einer lexikalischen Norm. Der Begriff des Genre-Stils fehite ebenso wie der Begriff des Funktionalstils ${ }^{12}$.

\footnotetext{
${ }^{10}$ Man kann das Genre-Prinzip sehr fruh ansetzen, wenn man entsprechende Kriterien veranschlagt: "Жанровой принцип классификации речевых стилей, как известно, имеет многовековую историю. Он использовался еще в античной поэтике (три стиля Аристотеля, древненндийские теории стиля)." (PIOTROVSKIJ $1954,56)$

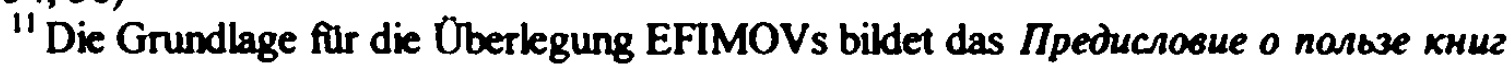
церковных (1757), bei dem es sich aber eher um einen skizzenhaften Entwurf als um eine ausgearbeitete Theorie handelt. Nach ISAČENKO (1983, 591 ff.) ist es daher eigentlich nicht angebracht, von einer 'stilistischen Theorie' zu sprechen, wie es EFIMOV und andere tun.

${ }^{12} \mathrm{Vgl}$. hierzu die weiteren Ausführungen unter 4.1
} 
Auch wenn der Begriff des Genre-Stils also nicht direkt von Lomonosov herrilhrt, hantierten viele Forscher mit ihm. So griff auch noch VINOGRADOV $(1946,225)$ bei seiner Stildefinition auf die verschiedenen Genres und Textsorten zurück und beschrieb diese als Stile. „Dabei ließ [er] sich von der Vorstellung leiten, es sei møglich, die fur jeden Stil konstitutiven sprachlichen Merkmale, die man zunăchst fast ausschließlich in der Lexik angesiedelt sah, aufzufinden [...]" (GOLUBZOWA 1991, 61). Von Lomonosov bis Vinogradov lag damit der Schwerpunkt der Stilbeschreibung auf der Lexik.

Erwăhnt werden soll noch LICHACEV, der ebenfalls den Begriff des Genres ausgiebig verwendet. Nach seiner Auffassung stellen die Genres ein abgeschlossenes System dar, welches in den verschiedenen Epochen unterschiedlich ist $(1986,78)$. Also handelt es sich um eine historische Kategorie. Im Grunde genommen rockt LICHACEV die Genres in die Năhe der Funktionalstile, denn wenn er sagt, daß sich die Genres final unterscheiden ("жанры различаются по тому, д л я ч е $r$ о они предназначены" (ders., S.63)), so ist darunter Funktionalităt zu verstehen, schließlich ergibt sich aus jeglicher finalen Bestimmung eine Funktion. Wenngleich LICHACEV nicht so sehr die Diskussion in der Linguistik beeinflußt, weil er in erster Linie Literaturwissenschaftler ist, sieht man doch. wie das Genre-Prinzip bis in jüngster Zeit (1986 !) angewendet wird.

Trotz der Langlebigkeit des Genre-Begriffs begann man sich in der russischen (sowjetischen) Linguistik doch beizeiten vom Genre-Prinzip abzuwenden. So schreibt BUDAGOV: "[...] языковые стили нельзя смешивать [...] с жанрами художественной литературы [...]" (1954, 67); damit wurde auch gewissermaßen der Inflation von Stilen ein Riegel vorgeschoben, denn zwar mag jeder Text eine Funktion haben. doch kann man deswegen nicht jedem Text einen Stil zuschreiben ${ }^{13}$.

\subsubsection{Textsorten}

Wie unter 3.1.3 gezeigt, ist die Text-Phase die jüngste Phase in der Fachsprachenforschung. Ausgangspunkt ist nun der Text. Auch sei an das zweite Verfahren von HAHN erinnert: man geht von den Text(sort)en aus, die in einem Fach verwendet werden, und versucht, Rückschlüsse auf die 'Sprache des Faches' zu ziehen. Auslðser

\footnotetext{
${ }^{13}$ Allerdings ist auch eine ähnliche Inflation bei dem Begriff 'Textsorte' zu verzeichnen.
} 
dieser Entwicklung war die Textlinguistik, welche die Beschrånkung der linguistischen Forschung auf den 'Satz' nun auf den 'Text' richtete, wobei diese Texte als Folge von Satzen angesehen werden.

Die Textlinguistik ist noch weit von einer geschlossenen Typologie der Textsorten entfernt, was nicht verwundert angesichts der inflationären Zahl der Textsorten: DIMTER $(1981,33)$ zäht im Rechtschreibduden von 1973 mehr als 1600 Textsortennamen, wobei er nur ca. 500 als 'grundlegend', die anderen als 'abgeleitet' bezeichnet.

Festzuhahen ist, daß durch diesen Ansatz einer differenzierenden Beschreibung Raum gegeben und eine idealisierende Konstruktion einer nicht vorhandenen Homogenităt vermieden wird. Weiterhin werden pauschale Aussagen nun eher durch konkrete Fakten ersetz, die nachweislich in den einzelnen Texten auftreten und die erlauben, die Makrostruktur der Texte offenzulegen.

Folgerungen für die Untersuchung:

Auch die vorliegende Untersuchung geht von den einzelnen Texten aus: so werden die einzelnen Untersuchungsabschnitte bewußt mit Text 1, Text 2 und Text 3 gekennzeichnet, um die textuelle Abgeschlossenheit zu unterstreichen. Der textlinguistische Ansatz erstreckt sich jedoch nur auf den praktischen Teil der Untersuchung. Was die theoretische Diskussion anbelangt, so erscheint das Konzept des Funktionalstils ungleich mehr fruchtbar, als wenn mit dem Begriff der Textsorte 'Geschichtstexte' operiert werden müßte. Vor allem aber greift der Begriff u.E. zu kurz, wenn historisch bedingte Funktionsăndenungen der Textsorte auftreten.

\subsection{Die Problematik des Begrifis 'Stil'}

Die Norm ${ }^{14}$ ist vor allem in den Bereichen der Phonetik, Orthographie und weitgehend auch in der Grammatik streng anwendbar. In den Bereichen der Syntax und Lexik hingegen kann eigentlich keine strenge Norm erstellt werden. Man brăuchte daher nicht wie GOLUBZOWA die Stilistik für alle sprachlichen Ebenen zustăndig erklăren:

Wăhrend die anderen linguistischen Disziplinen ihren Gegenstand ohne großere Schwierigkeiten auf phonetische, grammatische oder lexikalische Fakten eingrenzen konnen, muß die Stilistik a 11 e sprachlichen Fakten zu ihrem Untersuchungsgegenstand machen. (GOLUBZOWA 1991, 59)

\footnotetext{
14 'Norm' wird hier undifferenziert als Überbegriff verwendet. Es soll hier nicht weiter zwischen 'Norm', 'Usus' und 'Kodifikation' unterschieden werden.
} 
vielmehr kð̋nten die phonetischen und grammatischen Fakten als von der Norm 'regiert' ausgeklammert werden.

Zwar gibt es Ansătze, den Stil auch als Subkategorie der Grammatik aufzufassen. doch erscheint dies nicht angebracht, denn ,[d]as Sprachsystem ist so strukturiert, daß es neben den obligatorischen Regeln der Sprachnorm (Grammatik) auch fakultative Möglichkeiten des Sprachgebrauchs (Sti) zulät“" (SANDERS 1973, 67). Die obligatorischen Regeln der Grammatik lassen kaum einen Spielraum; sie sind in ihrer Anzahl endlich und begrenzt und können daher von der Norm ausreichend erfaßt und 'unter Kontrolle' gebracht werden. Da Stil aber vor allem die Vorstellung der ungezwungenen freien Auswahl und der Kreativităt beinhalte, könne Stil erst auf derjenigen sprachlichen Ebene einsetzen, welche ausreichend Spielraum fur verschiedene Realisationsmðglichkeiten bietet, nămlich auf der Ebene der Lexik, der Syntax und des Satzbaus. Stil resultiere demnach aus dem Selektionsvorgang aus mehreren aquivalenten Möglichkeiten der Sprache:

Wie das Inventar des Lexikons (Wortschatz) innerhalb bestimmter Grenzen die Wahl Laßt, einen zugrunde liegenden 'Realitătsgehalt' mit einem allgemeinen oder präzisen, einem indifferenten oder stilistisch gefarbten usw. Ausdruck zu bezeichnen, so ergeben sich auch syntaktisch zahtreiche Moglichkeiten, ein und denselben Sachverhatt als Satz zu formulieren [...] (SANDERS 1973, 76)

SANDERS legt hier die Annahme zugrunde, daß es ,inhaltlich identische, aber formal unterschiedliche Formulierungen von Sătzen gibt, die also in 'Paraphrasenrelation' zueinander stehen (der Begriff 'Paraphrasenrelation' entspricht auf der Satzebene der 'Synonymierelation' auf lexikalischer Ebene)" (ebd.).

Vor allem in der Syntax und im Textaufbau gebe es kaum noch Grenzen für die stilistische Individualităt, „da Syntaxregeln für die satzubergreifenden Zusammenhănge nicht existieren“" (ders., 79). Allerdings bedarf es hier einer gewissen Einsciłăukung: zwar gibt es keine Syntaxregeln fur den Text oberhalb der Satzgrenze, gleichwohl beobachtet man intuitiv (und im Teil B der vorliegenden Arbeit wird dies noch empirisch Bestătigung finden), daß der Stil eines Dichters sehr wohl bestimmte Textbauregeln zugrunde liegen hat. Diese Regeln treten nicht nur (um mit Chomsky zu sprechen) in der Tiefenstruktur auf, also etwa ăhnlich wie die vielgerahmte 'Logik' der franzosischen Sprache bzw. der 
franzosischen Schriftsteller ${ }^{15}$. Vielmehr laßt sich eine Regelmäßigkeit der Satzstrukturen und damit auch des Satzbaus ablesen, so da $\mathrm{B}$ anstelle einer vage anzunehmenden Tiefenstruktur doch eine klar feststellbare (und statistisch zahlbare) textliche Gestaltung und Umsetzung vorhanden ist.

Wir halten demnach für unsere Untersuchung als Ausgangsuberlegung fest: Stil manifestiert sich restringiert im Wortbereich, stårker auf der Satzebene und am deutlichsten im Textzusammenhang:

Erst auf der dem Satz ubergeordneten Ebene des 'Textes' besteht großere, wenn nicht sogar uneingeschrănkte Freiheit stilistischer Gestaltung: Das eigentliche Wirkfeld des Stils ware danach der Text.

(SANDERS 1973, 79 f.)

Folgerungen für die Untersuchung:

Für unsere Arbeit grenzen wir den Stilbegriff auf die Satzbauebene ein und bewegen uns damit zwischen der syntaktischen und der textuellen Ebene. Dadurch wird der Stilbegriff gegenüber dem auf die Lexik und Grammatik beschränkten klar abgegrenzt.

\subsection{Zusammenfassung der Ũberlegungen}

In diesem Kapitel konnten folgende Rahmenbedingungen der Untersuchung abgesteckt werden:

a) Der historiographische Stil wird unter den wissenschaftlichen Funktionalstil subsumiert.

b) Wir setzen hypothetisch eine 'Fachsprache der Historiographie' an und uberprüfen in der Untersuchung, ob sich eine solche in bezug auf die vier Parameter nachweisen laßt: außerdem sollen Methoden und Ergebnisse der Fachsprachenforschung für die Untersuchung herangezogen werden.

c) Das Konzept des wissenschaftlichen Funktionalstils wird herangezogen, um die historiographischen Texte unter funktionalem Aspekt zu betrachten, was aufgrund des zumindest in Ansätzen vorhandenen wissenschaftichen Charakters der untersuchten historiographischen Werke notwendig erscheint. Vor allem soll die global formulierte

\footnotetext{
${ }^{15}$ Es soll hier nicht das Gegenteil unterstellt werden. Die franzosische Sprache eignet sich hervorragend zur Darstellung logischer Strukturen, und auch viele franzðsischen Schriftsteller zeichnen sich aus durch einen bestechend klaren Stil, doch ist dies eher auf die Schulung zuruckzufuhren als auf ein innewohnendes Element der franzosischen Sprache (vgl. COSERJU 1988, 224).
} 
'theoretisch-wissenschaftliche Mitteilungsfunktion' für den historiographischen Stil näher bestimmt werden.

d) Die Untersuchung stützt sich in der Durchführung auf einen textlinguistischen Ansatz.

e) Die eigene Stildefinition (sowohl für den historiographischen als auch für den literarischen Stil) bezieht sich auf die Satzbauebene. 


\subsection{Zur Auswahl der Autoren und Werke}

Nachdem die Historiographie und die Stilproblematik erortert wurden, soll nun noch auf die Autoren bzw. auf die einzeinen Werke, die der Untersuchung zugrundeliegen, eingegangen werden. Wenn wir uns die schematische Ubersicht der Texte vor Augen fuhren:

\section{Geschichtswerke}

Lomonosov

"Древняя Российская история"

Karamzin

"Исторня государства Российского"

Puskin

"История Путачева" dichterische Werke

Karamzin

"Бедная Лиза"

Puskin

"Капитанская Дочка"

so fallt auf, daß fur Lomonosov kein dichterisches Werk angegeben ist; obwohl auch als Dichter tătig, waren seine Dichtungen ausschließlich nur in Versform verfaßt (Oden, Elegien). Da der Untersuchung aber Prosatexte zugnundeliegen, konnte kein dichterisches Werk von Lomonosov herangezogen werden.

Mit dem Stichwort 'Prosatext' haben wir einen Aspekt erwähnt, der wesentlich für die Untersuchung ist, denn die Entwicklung des historiographischen Stils steht unlठsbar mit der Entwicklung der Prosa in Verbindung; dasselbe gilt für den literarischen Stil. Die Fragestellung, welchen Einfluß die Entwicklung des historiographischen Stils auf die Entwicklung des literarischen Stils ausübr, kann man auch umdrehen: inwieweit beeinflußt die Entwicklung des literarischen Stils die Entwicklung des historiographischen Stils?

Fest steht, daß sich die Prosa in der Dichtung erst einmal etablieren mußte und ihr sehr lange die Konnotation des gemeinen, altăglichen und fachlichen eigen war. Gerade die genannten drei Autoren standen bei der Schaffung einer Prosa in vorderster Reihe, wobei die theoretische Diskussion der praktischen Umsetzung nachfolgte: erst Puskin erhob die Schaffung der Prosa explizit zum Programm. Lomonosov machte zwar große praktische Schritte in der Entwicklung des wissenschaftichen Funktionalstils, doch blieb er in der theoretischen Diskussion noch der antiken Stitheorie verhaftet. 


\subsection{Zu Lomonosov}

Lomonosov in seiner Rolle als uberragender Wissenschaftler ist maßgeblich an der Ausbildung der Fachsprache (d.h. des naturwissenschaftlichen Funktionalstils) beteiligt. Doch dürfen dabei nicht die große Vorarbeit und die bereits erzielten Resultate der Petrinischen Zeit übersehen werden. So war der Stil der naturwissenschaftlichen Bücher auf den Ebenen der Lexik und der Syntax (Satzbau eingeschlossen) im Vergleich zu den anderen Textsorten am besten ausgearbeitet (KISTINA 1964, 6). Wie bei den Erorterungen uber die Fachsprache bzw. die Sprache in den Naturwissenschaften angedeutet, konnte in diesen Disziplinen eine Normierung der Lexik und Konsolidierung des Stils am schnellsten vor sich gehen, weil die Untersuchungsgegenstände in der Technik und in den Naturwissenschaften klarer und konkreter definierbar sind als in den Humanwissenschaften.

Die Bedeutung Lomonosovs liegt darin, daß er nicht nur (Natur-)Wissenschaftler war, der die Notwendigkeit der Genauigkeit von Fachsprache erkannte und die Fachsprache weiter prăzisierte, sondern sich auch dichterisch betătigte.

Im Wortschatz der sich seit den Petrinischen Reformen im Umbruch befunden hatte und der gleichzeitig eine ungeheure Erweiterung erfahren hatte, war, ausgehend von den Terminologien der Naturwissenschaften, eine allmăhliche Stabilisierung eingetreten, die ihren Niederschlag in der lexikographischen Fixierung fand. Lomonosov nahm nun die năchste Ebene, die Ebene der Grammatik, in Angriff. Er legte den Grund fir die Normierung der russischen Sprache, indem er die Российская грамматика erstelte. Vergleichbar dem Ausbauprozeß in der Lexik war auch die Normierung der Grammatik gekennzeichnet durch eine Auswahl zwischen russischen und kirchenslavischen Elementen. Neben der Ebene der Grammatik. der Syntax im engeren Sinne', verblieb die textuelle Ebene, d.h. Satzbau und Stil. Hier konnte Lomonosov aber noch gar nicht 'regelnd' eingreifen, da noch zu wenig geschaffen worden war, was man hătte regeln können. Mit ISACENKO ist hier festzustellen, daß die russische Literatursprache zu Lomonosovs Zeit stilistisch erst am Anfang ihres Ausbaus stand ${ }^{2}$. Es verwundert daher nicht, daß in der Frage des Stils bzw. der Stile Lomonosov auf die antike Stitheorie

\footnotetext{
'Wir beziehen die Syntax nur auf die Beziehungen innerhalb des Satzes und weisen jegliche weitergehende Beziehung der Satzbau- bzw. Textebene zu (vgl. hierzu Anm. 1, S. 13).

${ }^{2} \mathrm{Vgl}$. hierzu ISACENKO 1983, $592 \mathrm{ff}$.
} 
zurückgriff und daß er 'Stil' vorwiegend lexikalisch definierte. Vom Begriff 'Prosa' ausgehend heißt das, daß die den neuen gesellschaftlichen und wissenschaftlichen Gegebenheiten der russischen Sprache angepaßte Prosa erst noch geschaffen werden muBte. Ferner waren die Vorbehatte gegen die Prosa in der Dichtung nicht zu unterschătzen.

Gleichwohl tat Lomonosov einen ersten Schritt zur Schaffung der literarischen Prosa, als er sein Geschichtswerk schrieb, denn wie in Kapitel 2 gezeigt, liegt der Historiographie das Erzahlen zugrunde. und letzteres ist eine Diskursform, die auch die literarische Prosa anwendet. Nicht zu vernachlässigen ist weiter die breite Rezeption der historiographischen Werke, da es sich um Themen und Inhalte handete, die jeder Laie verstand und verstehen sollte und dic auch viele Laien interessierten. Ferner wird die Bedeutung des historiographischen Stils bei Lomonosov daran deutlich, daß sich auch Karamzin uber diesen Stil geăuent hat; wohl auch deshalb, weil es, wie gesagt, das einzige nicht-technische und nicht-wissenschaftliche Prosawerk Lomonosovs war.

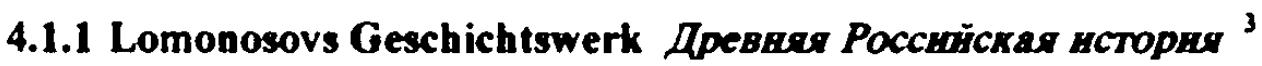

Bereits 1749 machte Lomonosov den Vorschlag, daß eine russische Geschichte geschrieben werden solte. Im September $1751^{4}$ teite er Suvalov mit, er plane, eine Geschichte über das atte Rußland zu schreiben. In der Folgezeit sammelte er das nötige Material. Ab dem Jahre 1753 trat die Arbeit Lomonosovs an der russischen Geschichte in eine neue Phase; er schrieb von 1754 bis 1758; also 4 Jahre. Im Jahre 1758 hatte er den ersten Band als Manuskript fertiggestelt und reichte ihn der Druckerei ein. Diese traf ihre Vorbereitungen wie Papierbeschaffung, Letternfertigung usw. Am 30. Oktober 1758 gab die Kanzlei Anweisung zum Drucken. Am 8. Mărz 1759 wurden die ersten drei Druckbrgen gedruckt.

Doch Lomonosov selbst unterbrach das Drucken. weil er die dem Text beigefugten Anmerkungen fur den Leser als störend empfand. Er zog sein Manuskript zurück und küzte es um die Anmerkungen, die er getrennt veroffentlichen wollte. Der redigierte Text wurde erst vier Jahre spăter, am 28. Februar 1763, von Lomonosov wieder

\footnotetext{
${ }^{3}$ Vgl. LOMONOSOV. Poln. sobr. soc, t. 6, $572 \mathrm{ff}$. und PAVLOVA 1986, $365 \mathrm{ff}$.

"Hier und im folgenden Angabe des Datums im alten Stil.
} 
eingereicht. Er war aber nicht vollstăndig, und die Druckerei wartete auf die Fortsetzung. Am 4. April 1765 starb Lomonosov; ehe das Werk erschienen war.

Ende Oktober 1766 erschienen die ersten beiden Teile (Часть I; Часть II). Weitere Teile sind nicht erhalten; ebenso wurden die der Kärzung zum Opfer gefallenen Anmerkungen nicht mehr entdeckt.

\subsubsection{Edition}

Das Manuskript blieb nicht erhalten.

Erstausgabe: 1766

М. В. Ломоносов. Древняя российская история. Санктпетербург. При императорской Академии Наух 1766.

Grundlage der Untersuchung:

М. В. Ломоносов. Полное собрание сочинений в 10 томах. Том шестой: труды по русской истории, общественно-экономическим вопросам и географии, 1747-1765 гт. Изд. Акад. наук СССР. Москва/ Ленинград 1952, 163286.

und daraus unsere Texte:

Untersuchungsabschnitt 1 (= Text 1):

Вступление

Untersuchungsabschnitt 2 (= Text 2): Глава $1,2,3$; Часть I

Untersuchungsabschnitt 3 (= Text 3): Глава 5 ; Часть II

\subsubsection{Editionsănderungens}

In der Ausgabe von 1952 wird zwar behauptet, daß die Ausgabe mit der Erstausgabe von 1766 übereinstimme: "Печатается по посмертному изданию 1766 г." (S.572) und: "Ках и в других томах, все редакторские вставки и конъектуры, вводимые в тексты Ломоносова, заключены в обычные прямые скобки [ ]." (S.540). Bei genauem Vergleich der beiden Ausgaben ergeben sich aber vor allem in der Interpunktion Unterschiede, und zwar nicht nur innerhalb der Sătze, sondern auch in bezug auf die Satzabgrenzungen ${ }^{6}$. Allerdings kann generell gesagt werden, daß die

\footnotetext{
${ }^{5} \mathrm{Da}$ sich die Untersuchung auf den Satzbau konzentriert, erschien es notwendig, die Editionen auf Änderungen in der Interpunktion zu überprufen.

${ }^{6}$ Vor allem in Text 3 weist die 1766-Ausgabe erhebliche Abweichungen gegenüber der der Untersuchung zugrundeliegenden Ausgabe auf: in der Ausgabe von 1766 weisen 14 Sătze eine andere Satzbegrenzung auf als in der untersuchten Ausgabe. Da der Text 3 aus Teil 2 (Чactb II) des Werkes stammt und dieser Teil im Manuskript vermutlich nicht
} 
Interpunktion der zur Untersuchung herangezogenen Ausgabe semantisch-syntaktisch plausibler ist als in der Ausgabe von 1766.

\subsubsection{Bedeutung des Geschichtswerkes}

Die Древняя Российская история stelte ein großes Ereignis in der russischen Historiographie dar. Es war das erste gedruckte Geschichtswerk, welches dem russischen Leser eine umfassende Darstellung der russischen Geschichte bot. Die Arbeit ist gewissermaßen das erste greifbare Ergebnis der Bemühungen russischer (und ausländischer) Gelehrter, seit im Jahre 1749 an der Petersburger Akademie der Wissenschaften die Historische Kommission eingerichtet worden war. Wohl hatte auch Tatišev (16861750) an einer Geschichte Rußlands gearbeitet, doch wurde seine Arbeit erst 1768-74 gedruckt (TERRAS 1991, 148); offensichtlich nachdem Lomonosovs Werk auf breite Resonanz gestoßen war.

Zwar ist Lomonosovs Werk unvollendet geblieben und entbehrt des wissenschaftlichen Apparates, doch lag ein solcher Apparat vor, und überhaupt wurden ausreichend strenge wissenschaftliche Kriterien von Lomonosov angewandt.

\subsection{Zu Karamzin}

Erst mit der Herausbildung von (neuen) Prosagenres wie Roman und Erzăhlung in den 60er Jahren des 18. Jahrhunderts wurde der Ausbau der literarischen Prosa notwendig. Die Schaffung dieser Prosagenres war nicht genuin russisch. vielmehr ist ihr Ursprung im Westen zu suchen. Wie die Bezeichnung 'Roman' bereits andeutet, waren es die romanischen Literaturen, in denen sich zuerst diese Gattung durchsetzte ${ }^{7}$. Für Rußland spielte Deutschland eine wichtige Vorreiterrolle: auch hier war die Schaffung einer Prosa eine neue Anforderung an die deutsche Sprache, denn in der Sachprosa hatte das Lateinische, in der literarischen Prosa das Franzosische vorgeherrscht. Es stellte sich für das Deutsche und das Russische das Problem in ahnlicher Weise: wie baut man die

überarbeitet wurde wie Teil 1, ist u.E. in der Ausgabe von 1766 wohl eher die Meinung des Setzers zu sehen als die Lomonosovs.

${ }^{7}$,Seit dem 12. Jahrhundert wurde in den romanischen Sprachen jedes nicht mehr lateinisch, sondern volkssprachlich abgefaßte Erzahlwerk als roman (altfrz.) oder romance (span.) bezeichnet. “ (VOGT 1990, 221) 
Syntax ${ }^{8}$ der eigenen Sprache adăquat aus, bzw. wie lőst man sich von dem Vorbild des schwerfalligen lateinischen und kirchenslavischen Satzbaus?

Obwohl sich Karamzin auch Verdienste auf dem Gebiet der Lexik erwarb, liegt doch sein wichtigster Beitrag auf dem Gebiet des Satzbaus. Zwar gab es auch Vorgănger, die die Entwicklung einer 'neuen' Prosa vorangebracht hatten, doch ragt Karamzin unübertroffen hervor. Dies wohl vor allem deshalb, weil er im Gegensatz zu Lomonosov ein klares Programm hatte, welches er selber umsetzte und welches explizit die Aufgaben des Satzbaus des "новый слог" so genau beschrieb, daß auch andere Autoren bewußt diesem neuen Stilideal folgen konnten ${ }^{9}$. Mit Karamzin wurde endgütig die Theorie der drei Stile überwunden und eine neue Sicht der Sprache und ihrer Aufgaben eingefuhrt. Als oberstes Ideal wurde die Verstandlichkeit im Dienste der Aufklärung angestrebr ${ }^{10}$.

Was nun die literarische Prosa anbelangt, so wurde hier nicht nur Verståndlichkeit, d.h. clareté, verlangt. sondern doch auch eine gewisse Erhabenheit, wie wir sie vom hohen Stil her kennen:

Dieses Streben nach Vereinigung von Erhabenheit (важность) und Klarheit (ясность) in einem Werk drükt ein Programm aus, das den Ansichten Lomonosovs widersprach. In seinen Arbeiten und in der literarischen Praxis um die Mitte des 18. Jahrhunderts waren diese beiden Kategorien einander gegenubergestelt. (ECKERT 1983, 210)

Die Erhabenheit fand vor allem in der Lexik ihren Ausdruck; demgegenuber war die Klarheit vor allem im Satzbau zu erreichen. Karamzin kritisierte explizit an Lomonosov, daß seine Satzperioden zu "lang" und ,ermüdend" seien und daß sie nicht immer der Gedankenfolge entsprăchen (MARTEL 1933, 102). Für Karamzin wie auch für die französischen und deutschen Aufklärer gab es eine 'natürliche' logische Denkordnung, die sich unmittelbar im Satzbau niederschlagen mußte ". Diese logische Denkordnung

\footnotetext{
${ }^{8}$ Der von Karamzin verwendete Begriff 'Syntax' schließt meist den Satzbau mit ein; wir versuchen im folgenden beide Phänomene zu unterscheiden (vgl. Anm. 1, S. 13).

${ }^{9}$ Das Programm findet sich nicht kompakt als Programmschrift bei Karamzin; vielmehr ist es uber mehrere Aussagen verteilt, und manche dieser Aussagen sind sogar in sich widersprüchlich: "Тем не менее современники Карамзина - как сторонники, так и противники - воспринимали эту концепцию как цельную и вполне последовательную, и именно это восприятие определило отношение к Карамзину как х реформатору русского литературного языка." (USPENSKIJ 1985, 8).

${ }^{10}$ Allerdings erstreckte sich die Aufgabe der Aufklărung wie auch die Verstăndlichkeit der Sprache anfangs noch nicht auf alle Volksschichten, sonderm in erster Linie auf den Adel und das Bildungsbürgertum.

"Vgl. RAECKE 1994, 239 ff.
} 
galt es, in der Prosa nachzubilden, wobei zugestanden werden muß, daß die Ausrichtung auf die gesprochene Sprache wohl auch diese Denkordnung widerspiegett, zumindest sind in der gesprochenen Sprache Sperrungen nicht ablich, und tatsăchlich zeigt sich auch die SVO-Ordnung in der gesprochenen Sprache hăufiger als in der geschriebenen ${ }^{12}$.

\subsubsection{Karamzins Geschichtswerk Нстория rосударства Россйското}

Im Jahre 1803 war Karamzin zum Hofhistoriker emannt worden. Seine Reputation als Historiker, die er sich mit seinen historischen Essays erworben hatte, war so groß, daß er zuvor auch Professuren von den Universităten Dorpat, Moskau und Char'kov angeboten bekam. Bereits 1790 Laßt sich in einem Brief Karamzins aus Paris der Plan, eine Russische Geschichte zu schreiben, nachweisen. Doch erst 1803 machte er sich an diese Aufgabe. Nach 12-jahriger Arbeit hatte er Ende 1815 die ersten 8 Bănde im Manuskript fertiggestelt. Die Drucklegung zog sich allerdings hin, so daß diese Bănde erst 1818 vollstăndig erschienen. Karamzin verband die Tradition der romantischen Geschichtsschreibung des 18. Jahrhunderts mit den kritischen geschichtswissenschaftlichen Techniken des 19. Jahrhunderts ${ }^{13}$. In seinen Anmerkungen (примечания) hielt sich Karamzin an die Methodik, die vor ihm durch den deutschen Historiker Schlözer begrundet worden war. Aus diesem Grunde schătzte auch Ranke in den 60er Jahren des 19. Jahrhunderts die Arbeit Karamzins.

Karamzin verbesserte die Древнея Российская история von Lomonosov an mehreren Stellen und qualifizierte sie als romantische patriotische Literatur ab. Es steht außer Zweifel, daß die Arbeit Karamzins sowohl die von Lomonosov als auch von Tatišev und Sxerbatov in den Schatten stelte, und zwar sowohl in methodischer als auch in sprachlicher Hinsicht. Für die methodische Gründlichkeit sprechen die umfangreichen Anmerkungen; für die sprachliche Güte der Umstand, daß das Werk oft eher als literarisches Werk angesehen wurde denn als historisches.

${ }^{12}$ Zum Beispiel dominiert im Schriftarabischen VSO, wohingegen das gesprochene Arabisch zu SVO tendiert (KAYE 1987, 683).

${ }^{13}$ Siehe die Erörterungen unter 2.3.2 


\subsubsection{Edition ${ }^{14}$}

Karamzin las selber wăhrend der Drucklegung die Korrektur.

1816

Vorabdruck an den Zaren ${ }^{15}$

1818, 28. Januar erste Ausgabe (die ersten acht Bănde auf einmal)

$1818-1819$ zweite Ausgabe mit Korrekturen

1821 der neunte Band erscheint (издание Сленина)

1824 der zehnte Band erscheint (издание Сленина)

Die beiden erwăhnten letzten Bănde gingen noch zu Lebzeiten Karamzins in Druck. Der elfte Band wurde bis zum 5. Mărz 1824 im Manuskript fertig; der zwölfte Band bis zum Tode Karamzins (22. Mai 1826) zu mehr als der Hălfte.

1850 - 1853 sechste Ausgabe (издание A.Смирдина - alle 12 Bănde)

Grundlage der Untersuchung:

Н. М. Карамзин. История государства Российского. Санкт-Петербург 1892. (12 Bănde). Slavistic Printings and Reprintings. Edited by C.H. von Schooneveld. Indiana University. The Hague/ Paris 1969.

Diese Ausgabe richtet sich nach der oben aufgefuhrten Smirdin-Ausgabe:

Первый том Истории [...] представляет собою самую точную перепечатку текста Карамзинского труда по известному Смирдинскому изданию, 1850-53 гт., которое было проверено по рукописям Историографа. (t. 1, IV)

und daraus unsere Texte:

Text 1: Том I ; Предисловие

Text 2: Том I ; Глава X

Text 3: Том II ; Глава XVI

\subsubsection{Editionsānderungen}

Wie schon bei Lomonosov beobachtet, sind auch bei Karamzin die Angaben zur Ausgabentreue sehr zuversichtlich:

В тексте Карамзина не изменено ни одной буквы, не перестановлено и не выпущено ни одно примечание, сохранена вполне и его оригинальная орфография [...] (t. 1, IV)

\footnotetext{
"Vgl. PONOMAREV (1883).

${ }^{15}$ Diese Erstausgabe wurde auch herangezogen, um die Interpunktionstreue zu überprüfen. Sie wird bei PONOMAREV noch nicht erwähnt; aber so aufgefunden in der РГБ in Moskau.
} 
doch zeigt ein genauer Vergleich mit der Erstausgabe von 1816, daß die Interpunktion nicht eingeschlossen wird; es gibt sehr wohl Änderungen in der Kommasetzung. Allerdings wird nie der Satzpunkt verrückt, so daß sich die Untersuchung ohne weiteres auf den Reprint der Smirdinschen Ausgabe stützen kann.

\subsubsection{Bedeutung des Geschichtswerkes}

Das Geschichtswerk Karamzins war der populărste Lesestoff in Rußland wăhrend der ganzen ersten Hălfte des 19. Jahrhunderts (BLACK 1975, 147). Dies ist nicht verwunderlich, wenn man bedenkt, daß mit dem Sieg aber Napoleon das russische Nationalbewußtsein einen gewaltigen Aufrieb bekommen hatte. War Lomonosovs Werk den rudimentären Fragen nach dem Ursprung der russischen Nation gewidmet und bestand seine Aufgabe vorwiegend darin, das Selbstbewußtsein überhaupt erst zu bilden, so stelt sich in dem Geschichtswerk von Karamzin das neue gewachsene Selbstbewußtsein der russischen Nation dar, was sich auch rein außerlich am Umfang widerspiegelt: 12 Bănde gegenaber einem schmalen Band bei Lomonosov !

Sprachgeschichtlich betrachtet sollte die Zahl der Leser dieses Werkes im Verlaufe des 19. Jahrhunderts noch erheblich anwachsen, und zwar nicht nur wegen der immer weitere Kreise der Bevolkerung erfassenden Alphabetisierung, sondern auch weil sich immer mehr Bürger für die Geschichte der eigenen Nation interessierten. Auf diese Weise konnte der historiographische Stil Karamzins eine Vorbildrolle für die Sachprosa im Russischen übernehmen.

\subsubsection{Karamzins literarisches Werk Бедная Лнза}

Die Herausbildung bzw. Durchsetzung der neuen Prosagattungen war auf das engste mit der Ausbildung der literarischen Prosa verbunden. Erst mit der empfindsamen Novelle Бедная Лuзa von Karamzin aber setzte sich diese Gattung durch. TOPOROV $(1995,45)$ sieht in diesem Werk sogar den Ursprung der russischen Prosa ("родина русской прозы"). Karamzin schrieb diese Erzăhlung mit 26 Jahren; sie erschien also 24 Jahre vor dem Geschichtswerk.

\subsubsection{Edition}

Die Erzăhlung erschien zum ersten Mal in der Juni-Ausgabe des Московский мурнал 
des Jahres 1792 (часть 6, кн. 3, 238-277).

\section{Grundlage der Untersuchung:}

Н. М. Карамзин. Бедная Лиза - повести. Ленинград 1970, 23-39.

Zugrunde liegt hier die Ausgabe von 1820 (vgl. auch unten 4.2.7)

\subsubsection{Editionsanderungen}

Wir haben es bei diesem Text zum ersten Mal mit dem Phănomen zu tun, daß der Autor sein Werk zu Lebzeiten noch einmal uberarbeitet. Die (letzte) Überarbeitung, die maßgebend fur die spăteren Ausgaben wurde, stammt von 1820. Die Änderungen betreffen in erster Linie die Lexik ${ }^{16}$ : einzelne Wendungen und Ausdrucke werden ersetzt wie z. B.:

сей столищы (1792) durch города сего (1820), по лутам и полям, по рощам и кусточкам (1792) durch по лугам и рощам, по хольмам в равнинам (1820), белые Лизины волосы (1792) durch светлые Лизины волосы (1820); einige свой werden gestrichen wie z. В. іп: дочери своей, сердцу своему и. a. Daneben gibt es auch Änderungen in der Interpunktion unterhalb des Satzpunktes. Was die Satzpunktsetzung und den Satzbau anbelangt, so wurde von Karamzin in der Ausgabe von 1820 nichts gegenuber der von 1792 verăndert !

\subsubsection{Bedeutung der Beдfas Лrsa}

Obwohl Karamzin später noch weitere literarische Werke schrieb, verband man mit seinem Namen vor allem die Беднаs Лиза. Sie stelte den Ausgangspunkt einer neuen literarischen Prosa dar, wodurch sowohl von der Sprache als auch vom Inhalt die Prosa der Versdichtung gegenuber als gleichrangig anerkannt wurde. Auch aufgrund des kompakten Charakters der Erzăhlung, ihrer inhattichen Klarheit und Prăgnanz, wurden die künstlerischen Gestaltungsmöglichkeiten, die die Prosa bot, in ihrer vollen Tragweite erkannt. Überspitzt formuliert stelt dieses Werk das erste Werk in literarischer Prosa im Russischen überhaupt dar: „Но Карамзин, сделавший так много д л я русской литературы и прежде всего д л я прозы, сделал и самое прозу [... $]^{\star}$ (TOPOROV 1995, 11).

\footnotetext{
${ }^{16}$ Das Verhältnis der Wortarten untereinander ăndert sich dadurch zwischen beiden Ausgaben nur unwesentlich.
} 


\subsection{Zu Pußkin}

Es wurde bereits auf die Vorherrschaft der Poesie in der zweiten Hălfte des 18. Jahrhunderts hingewiesen. Trotz Karamzins Bemühen um die Schaffung einer neuen Prosa und die Verlagenung des Akzents auf die Gattungen der Prosa hielt sich die Anschauung von der Poesie als hőhere Form der Literatur hartnăckig. So schrieb Puskin noch 1825-32 Евгений Онегин als Versroman; ein Zeichen dafür, daß die Prosa noch weit davon entfernt war, etabliert zu sein. Dies war auch Puskin bewußt, als er sich mit Beginn der 30er Jahre des 19. Jahrhunderts entschieden der Prosa zuwandte.

Puskin sah das Verdienst Karamzins auf dem Gebiet der dichterischen und historischen Prosa. Er erachtete die История zocydapcrвa Poccuücкozo sogar als die „beste Prosa“ der vorangegangenen Literatur (VINOGRADOV 1941, 516). Doch bei Puskin ist nun die Suche nach einer neuen erzählerischen Prosa organisch vertunden mit der Arbeit an einer 'metaphysischen'", abstrakten Sprache und einer publizistischen, historiographischen und vor allem wissenschaftichen Prosa. Nach VINOGRADOV sah er den Stil der historischen Werke als grundlegend für die 'metaphysische Sprache' an: "B концепция Пушкина исторнческий стиль представлял собою квинтэссевцию прозаического языка." (VINOGRADOV 1941, 525). Überhaupt ist festzustellen, daB Puskin die Sachprosa der dichterischen Prosa bereits in seinen theoretischen Oberlegungen gleichstelt. Seine Prinzipien fur den Prosastil sind:

Точность и краткость - вот первые достоинства прозы. Она требует мыслей и мыслей - без них блестящие выражения ни $x$ чему не служат. Стихи дело друтое [...] (PUSKKIN - Poln. sobr. soč., t. 11, 19)

Man kőnnte auch sagen, daß erst Puskin die Notwendigkeit der Ausbildung eines wissenschaftlichen Funktionalstils erkannte, denn obwohl sich Lomonosov in seiner Eigenschaft als Polyhistor schon mit der Sprache der Naturwissenschaften auseinandersetzte, ließ er ein theoretisches Konzept fur einen (gesamt)wissenschaftlichen Funktionalstil vermissen. Bemerkenswert bei Puskin ist, daß er es nicht bei theoretischen Öberlegungen belie $B$, sondern daß et bereits erste Schritte untermahm, um seinen eigenen Forderungen nachzukommen. In dieser Hinsicht kann man seinen historiographischen Stil

\footnotetext{
${ }^{17}$ Wir begegnen bei Puškin ofters dem Ausdruck "метафизический язык" - dabei ist festzuhalten, daß diese nichts mit unserem heutigen Ausdruck 'Metaphysik' zu tun hat, vielmehr ist damit der gesamte nicht-naturwissenschaftliche und nicht-technische Bereich gemeint. Die 'metaphysische Sprache' könnte man daher auch mit dem so postulierten 'humanwissenschaftlichen Stil' gleichsetzen.
} 
als Muster für die 'metaphysische Sprache"18 bzw. als Muster für einen (gesamt-) wissenschaftlichen Funktionalstil ansehen.

\subsubsection{Puß̌kins Geschichtswerk Нстория Путачевa}

Wie Karamzin, so wurde auch Puškin als Historiker in Regierungsdienste aufgenommen (1831); er soltte über Peter den Großen arbeiten. Aber Puškin nutzte den Zugang zum Archiv auch um uber die Zeit von Katharina II zil recherchieren. Urspranglich wolte er einen Roman über Pugacev schreiben, dann jedoch entschloß er sich zu einem reinen Geschichtswerk. Er widmete sich 2 Jahre allein der historischen Recherche.

\subsubsection{Edition}

Die История Пугачевa wurde im Dezember 1834 veroffentlicht ${ }^{19}$. Sie bestand aus zwei Bănden: Band 1: narrativer Text

Band 2: Quellenmaterial und Anmerkungen

Grundlage der Untersuchung:

А. С. Пушкин. Собрание сочинений в десяти томах. Москва 1962. Том седьмой. "История Пугачева", 7-157.

und daraus unsere Texte:

Text 1: Глава 1

Text 2: Глава 6

Text 3: Глава 8

\subsubsection{Editionssnderungen}

Der direkte Vergleich der Ausgabe von 1962 mit der Erstausgabe von 1834 zeigt vor aliem Abweichungen in der Interpunktion unterhalb des Satzpunktes. Verănderungen des Satzpunktes selbst gibt es nur jeweils einmal in Text 1 und in Text 3. Ansonsten gibt es noch vereinzelt Ersetzungen wie z.B.: жители уведены (1834) durch иконы ободраны и разломаны в щепы (1962); auch wenn diese Ersetzungen inhattich neuen Sinn ergeben. so ändern sie strukturell doch recht wenig. Die Zahl und Art der Verănderungen ist jedenfalls nicht relevant in bezug auf den zu untersuchenden Satzbaustil.

\footnotetext{
${ }^{18}$ Es soll nicht verschwiegen werden, daß Pußkin auch das Fehlen einer abstrakten Lexik im Russischen beklagte. Doch wie bereits ausgeführt, ist der Satzbau in den humanwissenschaftlichen Fächem ebenso wichtig wie die Lexik.

${ }^{19}$ Sie erschien zunächst unter dem Titel: История Пугачевского бунта.
} 


\subsubsection{Bedeutung des Geschichtswerkes}

Die История Пугачева ist ein beachtliches historisches Werk, nicht nur nach dem Standard von Puskins Zeit, sondern auch noch nach heutigen. Es uberrascht daher, daß seine Arbeit so wenig unter den russischen Historikern des 19. Jahrhunderts galt und daß sie auch in der russischen Öffentlichkeit der damaligen Zeit kaum Resonanz fand (DEBRECZENY 1983, 247). Vielleicht hatte das Publikum auch nicht den trockenen historiographischen Stil von Puskin erwartet, denn nach den Worten BRONEVSKIJs war in der История Пугачева, alles so kalt und trocken"; es gebe ,nicht ein einziges Gefuhl, noch einen Funken Lebens“ (zit. nach VINOGRADOV 1941, 525).

\subsubsection{Pư̌kins litera risches Werk Kanutauckas Дouxa}

Puskin begann mit dem ersten Entwurf zur Капитанская Дочка im Jahre 1835 und stelte ihn im Sommer 1836 fertig. Darauf schrieb er das Manuskript bis zum Herbst desselben Jahres. Somit benötigte er ungefăhr ein ganzes Jahr fur die dichterische Bearbeitung des Stoffes (DEBRECZENY 1983, 250). Veroffentlicht wurde das Werk am 22. Dezember 1836.

\subsubsection{Edition}

Die Erzahlung wurde in der letzten Ausgabe des Современник (том IV, 1836), die noch zu Lebzeiten Puškins erschien, veröffentlicht.

Grundlage der Untersuchung:

А. С. Пушкин. Собрание сочинений в десяти томах. Москва 1962. Том пятый. "Капитанская дочка", 286-399.

und daraus unsere Texte:

Text 1: Глава 1

Text 2: Глава 6

Text 3: Глава 14

\subsubsection{Editionsanderungen}

Auch hier wurde vor allem die Interpunktion verändert (wobei besonders die Zeichen betroffen sind, die die wơrtliche Rede markieren). Es gibt nur eine Satzpunkt-Veränderung: in Text 1. Daneben sind noch Einfugungen wie z.B. + /Mатушка была еще 
мною брюхатв, как уже/ in Text 1 (1962) und $+/ \mathbf{k} /$ in Text 2 (1962) sowie Auslassungen wie - /не мог/ in Text 3 (1962) zu erwăhnen. Diese Verănderungen sind aber ăußerst selten: in Text 1 gibt es zwei; in Text 2 eine und in Text 3 ebenfalls nur eine Veränderung, so daß sie fur die Untersuchung nicht statistisch relevant sein werden.

\subsubsection{Bedeutung der Kamrtäcкеs Дочка}

Unmittelbar auf das Erscheinen des Werkes waren die Reaktionen sehr verhalten. Nach dem Tode Puskins (29. Januar 1837) allerdings, ca. 6 Wochen nach dem Erscheinen des Werke, anderte sich dies, denn das Werk stellte nun das letzte vollendete Opus dar und wurde deshalb auch wohl als eine Art Vermăchtnis, als der krönende Abschluß des Puskinschen Schaffens gesehen. Das Werk erfreute sich immer großerer Beliebtheit. GOGOL' war der Ansicht, daß in diesem Werk zum ersten Mal in der russischen Literatur wirkliche russische Charaktere auftraten ("истинно русскве харахтеры") und ubberhaupt hielt er die Капитанская Дочка für das entschieden beste Werk der literarischen Prosa ("решительно лучшеe русское произведение в повествовательном роде") ${ }^{20}$.

Tatsăchlich gehort dieses Werk neben den Повести Белкина zu den Musterbeispielen der literarischen Prosa im Russischen uberhaupt; der Vorbildcharakter für die weitere Ausbildung der Sprache war auf jeden Fall sehr groß.

Was dieses Werk für die Untersuchung so wertvoll macht, ist die Tatsache, daß das dichterische Werk in direktem Bezug zum Geschichtswerk steht; es ist praktisch eine Bearbeitung derselben historischen Begebenheit. Somit kann an diesen beiden Werken der Unterschied zwischen dem historiographischen und literarischen Stil aufgezeigt werden.

\subsection{Zusammen fassung der Überlegungen}

In diesem Kapitel nahmen wir Bezug auf das Untersuchungsmaterial, dabei muBte auch die Editionstreue hinsichtlich der Interpunktion geklärt werden: es stellte sich heraus, daß nur bei Lomonosov $\mathbf{T} 3$ die Satzpunktsetzung mehrmals abwich; demgegenüber wurde sie in Puškins Texten nur zweimal verăndert. Wenn bei Puškin die Vernachlässigbarkeit offensichtlich ist, so konnte man bei Lomonosov eher das Heranziehen der Erstausgabe

${ }^{20}$ GOGOL'. Poln. sobr. sot., t. 8, Moskau 1952, 384. 
fordern. Doch sprechen zwei gewichtige Gründe dagegen: erstens ist gar nicht sicher, ob sich in der Interpunktion der Erstausgabe Lomonosovs Willen widerspiegett, da sie postum erschien; zweitens erschien uns wichtig, diejenigen Ausgaben heranzuziehen, die in den Bibliotheken des Landes eher vorhanden sind, um damit zu gewăhrleisten, daß der Rezipient auch dieselben Editionen zur Hand haben kann.

Die Wahl der Autoren gründet sich auf folgende Argumente:

- alle drei Autoren waren anerkannte Historiker ihrer Zeit und ihre Geschichtswerke wurden dementsprechend gut rezipiert (wenngleich bei Puskin etwas weniger);

- Karamzin und Puskin waren bereits zu Lebzeiten anerkannte Schriftsteller, deren dichterisches Schaffen die russische Prosa entscheidend gepragt hat:

- die Werke der drei Autoren wurden in dem Zeitraum 1766 bis 1836 geschaffen; die Zeitspanne von 70 Jahren erscheint uns ausreichend eng, um Entwicklungstendenzen aufspüren zu konnen.

Außerdem wurde der Begriff der Prosa bzw. der Sachprosa eingefuhrt: mit dem Begriff der Sachprosa kann die Untersuchung in den sprachgeschichtlichen Zusammenhang eingeordnet werden; mit dem der Prosa schließlich kőnnen alle Untersuchungstexte auf einen gemeinsamen Nenner gebracht und die Entwicklung des historiographischen und literarischen Stils auch unter dem Blickwinkel der Entwicklung der Prosa betrachtet werden. 


\subsection{Methodologische Vorüberlegungen}

Die Methodik unserer Arbeit (wie auch anderer Arbeiten) grundet

a) auf der Übernahme von Methoden aus anderen Arbeiten und

b) auf der Entwicklung eigener Methoden.

zu a):

Zwei Arbeiten. die einen überragenden Vorbildcharakter aufweisen, sollen hier angefuhrt werden (5.1 und 5.2). Weiter aber erscheint es wenig sinnvoll, jede einzelne Arbeit, die in irgendeiner Weise eine Anregung zu einem Gedanken gegeben hat, aufzufuhren, nur um damit zu dokumentieren, daß sie auch zur Kenntnis genommen wurde. Außerdem wurden auch fremde Ansătze viel zu sehr im Detail verăndert, als daß sich eine Zurückfuhrung auf die erste Anregung noch vertreten ließe.

zu b):

Die methodischen Probleme, die sich in unserer Untersuchung steliten, sollen sukzessive dargestellt werden. Dabei stellt die Ausarbeitung des methodischen Apparates tatsăchlich weitgehend eine eigene Bemühung dar, wobei nicht die oben erwăhnten Anregungen unterschlagen werden sollen, vielmehr mögen damit alle noch existierenden Unebenheiten und teilweise auch fur den Verfasser noch nicht befriedigend geløsten methodischen Schritte (wie z.B. die statistischen Prüverfahren) entschuldigt werden.

\subsection{Methodisches Konzept zur Satzbauanalyse}

KREYE (1989). Satzform und Stil.

KREYE versucht in seiner Monographie „die Bauformen deutscher Sătze auf mehreren Differenzierungsebenen zu beschreiben"(Vorwort). Auf der hierdurch gewonnenen Datengrundlage konne man Fragen nach dem Stil eines Textes entsprechend beantworten. Weiterhin erwăhnt der Autor, daß sich der in seiner Monographie beschriebene Ansatz als Beschreibungssystem bei der Stilanalyse literarischer Prosatexte „durchaus bewăhrt" hat (ebd.). Tatsăchlich entdeckt man in der Arbeit viele nützliche und praktisch anwendbare methodische Vorgehensweisen. Wichtig ist fur uns die Formalisierung von Satzbauformen mit den Symbolen

$$
\begin{aligned}
& H=\text { ubergeordneter Hauptsatz und } \\
& G=\text { abhăngiger Teilsatz (S.93). }
\end{aligned}
$$

Positiv ist auch der Versuch zu werten, ein 'Textprofil' zu erstellen, indem er die Satzlănge der einzelnen Sătze in einem Diagramm darstellt. Er faßt die Sătze aber nicht 
in Satzlăngenklassen zusammen, was nicht erforderlich zu sein scheint, da seine Untersuchungstexte nur Textfragmente sind, die lediglich um die 10 - 20 Sătze umfassen. Diese aus einem Gesamttext stammenden Textfragmente werden zwar nicht konsequent miteinander verglichen, um etwaige Regelmäßigkeiten festzustellen, gleichwohl versucht KREYE auf diese Weise „dem komplexen und schwierigen Problem năherzutreten, wie Satzbau und Stil miteinander in Beziehung stehen mogen" (S.199).

Folgerungen fur die Untersuchung:

KREYEs methodische Ansătze empfehlen sich auch für unsere Untersuchung. Die Formalisierung der komplexen Sătze ist unumgănglich, um einen anschaulichen Über blick und im Anschluß daran eine weitere Kategorisierung zu ermøglichen. Jedoch verlangen unsere Untersuchungstexte, die in der Regel mehr als 100 Satze aufweisen, eine Beschrănkung auf die komplexen Sătze; Einfachsătze werden besser nur quantitativ erfaßt (vgl. hierzu auch die Arbeitsschrittbeschreibung in Teil B). Die komplexen Sătze bzw. die Satzbauskelette der komplexen Sătze werden wir entsprechend ihrem Vorkommen im Text auffuhren. Von einer weiteren Kategorisierung wie zB.:

$$
\begin{array}{lll}
\text { „... im Text X gibt es } & 5 & \text { HS, HS, NS } \\
& 4 & \text { HS, NS; HS usw. “ }
\end{array}
$$

sehen wir ab. Sie würde weder maßgeblich zu einer anschaulichen Darstellung beitragen noch einen wirklichen Vergleich mit anderen Texten ermoglichen.

Um diesen Vergleich zu ermoglichen, werden wir die Kategorisierung viel weiter betreiben, nămlich in:

Einfachsatz; Satzreihe; Satzgefuge bzw. nur noch in zwei Kategorien wie:

Hypotaxe;

Nicht-Hypotaxe.

Mit Hilfe der letzten Kategorisierung wird der Parameter Satzkomplexităt auf eine einzige Zahl reduziert und ist damit mit anderen Texten leicht vergleichbar.

Was die Satzlängen anbelangt, so gitt hier das gleiche: aufgrund der Länge unserer Untersuchungstexte müssen die Satzlängen in Klassen zusammengefaßt werden. Auch wiirde ein Satzlăngenverlaufsprofil, das alle Sătze des Textes in ihrem linearen Verlauf auffuhren würde, den Vergleich mit anderen Texten stark erschweren. wenn nicht sogar unmoglich machen. 


\subsection{Methodisches Konzept zur statistischen Analyse}

SCHEFE (1975) (Diss.) Statistische syntaktische Analyse von Fachsprachen mit Hilfe elektronischer Rechenanlagen am Beispiel der medizinischen, betriebswirtschaftlichen und literaturwissenschaftichen Fachsprache im Deutschen.

Bei SCHEFE stelt (wie aus dem Titel seiner Arbeit ersichtlich) die Statistik die Grundlage der Untersuchung dar. Beachtenswert ist, daß er von Fachsprachen der Medizin, Betriebswirtschaftslehre und der Literaturwissenschaft spricht; er fuhrt also das theoretische Konzept der Fachsprache auch fur humanuissenschaftliche Disziplinen (BWL und Literaturwissenschaft) ein. Uberhaupt ist seine Arbeit exemplarisch fur eine zielstrebige statistische Untersuchung. Mit seiner Arbeit mochte SCHEFE auch zugleich die Syntaxforschung' vorantreiben:

Die relative Vernachlassigung der Fachsprachensyntax läß sich vor allem darauf zurückführen, daß die ăteren Untersuchungen und Darstellungen das Wesentliche der Fachsprache im Wortschatz bzw. in der Terminologie erblickten. (S.1)

Zwar geht SCHEFE auch von der Lexik aus, wenn er zuerst die 'Lexika' der Texte nach Haufigkeit und nach Alphabet geordnet untersucht, doch schreitet er rasch weiter zu größeren Einheiten. Die wichtigsten Parameter seiner Untersuchung sind u.E. folgende:

- Wortartenhäufigkeit

- Wortlăngenverteilung

- Phrasenlànge

- Nebensatzlăngenverteilung ${ }^{2}$

- Satzlănge

Darüber hinaus berechnet SCHEFE auch die Anzahl der Selbsteinbettungen von Nominalgruppen, die Anzahl der Inversionen von Nebensătzen u.a. Statistisch berechnet er die theoretische Poisson-Fucksverteilung für die Wortlănge, die Teilwerte für den Kolmogorov-Smirnov-Test u.a. Alles in ailem steht die Arbeit auf festem statistischem Grund. Was die Darstellung anbelangt, so herrscht die Tabelle vor (31 Tabellen; davon 26 direkt auf die Auswertung bezogen). Schaubilder, die die Ergebnisse klar veranschaulichen, sind dagegen seltener: die ganze Arbeit weist nur 5 Diagramme auf. Die textliche Darstellung ist bündig und präzise, wenngleich der statistische Jargon zuweilen die

\footnotetext{
'Er bezieht in einem großen Maße den Satzbau ein, faßt aber alles unter dem Begriff 'Syntax' zusammen (vgl. Anm. 1, S.13).

${ }^{2}$ Bei ihm: .Subsatzlängenverteilung".
} 
Oberhand gewinnt und man gerne statt der vielen Zahlen (und statistischen Mittel- und Testwerte) etwas mehr an konkretem Textmaterial sehen wirde, denn um einen Eindruck aber die Syntax bzw. den Satzbau zu bekommen, mußte das eine und andere Satzbaumuster aufgezeigt und an Textbeispielen illustriert werden.

Am meisten besticht die Arbeit von SCHEFE durch ihre klare Methodik. Sein Plan fiur die Durchfuhrung einer statistischen Untersuchung, der sich am Standard von OEVERMANN (1972) orientiert, sei daher in extenso dargelegt:

(1) Formulierung des Problems (möglichst konkret) z.B. Unterscheiden sich die Satzlangenverteilungen der medizinischen und der literaturwissenschaftlichen Fachsprache?

(2) Planung der Datenerhebung (des Versuchs)

(a) Auswahl des Textes [...]

(b) Festlegung des Stichprobenumfangs (nach Probezahlungen oder gemaß technischen Randbedingungen u.a.)

(c) Repräsentative Stichprobenauswahl (aufgnund der Kenntnis des Textes oder mit Hilfe von Zufallszahlen)

(d) Evtl. Zerlegung des Textes (...) in arbitrăre oder motivierte Abschnitte (...) zur Feststellung der Homogenităt bzw. Reliabilităt

(e) Merkmalsbestimmung (z.B. Satzlănge, gemessen in der Zahl der Wörter)

(f) Definition der Zăhl- und Maßeinheiten (z.B. 'Wort' = eine graphische Einheit)

(g) Feststellung des Skalierungstyps: Nominal, Ordinal, Intervall

(3) Durchfuhrung der Datenerhebung (des Versuchs)

(Eventuell Wiederholung mit Kontrollmerkmal)

(a) Erstellung der Urliste (kodierter Text, Versuchsergebnisse)

(b) Erstellung der Hăufigkeitslisten

(c) Eventuell graphische Darstellung

(4) Berechnung von Maßzahlen - z.B. Mittelwert, Median, Varianz, Entropie u.a.

(5) Statistische Schlußfolgerungen

"Schătzen": Schluß von der Stichprobe auf die Grundgesamtheit, z.B. Standardfehler einer Maßzahl bestimmen:

.Entscheiden“: Schluß auf die Signifikanz eines Unterschiedes: z.B. KolmogorovSmirnov-Test.

(6) Interpretation

(SCHEFE S.15 f.)

Folgerungen für die Untersuchung:

Die Arbeit von SCHEFE ist in mehreren Aspekten für uns vorbildlich. Vor allem die klare methodische Vorgehensweise versuchen wir nachzuahmen. Was die statistischen Tests anbelangt, so muß beachtet werden, daß sie sich nur auf die Lexik beziehen. Es wird noch zu prüfen sein, inwieweit die vorhersagende Statistik auch auf größere textuelle Strukturen als das Wort anwendbar ist (vgl. 5.5.2). Außerdem erfordert unsere Fragestellung, die sich mit diachronischer Entwicklung beschaftigt, eine andere Heran- 
gehensweise, denn wichtig ist für uns auch, eine Vergleichsmöglichkeit mit anderen Texten zu schaffen.

\section{3 Eingrenzung des Untersuchungsgegenstandes}

\subsubsection{Begrenzung der Untersuchungsebene}

Untersuchungen zum Stil werden weitgehend dadurch geleitet, was der einzelne Forscher als stilkonstituierend ansieht.

Wie in Kapitel 3 dargelegt, kann man 'Stil' auf alle sprachlichen Ebenen beziehen: Grammatik. Lexik und Syntax. Je nach Textsorte und Epoche moggen die crsten beiden Ebenen konstituierend fur den Stil sein, fulr die Textsorten unserer Untersuchung (Geschichtswerk und dichterische Erzahlung) erscheint uns der syntaktische ${ }^{3}$ Ansatz am ergiebigsten.

Die Untersuchungen zum Stil bzw. die Untersuchungen, die den Stil statistisch untersuchen wollen, zeichnen sich durch eine Vielzahl von methodischen Ansătzen aus, die zum Teil recht unterschiedlich sind ${ }^{4}$. Letztendlich wird fast jede Untersuchung zu einem methodischen Vorschlag. In dieser Hinsicht stellt auch diese Arbeit einen Versuch dar, ein methodisches Instrumentarium zu entwickeln, mit weichem das Phănomen 'Stil' quantifizierbar gemacht wird. Mit der Quantifizierbarkeit ist der Wunsch verbunden, die Ergebnisse anschaulich darzustellen; auf jeden Fall wird das Abricken von einer rein beschreibenden Darstellung bezweckt, wobei diese jedoch nicht gănzlich verworfen und aufgegeben wird ${ }^{s}$. Da die Syntax bzw. der Satzbau von Regeln ${ }^{6}$ bestimmt wird, muß in

\footnotetext{
'Syntax' schließt in diesem Falle den Satzbau ein und wird als Uberbegriff verwendet, um gegen den lexikalischen Ansatz abzugrenzen.

' Zu den ersten Ansătzen siehe die historische Ubersicht von BAILEY 1969, 217-236; zu den methodologischen Ansătzen in der Russistik siehe KEMPGEN (1995). Außerdem ist für die Slavistik der grundlegende Artikel von FRUMKINA (1973) hervorzuheben. An neueren Arbeiten aus der Slavistik waren nützlich: HENTSCHEL (1992) bezilglich des Problems SVO (siehe 5.3.2); KEMPGEN (1995), dessen Arbeit ein in jeder Hinsicht hilfreiches Material darstellte, und schließlich die bereits erwăhnten Arbeiten von RAECKE bezilglich der methodologischen Voruberlegungen und Fragen der Darstellung.

${ }^{5} \mathrm{Vgl}$. dazu 5.6

${ }^{6}$ Vgl. KALVERKÄMPFER (1981, 37): „Das Funktionieren von Texten unterliegt bestimmten Gesetzmaßigkeiten und Geregeltheiten (um nicht sogar zu sagen: gewissen Regeln). Sie zielen in erster Linie auf die Aufgabe, die textuelle Kohărenz zu ermð̋lichen und aufrecht zu erhalten und somit die Textualităt zu gewăhrleisten."
} 
jedem Stil eine RegelmaBigkeit entstehen. Diese Regelmaßigkeit laßt sich u.E. herauskristallisieren und auch adăquat darstellen (so z.B. in Diagrammen und statistischen Zahlenwerten).

\subsubsection{Begrenzung der Parameter}

Wir begrenzen unsere Untersuchung auf folgende vier Parameter:
a) Satzlänge
b) Satzkomplexităt
c) 'logische' Satzordnung
d) Pradikativităt

\section{zu Parameter a: Satzlange}

Die Satzlănge ist ein stilistisch wichtiges Gestaltungsmittel, denn eine Informationsmenge oder ein Gedankengang kann auf mehrere Sătze verteih oder in wenige oder gar einen einzigen Satz verdichtet werden. Gleichzeitig ist der Satz die kleinste Einheit der Sprache, mit der ein Sinnzusammenhang ausgedrïckt werden kann. Obwohl dieser Parameter formal sehr leicht bestimmt werden kann, bedeutet das nicht, daß die Verteilung der Satzlănge wie auch die mittlere Satzlănge nur Aussagen über formale Äußerlichkeiten erlauben. vielmehr spiegelt sich darin schon sehr anschaulich wider, wie der Autor Denkabschnitte strukturiert. Aus diesem Grunde kann keine Stilanalyse auf die Untersuchung der Satzlănge verzichten ${ }^{7}$.

\section{zu Parameter b: Satzkomplexităt}

Ein weiteres stilistisches Gestaltungsmittel ist die Satzkomplexităt ${ }^{8}$. Wenn sich der Parameter der Satzlange noch am Äußeren des Satzes orientiert hat, so zielt dieser

${ }^{7}$ Ober die Aussagefahigkeit dieses Parameters vgl. die in ihren Ergebnissen und auch in ihrer Darstellung bestechende Arbeit von FUCKS 1968 sowie fur das Russische die Arbeiten von LESSKIS 1962, 1963a, 1964 und AKIMOVA 1973.

${ }^{8}$ Ober die Aussagefahigkeit dieses Parameters vgl. auch die Arbeiten von LESSKIS 1963b und 1968, in denen LESSKIS allerdings (wie SCHEFE) mehr auf die Länge der Nebensătze eingeht als auf die kategoriale Verteilung von Einfachsătzen, Satzreihen und Satzgefugen, wie sie unserer Arbeit zugrunde gelegt wird; so faßt LESSKIS unter "сложные предложения" Satzreihen und Satzgefüge zusammen, wodurch nur die Kategorie 'Einfachsătze' bei ihm und uns gemeinsam ist und wodurch die uns als wichtig erscheinende Kategorie 'Satzgefuge' leider nicht getrennt untersucht wird. 
Parameter auf das Innere des Satzes. Dabei ist festzuhalten, daß die Satzkomplexităt nicht in Korrelation zur Satzlănge steht ${ }^{9}$ : es kann nămlich sehr lange Einfachsătze geben, und sowohl durch Parataxe als auch durch Hypotaxe ${ }^{10}$ kann der Satzumfang zunehmen. Gerade die Kombination von Parataxe und Hypotaxe zeigt die Vorstellungen und Absichten des Autors über die stilistische Gestaltung eines Textes. Von der Seite der Rezeption /des Lesers betrachtet laufen Einfachsătze und Satzreihen rasch und glatt ab, wohingegen Nebensătze retardieren, besonders wenn eine unterordnende Konjunktion den Leser zwingt, das logische Denken des Schreibers nachzuvollziehen. Wir werden die Texte konkret auf die Anzahl der Einfachsătze, Satzreihen (= Parataxe) und Satzgefuge (=Hypotaxe) untersuchen. wobei aber, um den Vergleich der Texte miteinander zu ermöglichen, nur mit dem Wert für die Hypotaxe gearbeitet wird.

Die Frage nach Asyndese / Syndese in den Satzreihen wird nicht weiter verfolgt " : es geht nur um die Einordnungskategorie 'Satzreihe'; die parataktischen Konjunktionen interessieren nicht weiter, da das Phănomen Parataxe ausreichend durch die Hăufigkeit der Satzreihen bestimmt wird. Anders verhăh es sich mit den hypotaktischen Subjunktionen (Relativpronomen und unterordnende Konjunktionen): durch die Auflistung derselben könnten Aussagen über die Hăufigkeit von expliziten Kausalbezügen sowie von finalen, modalen u.a. Bezügen gewonnen werden.

\section{zu Parameter c: 'logische' Satzordnung}

Auch dieser Parameter ist unabhăngig von den anderen Parametern. Er sagt sehr viel über die inhaltliche und vor allem die logische Strukturienung der Sătze und des Textes aus. Grundsätzlich ist im Russischen die Wortstellung frei:

In Russian, for instance, any permutation of $S, O$, and $V$ will give a grammatical sentence, but the order SVO is much more frequent than all of the other orders put together, and is moreover the preferred interpretation for sentences with the sequence NP- V - NP when the morphology, exceptionally, does not indicate which noun phrase is subject and which one is direct object. (COMRIE 1981, 82)

\footnotetext{
${ }^{9}$ Somit können statistische Tests, die eine Korrelation zugrunde legen, nicht angewandt werden.

10 'Parataxe' bezieht sich auf die Satzreihen. 'Hypotaxe' hingegen auf die Satzgefuge.

"Folglich stellt sich auch nicht das Problem, ob es sich bei Hypotaxe / Parataxe und Asyndese / Syndese um eine Kreuzklassifikation handeh (vgl. WEISS 1989, 287).
} 
Wir gehen davon aus, daß die SVO-Ordnung durchaus einen allgemeinen Zug des Russischen darstelit ${ }^{12}$, doch ungleich mehr fakultativ ist als z.B. im Englischen, wo keine Kasusendung die Opposition Nominativ/ Subjekt : Akkusativ/ Objekt stützt. Da sich Karamzin in dieser Hinsicht auf die Vorbildfunktion des Franzosischen beruft ${ }^{13}$, liegt es nahe, seine und auch die anderen Texte auf diesen Parameter zu untersuchen. Außerdem erheben Geschichtstexte den Anspruch auf objektiv-logische und wissenschaftliche Darstellung, womit nicht gesagt werden soll, daß die SVO-Ordnung die einzig logische und wissenschaftlich angemessene Ordnung sei ${ }^{14}$, doch entspricht sie eher dem sachlich-wissenschaftlichen Diskurs als VS oder SOV. Der ausschlaggebende Grund fur die Auswahl dieses Parameters ist die Annahme. daß ein Autor in den Untersuchungstexten bewußt SVO einseta.

\section{zu Parameter d: Pradikativit}

Dieser Parameter stützt sich auf die Untersuchung der Wortartenverteilung. Obwohl Einheiten der Sprache unterhalb des Satzes gezăhlt werden, bezieht sich seine Aussagekraft doch auf den gesamten Text, da ja die Verteilung innerhalb des Textes betrachtet wird ${ }^{\text {is }}$. Die Erkenntnisse aus dem theoretischen Teil verwertend kann gesagt werden:

a) Geschichtstexte sind der Sachprosa zuzuordnen, folglich ist ein Parameter, der sich auf die Nominalităt stützt, wenig aussagekräftig, da die Verteilung bereits durch die Textsorte bedingt wird ${ }^{16}$;

\footnotetext{
${ }^{12} \mathrm{Vgl}$. auch HENTSCHEL 1992.

${ }^{13} \mathrm{Vgl} .4 .2$ und RAECKE $1994,239 \mathrm{ff}$.

14 Aus diesem Grunde wird das 'logisch' in Anfuhrungszeichen gesetzt. RAECKE (1997). gefaßt als Nomina) in den Untersuchungstexten sind folgende:

Geschichtswerke Dichterische Werke

$\begin{array}{lll}\text { Lomonosov: } & 46 \% & \\ \text { Karamzin: } & 47 \% & 35 \% \\ \text { Puskin: } & 41 \% & 35 \%\end{array}$
}

${ }^{15}$ Untersuchungen auf die Wortartenverteilung werden auch von RAECKE durchgeführt, der damit charakteristische Unterschiede zwischen Mündlichkeit und Schriftlichkeit aufzeigt. RAECKE mißt der Wortartenverteilung große Bedeutung bei; seiner Meinung nach konnen die Unterschiede in den Wortart-Werten und in den Wortwiederholungs-werten als Maßstab fur die Literatursprachlichkeit herangezogen werden. Vgl.

${ }^{16}$ Die Mittelwerte der Verteilung von Substantiven und Adjektiven (zusammen- 
b) den Geschichtstexten wie auch den dichterischen Texten liegt das Erzăhlen als Diskursform zugrunde, folglich erscheint es ergiebiger, wenn sich der Parameter auf die Verbalităt stützt ${ }^{17}$. Die Untersuchung der Verbalităt allein ist aber nicht ausreichend, denn es gibt die Möglichkeit, ein einzelnes Prădikat mit mehreren Verben 'anzureichern', also mehr Prädikationen zu schaffen. Die Anzahl der Prădikationen kann daher mehr uber den historiographischen und literarischen Stil aussagen als der Anteil der Verben ${ }^{18}$.

U.E. stellen diese Parameter den Stil, der mit den ersten drei Parametern auf die Ebene des Satzbaus eingeengt wurde, für die Untersuchung ausreichend dar.

\subsubsection{Begrenzung der Untersuchungseinheit}

Was die Untersuchungseinheiten anbelangt, so wird bei den ersten drei Parametern vom Satz ausgegangen. Beim vierten Parameter (Pradikativităt) wird als Untersuchungseinheit der ganze Text zugrundegelegt. Großere Einheiten als der Satz werden auch erfaßt, wenn die Verteilung der Satzlăngen für den ganzen Text gezeigt wird. Dabei bringt die Überschreitung der Satzgrenze eine Fulle von Darstellungsproblemen. Wir versuchen deshalb, einige als Vorschläge zu verstehende Darstellungsarten einzufuhren: so z.B. das Satzlăngenverteilungsprofil oder auch das Satzskelettprofil; in beiden Făllen ethalten wir anschauliche Darstellungen, die den abstrakten Zahlen zur Seite gestell einen ganzheitlichen Eindruck uber die Textstruktur geben sollen.

Obwohl zu Recht vorgeworfen wird, daß der Satz deswegen im Mittelpunkt syntaktischer und stilistischer Untersuchungen steht, weil er „dem Wunsch nach Uberschaubarkeit des Forschungsobjekts“ entgegenkommt (KALVERKÄMPFER 1981, 5), hat er

also ganz klar eine Verteilung nach Sachprosa und dichterischer Prosa. (Einzelwerte der nominalen Verteilung siehe Anhang, S.194 f.)

Die Werte von Lomonosov und Karamzin stimmen mit den Ergebnissen von HOFFMANN $(1976,275)$ uberein, nach welchen sich der Anteil von Nomina zwischen $47 \%$ in der 'wissenschaftlichen Zeitungsinformation' bis zu $58 \%$ in der Fachsprache der Chemie bewegt. Die dichterische Prosa weist nach seiner Angabe, die sich auf MARKOV $(1960,19)$ stutzt, $38 \%$ Nomina auf.

${ }^{17}$ Beim Erzăhlen spielt vor allem das Verb eine große Rolle, vgl. RAECKE (1988. 307 ff.)

${ }^{18}$ Der Verbanteil, der sich nur auf morphologische Kriterien stützt, unterscheidet sich doch beträchtlich von dem Wortanteil der Prädikativităt, bei welchem neben finiten Verben auch Prädikative und vor allem die der sekundären Prådikation dienlichen Partizipien und Adverbialpartizipien einbezogen werden. 
durchaus seine Berechtigung. Denn in der Schriftsprache stell der Satz ein bewußt vom Autor gestahtetes Ausdrucksmittel dar: mit jedem Satz bringt der Autor einen relativ abgeschlossenen Denkabschnitt zu Papier. Er ist relativ abgeschlossen, weil er textuell noch weiter verbunden werden kann. Letztendlich besteht jeder schriftsprachliche Text aus einer Folge von Sătzen. Zwar wăhlen wir den Satz zugegebenermaßen auch der Oberschaubarkeit willen, doch um den Text/Stil als Ganzes zu untersuchen, muß auf das konstituierende Element desselben zurückgegriffen werden.

\subsubsection{Begrenzung auf aarrative Prosa}

Da es in allen Texten eng definiert um narrative Prosa und weit definiert um schriftsprachliche Prosa geht, kơnnen und dürfen umgangssprachliche Einschübe sowie Zitate nicht berdcksichtigt werden. Dies umso mehr, als es bei der wörtlichen Rede stets um eine Wiedergabe der Sprache eines anderen geht: es muß davon ausgegangen werden, daß der Autor seine eigenen Satzbaupläne bewußt verdrăngt hat, um

a) stilistisch den Sprecher zu markieren,

b) der Mündlichkeit der wörtlichen Rede Rechnung zu tragen ${ }^{19}$,

c) im Zitat ein fremdes Satzbaumuster unverändert zu ubernehmen.

Daraus folgt:

Die mündliche Rede und Zitate, wie sie zwischen Anführungszeichen auftreten. müssen ausgeschlossen werden, damit Eigenheiten des Satzbaus der Umgangssprache und fremder Autoren nicht die Analyse verfälschen. Es scheint außerdem angebracht. die narrativen 'Stützen' ebenfalls auszuschließen, vor allem wenn sie nur aus zwei oder drei Worter bestehen. z.B. он сказал: "... ", da sie andernfails den Anteil der Kurzsätze ungebührend erhöhen würden, denn diese Stützen sind nicht mit den anderen Kurzsătzen zu vergleichen, vielmehr stellen sie unvollständige Sătze dar (die wörtliche Rede fungiert hier als das Objekt des Verbs des Sagens).

Da bei einer undifferenzierten und rigorosen Ausschließung der 'Stưtzsătze' jedoch auch wichtige Satzbaustrukturen der Untersuchung verloren gingen, wie z.B. in:

Они громко роптали, и Иван Игнатьич, исполнитель комендантского распоряжения, слышал своими ушами, как они говорили: "..." (Капитанская Дочка, 331)

${ }^{19}$ Die fundamentalen Unterschiede zwischen mündlicher und schrifticher Ausdrucksform sollen hier nicht weiter behandeh werden. vgl. hierzu besser RAECKE $(1989,1990$, 1997). 
ist ein differenzierter Ansatz wohl der ergiebigste: sobald es kein unvollstăndiger Satz mehr ist, sondern ein vollstăndiger in dem Sinne, daß er auch ohne wortliche Rede syntaktisch vollstăndig ist, wird er gezăhlt; es soll schließlich keine Hypotaxe in den narrativen Sătzen ungezăhl bleiben ! (Der oben angefuhrte Satz wird demnach als ein Satz mit 15 Wortern gezăhlt.) Außerdem soll die Vergleichsgrundlage immer die gleiche sein, d.h. es sollen nicht für den Parameter 'Satzlănge' andere Sătze untersucht werden als beim Parameter 'Satzkomplexităt'.

\subsubsection{Begrenzung des Stichprobenumfangs}

Warum wird die Stichprobe auf ein Kapitel begrenzt - und nicht etwa auf 50 Sătze oder auf eine Seite?

Es ist uns nicht bekannt, ab welcher Schwelle der Leser textliche Wiederholungen als solche wahmimmt. Es ist jedoch anzunehmen, daß sich nach einigen Absătzen (Gegenprobe: ein einziger Absatz reicht wohl noch nicht) der Leser einen Eindruck aber den Stil gebildet hat. Sind das nun 10 Sătze, 20 Sătze oder gar 100 Sătze ?

U. E. müßte ein Kapitel ausreichen. um dem Leser einen Eindruck uber den Stil zu geben. Mit anderen Worten: fließendes Lesen vorausgesetzt 'holt' der Leser nach jedem Absatz 'Luft'; zwischen den Sătzen soltte er es nicht, weil dann die Konzentration zu weit abfallen wïrde. Die Buchseite mag dagegen wohl auf den ersten Blick als Zasur empfunden werden. sie ist jedoch keine textuelle Einheit, dafur spricht schon die Tatsache. daß sie in den seltensten Fällen mit einem Satz endet und meist nicht nur Sătze, sondern sogar Worter durch den Seitenumbruch entzweigerissen werden. Nach dem Kapitel aber ist jegliche Argumentation abgeschlossen. Das Kapitel erlaubt dem Leser, das Buch wegzulegen, und die Einteilung in Kapitel gibt dem Leser klar zu verstehen, wann der Text eine Pause erlaubt.

Folgerung: (Spätestens) nach der Lektüre eines Kapitels hat sich der Leser einen Eindruck uber den Stil gebildet. Dieser Eindruck kann sich von Kapitel au Kapitel andern. so daß der Stil des Werkes durchaus eine Varianz aufweisen kann. Wir wissen nicht, wie groß diese Varianz sein darf, um noch vom Leser als (einheitlicher) Stil akzeptiert zu werden, doch darf u.E. diese Varianz beträchtlich großer sein, als es die statistischen Tests erlauben ${ }^{20}$. Zu beachten ist dabei. daß der Stil immer aus mehreren

\footnotetext{
${ }^{20} \mathrm{Vgl}$. dazu auch 5.5.2 zu der Bedeutung statistischer Tests.
} 
Parametern zusammengesetzt ist. Wenn also z. B. die Satzlänge aus dem Rahmen fällt, so kann sich immer noch der Parameter der Satzkomplexităt oder der Prädikativität im 'durchschnittlichen Rahmen' bewegen.

\subsubsection{Zur Auswahl der Untersuchungseinheiten}

Annahme: Der Autor schreibt jedes Werk in einem gewissen Zeitraum; maximal in mehreren Jahren. so daß sich der Autor selbst bei einem opus magnum in einem bestimmten Stadium seiner stilistischen Entwicklung befindet ${ }^{21}$.

Methode: Am besten wird dies verifiziert, indem bestimmte Kapitel untersucht werden. nămlich Anfangs- und Endkapitel bzw. ein letzteres Kapitel ${ }^{22}$, denn a) angenommen der Autor schreibt linear und überarbeitet nichts, so beweist eine Übereinstimmung von Anfang und Schluß, wie einheitlich der Autor seinen Stil im Griff hat. Falls er aber im Falle b) am Ende den Anfang ubberarbeitet oder erst am Ende die Einleitung schreibt, ist die Übereinstimmung von Anfangs- und Schlußkapitel zwar weniger erstaunlich, beweist aber immer noch die Absicht einer stilistisch einheitlichen Gestaltung. In jedem der beiden Falle ist die Untersuchung eines mittleren Kapitels aufschlußreich: falls eine Verănderung stattfindet, muß sie sich irgendwo, also auch in der Mitte abzeichnen; falls aber alles gleichmaßßig ist, darf das mittlere Kapitel nicht aus der Reihe treten.

Nachdem drei verschiedene Textabschnitte untersucht worden sind, wird versucht, vorhandene Regelmäßigkeiten aufzudecken. Um eine Aussage über eine Regelmäßigkeit machen zu können. würden zwei Textabschnitte nicht genügen; der Mittelwert wăre immer 'richtig' und doch gleichzeitig 'falsch'. Denn wie die Bezeichnung widerspiegeh. ist der Mittelwert immer gemittelt und erweckt somit den Eindruck von Ausgewogenheit und Gleichmaßigkeit. Durch die separate Angabe der drei Einzelwerte hingegen wird deutlich, ob eine RegelmäBigkeit vorliegt oder nicht:

a) entweder fallt der dritte Wert in das Intervall der beiden ersten Werte (ersichtlich durch ein Verharren oder Einpendeln)

b) oder nicht (ersichtlich durch einen aus der Reihe fallenden Wert).

\footnotetext{
${ }^{21}$ Ausnahmen sind wohl fortgesetzte Werke, deren Abfassung uber mehrere Jahrzehnte geht.

${ }^{22}$ Bei Puskins Geschichtswerk wie auch bei seinem dichterischen Werk wird das Endkapitel herangezogen; bei Lomonosovs und Karamzins Geschichtswerk dient ein Kapitel aus dem zweiten Teil bzw. aus dem zweiten Band als letzteres Kapitel.
} 
Der Mittelwert bezeichnet also im Fall a) eine tatsăchlich vorhandene Größe, wogegen er im Fall b) lediglich das arithmetische Mittel der drei Werte darstellt. (Allerdings wird generell das arithmetische Mittel errechnet, um einen Vergleichswert für die spätere Auswertung zu haben.)

\subsection{Methodische Grundlagen des Vergleichs und Bedeutung der Zahlenwerte}

Die Vergleiche sind dann am ergiebigsten, wenn 2 Einheiten direkt gegenubergestellt werden (Zahlen oder Diagrammsăulen), daher spielt die Umrechnung in Prozentanteile und die Reduzierung auf einen Wert fur jedes Werk eine große Rolle. Keinesfalls soll damit eine hohere oder gar absolute Genauigkeit suggeriert werden. Es ist z.B. vollig irrelevant, ob Karamzin einmal $47 \%$ oder $45 \%$ Hypotaxe verwendet. Die Prozentwerte geben zum einen die Vergleichsmöglichkeit und zum anderen einen Eindruck über die quantitative Großenordnung. Schließlich ist es nicht besonders aufschlußreich von einem 'grőßen Teil' zu sprechen, denn der 'großte Teil' kann

- relativ gesehen, schon ein Anteil von 30\% sein, wenn die anderen Anteile unter $30 \%$ liegen.

- absolut gesehen, ein Anteil von 51\% sein, wenn der andere Anteil bzw. die anderen Anteile unter $50 \%$ liegt/ liegen.

Durch die Angaben der genauen Prozentwerte konnen hier Mißverstăndnisse vermieden werden. Die quantitativen Großenordnungen sind es gerade, die in den meisten Stiluntersuchungen fehlen, was nicht verwundert, da vorwiegend die beschreibende Methode angewandt wird. Diese Arbeit hingegen soll die quantitativen Großenordnungen aufzeigen und damit die ungenauen intuitiven Angaben, die in viel $z u$ vielen Stiluntersuchungen auftauchen, ersetzen ${ }^{23}$. So liest man beispielsweise bei KOVTU. NOVA (1969, 192 f.):

Если сопоставить художественную прозу Пушкина с "изяшной прозой" Карамзина и ораторской прозой Ломоносова, то окажется, что в отношении языковых норм Пушкин близок к Карамзину и оба очень далеки от языковой системы Ломоносова; но в отношении самых общих принципов стилистической организации языкового материала Карамзин гораздо блике к Ломоносову, а Пушкин неизмеримо далек от обоих. [eigene Hervorhebung]

${ }^{23}$ Für die vorliegende Untersuchung konnen somit solche rein beschreibenden Arbeiten nicht herangezogen werden, da unsere Fragestellungen nur mit Hilfe von quantitativen Grőßenordnungen beantwortet werden kơnnen. 
zum einen stoßen wir hier auf die typisch intuitive Angabe (2opasdo 6ruxce), weitaus bezeichnender aber ist die Behauptung, daß der Abstand „unermeBlich“ (неизмеримо) sei. Die metaphorische Bedeutung einmal beiseite gelassen, ist es gerade diese Art von Behauptung, die gewissermaßen eine Herausforderung an unsere Arbeit stellt. Denn wir sind der Überzeugung, daß der Abstand meßbar sein muß und daß er in klaren quantitativen Großenordnungen ausgedrückt werden kann.

\subsection{Statistische Grundlagen 24}

\subsubsection{Beschreibende Statistik}

Die beschreibende Statistik betriff

- beim Parameter a) Satzlange: die durchschnittliche Satzlange, die Variationsweite und die Streuungswerte Varianz und Standardabweichung ${ }^{25}$;

- bei den Parametern b) Satzkomplexităt, c) 'logische' Satzordnung und d) Pradikativităt: die relativen Häufigkeiten eines einzelnen Merkmals.

\subsubsection{Profatatistik}

Im Verlauf der Untersuchung ist es notwendig, von den drei Stichproben eines Werkes auf die Verteilung des Gesamtwerkes zu schließen. Damit wird das Gebiet der beschreibenden Statistik verlassen und das der Prufstatistik (Wahrscheinlichkeitsrechnung) betreten. Die Prüfstatistik vergleicht die Werte aus den einzelnen Stichproben. wobei festgestelt werden soll, ob die drei Stichproben aus der gleichen Grundgesamtheit stammen kơnnen. Die Grundgesamtheit schließlich besitzt eine Gesamtverteilung. welche nicht unbedingt schon in den einzelnen Stichproben erkennbar ist. sondern vielmehr mit Hilfe der Stichproben festgestellt werden soll.

Unsere Arbeitshypothese lautet: Der Stil manifestiert sich nicht erst in dem Gesamttext (=Grundgesamtheit), sondern bereits in jedem Kapitel (= Stichprobe). Gemăß dieser Hypothese gleichen sich die Strukturen in den einzelnen Kapiteln, d.h. die Struktur als solche ändert sich nicht wesentlich innerhalb des Werkes, also auch nicht von Kapitel zu Kapitel bzw. von Stichprobe zu Stichprobe. Letztendlich handelt es sich

\footnotetext{
${ }^{24}$ Siehe CLAUS (1974): Grundlagen der Statistik; und SACHS (1993): Statistische Methoden.

${ }^{25}$ Die Streuungswerte werden den Schaubildern als mathematische Veranschaulichung der Streuung zur Seite gestellt.
} 
daher auch nicht um Zufallsstichproben, sondern um strukturierte Stichproben, d.h. jede dieser Stichproben stellt einen Querschnitt durch eine Struktur dar. Bereits unter 5.3.5 wurde gezeigt, daß das Kapitel den besten Ausgangspunkt fur unsere Stiluntersuchung bietet. Diese Art von Stichprobe ist begrenzt und kann nicht erweitert werden, ohne daß der formulierte Stilbegriff ad absurdum geführt werden wïrde.

Die Struktur des Stils selbst setzt sich aus mehreren Komponenten (Parametem) zusammen. Es kann daher durchaus eine Komponente Unregelmaßigkeiten aufweisen, ohne daß die Struktur als ganzes in Mitleidenschaft gezogen wird. Hier liegt eine große Problematik der statistischen Tests: wie kann man die Verteilung von vier verschiedenen Komponenten sinnvoll überprüfen, zumal sie nicht miteinander korrelieren ?

Die wirkliche Cnux aber liegt in einem anderen Punkt: die statistischen Tests uber prüfen Verteilungen und können auch nur Verteilungen uberprufen, nicht aber Strukturen $^{26}$. Die Verteilungswerte machen nur zum Teil die Strukturen sichtbar, womit sich die Bedeutung der Verteilungswerte der einzelnen Stilkomponenten (Parameter) verringert. Daher solten auch die Verteilungswerte nur auf ihre Regelmaßigkeit, welche sich in gleichen quantitativen Grőßenordnungen widerspiegelt, uberprüf werden; nicht aber sollten sie am absoluten Durchschnittswert des Werkes gemessen werden. Die statistischen Tests aber verfahren genau auf letztere Weise, wenn sie geringe Schwankungen von Stichprobe zu Stichprobe voraussetzen, um eine Gesamtkurve oder einen Kennwert für das ganze Werk erstellen zu können. Oftmals sind die prüfstatistischen Vorgaben $2 \mathrm{~s}$ streng, um auf unsere Untersuchung angewandt werden $z$ kőnnen. so widerlegten z. B. die statistischen Prüfverfahren in bezug auf den Parameter Satzlänge die Homogenităt der Texte (=Kapitel) innerhalb eines Werkes ${ }^{27}$ ! Der Leser aber kann keine Inhomogenităt (was gleichbedeutend mit einem 'Stilbruch' wăre) in diesen Werken feststellen. Es muß daher davon ausgegangen werden, daß die menschliche Auffassungsgabe hier wesentlich mehr an Streuung 'akzeptiert', als die

\footnotetext{
${ }^{26}$ Zwar stützt sich auch die vorliegende Arbeit auf die Untersuchung von Verteilungen, doch wird die Hilfsfunktion dieses Ansatzes nie aus den Augen verloren.

${ }^{27}$ Selbst in Puskins Geschichtswerk, welches sich durch eine sehr hohe Regelmæßigkeit in der Verteilung der Satzlăngen auszeichnet, waren die Verteilungen der einzelnen Texte (=Kapitel) zu sehr unterschiedlich, als daß diese einer einzigen distinkten Verteilung angepaßt werden konnten: Text 1 zeigte eine Thomas-Verteilung; Text 2 eine Haight-Poisson-Geometrische-Verteilung und Text 3 eine Hyperpascal-Verteilung. (Persơnliche Mitteilung von Herm Prof. Köhler, Trier)
} 
statistischen Tests erlauben ${ }^{28}$. (Vergleichbar ist dies wohl dem hohen Abstraktionsvermögen des Menschen, welches beispielsweise hinter einer Vielzahl von unterschiedlichen Baumarten immer noch das Konzept 'Baum' sehen kann)

Es geht also nicht um die genaue Verteilung in einem Werk, sondern darum, ob sich ein Profil bereits in den Kapiteln abzeichnet. Denn wenn wir davon ausgehen, daß der Autor einen bestimmten Stil verwendet, dann muß sich die für ihn typische Verteilung in beliebigen Kapiteln festmachen lassen. Dies wird dadurch bestatigt, daß selbst verschieden große Stichproben dasselbe Profil bezaglich drei von vier Parametern bieten (z.B. schwankt bei Lomonosov der Stichprobenumfang zwischen der ersten Stichprobe mit 27 Sătzen und der dritten mit 135 Sătzen um das 5-fache).

Fazit:

Ein Stil, der erst auf der Grundlage des gesamten Werkes feststellbar wăre, verdiente nicht die Bezeichnung Sril. Wir sind der Meinung: entweder manifestiert sich der Stil in den drei Stichproben (=Kapiteln) ausreichend oder es gibt keinen Stil. Denn der Stil als solcher muß sich bereits in jedem einzelnen Kapitel manifestieren; daher reichte eigentlich schon die Untersuchung eines einzelnen Kapitels, um eine grobe Vorstellung vom Stil zu bekommen. Die Untersuchung der beiden weiteren Kapitel dient nur dazu, die Streuung der Großenordnungen in den einzeinen Parametern festzustellen, also die Stilvorstellung au verfeinern ${ }^{29}$.

\subsubsection{Zu den Vengleichswerten (Mittetwerten)}

In der vorliegenden Untersuchung wird von der Verteilung in den drei Stichproben auf die Verteilung des Werkes geschlossen, indem der gewogene Mittelwert aus den drei Stichproben bestimmt wird. Dieser gewogene Mittelwert ist ein Wahrscheinlichkeitswert $^{30}$ : er entspricht nicht der genauen Verteilung im Gesamtwerk ! Seine Bedeutung und damit das Gewicht eines etwaigen Fehlers verringert sich dadurch, daß die Mittel-

\footnotetext{
${ }^{28} \mathrm{Vgl}$. hierzu auch DOLEŽEL 1969, 272 f. und genau auf das vorliegende Problem Bezug nehmend: MARZARI 1998.

${ }^{29}$ Ironischerweise wird die grobe Vorstellung durch einen einzelnen, daher genau anmutenden Zahlenwert verkorpert. Wohingegen die verfeinerte Stilvorstellung stets durch das von zwei Extremwerten begrenzte Intervall vertreten wird. Auch hier sei das Beispiel des Baumkonzeptes angefuhrt: die grobste Vorstellung hat das Kind, das nur eine einzige Baumart kennt; die verfeinerte Vorstellung hat der Erwachsene, der eine Vielzahl von Baumarten kennt.

${ }^{30}$ In der Statistik auch Schätzwert genannt.
} 
werte von vier Stilkomponenten (Parameter) zur Beurteilung des Stils herangezogen werden.

\subsection{Methodensynthese}

Streng genommen kann man die meisten stilistischen Untersuchungen zwei vollkommen unterschiedlichen Darstellungsarten, die allerdings meist von der Methodik vorbestimmt sind, zuordnen:

a) der rein beschreibenden, die mit 'literaturwissenschaftlicher Methode' bezeichnet werden könnte und die streng linear gelesen werden kann;

b) der statistisch analysierenden, die eine Vielzahl von Tabellen, statistischen Kennwerten und eventuell Schaubilder aufweist und in der sozusagen die mathematische Beschreibung dominiert. In diesem Falle muß der Öberblick erarbeitet werden, indem die Arbeit rekursiv gelesen wird: meist ist eine mehrfache Hin- und Herbewegung zwischen Tabelle (Zahl) und Text nötig; selbst Rekursionen uber mehrere Seiten hinweg sind moglich.

In dieser Arbeit wird versucht, beide Darstellungsarten zu kombinieren. Einerseits bietet die Darstellung in Diagrammen neue Vergleichsmøglichkeiten und uberhaupt auch eine neue Art der Darstellung: so kann z.B. anhand von Săulendiagrammen die Streuung der Satzlănge veranschaulicht werden, und mit Hilfe der Streuungswerte kơnnen die visuell wahrgenommenen 'Unebenheiten' in den Schaubildern genau berechnet, auf eine Zahl reduziert und damit mit anderen Werten verglichen werden. Ebenso sind die Mittelwerte die Grundlage des Vergleichs.

Andererseits ist die 'Beschreibende Darstellung' (S.144-165) eine wichtige Ergănzung, um sozusagen dem 'Zahlenskelett' Substanz hinzuzufugen. Dabei geht die Anschaulichkeit allerdings auf Kosten der vollstăndigen Erfassung, d.h. die Beispiele konnen immer nur stellvertretend und exemplarisch sein. 
5.7 Ûbersicht äber die Untersuchungseinheiten

(gesamt)

LOMONOSOV: Geschichtswerk

$\begin{array}{lrrr}\text { Text 1: } & 702 \text { Worter } & \text { 27 Sătze } & = \\ \text { Text 2: } & 2229 \text { Worter } & \text { 106 Sătze } & = \\ \text { Text 3**: } & 2579 \text { Wơrter } & 135 \text { Sătze } & (2900 \text { Worter }) \\ & 5510 \text { Worter } & 268 \text { Sătze } & \end{array}$

KARAMZIN: Geschichtswerk

\begin{tabular}{llll} 
Text 1**: & 2592 Worter & 103 Sătze & (2 607 Worter) \\
Text 2**: & 3389 Worter & 147 Sătze & (3 634 Worter) \\
Text 3**: & 2896 Wörter & 123 Sătze & (3 132 Worter) \\
\hline & 8875 Wörter & 373 Sătze &
\end{tabular}

KARAMZIN: Dichterisches Werk

Gesamttext**: 3323 Wơrter 196 Sătze $\quad$ (5 002 Worter)

PUŠKNN: Geschichtswerk:

\begin{tabular}{lllc} 
Text 1**: & 1667 Worter & 107 Sătze & (1 679 Worter) \\
Text 2: & 2231 Worter & 170 Sătze & $=$ \\
Text 3**: & 4003 Worter & 307 Sătze & (4 466 Worter) \\
\hline & 7900 Worter & 584 Sătze &
\end{tabular}

PUSKKNN: Dichterisches Werk:

$\begin{array}{cccc}\text { Text 1**: } & 1597 \text { Worter } & 124 \text { Sătze } & (2265 \text { Worter }) \\ \text { Text 2**: } & 1520 \text { Worter } & \text { 106 Sătze } & \text { (2 560 Worter) } \\ \text { Text 3**: } & 2241 \text { Worter } & \text { 152 Sătze }\end{array}$

** In diesen Texten kamen wörtliche Rede und Zitate vor, die nach 5.3.4 ausgeschlossen wurde. Die ersten beiden Zahlenspalten beziehen sich auf den Teil des Textes, der untersucht wurde; die Zahlenspalte in Klammern bezieht sich auf die Gesamtzahl der Worter in den betreffenden Texten. 


\section{Teil B:}

\section{Untersuchung}




\section{4h pot}

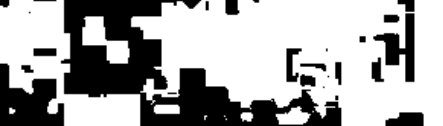

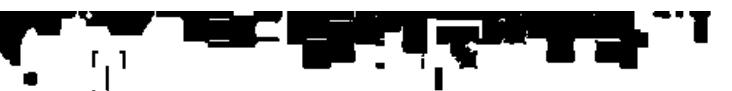

17.1

$$
\text { S }
$$

18

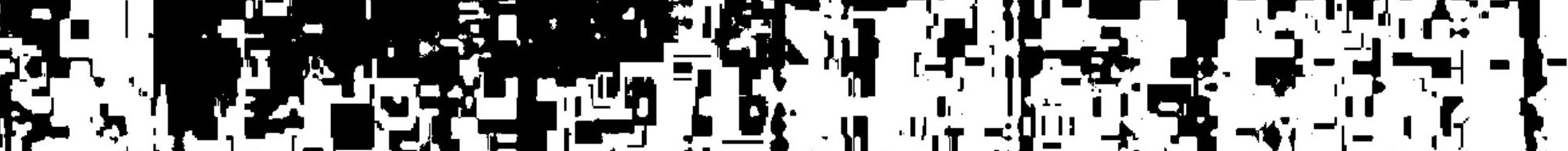
on

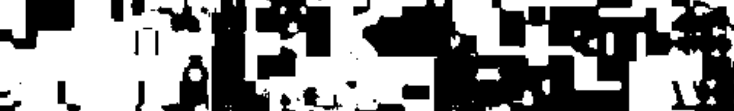

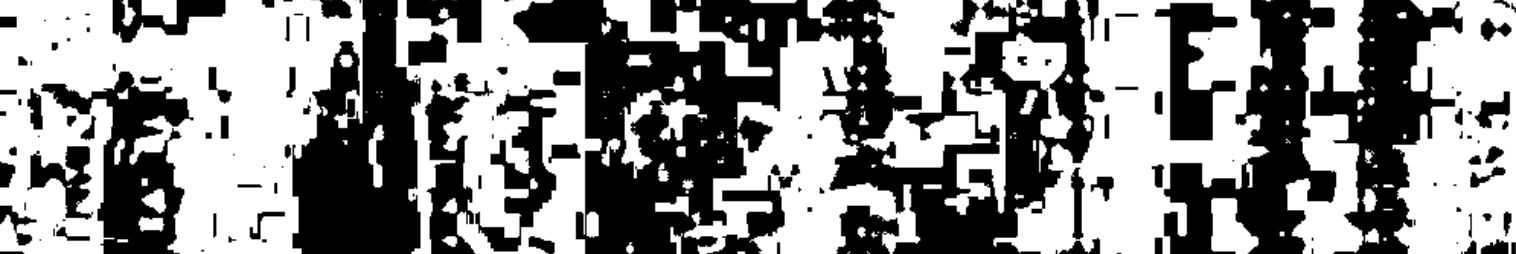
2 - S

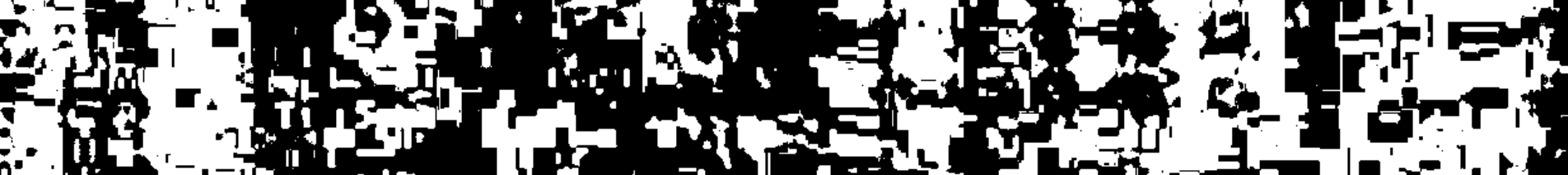
$x=$ Q 250 , in +24 t

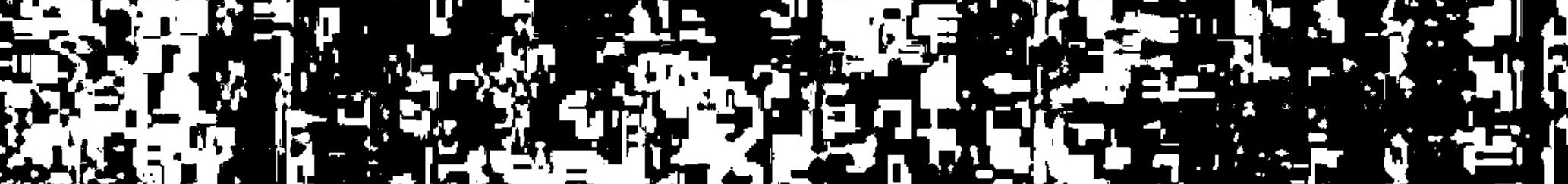

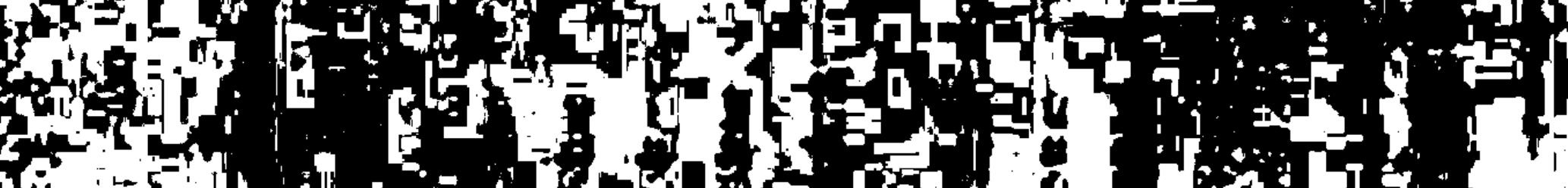
5140 - 150 Q1)

$\rightarrow 4$

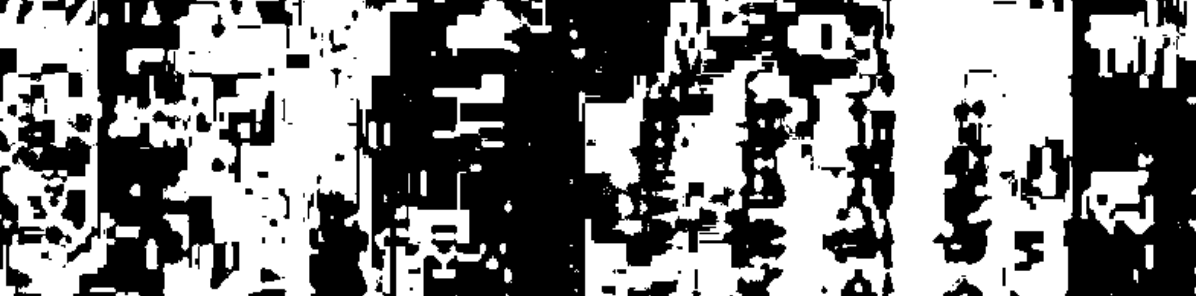

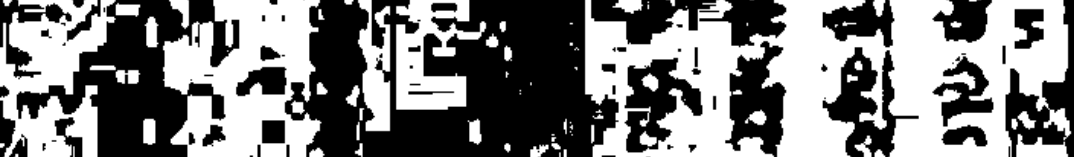

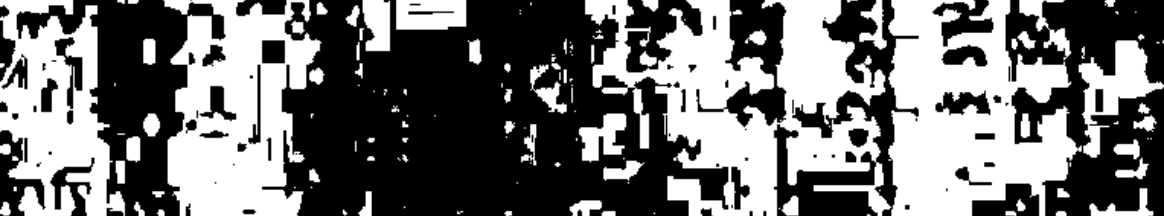

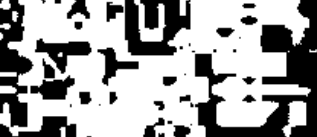

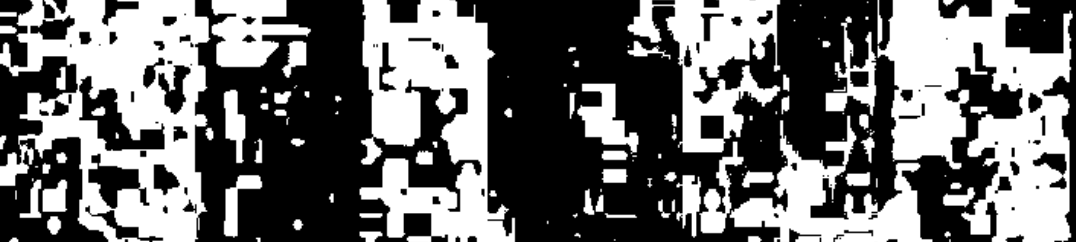

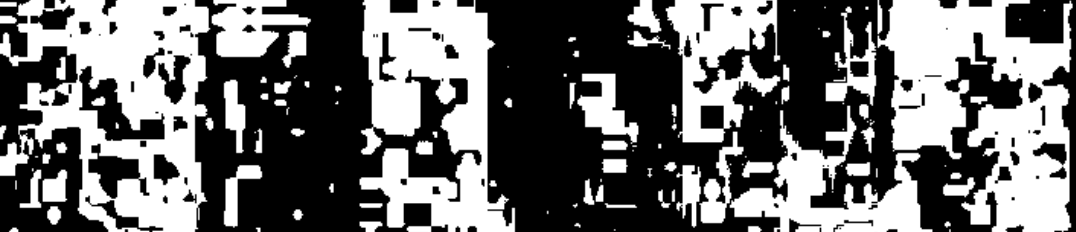

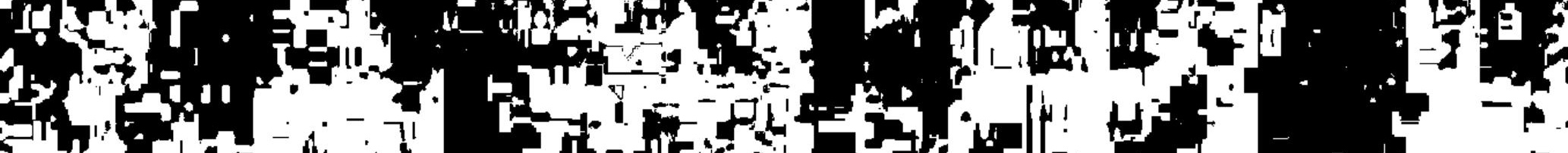

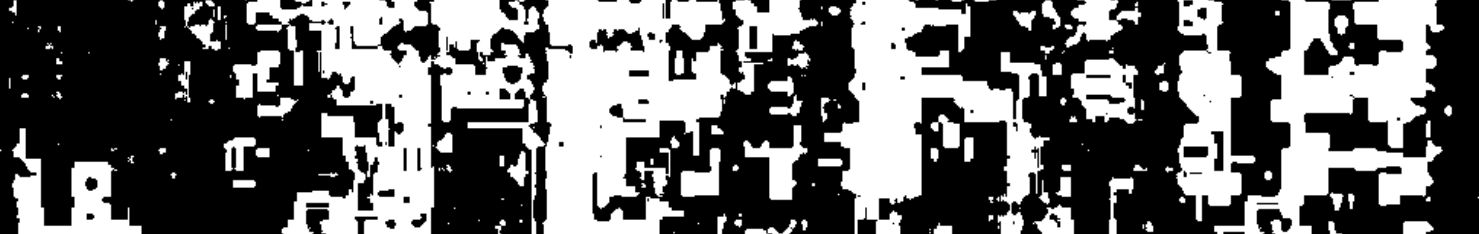
(s) 10

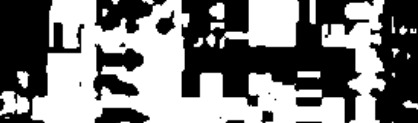

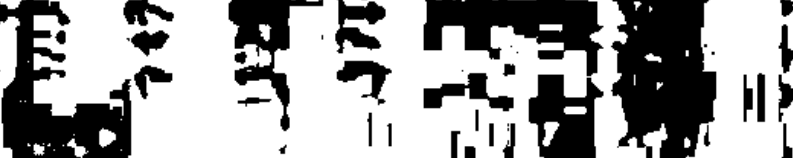

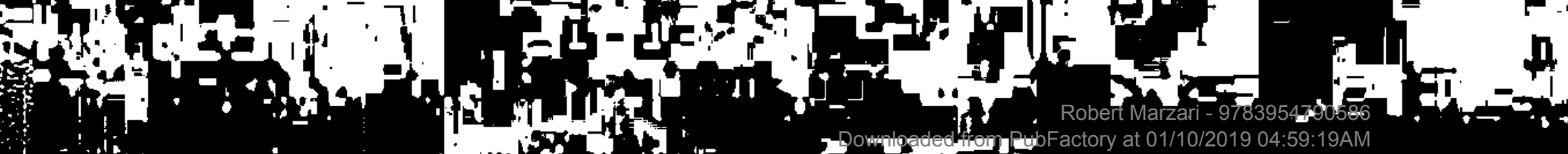

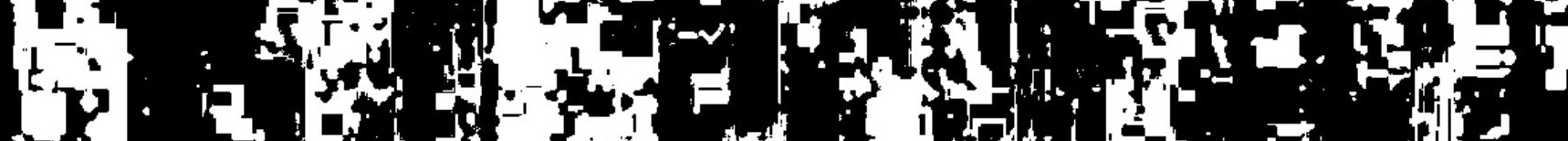

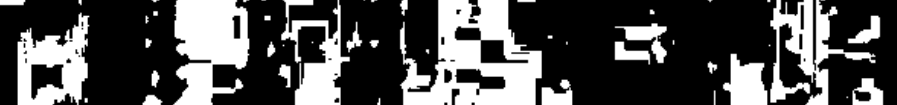
A

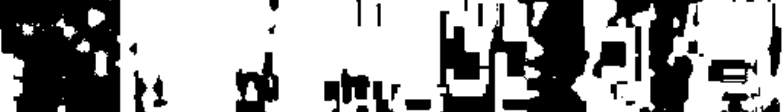




\section{a) Parameter Satzlånge:}

\section{Definitionen und Untersuchungsschritte:}

Im ersten Schritt soll die Satzlänge untersucht werden. Dies geschieht durch einfaches Auszăhlen. An Definitionen sind vorab zu treffen: es wird gezăhlt, was durch einen Satzpunkt, ein Frage- oder Ausrufezeichen begrenzt wird '; Doppelpunkt und Strichpunkt werden als untergeordnete Gestaltungsmittel des Autors angesehen ${ }^{2}$.

Die Sătze werden auf das einzelne Wort genau gezăhtt. Als Wort zăhlt, was durch einen Zwischenraum getrennt wird; es entscheiden graphische Indikatoren. Auch mehrstellige Ziffern werden als ein einziges Wort gehandelt (sowohl romische als auch arabische).

In der Auswertung werden die Satzlängen in Zehner-Intervallen erfaßt:

also Sătze mit 10-19 Wortern; mit 20-29 Wortern usw.

Um Kurzsătze zu isolieren, wird das Intervall von 1.9 noch einmal aufgeteit in Sătze mit 1-5 Wortern und 6-9 Wortern. Die Sătze über 40 Worter werden nicht mehr nach Zehnereinheiten differenziert.

Diese Aufteilung in die verschiedenen Satzlängenintervalle wird in einer Tabelle dargestelt; dabei wird die Anzahl der Sătze absolut ausgedrlickt:

\begin{tabular}{|c|c|}
\hline $\begin{array}{l}\text { Beispiel: } \\
\text { Wortanzahl }\end{array}$ & Satzo \\
\hline$x \leq 5$ & 0 \\
\hline $5<x<10$ & 1 \\
\hline $10 \leq x<20$ & 10 \\
\hline $20 \leq x<30$ & 10 \\
\hline $30 \leq x<40$ & 2 \\
\hline$x \geq 40$ & 4 \\
\hline
\end{tabular}

Für das nachfolgende Schaubild wird die Anzahl der Sătze in Prozentanteile umgerechnet. Das Schaubild vermittelt somit die prozentuale Verteilung der Satzlangen bezüglich des untersuchten Textes.

'Wir können davon ausgehen, daß die unserer Untersuchung zugrundeliegende Edition die Satzpunktsetzung der autorisierten Fassung des Autors wiedergibt (siehe dazu die Ausfuhrungen unter 'Editionsănderungen' im 4. Kapitel).

${ }^{2} \mathrm{Zu}$ unterscheiden ist in diesem Zusammenhang der 'graphische Satz' vom 'syntaktischen Satz': der graphische Satz, der sich von Punkt zu Punkt erstreckt, wird in der Untersuchung nur als 'Satz' bezeichnet. Syntaktische Sătze sind Hauptsatz und Nebensatz. Wenn ein Satz, durch einen einzigen Hauptsatz gebildet wird, wird er auch als 'Einfachsatz' bezeichnet (vgl. dazu die Definitionen zu Parameter b Satzkomplexităt). 
Beispiel:

Anteil der Satze in Prozent:

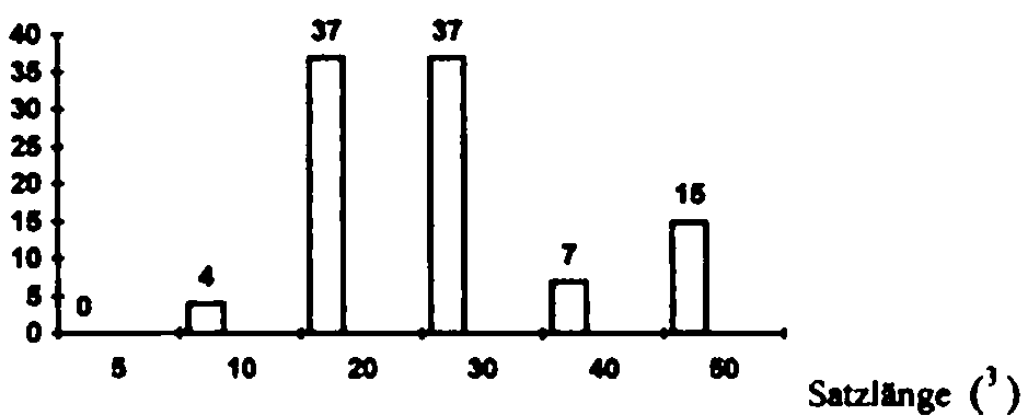

Dieses Profil laßt sich mit anderen Profilen vergleichen; es ist aber auch schon allein aussagekraftig.

Verglichen werden zuerst die Profile innerhalb eines Textes. Die Fragestellung lautet dabei, ob und inwieweit ein Autor eine RegelmäBigkeit in der Satzlängenverteilung aufweist.

Durch die Erstellung des Satzlăngenprofils kann zunăchst formal die Regelmäßigkeit des Satzbaus erschlossen werden.

Der Vergleich der Profile ergibt ein ausreichend genaues Bild von der RegelmaßBigkeit bzw. der Unregelmåßigkeit der Satzlängenverteilung. Wenn man dagegen kleinere Intervalle wăhlen wörde (z.B. 5-er Intervalle), so wirde das auf Kosten der Anschaulichkeit gehen, davon abgesehen wăre auch der Vergleich mit den anderen Autoren erschwert.

Die Satzlăngenprofile werden im Laufe der Untersuchung der einzeinen Kapitel sukzessiv miteinander verglichen, d.h. das erste Kapitel wird zum Vergleich mit dem mittleren herangezogen, und mit dem letzten Kapitel schließlich werden alle drei Profile nebeneinander gestelth.

Weit wichtiger als eine exakte Ubereinstimmung der Werte ist die Kristallisation eines oder zweier Intervalle als hăufigste(s) Satzlängenintervall(e), also die Abzeichnung eines Profils '. Davon darf jedoch nicht abgeleitet werden, der Autor wolle und könne die Satzlăngen genau bemessen. Er kann bei aller zugestandenen Genialităt nur die zu langen Sătze in kürzere aufbrechen oder kurze Sătze zu lăngeren und komplexeren zusammenfassen. Die Spitze des Profils bzw. die prozentualen Spitzenwerte der Verteilung geben also Aufschluß uber die bevorzugten Satzlängen des Autors.

\footnotetext{
${ }^{3}$ Mit Hilfe der zur Verfugung stehenden Software konnte leider keine genauere Beschriftung des Schaubildes stattfinden: so werden die Sătze mit $\geq 40$ Wơrtern uber der Zahl 50 eingeordnet; ansonsten bezeichnen die Zahlen die Obergrenze der Intervalle.

${ }^{4}$ Mit diesem Profil soll nicht eine Gesamtkurve oder eine Gesamtverteilung für das Werk erstelt werden. (Siehe hierzu die Erörterungen unter 5.5.2)
} 
Folgende statistische Werte werden angegeben:

Die durchschnittliche Satzlange: es handelt sich hier um das arithmetische Mittel, wobei keine Klassen angenommen wurden. sondern jede Satzlänge einzeln addiert wurde.

An Streuungswerten werden angegeben:

1) Die Variationsweite durch Angabe des kürzesten Satzes und des längsten Satzes;

2) die Varianz $s^{2}:$ Berechnung nach $s^{2}=\frac{\sum(x-\bar{x})^{2}}{n-1}$;

3) die Standardabweichung $s$ : Berechnung nach $s=\sqrt{\frac{\sum(x-\bar{x})^{2}}{n-1}}$.

\section{Untersuchungsergebnisse:}

\section{LOMONOSOV - Geschichtswerk}

\section{Text 1:}

Anzahl der Sătze: $27 \quad--702$ Worter

durchschnittliche Satzlänge: $\quad 26$ Worter $\quad(26,0)$

kürzester Satz: $\quad 7$ Worter ; lăngster Satz: $\quad 94$ Worrter

Die Satzlange verteit sich folgendermaßen:

\begin{tabular}{rr} 
Wortanzahl & Sătze \\
\hline$x \leq 5$ & 0 \\
$5<x<10$ & 1 \\
$10 \leq x<20$ & 10 \\
$20 \leq x<30$ & 10 \\
$30 \leq x<40$ & 2 \\
$x \geq 40$ & 4 \\
&
\end{tabular}

Varianz $\left(^{5}\right) s^{2}=331$

Standardabweichung $s=18$

${ }^{5}$ Der Berechung der Varianz und der Standardabweichung wurden gleich große und geschlossene Klassen zugrunde gelegt; siehe Anhang S.186-187. 
Graphisch dargestellt: (Lomonosov Geschichtswerk Text 1)

Anteil der Satze in Prozent:

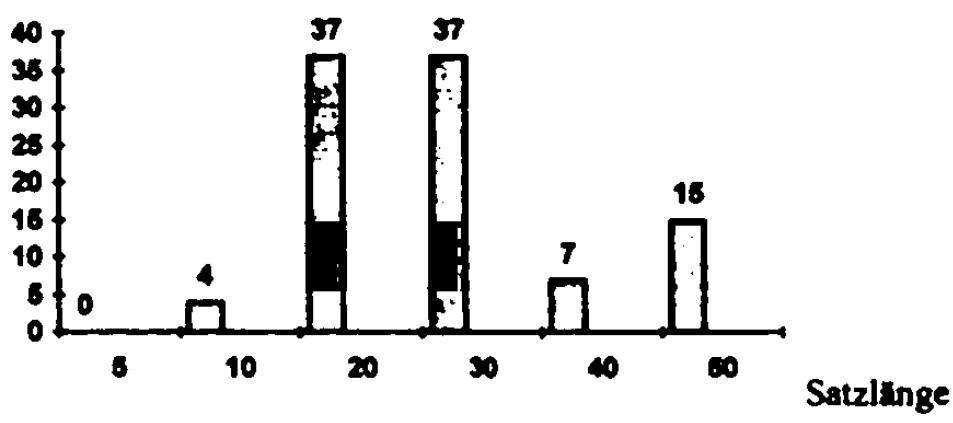

Lomonosov Geschichtowerk Text 2:

Anzahl der Sătze: $\quad 106 \quad-2229$ Worter

durchschnittliche Satzlange : 21 Worter $\quad(21,0)$

küzester Salz: $\quad 3$ Wơrter ; $\quad$ lăngster Satz: $\quad 77$ Worter

Die Satzlange verteitt sich folgendermaßen:

Wortanzahl Satze

\begin{tabular}{rr}
\hline$x \leq 5$ & 4 \\
$5<x<10$ & 11 \\
$10 \leq x<20$ & 45 \\
$20 \leq x<30$ & 24 \\
$30 \leq x<40$ & 14 \\
$x \geq 40$ & $\frac{8}{106}$
\end{tabular}

Varianz $s^{2}=172$

Standardabweichung $s=13$

Graphisch dargestellt: (Lomonosov Geachichtswerk Text 2)

Anteil der Satze in Prozent:

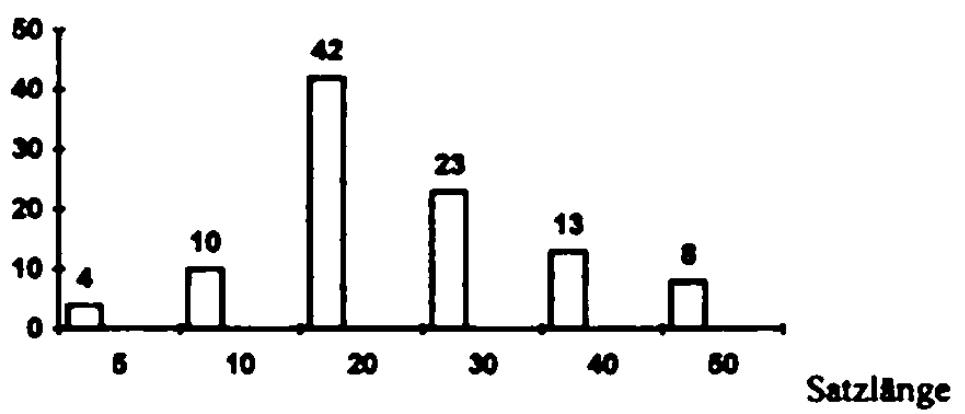


Vergleich von Text 1 und Text 2:

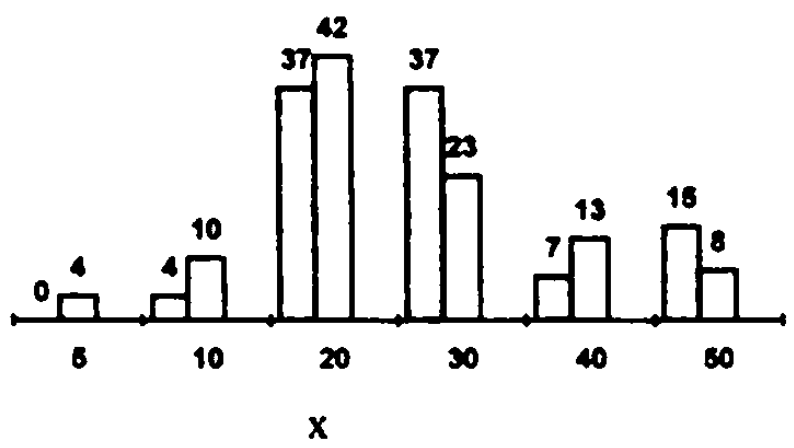

Die einzige Gemeinsamkeit scheint bei dem Satzintervall $/ 10 \leq x<20 /$ (mit x markiert) zu liegen: hier beträgt die Streuung nur 5\%.

\section{Lomonosov Geschichtswerk Text 3:}

Anzahl der Sătze: 135

-2579 Worter

durchschnittliche Satzlănge:

19 Wörter $\quad(19,1)$

kürzester Satz: $\quad 4$ Worter; $\quad$ längster Satz: $\quad 54$ Worter

Die Satzlănge verteilt sich folgendermaßen:

Wortanzahd Sătze

$x \leq 5 \quad 4$

$5<x<10 \quad 13$

$10 \leq x<20 \quad 61$

$20 \leq x<30 \quad 40$

$30 \leq x<40 \quad 9$

$x \geq 40 \quad \frac{8}{135}$

Varianz $s^{2}=113$

Standardabweichung $s=11$

Graphisch dargestellt:

Anteil der Satze in Prozent: $\left({ }^{6}\right)$

(Lomonosov Geschichtswerk Text 3)

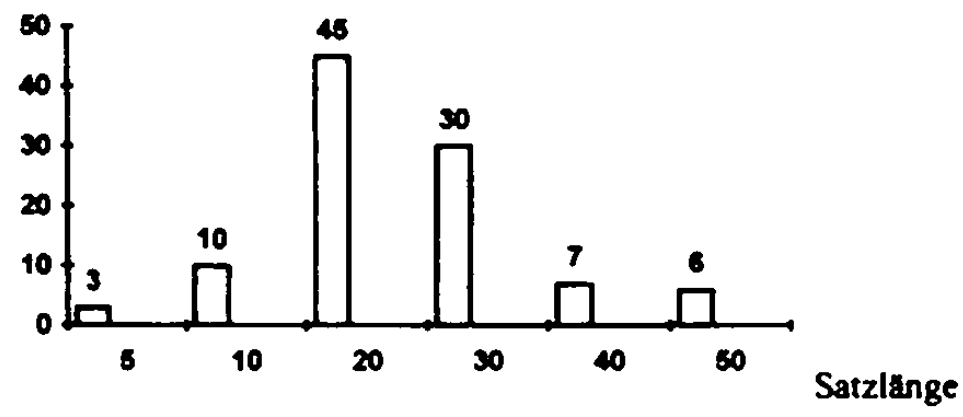

${ }^{6}$ Durch Aufrundung einiger Werte betrăgt die Summe 101\%! 
Vergleich von Tert 1, Text 2 und Text 3:

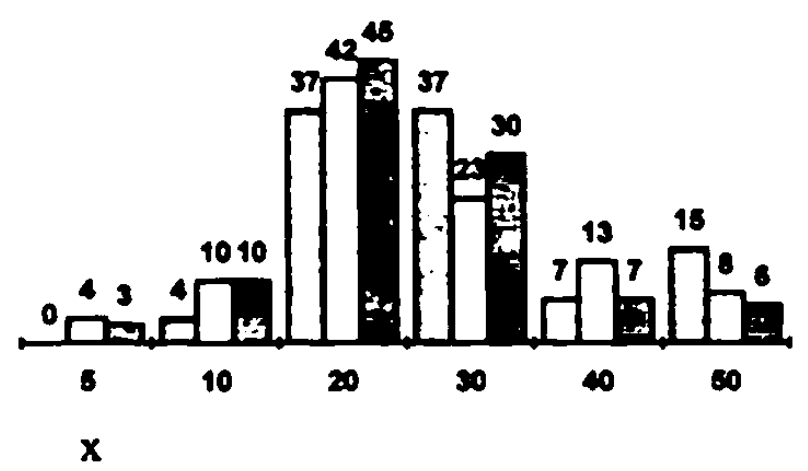

Nur ein Block (mil $\times$ markiert) weist eine Streuung unter 5\% auf; die restlichen Blocke haben eine Streuung von 6\%, 8\%, 14\%, 6\% und 9\%. Trotz dieser Abweichungen innerhalb der einzelnen Blocke laßt sich doch ein Profil erkennen '. Erstaunlich ist. daß oft sogar zwei Zahlen in den Blocken übereinstimmen. Es erscheint daher berechtigt, durch die Ermittlung des gewogenen Mittelwertes der einzelnen Blocke ein Satzlangenprofil fiur Lomonosovs Geschichtswerk zu erstellen.

Der gewogene Mittehrert der durchschnittlichen Satzlänge für die Texte aus Lomonosovs Geschichtswerk betragt 21 Wठrter $(20,6)^{8}$.

Es ergibt sich folgendes gemitteltes Satzlăngenprofil:

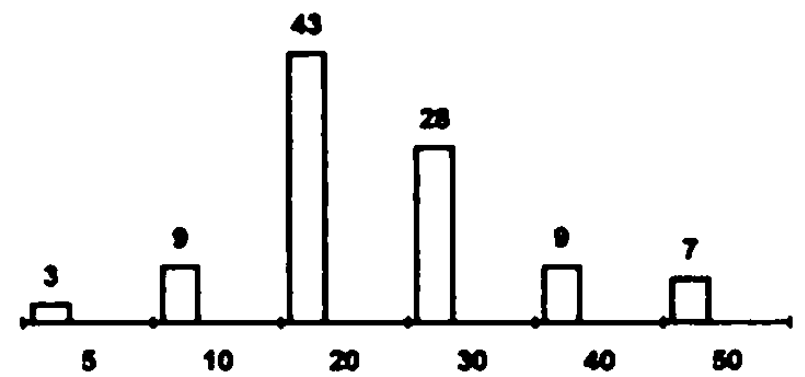

Dieses Schaubild wird stellvertretend fir Lomonosovs Geschichtswerk angesehen; es wird im folgenden zum Vergleich mit den anderen Profilen herangezogen.

\footnotetext{
${ }^{7}$ Obwohl die Varianzen zum Teil recht weit auseinanderliegen, wie die Quotienten $\frac{s_{1}{ }^{2}}{s_{2}{ }^{2}}=\frac{331}{172}=1,9 ; \quad \frac{s_{1}{ }^{2}}{s_{3}{ }^{2}}=\frac{331}{113}=2,9 ; \quad \frac{s_{2}{ }^{2}}{s_{3}{ }^{2}}=\frac{172}{113}=1,5 \quad$ verdeutlichen, zeichnet sich ausreichend deutlich ein Profil ab.

AKIMOVA $(1973,69)$ erhalt den gleichen Wert: 20,5 , wobei zu beachten ist, daB sie andere Stichproben zugrunde legt, deren Umfang leider nicht klar gekennzeichnet ist: "Были сделаны выборки ..." (S.68). Nichtsdestoweniger ist aber sicher, daß sie andere Stichproben ausgewăht hat. Da unser Mittelwert nahezu identisch ist $(20,6$ gegenüber 20,5), wird die Zuverlăssigkeit des Mittelwerts als Wahrscheinlichkeitswert untermauert.
} 
KARAMZIN - Geschichtswerk

\section{Text 1:}

Anzahl der Sătze: $\quad 103 \quad$ - 2592 Worter

durchschnittliche Satzlănge: $\quad 25$ Worter $\quad(25,1)$

kurzester Satz: $\quad 4$ Worter ; $\quad$ lăngster Satz: $\quad 97$ Worter

Die Satzlănge verteit sich folgendermaßen:

Wortanzahl Sătze

\begin{tabular}{rr}
\hline$x \leq 5$ & 2 \\
$5<x<10$ & 11 \\
$10 \leq x<20$ & 33 \\
$20 \leq x<30$ & 29 \\
$30 \leq x<40$ & 11 \\
$x \geq 40$ & $\frac{17}{103}$
\end{tabular}

Varianz $s^{2}=265$

Standardabweichung $s=16$

Graphisch dargestell: (Karamzin Gescbichtswerk Text 1)

Anteil der Satze in Prozent:

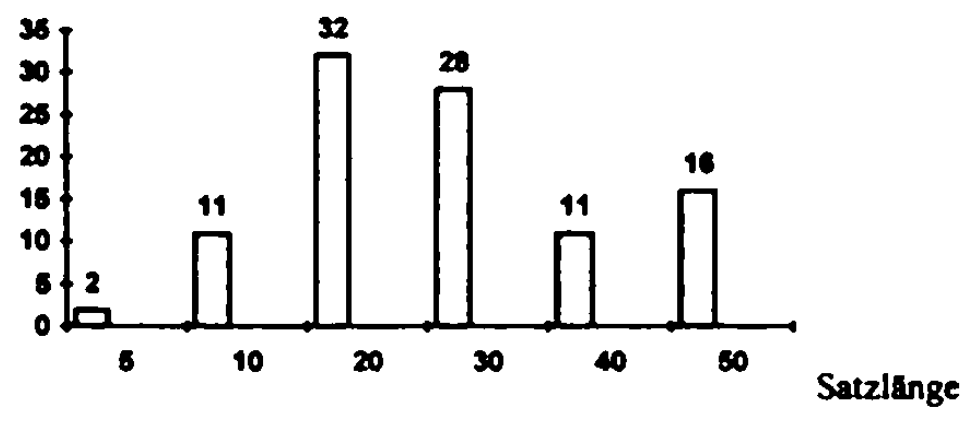

Karamzin Geschichtswerk Text 2:

Anzahl der Sătze: $\quad 147 \quad-3389$ Wörter

durchschnittliche Satzlänge: $\quad 23$ Worter $\quad(23,0)$

kürzester Satz: $\quad 5$ Wơrter ; längster Satz: $\quad 78$ Wơrter

Die Satzlăge verteilt sich folgendermaßen:

Wortanzahl Sătze

$x \leq 5 \quad 1$

$5<x<10 \quad 17$ 


$$
\begin{aligned}
& 10 \leq x<20 \quad 49 \quad \text { Varianz } s^{2}=195 \\
& 20 \leq x<30 \quad 45 \quad \text { Standardabweichung } s=14 \\
& 30 \leq x<40 \quad 21 \\
& x \geq 40 \quad \frac{14}{147}
\end{aligned}
$$

Graphisch dargestellt: (Karamzin Geschichtswerl Text 2)

Anteil der Sătze in Prozent:

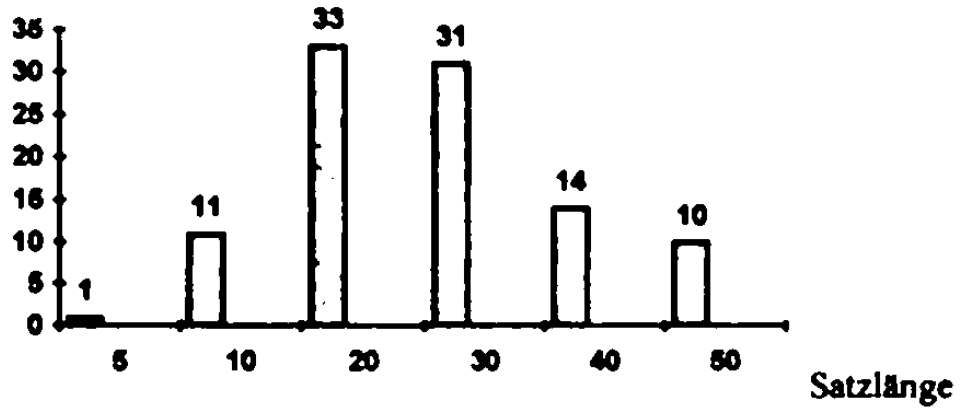

Vergleich von Tert 1 und Text 2:

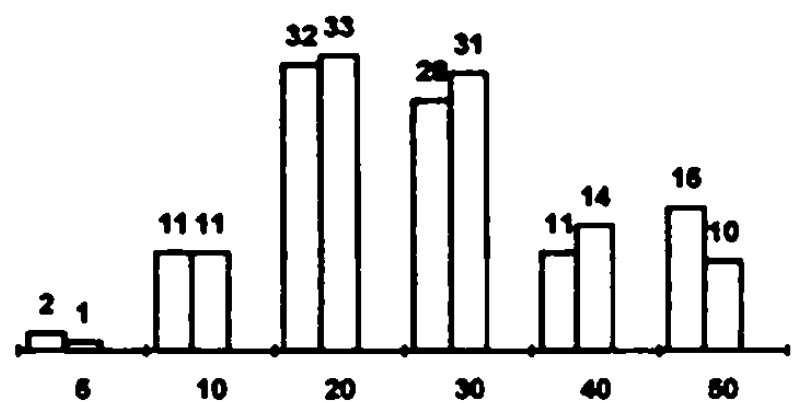

Bis auf das letzte Satzlängenintervall weisen alle eine Streuung von höchstens $3 \%$ auf.

\section{Karamzin Geachichtswerk Text 3:}

Anzahl der Sătze: $\quad 123 \quad-2896$ Worter

durchschnittliche Satzlănge: $\quad 24$ Worter $\quad(23,5)$

kürzester Satz: $\quad 3$ Wơrter; $\quad$ lăngster Satz: $\quad 63$ Wơrter

Die Satzlănge verteilt sich folgendermaßen:

\begin{tabular}{rr} 
Wortanzahl & Sătze \\
\hline$x \leq 5$ & 2 \\
$5<x<10$ & 8 \\
$10 \leq x<20$ & 42
\end{tabular}

Varianz $s^{2}=148$ 
$20 \leq x<30 \quad 35$

$30 \leq x<40 \quad 23$

$x \geq 40 \quad 13$

$\frac{13}{123}$

Graphisch dargestellt: (Karamzin Geschichtswerk Text 3)

Anteil der Satze in Prozent:

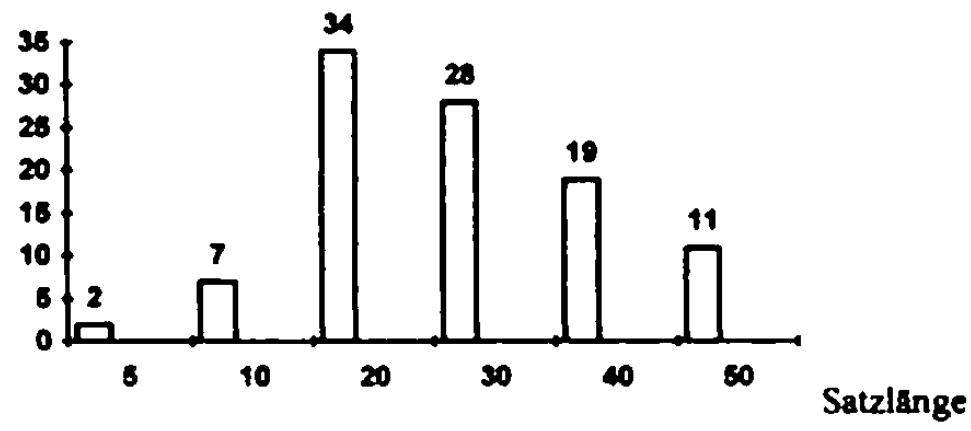

Vergleich von Text 1, Text 2 und Text 3:

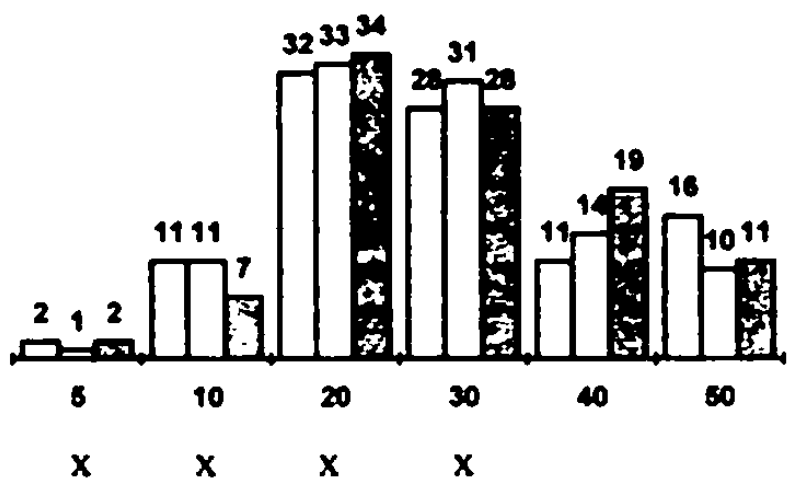

Das Satzlangenprofil verhält sich bei Karamzin sehr regelmaßig: nur in den beiden letzten Blöcken beträgt die Streuung über 5\%, nämlich $8 \%$ bzw. 6\%, sonst unter 5\% (mit $\mathrm{x}$ markiert). Das Profil ist bedeutend regelmäBiger als bei Lomonosov $"$

Der gewogene Mittehwert der durchschnittlichen Satzlänge für die Texte aus Karamzins Geschichtswerk beträgt 24 Worter $(23,8)$.

'Die Varianzen liegen năher beieinander als bei Lomonosov; die Quotienten bewegen sich zwischen 1,3 und 1,8: $\quad \frac{s_{1}{ }^{2}}{s_{2}{ }^{2}}=\frac{265}{195}=1,4 ; \frac{s_{1}{ }^{2}}{s_{3}{ }^{2}}=\frac{265}{148}=1,8 ; \frac{s_{2}{ }^{2}}{s_{3}{ }^{2}}=\frac{195}{148}=1,3$. 
Es ergibt sich folgendes gemitteltes Satzlängenprofil:

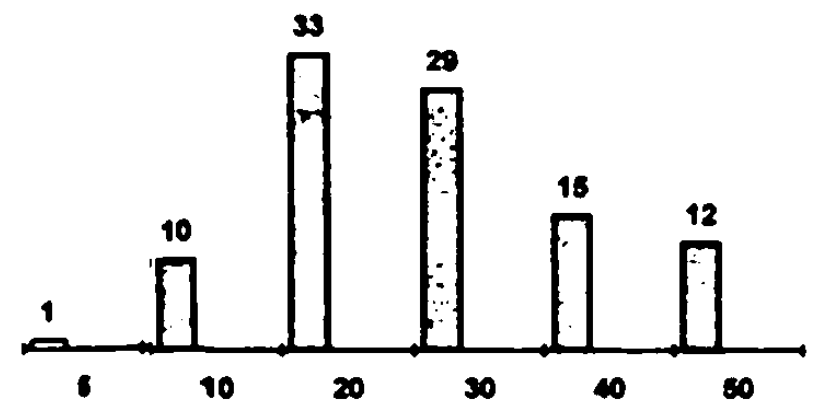

Dieses Sichaubild wird stellvertretend fur Karamzins Geschichtswerk angesehen; es wird im folgenden zum Vergleich mit den anderen Profilen herangezogen.

KARAMZIN - Dichterisches Werk

Geanmtcext:

Anzahl der Sătze: $\quad 196 \quad-3323$ Wơrter

durchschnittliche Satzlänge: $\quad 17$ Worter $\quad(17,0)^{10}$

kürzester Satz: $\quad 2$ Worter ; längster Satz: $\quad 68$ Wörter:

Die Satzlange verteitt sich folgendermaßen:

\begin{tabular}{rr} 
Wortanzahl & Satze \\
\hline$x \leq 5$ & 20 \\
$5<x<10$ & 36 \\
$10 \leq x<20$ & 76 \\
$20 \leq x<30$ & 36 \\
$30 \leq x<40$ & 18 \\
$x \geq 40$ & 10 \\
\cline { 2 - 2 } & 196
\end{tabular}

${ }^{10}$ Auch LESSKIS (1963a) erhăt den gleichen Wert: die "cnлoumoe aвторcкоe no вествованде" umfaßt bei ihm 3031 Worter zu 182 Sătzen, was eine durchschnittliche Satzlănge von 16,6 Wörtern ergibt (S. 94)! (Der Unterschied von seinem Textumfang zu unserem ergibt sich daraus, daß wir bei den Sătzen mit wơrtlicher Rede die 'Stútzsătze', die eine hypotaktische Struktur aufwiesen, mitgezahh haben. Vgl. 5.3.4) 
Graphisch dargestellt: (Karamzin dichterisches Werk Gesamttext)

Anteil der Satze in Prozent:

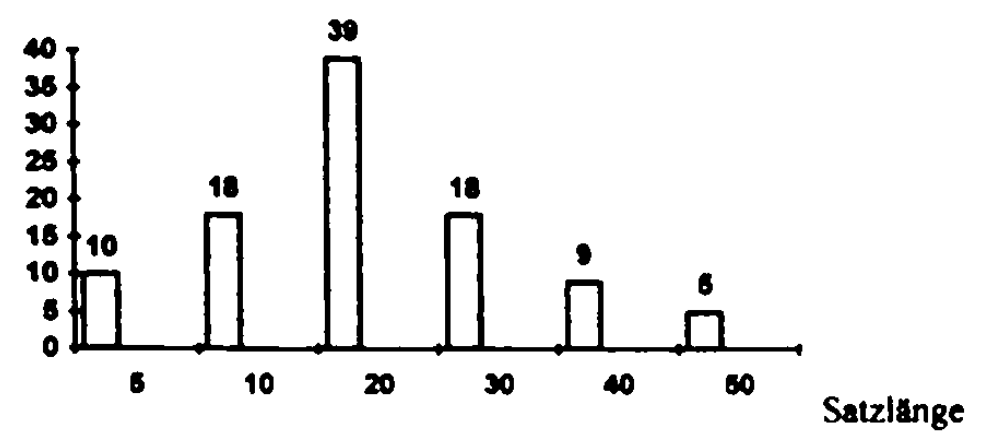

Da hier der Gesamttext untersucht wurde. konnte auch keine Streuung festgestellt werden.

\section{PUSKIN - Geschichtswerk}

\section{Text 1:}

Anzahl der Sătze: $\quad 107 \quad-1667$ Wörter

durchschnittliche Satzlänge: $\quad 16$ Wörter $\quad(15,6)$

kürzester Satz: 2 Wörter ; längster Satz: 56 Wơrter

Die Satzlănge verteilt sich folgendermaßen:

\begin{tabular}{rrr} 
Wortanzahl & Satze & \\
\hline$x \leq 5$ & 18 & \\
$5<x<10$ & 17 & \\
$10 \leq x<20$ & 38 & Varianz $s^{2}=122$ \\
$20 \leq x<30$ & 24 & Standardabweichung $s=11$ \\
$30 \leq x<40$ & 5 & \\
$x \geq 40$ & $\frac{5}{107}$ &
\end{tabular}


Graphisch dargestelt: $\quad$ (Puykin Geschichtswerk Text 1)

Anteil der Satze in Prozent:

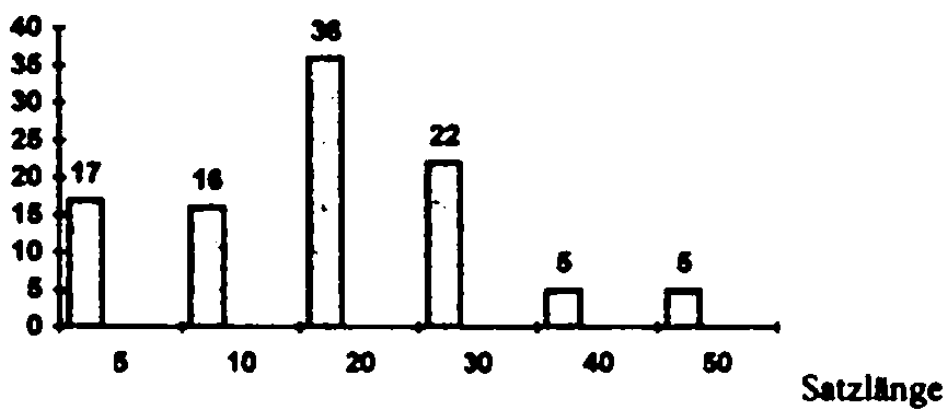

Puskin Geschichtswerk Text 2:

Anzahl der Sătze: $\quad 170 \quad-2231$ Worter

durchschnittliche Satzlănge: $\quad 13$ Worter $\quad(13,1)$

karzester Satz: $\quad 2$ Worter ; langster Satz: $\quad 47$ Worter

Die Satzlange verteih sich folgendermaßen:

Wortanzahl Satze

$x \leq 5 \quad 26$

$5<x<10 \quad 40$

$10 \leq x<20 \quad 75$

$20 \leq x<30 \quad 20$

$30 \leq x<40 \quad 7$

Varianz $s^{2}=76$

$x \geq 40 \quad \frac{2}{170}$

Standardabweichung $s=9$

Graphisch dargestelt: $\quad$ (Puskin Geschichtswerk Text 2)

Anteil der Satze in Prozent:

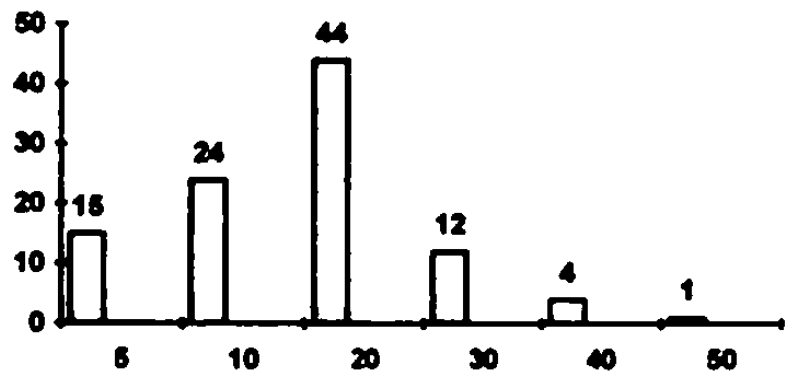

Satzlange 
Vergleich von Text 1 und Text 2:

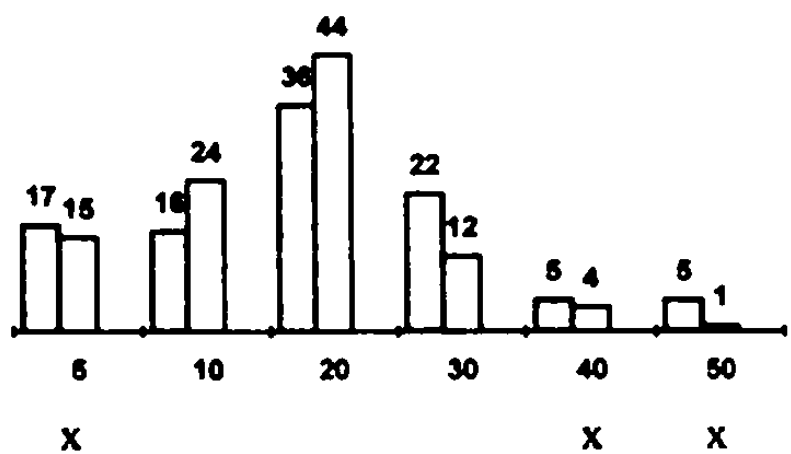

Drei Satzlängenintervalle (mit $\times$ markiert) weisen eine Streuung unter 5\% auf; die anderen drei über $5 \%$, nämlich $8 \%, 8 \%$ und $10 \%$.

Pußkin Geschichtswerk Text 3:

Anzahl der Sătze: $\quad 307 \quad--4003$ Wörter

durchschnittliche Satzlănge: $\quad 13$ Worter $\quad(13,0)$

kürzester Satz: 2 Worter; $\quad$ lăngster Satz: 52 Worter

Die Satzlånge verteilt sich folgendermaßen:

Wortanzahl Sătze

$x \leq 5 \quad 50$

$5<x<10 \quad 78$

$10 \leq x<20 \quad 116$

$20 \leq x<30 \quad 48$

Varianz $s^{2}=84$

$30 \leq x<40 \quad 11$

$x \geq 40 \quad \frac{4}{307}$

Standardabweichung $s=9$

Graphisch dargestellt: (Puł̌kin Geschichtswerk Text 3)

Anteil der Satze in Prozent:

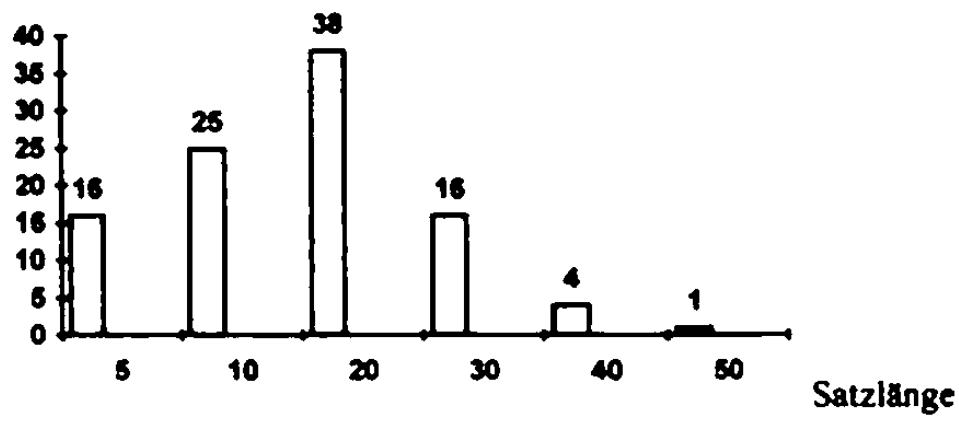


Vergleich von Text 1, Text 2 und Text 3:

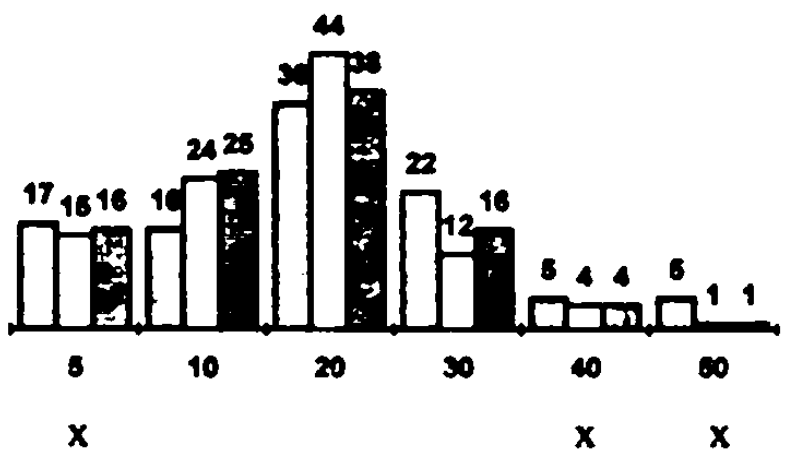

Das Satzlangenprofil verhalt sich in Puškins Geschichtswerk regelmaßig, wenngleich drei Blocke Streuungen über 5\% aufweisen. namlich $9 \%$. 8\% und $6 \%$ (die drei mit $\mathrm{x}$ markierten Blocke liegen unter 5\%). Damit fallt Puškin sogar etmas hinter Karamzins Geschichtswerk zurück".

Der gewogene Mittehrert der durchschnittlichen Satzlänge fur die Texte aus Puskins Geschichtswerk beträgt 13,5 Worter.

Es ergibt sich folgendes gemittehtes Satzlăngenprofil:

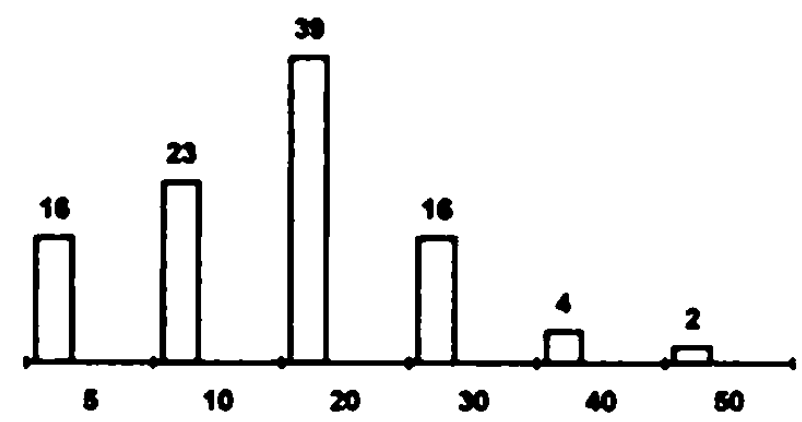

Dieses Satzlängenprofil wird stellvertretend fur Puskins Geschichtswerk angesehen; es wird im folgenden zum Vergleich mit den anderen Profilen herangezogen.

"Die Varianzen sind allerdings erheblich niedriger als bei Karamzin. Die Quotienten liegen ahnlich nah beieinander; sie bewegen sich zwischen 1,1 und 1,6:

$\frac{s_{1}^{2}}{s_{2}^{2}}=\frac{122}{76}=1,6 ; \frac{s_{1}{ }^{2}}{s_{3}{ }^{2}}=\frac{122}{84}=1,45 ; \frac{s_{3}{ }^{2}}{s_{2}^{2}}=\frac{84}{76}=1,1$. 
PUŠKIN - Dichterisches Werk:

Text 1:

Anzahl der Sătze: $\quad 124 \quad-1597$ Worter

durchschnittliche Satzlänge: $\quad 13$ Worter $\quad(12,9)$

kürzester Satz: $\quad 2$ Wơrter ; lăngster Satz: $\quad 37$ Worter

Die Satzlänge verteitt sich folgendermaßen:

Wortanzahl Satze

$x \leq 5 \quad 30$

$5<x<10 \quad 23$

$10 \leq x<20 \quad 43$

$20 \leq x<30 \quad 21$

$30 \leq x<40 \quad 6$

$x \geq 40 \quad \frac{1}{124}$

Varianz $s^{2}=85$

Standardabweichung $s=9$

Graphisch dargestelt: (Puskkin dichterisches Werk Text 1)

Anteil der Salzze in Prozent:

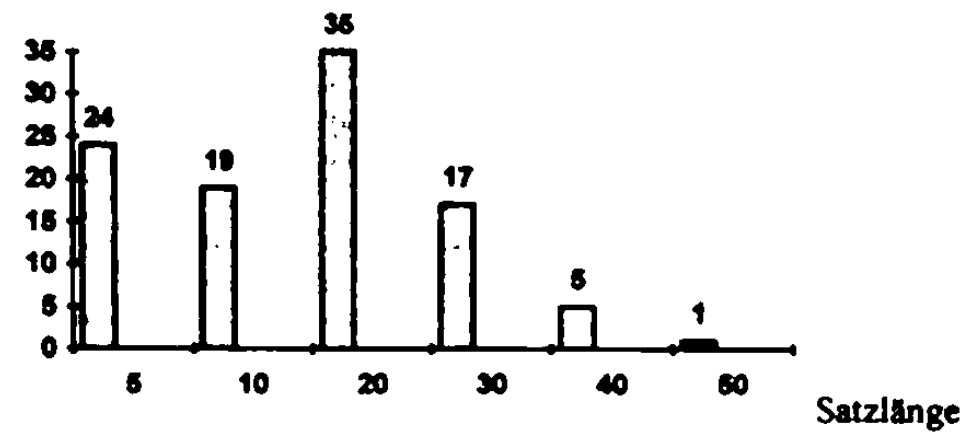

Pußkkin dichterisches Werk Text 2:

Anzahl der Sătze: $106 \quad-1520$ Worter

durchschnittliche Satzlänge: $\quad 14$ Worter $\quad(14,3)$

kürzester Satz: $\quad 2$ Wơrter ; lăngster Satz: $\quad 44$ Wơrter

Die Satzlange verteitt sich folgendermaßen:

$$
\begin{array}{ccc}
\text { Wortanzahl } & \text { Satze } & \\
\hline x \leq 5 & 18 & \\
5<x<10 & 20 & \\
10 \leq x<20 & 41 & \text { Varianz } s^{2}=86
\end{array}
$$


$\begin{array}{rr}20 \leq x<30 & 22 \\ 30 \leq x<40 & 3 \\ x \geq 40 & \frac{2}{106}\end{array}$

Standardabweichung $s=9$

Graphisch dargestellt: (Pußkin dichterisches Werk Text 2)

Anteil der Satze in Prozent:

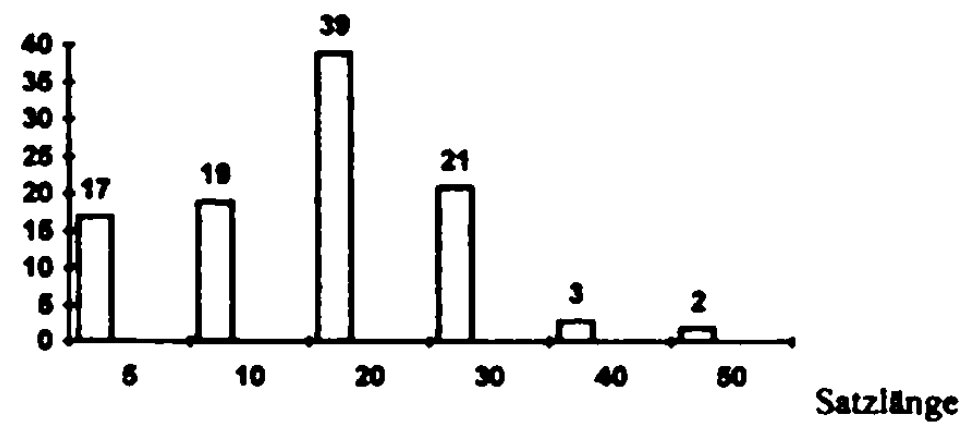

Vergleich von Text 1 und Text 2:

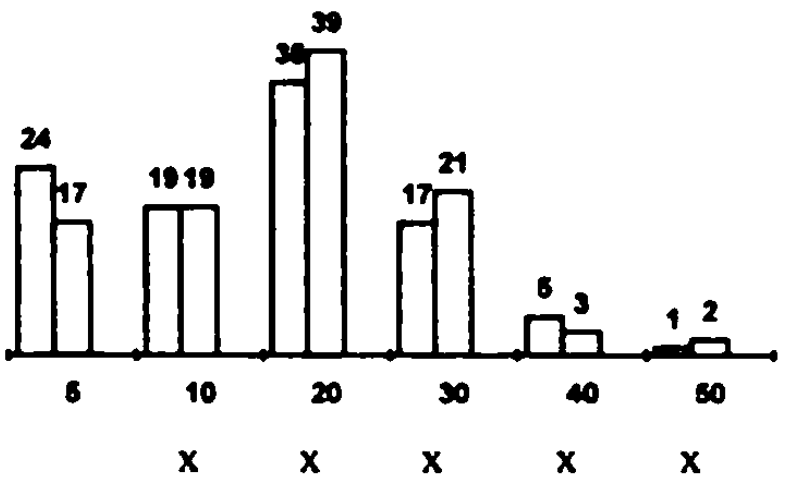

Fünf Satzlängenblocke (mil $x$ markiert) weisen eine Streuung unter S\% auf; nur der erste hat eine Streuung von $7 \%$.

\section{Pußkin dichterisches Werk Text 3:}

Anzahl der Sătze: $\quad 152 \quad--2241$ Wơrter

durchschnittliche Satzlänge: $\quad 15$ Worter $\quad(14,7)$

kürzester Satz: $\quad 2$ Worter ; lăngster Satz: $\quad 62$ Worter

Die Satzlănge verteilt sich folgendermaßen:

\begin{tabular}{rc} 
Wortanzahl & Satze \\
\hline$x \leq 5$ & 29 \\
$5<x<10$ & 31 \\
$10 \leq x<20$ & 54
\end{tabular}

Varianz $s^{2}=128$ 
$\begin{array}{rr}20 \leq x<30 & 26 \\ 30 \leq x<40 & 6 \\ x \geq 40 & \frac{6}{152}\end{array}$

Graphisch dargestellt: (Pußkin dichterisches Werk Tert 3)

Anteil der Satze in Prozent:

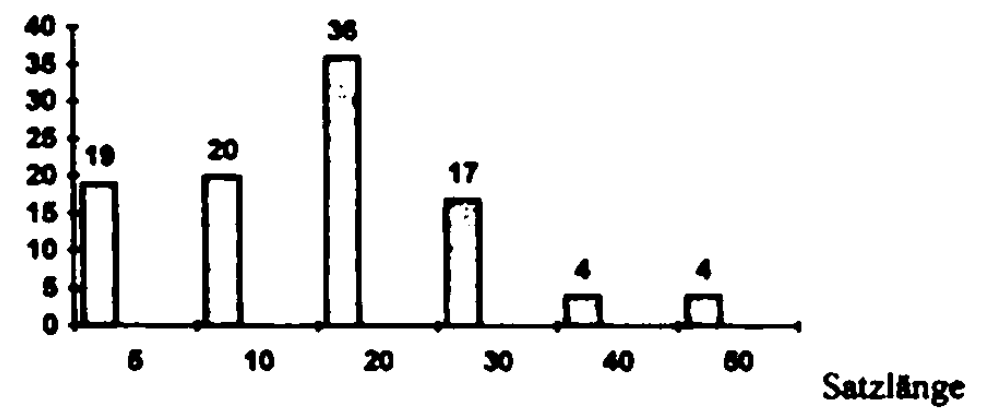

Vergleich von Text 1, Tert 2 und Text 3:

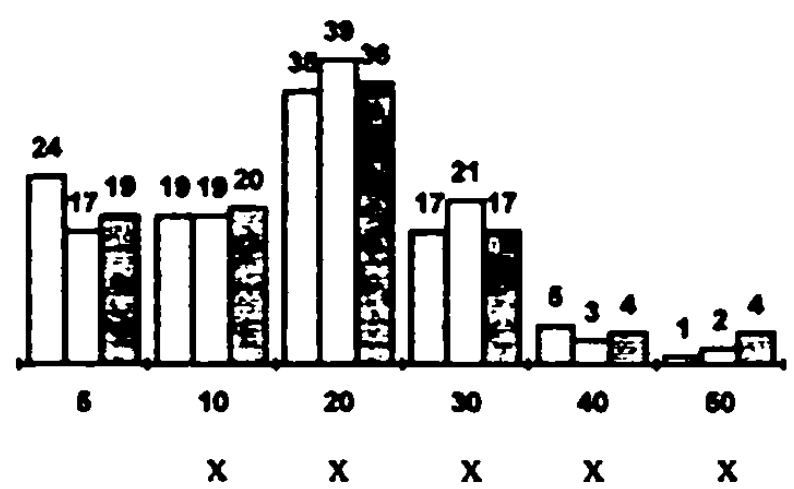

Das Satzlangenprofil verhalt sich in Puškins dichterischem Werk überaus regelmaßig. nur der erste Block weist eine Streuung über 5\% auf. Dieses Satzlängenprofil ist verglichen mit den anderen das regelmäßigste ${ }^{\prime 2}$.

Der gewogene Mittelwert der durchschnittlichen Satzlange fur die Texte aus Puskins dichterischem Werk beträgt 14 Worter $(14,0)$

${ }^{12}$ Auch die Varianzen sind in Puskins dichterischem Werk am niedrigsten. Die Quotienten liegen gleich nahe beieinander wie in seinem und Karamzins Geschichtswerk; sie bewegen sich zwischen 1,0 und 1,5: $\frac{s_{2}{ }^{2}}{s_{1}{ }^{2}}=\frac{86}{85}=1,0 ; \frac{s_{3}{ }^{2}}{s_{1}{ }^{2}}=\frac{128}{85}=1,5 ; \frac{s_{3}{ }^{2}}{s_{2}{ }^{2}}=\frac{128}{86}=1,5$. 
Es ergibt sich folgendes gemitteltes Satzlăngenprofil:

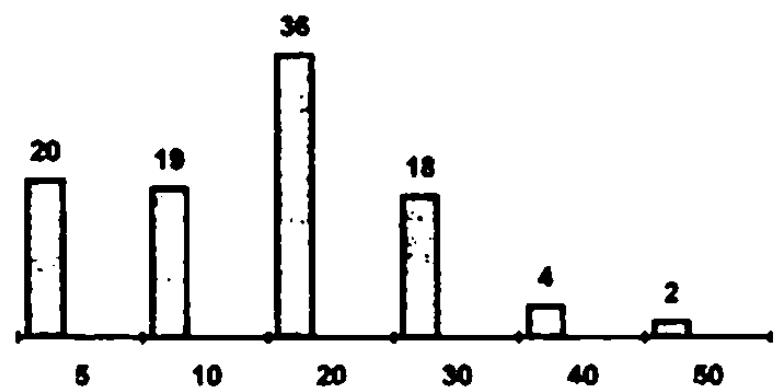

Dieses Satzlängenprofil wird stellvertretend für Puskins dichterisches Werk angesehen; es wird im folgenden zum Vergleich mit den anderen Profilen herangezogen. 
Vergleichende Gegenüberstellung der Ergebnisse

a) Vergleich innerhalb der Geschichtswerke

durchschnittliche Satzlange in den Geschichtswerken:

Lomonosov

Karamzin

Puskin
21 Worter

24 Worter

14 Worter

Satzlängenprofile:

Lomonosov (Geschichtswerk):

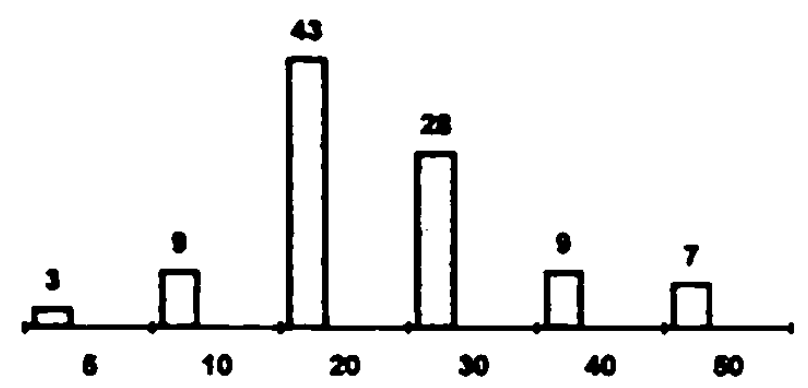

Karamzin (Geschichtswerk):

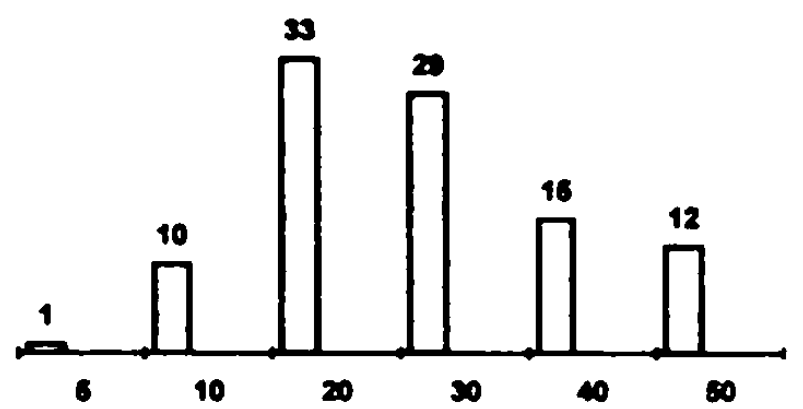

Puskin (Geschichtswerk):

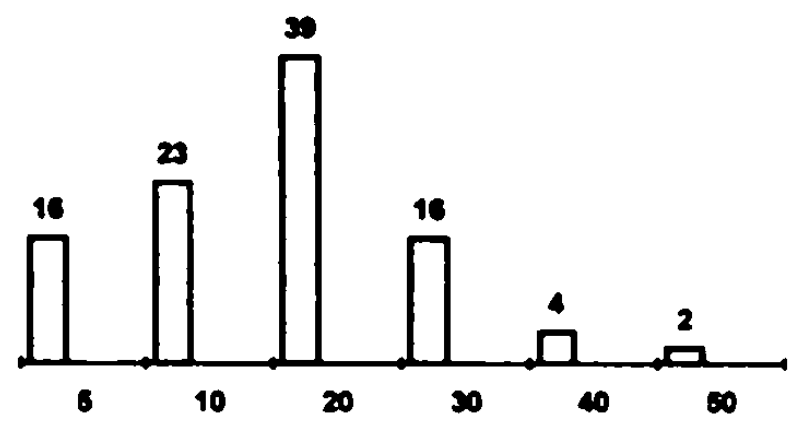


Vengleich: Lomonosov: Karamzin

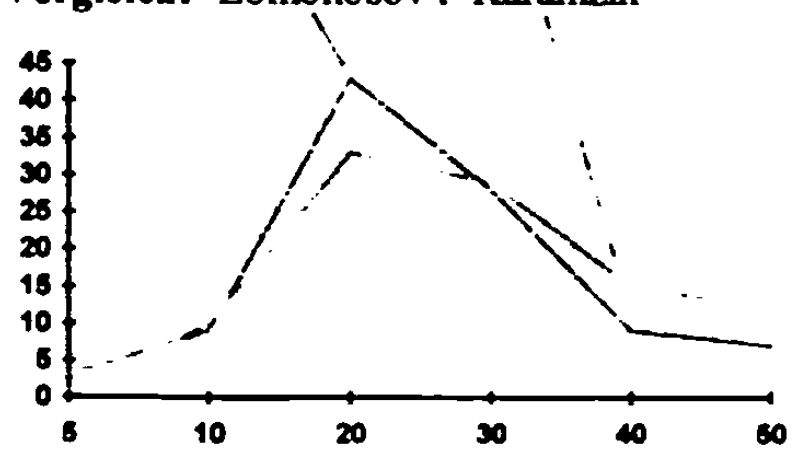

Wie bereits das Verhaltmis der Mittelwerte andeutet (21 Worter bei Lomonosov zu 24 Wörtern bei Karamzin), ist der Anteil der längeren Särze bei Karamzin höher als bei Lomonosov. Formal gesehen werden die Satze bei Karamzin umfangreicher.

Vengleich: Puskin : Lomonosov

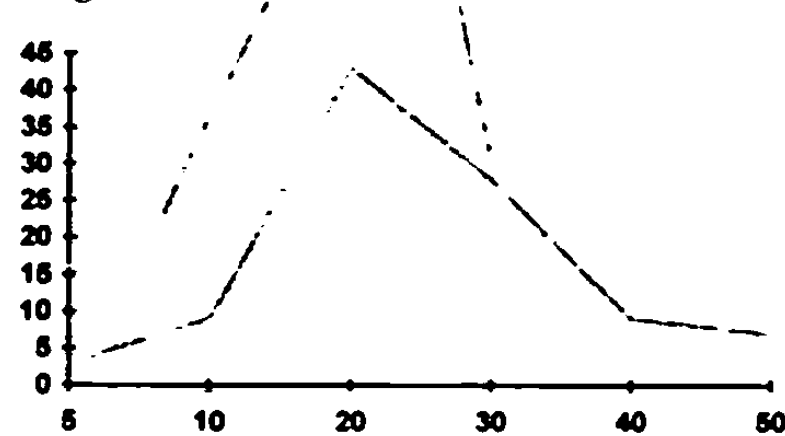

Dieser Vergleich zeigt sehr deutlich den Bruch, der zwischen Lomonosov und Puskin stattfand. Lediglich das Satzlangenintervall von 10-19 Wortern bleibt bei beiden Autoren der Scheitelpunkt. Die Verlagerung zu den kurzen Sätzen ist bei Pǔ̌kin sehr ausgeproggt. Durchschnittlich wird der Satz bei Puskin im Vergleich zu Lomonosov um ein Drittel kürzer $(14: 21)$.

Vergleich: Puskin : Karamzin

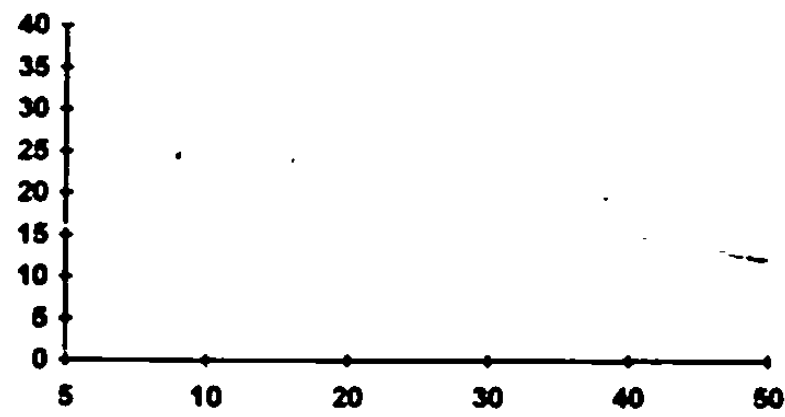

Was den Parameter der Satzlänge in den historiographischen Texten anbelangt, so kann Karamzin nicht als Vorreiter von Puskin angesehen werden. Vielmehr liegt er näher bei Lomonosov. 
b) Vergleich innerhalb der dichterischen Werke

durchschnittliche Satzlănge in den dichterischen Werken:

$\begin{array}{ll}\text { Karamzin } & 17 \text { Worter } \\ \text { Puskin } & 14 \text { Worter }\end{array}$

Vergleich der Satzlängenprofile: (Karamzin : Pußkin)

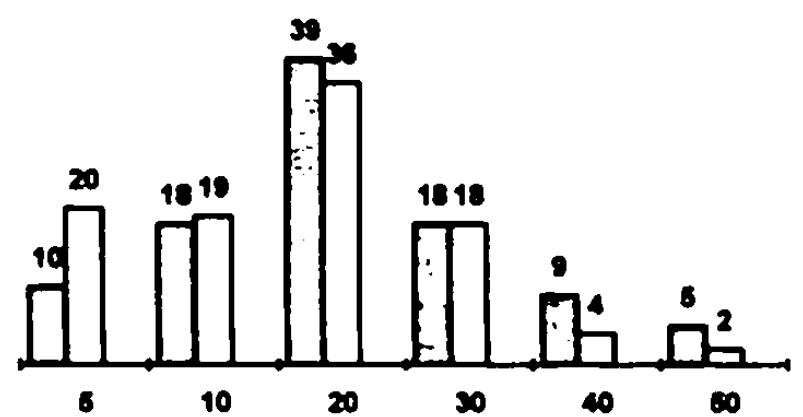

Im Gegensatz zu den Geschichtswerken liegen die Satzlangenprofile in den dichterischen Werken der beiden Autoren bedeutend naher. Wenn man vom ersten Block (den Kurzatzen mit bis zu 5 Wortern) absieht, so kann man von einer weitgehenden Ubereinstimmung sprechen, da die anderen Blöke allesamt nur noch eine Streuung von maximal $5 \%$ aufweisen.

c) Vergleich innerhalb eines Autors

\section{KARAMZIN:}

durchschnittliche Satzlänge im Geschichtswerk bzw. im dichterischen Werk:
24 Worter
vs.
17 W8rter

Die durchschnittliche Satzlange im Geschichtswerk ist bedeutend großer als im dichterischen Werk, und zwar um rund ein Drittel.

Vergleich der Satzlängenprofile: (Geschichtswerk : dichterisches Werk)

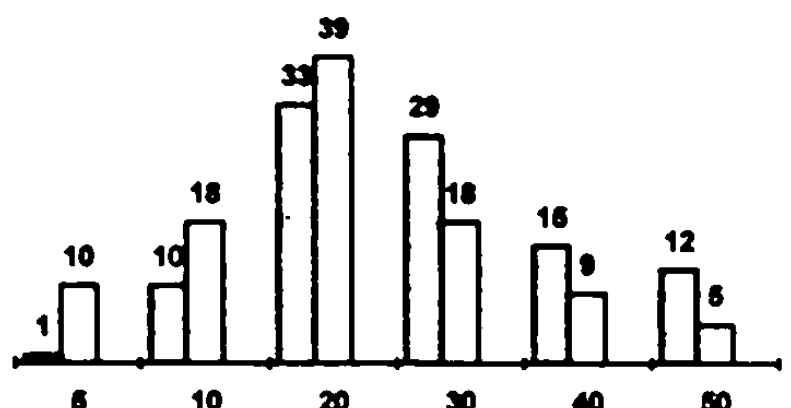


oder anders dargestellt:

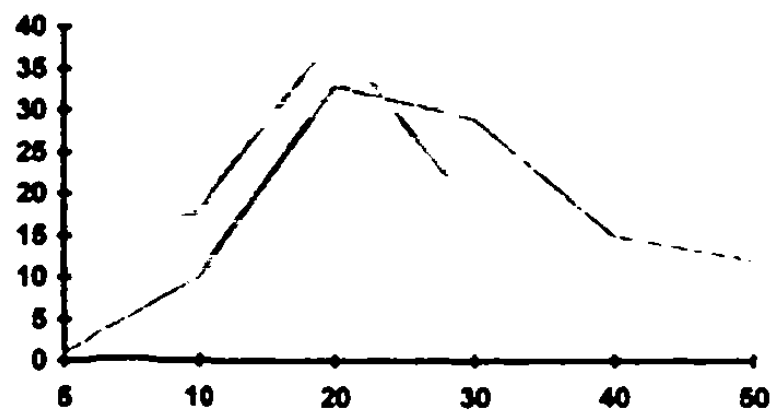

Es herrscht kcine Ubereinstimmung bei den Satzlängenprofilen: in jedem Block beträgt die Streunng mehr als 5\% ! Das heißt, es gibt bei Karamzin einen klaren formalen Unterschied zwischen seinem Geschichtsstil und seinem dichterischen Stil.

\section{PUSKIN:}

durchschnittliche Satzlänge im Geschichtswerk bzw. im dichterischen Werk
13,5 Worter
vs.
14 Worter

Die durchschnittliche Satzlänge stimmt in den beiden Textsorten praktisch überein.

Vergleich der Satzlängenprofile:

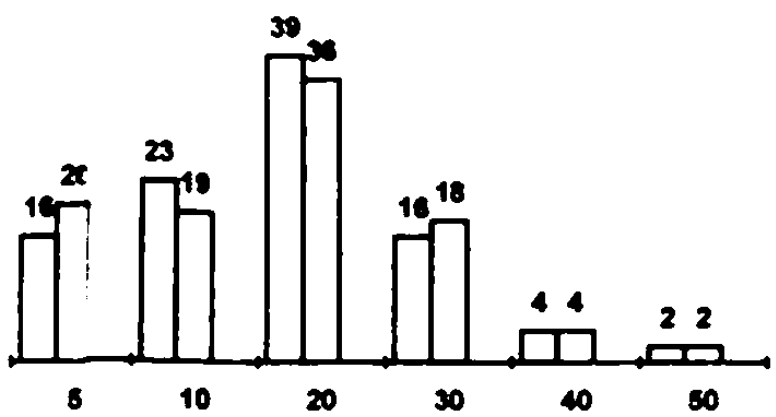

Die Cegenüberstellung der Satzlängenprofile besticht ebenfalls durch eine große Übereinstinmung. Am meisten fallen die sich genau entsprechenden Werte von $4 \%$ und $2 \%$ bei din Satzen mit über 30 bzw. über 40 Wortern auf; bedeutend ist auch, daß alle Block: eine Streuung von höhstens $4 \%$ aufweisen.

\section{Bewetang des Parameters a:}

Die Fagestellung für den Parameter Satzlănge lautete: gibt es eine Regelmăßigkeit innerhalb er (willkürlich ausgewăhten) Kapitel eines Werkes ? Diese Frage kann für jedes der urtersuchten Werke positiv beantwortet werden. Ober die bloße Bestătigung hinaus erhielen wir außerdem noch Aussagen über die unterschiedlichen quantitativen Großenordnuigen. 


\section{b) Parameter Satzkomplexităt:}

\section{Definition en:}

Den Einteilungskategorien werden folgende Definitionen zugnunde gelegt ':

Einfachsatze bestehen aus einem einzigen Hauptsatz;

als Satzreihen werden nebeneinander gestellte selbstăndige Hauptsătze bezeichnet;

Satzgefüge enthaten außer dem Hauptsatz mindestens einen Nebensatz.

\section{Beispiele: Einfachsatz:}

Пугачев быстро переходил с одного места на другое.

Он принял начальство над гарнизоном

и , на них напав, принуднл их возвратиться на прежние жилища.

Овчиннихов и Перфильев, преследуемые майором Певичем, проскакали через Сахмарскую линию с тремястамн янцких казахов

h успели с ним соединиться.

Satzreihe:

Михельсон

но распутица

Дороги

люди

реки

ручьи силился пресечь ему дорогу;

ero спасала.

были непроходимы, вязли в бездонной грязи; разливались на несколько верст; становились реками.

\section{Einfaches Satzagefoge:}

Путачев,

коего положение казалось отчаянным,

явился на Авзяно-Петровских заводах.

Mehrfaches Satzgefinge:

Когда же государыня узнала о взятии Казани и о перенесения

тогда она уже

думала сама ехать в край,

бувта за Волгу,

где усиливалось бедствие и опасвость,

и лично предводительствовать войском.

' Vgl. EGGERS (1961, 54), dessen Definitionen konzise formuliert und immer noch nicht verahet sind. 


\section{Untersuchungssehritt ${ }^{2}$ :}

Im ersten Schritt werden die Sătze auf ihre Struktur reduziert, also z.B.

HS

HS, NS NS $=$ untergeordneter Nebensatz

HS. RS RS = Relativsatz

Außerdem wird auch zur semantischen Auswertung ${ }^{3}$ die Art des Nebensatzes durch die Notierung des Pronomens / der Subjunktion festgehalten:

HS, который oder HS, что

\section{Untersuchungsschritt ${ }^{4}$ :}

In der Auswertung werden die Einfachsătze und die Satzreihen nur noch zahlenmăßig aufgeführt; falls vorhanden, werden zu den Einfachsătzen noch die Fragesătze (FS) gezahlt, die keine Hypotaxe aufweisen.

Die einfache Hypotaxe, d.h. Hauptsătze mit nur einem Nebensatz, wird gemăß der Art der Nebensătze zusammengefaßt in:

HS und ein Relativsatz

HS und ein untergeordneter Nebensatz

Die mehrfache bzw. zusammengesetzte Hypotaxe ${ }^{3}$ wird nicht nur quantitativ erfaßt, sondern auch qualitativ. Die Struktur der zusammengesetzten Hypotaxen wird folgendermaßen skizziert (Satzskelett): $\quad$ HS, который ..., что (2.Grad), wobei die Konjunktionen und die Interpunktion genau wiedergegeben werden.

Die 'Satzskelette' sollen die Satzkomplexităt direkt linear widerspiegeln: je länger das Schema sich nach rechts erstreckt, desto komplexer der Satz. Die Bezeichnungen (2.Grad), (3.Grad), usw. werden in Klammern den entsprechenden Konjunktionen beigegeben. um den Komplexitätsgrad des Nebensatzes zu kennzeichnen. Auf diese Weise ergibt sich für den einzelnen Text ein 'Satzskelettprofil', welches einen optischen Eindruck über die Art und Anordnung der Hypotaxe vermitteln soll.

Der Arbeit liegt hinsichtlich der Konjunktionen keinerlei historische oder diachronische Fragestellung zugrunde, folglich fallen vereinzelt strittige Zuordnungen der Konjunktionen nicht ins Gewicht. Historische Grammatiken wurden nur in einzelnen Fallen zu Rate gezogen (z.B. bei 6yde), wobei sich aber auch hier die Frage nach der Einordnung kaum stellte ${ }^{6}$.

${ }^{2}$ Wird nicht in der Untersuchung aufgeführt.

${ }^{3}$ Siehe Anhang S.188-193.

4 Wird in der Untersuchung aufgefuhrt.

'In der 'mehrfachen Hypotaxe' treten untergeordnete Nebensătze gleichen Grades auf, wohingegen die 'zusammengesetzte Hypotaxe' Nebensätze unterschiedlichen Grades besitzt.

${ }^{6}$ Bei der Einordnung der Konjunktionen im Anhang wurden diese nur unter dem kategorialen Gesichtspunkt betrachtet; folgende Einteilungskategorien wurden dabei angesetzt: final, kausal, konditional, konsekutiv, konzessiv, modal, temporal. Eine 
Es werden alle Sătze mit mehrfacher und zusammengesetzter Hypotaxe einzeln aufgefuhrt. Durch die einzelne Auffuhrung dieser Sătze wird versucht, einen qualitativen Eindruck aber die Strukturen des Textes zu geben, was nicht moglich wäre, wenn nur mit Endresultaten in Form von Zahlen gearbeitet würde. Damit soll versucht werden, Beschreibung und komprimierte Analyse (in Form eines einzigen Zahlenwertes) zu verbinden.

Nach der Untersuchung der drei Texte eines Werkes wird die Verteilung der Satzkomplexităt in einer Tabelle dargestelth, in der die Anteile der Einfachsătze, Satzreihen und Satzgefuge zuerst in absoluten Zahlen, dann prozentual einander gegenübergestellt werden.

Daneben wird der gewogene Mittehwert berechnet; er fungiert im weiteren als Vergleichswert furr das betreffende Werk. Schließlich werden noch die Satzgefuge nach ihrem Komplexitatsgrad unterteit betrachtet, wobei auch hier der gewogene Mittelwert bestimmt wird.

\section{Untersuchungsergebnisse:}

\section{LOMONOSOV - Geschichtswerk}

\section{Text 1:}

$\begin{array}{lr}\text { Einfachsătze: } & 7 \\ \text { Satzreihen: } & \underline{2} \\ & 9 \\ \text { Satzgefuge: } & 18\end{array}$

Anteil der Hypotaxe: 18 von 27 Sătzen, d.h. die Hypotaxe macht 67\% aus.

einfache Hypotaxe: $\quad$ 19/

Hauptsatz und ein Relativsatz:

Hauptsatz und ein untergeordneter NS 4

weitergehende Untersuchung der Konjunktionen war für die Fragestellung der Arbeit nicht mehr relevant. Oberhaupt wurden die Konjunktionen im Anhang nur deshalb aufgefuhrt, um sekundäre Untersuchungsergebnisse, die in der Arbeit nicht weiter verwendet werden konnten, festzuhalten, denn sie konnen doch interessante Einblicke in die explizite Kausalităt von Texten geben (vgl. die 'semantische Auswertung' der Konjunktionen im Anhang auf S.193). Im Grunde genommen aber müssen Untersuchungen, die kausale Beziehungen weiter untersuchen, in die Textlinguistik verwiesen werden, wobei unter Umstănden ein hochdifferenzierender Ansatz, wie WEISS 1988 ihn vorstellt, wohl mehr erbringen würde als die von uns angesetzte Kategorisierung. 
mehrfache/ zusammengesetzte Hypotcaxe: 191

Hauptsatz und $\geq 2$ Nebensătze $/ 5 /$

HS, что ... ежели (2.Grad), что (2.Grad)

HS, что ..., какую (2.Grad)

HS, как ..., которые (2.Grad)

Korдa ..., то HS, которая ...

HS, где ..., дабы ...

22 Hauptsătze und Nebensatz/-sătze /4/

HS : HS, которая ...; но HS; HS

HS, xоrда ..., HS

HS, кто ..., но HS , каковыми ...

HS, rде ...; HS ; noтом HS

Lomonosov Geschichtswerk Text 2:

Einfachsătze: $\quad 41$

Satzreihen: $\quad \underline{12}$

53

Satzgefinge: $\quad 53$

Anteil der Hypotare: 53 von 106 Satzen, d.h. die Hypotaxe macht $50 \%$ aus.

einfache Hypotaxe: $\quad$ 28/

Hauptsatz und ein Relativsatz 10

Hauptsatz und ein untergeordneter NS $\quad 18$

mehrfache/ zusammengesetzte Hypotaxe: 125/

Hauptsatz und $\geq 2$ Nebensatze /12/

HS, и60 ... и ...

HS, что ..., коему (2.Grad)

HS, которые ..., xотя (2.Grad)

HS, где ..., которых ...

хотя ..., HS, чтобы ...

HS, когда ..., что (2.Grad), когда ...

HS, когда ..., как (2.Grad)

HS, чro ..., rде (2.Grad)

HS, чTO ..., чTro (2.Grad)

HS, что ..., почему (2.Grad)

HS, что ..., когда ( 2.Grad), что ...

HS, чro ..., в korx (2.Grad)

22 Hauptsătze und Nebensatz/-sătze

/13/

HS, но в HS, что..., которых (2.Grad), хотя (3.Grad)

хотя ... , затем HS, однако HS

HS, HS, что ...

HS; HS, чTo ...

хотя ..., HS, что ...; и нS 
HS, которое ...; в HS, чтобы ..., что (2.Grad)

HS; и HS, что ...

HS; HS, чTo ...; [Zitat:" HS: HS“]

HS, xоторые ..., HS

FS, чтобы ..., потом HS ?

HS; HS, что ...

HS; HS, पTO ...

HS, потом HS, которое хотя (2.Grad)

\section{Lomonosov Geschichtswerk Text 3:}

Einfachsătze: $\quad 81$

Satzreihen: $\quad 13$

Satzgefuge: $\quad 44$

Anteil der Hypotare: 41 von 135 Satzen, d.h. die Hypotare macht $30 \%$ aus.

einfache Hypotaxe:

122

Hauptsatz und ein Relativsatz 9

Hauptsatz und ein untergeordneter NS 13

mehrfache/ zusammengesetzte Hypotaxe: /19/

Hauptsatz und $\geq 2$ Nebensătze /12/

HS, в котором ..., которых (2.Grad)

HS, и что ..., дабы (2.Grad)

Ехели ..., HS: что ..., что ..., затем что ...

HS, чтобы ... хотя (2.Grad)

HS, дабы ..., нежели (2.Grad)

HS, хоторый ..., что (2.Grad) ехкели (3.Grad), то (2.Grad)

HS, ибо ..., чтобы (2.Grad)

HS, xoтopoe ... : в60 ...

И каx ..., HS, в хоем ...

HS, что ..., чтобы (2.Grad)

HS, что ... ежели (2.Grad), которую (3.Grad), ках (4.Grad)

HS, и6о ..., что (2.Grad)

$\geq 2$ Hauptsătze und Nebensatz/-sătze 171

HS, чTо ..., HS

HS; HS, хоторый ...

HS; HS, что буде (2.Grad); HS

HS, что ..., который (2.Grad), HS

HS, чтобы ..., кого (2.Grad); буде ..., то HS

HS, хотя ..., однако HS

HS; HS, xоторые ... 
Die Satztypenverteilung in den Texten von Lomonosovs Geschichtswerk ist folgende:

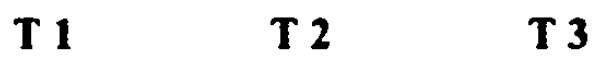

\begin{tabular}{lrrr} 
Einfachsătze: & 7 & 41 & 81 \\
Satzreihen: & 2 & 12 & 13 \\
Satzgefulge: & 18 & 53 & 41 \\
\hline & 27 & 106 & 135
\end{tabular}

prozentual:

Einfachsătze:

Satzreihen:

Satzgefuge:

$\begin{array}{rr}26 \% & 39 \% \\ 7 \% & 11 \% \\ 67 \% & 50 \%\end{array}$

$60 \%-$ Mittehwert $48 \%\left({ }^{7}\right) *\left({ }^{8}\right)$

$10 \%-$ Mittelwert 10\%

$30 \%$ - Mittelwert 42\% *

Man kann nicht von einer eindeutigen Dominanz irgendeines Satztypes sprechen; allerdings stellt das Satzgefüge immer einen bedeutenden Anteil dar. Daneben ragt auch der Einfachsatz hervor. Es ist aber keine Regelmäigkeit zu erkennen.

zur Hypotaxe:

T 1 T 2 T 3

a) einfache Satzgefüge

$9 \quad 28 \quad 22$

b) zusammengesetzte Satz-

gefüge (nur $1 \mathrm{NS}=1$.Grad)

$\begin{array}{lll}2 & 8 & 4\end{array}$

c) - - (mehrere NS, aber 1.Grad) $4 \quad 5 \quad 3$

d) mehrfache Satzgefuge (>1.Grad) \begin{tabular}{rrrr}
3 & 12 & 12 \\
\hline 18 & 53 & 41
\end{tabular}

daraus folgt die prozentuale Verteilung:

Satzgefüge mit nur einem NS (a+b) $\quad 61 \% \quad 68 \% \quad 63 \%$ - Mittelwert $65 \%$

nach Komplexitat:

nur 1.Grad $(a+b+c)$

$83 \% \quad 77 \% \quad 71 \% \quad-$ Mittehwert $76 \%$

22.Grad (d)

$17 \% \quad 23 \% \quad 29 \%-$ - Mittelwert $24 \%$

Im Gegensatz zu den sehr uneinheitlichen Anteilen der Satztypen zeichnet sich beim Gebrauch der Satzgefüge mehr Regelmäßigkeit ab. Es überrascht, daß Lomonosov doch immerhin durchschnittlich zwei Drittel der Satzgefüge mit nur einem Nebensatz kon-

7 Hier und im folgenden handelt es sich bei dem Mittelwert jeweils um den gewogenen Mittelwert; also nicht um den Durchschnitt der Prozentangaben.

${ }^{8}$ Aufgrund der großen Streuung handelt es sich nicht um ein vorhandenes, sondern lediglich um ein arithmetisches Mittel; in einem solchen Fall kennzeichnen wir den Mittelwert mit *. 
struiert; andererseits ist aber der hohe Anteil von rund einem Viertel an Satzgefügen mit Nebensätzen $\geq 2$. Grades doch außerordentlich hoch.

\section{KARAMZIN - Geschichtswerk}

\section{Text 1:}

Einfachsatze: $\quad 31$

Satzreihen: $\quad 21$

52

Satzgefuge: $\quad 51$

Anteil der Hypotaxe: 51 von 103 Satzen; d.h. die Hypotaxe macht $50 \%$ aus.

einfache Hypotoxe:

$/ 11 /$

Hauptsatz und ein Relativsatz

Hauptsatz und ein untergeordneter NS 6

mehrfache/ zusammengesetzte Hypotaxe: 140/

Hauptsatz und $\geq 2$ Nebensătze /8/

HS, кak ..., чтобы (2.Grad)

Eсли ..., как (2.Grad): HS

HS, xorдa ..., чro (2.Grad)

HS, если ..., что (2.Grad)

HS, что ..., а не что ...

HS, что ..., которые (2.Grad), rде (3.Grad)

HS, koero ..., если (2.Grad)

HS, что ...; что ...

$\geq 2$ Hauptsătze und Nebensatz/-sătze /32/

HS; HS, чro ...; HS, которая ...

HS; HS, чTо ...

HS: HS; HS, хоторые ...

HS; HS: HS, n60 ...

HS, a HS, где ...

HS: HS, чтобы ..., хоторый (2.Grad)

HS, что ...: и6о (2.Grad); HS, что ...

HS - и HS, xoero ...

HS, что ...; что ...: во HS, и HS, где ...: HS

Если ..., HS: HS

HS; HS, хоторые ...

HS, когда ... : HS

HS, что ... : HS: HS

HS: HS, xoro ..., xoro ... ?

HS; но HS, которая ... ?

HS; и если ..., то HS : HS 
HS: HS, rде ...; HS; HS

HS, который ...: HS - и HS

HS: HS; HS; HS, что ... ; HS, если ... - HS, что ...

HS: HS, पто ...

HS; HS, чтобы ...

HS; HS, xоторые ...

HS: HS; HS, rдe ...

HS: HS: и60 ...

HS: HS, когда ...

HS; HS; HS; HS, что ...; HS, что ...; HS; HS: и6о ...

HS, HS; HS; и60 ...

HS, что ...: HS

HS: HS, в коем ...

Если ..., то HS; но когда ...; когда ... - HS

HS; но HS, что ...

HS: HS; HS; HS, если ...

\section{Karamzin Geschichtswerk Text 2:}

Einfachsătze: $\quad 44$

Satzreihen: $\quad \frac{37}{81}$

Satzgefige: $\quad 66$

Anteil der Hypotare: 66 von 147 Sătzen; d.h. die Hypotaxe macht 45\% aus.

einfache Hypotaxe: $\quad$ 26/

Hauptsatz und ein Relativsatz 14

Hauptsatz und ein untergeordneter NS $\quad 12$

mehrfache/ zusammengesetzte Hypotaxe: $140 /$

Hauptsatz und $\geq 2$ Nebensatze $19 /$

HS, что ...; что ..., и что ...

HS, что ...; что ..., который (2.Grad); что ...

Ежели ..., HS: и6о ...

HS, когда ... и когда ...

HS, что ... и что ..., rде (2.Grad)

HS, чего ..., что (2.Grad)

HS, что ... и что ...

HS: FS ? FS, конми ...

HS: FS ? Kax ..., FS ?

$\geq 2$ Hauptsătze und Nebensatz/ -sătze /31/

HS; HS, за хокми ... (почему - 2.Grad)

HS; HS, с хоим ...

HS: HS, кому ...

HS: HS, rде ...

HS: HS, ежели ..., что (2.Grad); HS; HS 
HS, что ..., которые (2.Grad) .. (HS); HS, что ..(HS): HS -HS: HS, что ..; HS (78 Worter !)

HS; HS, за коими ...

HS, HS: HS; HS, что ... и что ...

HS, xоторые ... : HS

HS, из конх ... : и60 ...; HS

HS, что ..., HS

HS: HS, что ..., которые (2.Grad)

HS, что ... : HS

HS, если ... : НS

HS; HS, чTо ...

HS; HS, для того, что ...

HS: HS, что ..., куда (2.Grad)

HS, что ...; HS; HS; HS

HS, чтобы ... : HS, что ...

HS, что ..., HS

HS, HS, HS, чTO ...

HS; HS, чтобы ...

Хотя ... (в6о - 2.Grad), HS: HS, чтобы ..., HS, которые ...

HS, что ...: HS, HS

HS: 160 ...; HS, что ...

HS: xогда ..., HS

HS, что ...; HS

HS: HS, $\operatorname{kax} \ldots$

HS; HS: 460 ...

HS: HS; FS ?

HS: HS, хоторый ...

\section{Karamzin Geschichtswerk Text 3:}

Einfachsătze: $\quad 55$

Satzreihen: $\quad 22$

$\begin{array}{ll} & 77 \\ \text { Satzgefuge: } & 46\end{array}$

Anteil der Hypotaxe: 46 von 123 Satzen; d.h. die Hypotare macht $37 \%$ aus.

einfache Hypotoxe: /19/

Hauptsatz und ein Relativsatz 9

Hauptsatz und ein untergeordneter NS 10

mehrfache/ zusammengesetzte Hypotaxe: $\quad 1271$

Hauptsatz und $\geq 2$ Nebensătze $/ 6 /$

HS, который ..., где (2. Grad)

HS, что ..., ибо (2.Grad), и что ...

HS, что ..., что ..., что ..., и что ...

HS, где ..., чтобы (2.Grad)

HS, что ..., если (2.Grad) 


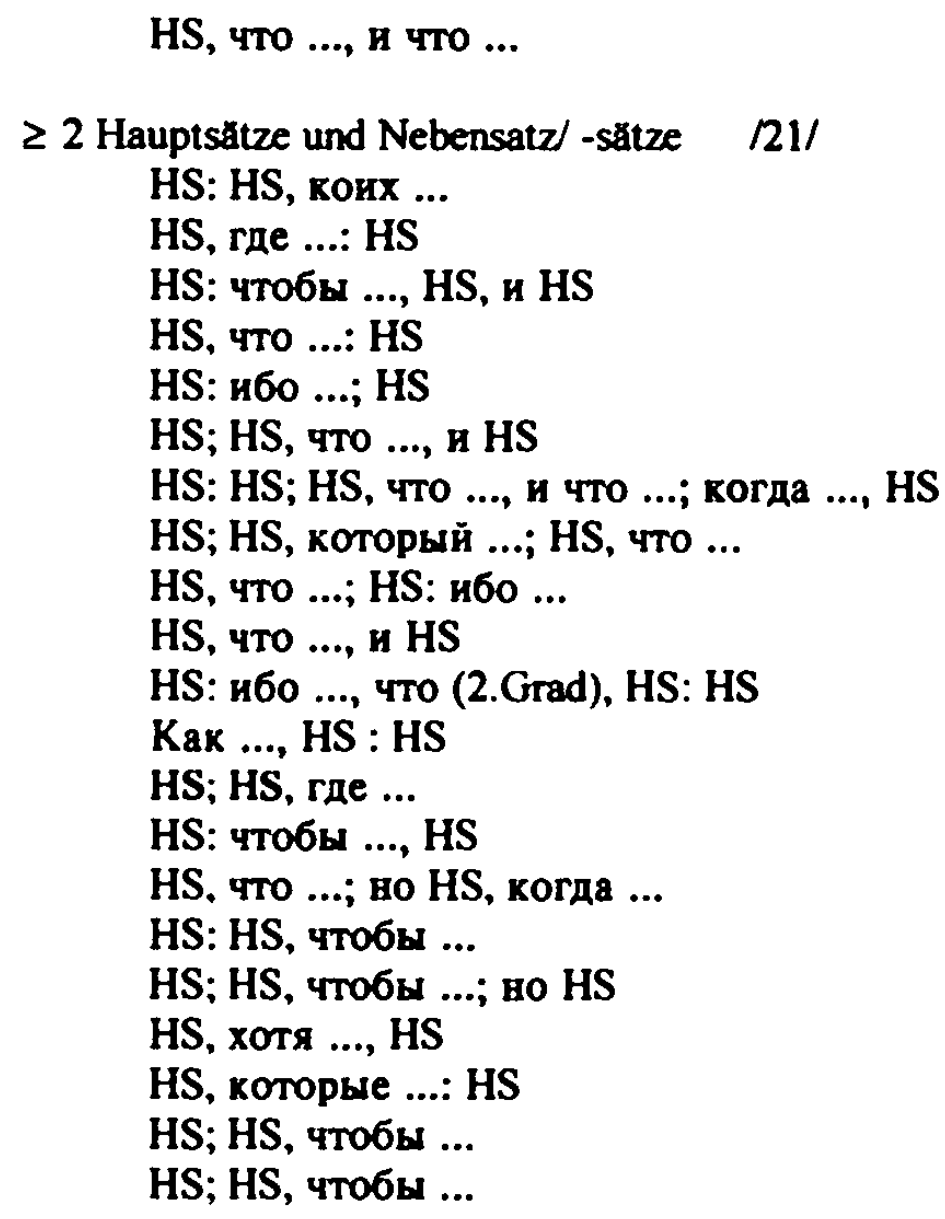

Die Satzypenverteilung in den Texten von Karamzins Geschichtswerk ist folgende:

$\begin{array}{lll}\text { T } 1 & \text { T } 2 & \text { T } 3\end{array}$

\begin{tabular}{lrrr} 
Einfachsătze: & 31 & 44 & 55 \\
Satzreihen: & 21 & 37 & 22 \\
Satzgefuge: & 51 & 66 & 46 \\
\hline & 103 & 147 & 123
\end{tabular}

prozentual:

$\begin{array}{lllll}\text { Einfachsătze: } & 32 \% & 30 \% & 45 \% & - \text { Mittebwert 35\% } \\ \text { Satzeihen: } & 20 \% & 25 \% & 18 \% & \text { - Mittelwert 21\% }\end{array}$

${ }^{9}$ Nach LESSKIS (1968) betrăgt der Anteil der Einfachsătze 31,7\% (eigentlich gibt er nur den Anteil der "сложные предложения" mit 68,3\% an, die sowohl Satzreihen wie auch Satzgefuge umfassen; siehe таблица 2, S.73). Dem Wert von LESSKIS liegt als Stichprobe der gesamte Bd. 1 des Karamzinschen Geschichtswerk zugrunde; $\mathrm{Tl}$ und T2 unserer Untersuchung stammen ebenfalls aus Bd. 1; der Gesamtwert von LESSKIS laßßt sich sehr deutlich in diesen beiden ersten Stichproben erkennen: $32 \%$ und $30 \%$ gegenuber dem Durchschnittswert von $31,7 \%$ bei LESSKIS. Allerdings weicht T3, der aus dem zweiten Band des Karamzinschen Geschichtswerk stammt. erheblich ab; und zwar in einem Verhältnis, wie wir es schon bei Lomonosov bei diesem Parameter feststellen mußten. 
$\begin{array}{lllll}\text { Satzgefuige: } & 48 \% & 45 \% & 37 \% & - \text { Mittelwert } 44 \%\end{array}$

Innerhalb der Satztypen ragt das Satzgefüge mit einem konstant hohen Anteil hervor, der stets über einem Drittel liegt.

zur Hypotaxe:

a) einfache Satzgefuge

b) zusammengesetzte Satzgefüge (nur $1 \mathrm{NS}=1 . \mathrm{Grad}$ )

c) -- (mehrere NS, aber 1.Grad) $8 \quad 10 \quad 6$

d) mehrfache Satzgefuge (>1.Grad) \begin{tabular}{rrrr}
8 & 9 & 5 \\
\hline 51 & 66 & 46
\end{tabular}

daraus folgt die prozentuale Verteilung:

Satzgefüge mit nur einem NS (a+b) $\quad 69 \% \quad 71 \% \quad 76 \% \quad-$ Mittelwert $72 \%$

nach Komplexitat:

nur 1.Grad $(a+b+c) \quad 84 \% \quad 86 \% \quad 89 \% \quad$ - Mittelwert 87\%

$\geq 2$. Grad (d) $\quad 16 \% \quad 14 \% \quad 11 \% \quad-$ Mittelwert $13 \%$

Die Verteilung ist relativ gleichmäßig: die Streuung bei den Satzgefügen mit nur einem Nebensatz liegt bei 8\%; die Verwendung der Satzgefüge ersten Grades streut noch weniger, nämlich nur um $5 \%$.

KARAMZIN - Dichterisches Werk

Einfachsätze: $\quad 83$

Satzreihen: $\quad \underline{37}$

120

Satzgefüge: $\quad 76$

Anteil der Hypotaxe: 76 von 196 Sătzen, d.h. die Hypotaxe macht 39\% aus.

einfache Hypotaxe: $142 /$

Hauptsatz und ein Relativsatz $\quad 16$

Hauptsatz und ein untergeordneter NS 26 
mehrfache/ zusammengesetzte Hypotaxe: $\quad / 34 /$

Hauptsatz und $\geq 2$ Nebensătze /11/

HS,

HS, когда ..., и когда ...

HS, чтобы ..., что (2.Grad)

HS, в которые ... , если (2.Grad)

HS, что ..., чего (2.Grad)

HS, чтобы ..., которое (2.Grad)

HS, xak ..., kax ...

HS, что ..., что ...

HS, которыми ... и которые ...

HS, которая ..., что (2.Grad)

HS, чтобы ..., хоторую (2.Grad)

$\geq 2$ Hauptsătze und Nebensatz/ -sătze $\quad$ 123/

HS, потому что ..., ..., HS

HS, которая ...: HS, когда ..., когда ...

HS, a HS, xоторые ...

HS, подле которой ...; HS

HS и HS, которые ... - HS

HS ! HS, что ..., и что ...

HS, во HS, что ...

HS, для того, что ..., во HS

HS, которую ...; HS; HS

HS: HS, HS, HS, чтобы ...

HS, и HS, kax ...; HS, и HS

HS - HS: 460 ...

HS, что ... : : HS, что ...

HS, так, что ..., и HS

HS, но HS, который ...

HS, которыми ...; HS

HS - HS - KaK ...

HS, тax, что ...; HS

HS - HS, что ...

HS, HS - HS, что ...

HS - HS, HS, HS, что ...

HS - HS- HS, хоторый ... - HS, и HS

HS, которую ... : HS

Die Satztypenverteilung in Karamzins dichterischem Werk ist folgende:

Einfachsătze: 83

Satzreihen: $\quad 37$

prozentual:

Satzgefuge: $\quad 76$

196

$39 \%$ 
zur Hypotaxe:

a) einfache Satzgefüge

b) zusammengesetzte Satz-

c) - (mehrere NS, aber 1.Grad)

d) mehrfache Satzgefüge (>1.Grad) gefüge (nur $1 \mathrm{NS}=1$. Grad)

(Gesamttext:)

42

20

8

76

daraus folgt die prozentuale Verteilung:

Satzgefuge mit nur einem NS $(a+b)$

$82 \%$

nach Komplexitat:

nur l.Grad $(a+b+c)$

$92 \%$

$\geq 2$. Grad (d)

$8 \%$

Da das Werk als Ganzes untersucht ururde (aufgrund einer fehlenden Kapitelgliederung), ist keine Aussage über eine Streuung in der Verteilung der Satzarten möglich.

PUSKIN - Geschichtswerk

\section{Text 1:}

Einfachsătze: $\quad 69$

Satzreihen: $\quad \underline{26}$

Satzgefüge: $\quad 12$

Anteil der Hypotaxe: 12 von 107 Sătzen, d.h. die Hypotaxe macht $11 \%$ aus.

einfache Hypotaxe: $\quad$ 17/

Hauptsatz und ein Relativsatz 3

Hauptsatz und ein untergeordneter NS 4

mehrfache/ zusammengesetzte Hypotaxe: 15/

Hauptsatz und 2 Nebensatze ///

HS. что ..., и что ...

$\geq 2$ Hauptsătze und Nebensatz/-sătze /4/

HS; HS, где ... и где ...

HS; HS; HS, где ... 
HS, a HS, на котором ...

HS, где ... и где

\section{Pułkin Geschichtswerk Text 2:}

Einfachsătze: $\quad 125$

Satzreihen: $\quad \underline{26}$

151

Satzgefuge: $\quad 19$

Anteil der Hypotaxe: 19 von 170 Sătzen, d.h. die Hypotaxe macht $11 \%$ aus.

einfache Hypotaxe: $\quad$ /13/

Hauptsatz und ein Relativsatz. 4

Hauptsatz und ein untergeordneter NS 9

mehrfache/ zusammengesetzte Hypotaxe: 16/

22 Hauptsătze und Nebensatz/-sătze

HS; HS, что ...

HS; но HS, что ...

HS; HS, что ...

HS, что ...; HS

HS: HS, где ...

HS; HS, дабы ..., а HS

\section{Puß̌kin Geschichtswerk Text 3:}

Einfachsătze: $\quad 206$

Satzreihen: $\quad 47$

253

Satzgefüge: $\quad 54$

Anteil der Hypotaxe: 54 von 307 Sătzen, d.h. die Hypotaxe macht $18 \%$ aus.

einfache Hypotaxe: $\quad$ /35/

Hauptsatz und ein Relativsatz 14

Hauptsatz und ein untergeordneter NS 21

mehrfache/ zusammengesetzte Hypotaxe: /19/

Hauptsatz und $\geq 2$ Nebensătze $\quad / 7 I$

3 HS, что ... и что ...

Когда ..., (HS] тогда ..., где ...

HS, как ..., дабы ...

HS, где ... и где ...

HS, что ..., что ..., но что ... 
$\geq 2$ Hauptsătze und Nebensatz/-sătze /12/

HS; HS; HS; HS; HS, дабы ...

HS, и HS, где ...

HS; HS, которая ...

HS; HS, где ...

HS: HS, xоторые ...

HS, дабы ..., и HS: но HS

HS; HS, чтобы ...

HS, который ...; HS, дабы ...

HS; HS, что ...

HS, rдe ..., HS

HS; HS, rдe ...

HS; HS: HS, к которому ...

Die Satzaypenverteilung in den Texten von Puskins Geschichtswerk ist folgende:

$\begin{array}{lll}\text { T } 1 & \text { T } 2 & \text { T } 3\end{array}$

\begin{tabular}{lrrr} 
Einfachsatze: & 69 & 125 & 206 \\
Satzreihen: & 26 & 26 & 47 \\
Satzgefuge: & 12 & 19 & 54 \\
\hline & 107 & 170 & 307
\end{tabular}

prozentual:

Einfachsatze:

Satzreihen:

Satzgefüge:

$\begin{array}{lll}64 \% & 74 \% & 67 \% \\ 24 \% & 15 \% & 15 \% \\ 11 \% & 11 \% & 18 \%\end{array}$

- Mittelwert 68\% ${ }^{10}$

- Mittelwert 17\%

- Mittelwert 15\%

Die Verteilung der Satztypen zeichnet sich durch eine beachtenswerte Regelmaßigkeit aus: bei den Einfachsätzen beträgt die Streuung 10\%; bei den Satzreihen $9 \%$ und bei den Satzgefügen 7\%. Im Gegensatz zu Lomonosov aber auch zu Karamzin ist bei Puškin eine Regelmäßigkeit deutlich erkennbar, wobei der Einfachsatz den absolut größten Anteil mit jeweils über zwei Dritteln aufweist.

zur Hypotaxe:

$\begin{array}{lll}\text { T } 1 & \text { T } 2 & \text { T } 3\end{array}$

a) einfache Satzgefüge

$\begin{array}{lll}7 & 13 & 35\end{array}$

b) zusammengesetzte Satzgefuge (nur $1 \mathrm{NS}=1 . \mathrm{Grad}$ )

$2 \quad 6 \quad 11$

${ }^{10}$ Nach LESSKIS (1968) betrăgt der Anteil der Einfachsătze 68,4 \% (LESSKIS gibt den Anteil der "сложные предложения" mit 31,6\% an; siehe таблица 1, S.72). Es handelt sich um eine andere Stichprobe als unsere; da der Wert aber faktisch gleich ist, wird der Mittelwert $68 \%$ als Wahrscheinlichkeitswert in denkbar bester Weise bestătigt. 
c) - - (mehrere NS, aber 1.Grad) $3 \quad-\quad 8$

$\begin{array}{lrrr}\text { mehrfache Satzgefüge }(>1 . \text { Grad }) & - & - & -\end{array}$

daraus folgt die prozentuale Verteilung:

Satzgefüge mit nur einem NS (a+b) $\quad 75 \% \quad 100 \% \quad 85 \% \quad$ - Mittelwert $87 \%$

nach Komplexitat:

nur 1. Grad $(a+b+c) \quad 100 \% \quad 100 \% \quad 100 \%$

Auch innerhalb der Satzgefüge laßt sich eine Regelmaßigkeit erkennen: Puškin verzichtet gänzlich auf komplexere Satzgefüge. Den überwiegenden Anteil stellen die Satzgefüge mit nur einem Nebensatz. Seltener verwendet Puškin mehr als einen Nebensatz. wobei er aber nicht komplexere Satzgebilde einsetzt.

PUSKIN - Dichterisches Werk

Text 1:

Einfachsătze: $\quad 81$

Satzreihen: $\quad \frac{7}{88}$

Satzgefïge: $\quad 36$

Anteil der Hypotaxe: 36 von 124 Sătzen, d.h. die Hypotaxe macht 29\% aus.

einfache Hypotaxe: $\quad 121 /$

Hauptsatz und ein Relativsatz 8

Hauptsatz und ein untergeordneter NS 12

Sprichwort (Семь бед, один ответ.) 1

mehrfache / zusammengesetzte Hypotaxe: /15/

Hauptsatz und $\geq 2$ Nebensätze /4/

HS, что ..., и [что]...

HS. где ..., что (2.Grad)

HS, что ..., что ...

HS, чтоб ..., что (2.Grad)

$\geq 2$ Hauptsătze und Nebensatz/ -sătze /11/

Если ..., HS и НS

HS; HS, от которых ...

как ..., и то HS, то HS, кak ...

HS, хотя ..., но HS - и HS 
HS : HS, если ...?

HS, HS, noka ...

HS, что ...; HS, от которых ..., и HS

HS; a HS, что ...

HS; HS, который ...

HS; HS, что ...

HS, что если (2.Grad), то [HS]

Puškin dichterisches Werk Text 2:

Einfachsătze: $\quad 64$

Satzreihen: $\quad \frac{11}{75}$

Satzgefuige: $\quad 31$

Anteil der Hypotaxe: 31 von 106 Sătzen, d.h. die Hypotaxe macht $29 \%$ aus.

einfache Hypotaxe: $\quad / 16 /$

Hauptsatz und ein Relativsatz 4

Hauptsatz und ein untergeordneter NS 12

mehrfache/ zusammengesetzle Hypotaxe: /15/

Hauptsatz und $\geq 2$ Nebensătze /8/

Прежде нежели ..., коим (2.Grad), HS, в котором ...

HS, будто бы ..., которые (2.Grad)

HS, что ... и что ...

HS, что ..., о чем (2.Grad)

HS, что ... (HS) что ...

Когда ..., HS, в котором ...

Когда ..., что ... и что ...(beide 2.Grad), HS

если ..., HS, что ..., которые (2.Grad)

$\geq 2$ Hauptsătze und Nebensatz/ -sătze $\quad 17 /$

HS; HS, которые ...

HS; HS, что ..., которые (2.Grad)

HS: HS, что ..., который (2.Grad)

HS, и HS, как ...

HS, что ..., HS; если ..., HS

HS, которые ..., и HS

HS: HS, чTO ...

\section{Puškin dichterisches Werk Text 3:}

Einfachsătze: $\quad 87$

Satzreihen: $\quad 19$

106

Satzgefuge: $\quad 46$ 
Anteil der Hypotaxe: 46 von 152 Sătzen, d.h. die Hypotaxe macht 30\% aus.

einfache Hypotoxe: $\quad$ 125/

Hauptsatz und ein Relativsatz $\quad 8$

Hauptsatz und ein untergeordneter NS $\quad 17$

mehrfache/ zusammengesetzte Hypotaxe: 121 /

Hauptsatz und $\geq 2$ Nebensătze /11/

HS, как ... как ...

HS, что ...; но что ...

HS, когда ...: чем (2.Grad) - (HS), что ...

HS, чтобы ..., kоero (2.Grad)

HS, что ..., что ..., но что ...

Будучи уверена, что..., когда (2.Grad), HS

HS, что ... и что ...

HS, что ..., что ...

HS, что ..., чтоб (2.Grad), в чем (2.Grad)

HS, что ...; что ..., который (2.Grad), которая (3.Grad)

HS, который ..., что (2.Grad)

$\geq 2$ Hauptsătze und Nebensatz/ -sătze

$110 /$

HS, что если (2.Grad) ...; и HS, что ...

HS; HS, дабы .., что (2.Grad); HS, что ..., дабы (2.Grad)

HS: HS. оттого, что ..., которая (2.Grad); оттого, что ..., которое (2.Grad),

$$
\text { - как ..., HS }
$$

HS, о чем; HS, что ... и что, будто (2.Grad)

HS, что ... и что-де ; HS, что ...

HS; HS, чтоб ...

HS, и HS, который ..., что (2.Grad)

HS (Она рассказала,) в котором ..., какие ..., что ..., кого ..., - HS

HS, $\operatorname{kax~...,~и~НS,~что~...~}$

HS, и HS, с которой ...

Die Satztypenverteilung in den Texten von Puškins dichterischem Werk ist folgende:

$\begin{array}{lll}\text { T1 } & \text { T2 } & \text { T3 }\end{array}$

\begin{tabular}{lrrr} 
Einfachsätze: & 81 & 64 & 87 \\
Satzreihen: & 7 & 11 & 19 \\
Satzqefüge: & 36 & 31 & 46 \\
\hline & 124 & 106 & 152
\end{tabular}


prozentual:

Einfachsătze:

$65 \%$

$60 \%$

$57 \%$

- Mittelwert 61\%"

Satzreihen:

$6 \%$

$10 \%$

$13 \%$

- Mittelwert 10\%

Satzgefuge:

$29 \%$

$30 \%$

$30 \%$

- Mittelwert 30\%

Die Verteilung der Satztypen zeichnet sich (wie schon beim Geschichtswerk Puškins festgestellt) durch eine beachtenswerte Regelmaßigkeit aus: bei den Einfachsatzen beträgt die Streuung 8\%; bei den Satzreihen 7\% und bei den Satzgefügen sogar nur 1\%!! Der Einfachsatz besitzt jeweils den großßen Anteil; danach folgt das Sarzgefüge, das immerhin die Halfte des Anteils des Einfachsatzes erreicht.

zur Hyporaxe:

a) einfache Satzgefuge

b) zusammengesetzze Satzgefuge (nur $1 \mathrm{NS}=1 . \mathrm{Grad}$ )

c) - - (mehrere NS, aber 1.Grad)

\begin{tabular}{lrrr} 
d) mehrfache Satzgefuge (>1.Grad) & 3 & 7 & 11 \\
\hline 36 & 31 & 46
\end{tabular}
T 1 T 2 T 3

$21 \quad 16 \quad 25$

$8 \quad 4 \quad 2$

$\begin{array}{lll}4 & 4 & 8\end{array}$ $\frac{1}{46}$

daraus folgt die prozentuale Verteilung:

Satzgefuge mit nur einem NS (a+b) $\quad 81 \% \quad 65 \% \quad 59 \% \quad$ - Mittelwert $67 \%$

nach Komplexitat:

nur l.Grad $(a+b+c)$

$92 \% \quad 77 \% \quad 76 \%-$ Mittelwert $81 \%$

$\geq 2$. Grad (d)

$8 \% \quad 23 \% \quad 24 \%$ - Mittelwert $19 \%$

Gleiche Großßenordnungen treten erst zwischen $T 2$ und $T 3$ auf. Puškin greift in seinem dichterischen Werk of zu komplexeren Satzgebilden; der Anteil von 24\% für Säzze mit Nebensatzkonstruktionen mit mindestens zweitem Grad ist recht beachtlich.

"Nach LESSKIS (1968) betrăgt der Anteil der Einzelsătze 63,8\% (LESSKIS gibt den Anteil der "сложные предложения" mit 36,2\% an; siehe таблица 5, S.74). Es handeh sich um eine andere Stichprobe als unsere; da sein Wert aber sehr nahe dem unseren liegt, wird der Mittelwert $61 \%$ als Wahrscheinlichkeitswert bestătigt. 


\section{Vergleichende Gegenüberstellung der Ergebnisse}

a) Vergleich innerhalb der Geschichtswerke

\section{Lomonosov}

Einfachsătze (Mittelwert):

Satzreihen (Mittelwert):

Satzgefuge (Mittelwert):

\section{$48 \% *$}

$10 \%$

$42 \% *$
Karamzin

$35 \%$

$21 \%$

$44 \%$
Puskin

$68 \%$

$17 \%$

$15 \%$

Zwischen Lomonosov und Karamzin läßr sich beim Satzgefüge eine Entsprechung feststellen, die allerdings nicht zu hoch veranschlagt werden darf, da erstens die Mittelwerte bei Lomonosov nur arithmetisch sind und nicht die tatsächliche Verteilung aufzeigen und da zweitens näher auf die Art der Satzgefüge eingegangen werden muß:

zur Hypotaxe: (Mittelwerte)

Satzgefuge mit nur einem NS

nach Komplexität:

nur I.Grad

22.Grad

\section{Lomonosov}

$65 \%$

$76 \%$

$24 \%$
Karamzin

$72 \%$

$87 \%$

$13 \%$
Puškin

$87 \%$

$100 \%$

$0 \%$

\section{Zusammen fassung:}

Bei einer weiteren Aufschlüsselung der verschiedenen Hypotaxen zeigt sich klar der Unterschied zwischen Karamzin und Lomonosov. Wăhrend bei Lomonosov die Satzgefüge mit mindestens zweitem Grad einen Anteil von durchschnittlich einem Viertel ausmachen, sind diese komplexen Satzgebilde bei Karamzin um 10\% weniger vertreten. Überhaupt ist bei Karamzin die Tendenz zur Vereinfachung der Satzgefüge deutlich erkennbar; selbst in seinen Satzgefügen dominiert das parataktische Element: er gebraucht zahlreiche Satzgefüge vom Typ $H S ; H S, N S$ oder $H S ; H S ; H S ; H S, N S$, die doch sehr stark an der Satzreihe und damit an der Parataxe orientiert sind.

Bei Puškin sticht die Vereinfachung sofort ins Auge: sämtliche Satzgefuge sind nur ersten Grades. Die Vereinfachung des Satzbaus läßt sich auch aus dem hohen Anteil der Einfachsătze ablesen: nahezu 70\%, also doppett soviel wie bei Karamzin! Die Satzgefuge sind mit durchschnittlich $14 \%$ noch weniger vertreten als die Satzreihen mit $17 \%$. Bemerkenswert ist, daß die Satzlänge eine Regelmăßigkeit aufweisen kann und die Satztypenverteilung keine. So zeigt Z.B. die Untersuchung bei Lomonosov, daß trotz eines grob vorhandenen Satzlăngenprofils: 


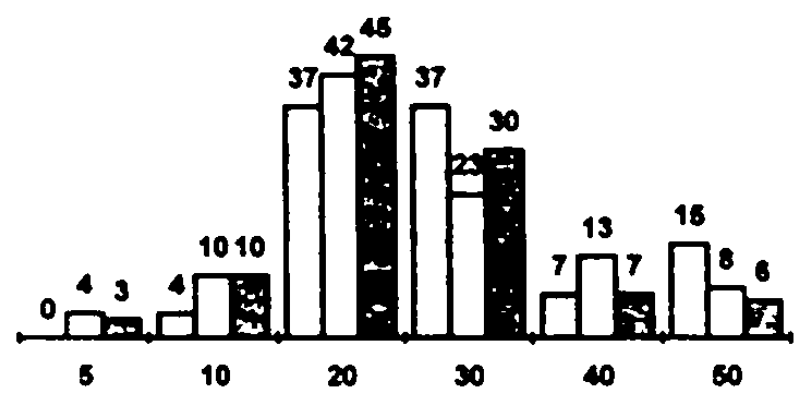

die Satztypenverteilung vom ersten bis zum dritten Text sogar gegenlăufig sein kann:

$\begin{array}{lrrr}\text { Einfachsătze: } & 26 \% & 40 \% & 60 \% \\ \text { Satzreihen: } & 7 \% & 10 \% & 10 \% \\ \text { Satzgefulge: } & 67 \% & 50 \% & 30 \%\end{array}$

Dies beweist, daß der Parameter der Satzlänge allein keine ausreichende Beschreibung gewăhrleistet.

Die Untersuchungen bei den anderen Autoren zeigen dagegen auch in der Satztypenverteilung ein Profil, selbst wenn die Streuungen zwischen den Texten einen recht großen Ausschlag aufweisen (bei Karamzins Einfachsătzen bis zu 15\%; bei Puškins Einfachsătzen bis zu 10\%). In beiden Fällen lassen sich aber stets Klare GröBenordnungen erkennen, die wiederum auf eine bewußte Einsetzung der Satzkomplexită durch den Autor schließen lassen.

Zur Annahme einer historiographischen Fachsprache:

Neben dem Parameter Satzlănge zeigt auch der Parameter Satzkomplexităt, daß innerhalb der Geschichtswerke keine Einheitlichkeit herrscht. Die hypothetische Annahme einer einheitlichen historiographischen Fachsprache erhält damit bisher keine Untermauerung mit konkreten Fakten.

b) Vergleich innerhalb der dichterischen Werke

$\begin{array}{lll} & \text { Karamzin } & \text { Puskin } \\ \text { Einfachsatze: } & \text { Gesamtwert 42\% } & \text { Mittehwert 61\% } \\ \text { Satzreihen: } & \text { Gesamtwert 19\% } & \text { Mittehwert 10\% } \\ \text { Satzgefüge: } & \text { Gesamtwert 39\% } & \text { Mittelwert 30\% }\end{array}$

Der deuflichste Unterschied (19\%) tritt beim Anteil der Einfachsätze auf. zur Hypotaxe:

Satzgefüge mit nur einem NS $\quad$ Gesamtwert 82\% $\quad$ Mittelwert 67\% 
nach Komplexirat:

nur 1.Grad

Gesamtwert 92\%

Gesamtwert $8 \%$
Mittelwert $81 \%$

Mittelwert $19 \%$

Während Karamzin in seinem dichterischen Werk die komplexeren Satzgefüge auf $8 \%$ reduziert, verwendet sie Puskin in seinem dichterischen Werk doppelt so oft (19\%).

Vergleich der Satzlăngenprofile:

Karamzin / Pu§kin (Бедная Лиза/ Капитанская Дочка)

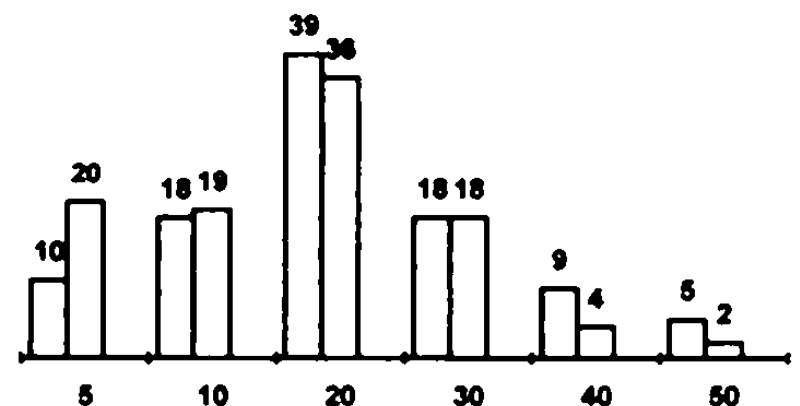

Der hohe Anteil an Einfachsätzen macht sich im Block der Kurzsäze von 1-5 Wörtern bemerkbar. Dies zeigt. daß die Blocke der kurzen Säze überwiegend den Anteil der Einfachsätze wiederspiegeln und daß sich bei den Blöcken der längeren Sătze alle drei Satztypen verbergen können.

c) Vergleich innerhalb eines Autors

$\begin{array}{lll}\text { KARAMZIN: } & \text { Geschichtswerk } & \text { dichterisches Werk } \\ \text { Einfachsătze: } & \text { Mittelwert 35\% } & \text { Gesamtwert 42\% } \\ \text { Satzreihen: } & \text { Mittelwert 21\% } & \text { Gesamtwert 19\% } \\ \text { Satzgefüge: } & \text { Mittelwert 44\% } & \text { Gesamtwert 39\% }\end{array}$

Die Differenz der Anteile beträgt maximal 7\% bei den Einfachsätzen; bei den Satzgefügen nur noch 5\% und bei den Satzreihen sogar nur 2\%. Die Verwendung von Parataxe bzw. Hypotaxe ist bei Karamzin also nicht textsortenbedingt.

zur Hypotaxe:

Satzgefüge mit nur einem NS

nach Komplexitär:

nur 1.Grad

$\geq 2$. Grad
Geschichtswerk

Mittelwert $72 \%$

Mittełwert $87 \%$

Mittelwert $13 \%$ dichterisches Werk

Gesamtwert 82\%

Gesamtwert 92\%

Gesamtwert $8 \%$ 
Der Vergleich der Satzgefüge zeigt gleiche Großenordnungen; beachtenswert ist, daß Karamzin in seinem dichterischen Werk die komplexeren Satzgefüge reduziert.

Der Parameter Satzkomplexităt zeigt auf jeden Fall mehr Einheitlichkeit des Karamzinschen Stils als der Parameter Satzlange:

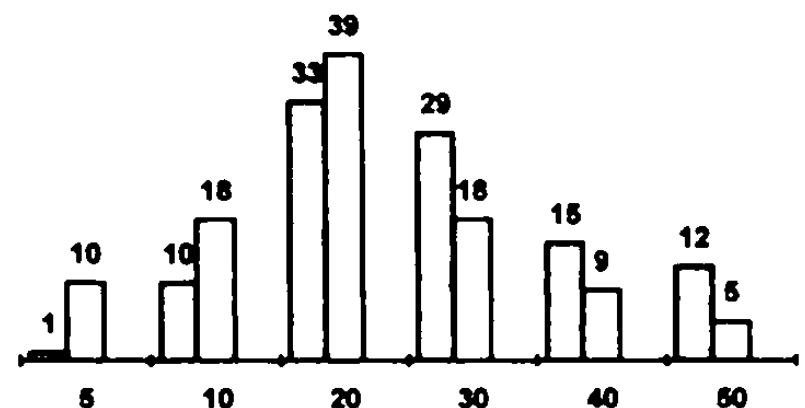

\begin{tabular}{lll} 
PUSKIN: & Geschichtswerk & dichterisches Werk \\
\hline Einfachsatze: & Mittelwert 68\% & Mittelwert 61\% \\
Satzreihen: & Mittelwert 17\% & Mittetwert 10\% \\
Satzgefuge: & Mittelwert 15\% & Mittelwert 30\%
\end{tabular}

Nur der Einfachsatz stellt in beiden Textsorten ungefähr den gleichen und auch großten Anteil dar (Streuung 7\%); die anderen Satztypen sind dagegen offensichtlich anders verteilt: im dichterischen Werk benutzt Puškin die Hypotaxe zweimal so häufig wie im Geschichtswerk. Dementsprechend vermindert sich auch der Anteil der Satzreihen im dichterischen Werk.

zur Hypotaxe: Geschichtswerk dichterisches Werk

Satzgefüge mit nur einem NS Mittelwert $87 \% \quad$ Mittelwert 67\%

nach Komplexitat:

nur 1. Grad

Mittelwert $100 \%$

Mittelwert 81\%

$\geq 2$.Grad

Mittelwert 19\%

Das Satzgefüge im dichterischen Werk Puškins weist einen beachtlich hohen Anteil von komplexeren Satzgebilden auf. 
Vergleich der Satzlăngenprofile: (Geschichtswerk / dichterisches Werk)

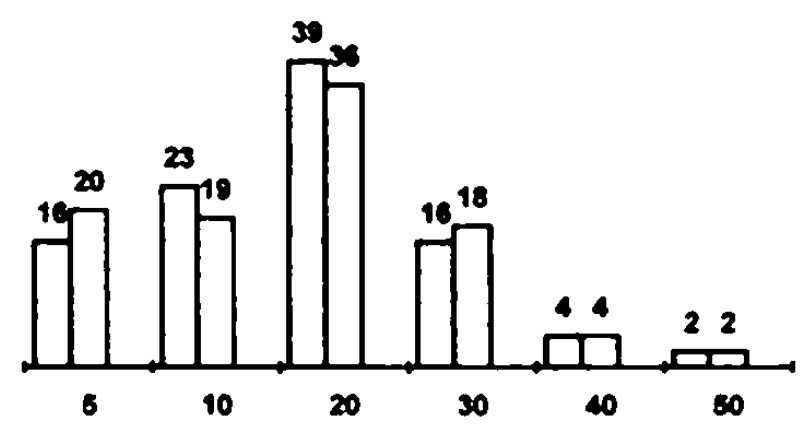

Wie schon bei Karamzin und Lomonosov beobachtet, widerspiegelt der Parameter Satzlange nicht die Ergebnisse des Parameters Satzkomplexitat. Denn obwohl Puskkin in seinem dichterischen Werk bedeutend mehr komplexe Sätze verwendet, zeigt der Vergleich der Satzlangenprofile überraschend hohe Übereinstimmung, merkwürdigerweise vor allem bei den langeren Satzen über 30 Wörtern, wo man eigentlich die komplexeren Satzgebilde vermutet, und die deshalb im dichterischen Werk doch häufiger vertreten sein müßten. Demnach ist Puškins Stil hinsichtlich der Satzlängen einheitlich; hinsichtlich der Verteilung der Satztypen aber deutlich textsortenabhangig.

\section{Bewertung des Parameters b:}

Mit Hilfe des Parameters Satzkomplexităt konnten wichtige Aussagen aber die Charakteristik des Textes gewonnen werden. Damit wurde der sich auf rein formale Kriterien stützende Parameter Satzlänge durch einen sich auf inhahtliche Kriterien stützenden Parameter ergănzt. Eine wichtige Erkenntnis ist, daß die Satzlănge nicht in direkter Relation zur Satzkomplexităt steht: weder bei Lomonosov noch bei Karamzin noch bei Puskin weisen die langen Sătze und uberlangen Sătze automatisch hypotaktische Komplexităt auf. Regelmaßßigkeiten innerhalb eines Werkes sind allerdings nur bei Puskin zu beobachten; bei Karamzin kann man zwar immer noch von gleichen Großenordnungen sprechen, aber schon weit weniger von RegelmäBigkeiten: der Anteil der Einfachsătze betrăgt $30 \%$ (T2) bis $45 \%$ (T3). Bei Lomonosov gar läßt sich nicht einmal eine gemeinsame Grobenordnung erkennen: in seinen Texten streuen die Werte bis um das doppelte: Einfachsătze 26\% - 60\%; bzw. Satzgefuge 67\% - 30\%.

Man könnte nun daraus folgern, daß sich der Parameter Satzkomplexität nicht für eine Stiluntersuchung eignet! Dies muß aber verworfen werden: erstens, weil (wie unter 5.3.2 begrundet wurde) der Parameter viel zu sehr ein stilistisches Gestaltungsmittel darstellt; zweitens wird die Struktur des Satzbaustils nicht durch die Unregelmäßigkeiten im Parameter Satzkomplexităt zerstơrt, da diese von den Regelmåßigkeiten im Parameter Satzlänge aufgefangen werden kठnnen. Bevor aber hieruber endgütig geurteilt wird, gilt es zu überprüfen, ob und inwieweit die anderen Parameter Regelmaßigkeiten aufweisen.

Nützlich war jedenfalls auch die weitere Differenzierung der Hypotaxe. Sie zeigte den qualitativen Unterschied zwischen Lomonosov und Karamzin auf; gleichzeitig konnten dadurch die verschiedenen Satzbautypen klassifiziert werden. 


\section{c) Parameter 'logische' Satzordnung:}

\section{Definitionen:}

a) Bei Satzreihen und Satzgefügen wird stets nur der erste Hauptsatz betrachtet.

b) 'Strenge SV(O)' bedeutet, daß auf das Subjekt bzw. den Subjektsverband sofort das Verb bzw. der Prădikatsausdruck folgt. Beispiel: IIIax жаловался царю.

Attributsătze werden nicht zum Subjektsverband gezăhlt. Beispiel: Обстоятельства, до особенных людей надлехкащие, не должны здесь ожидать похлебства, ...

Da im Russischen das finite Verb auch bereits das Subjekt ausdrücken kann, wird dies auch als strenge $\mathrm{SV}(\mathrm{O})$ gezăhlt. Beispiele:

Не будем суеверны в нашем высоком понятии о дееписаниях древности.

Однако не запрещал своим подданным креститься; ...

c) SV(O) mit Einschüben; Einschübe sind: Attributsătze (wie oben), auf das Subjekt bezogene Relativsătze, durch Kommata abgetrennte Appositionen, Adverbialausdrucke.

Beispiele:

Путачев, коего полохсение казалось отчаянным, явился ...

Овчинников и Перфильев, преследуемые майорам Шевичем, проскакали ...

Пугачев быстро переходил с одного места на другое.

Пугачев, замсегши ограбленные ин Белорецкие заводы, быстро перешел ...

\section{Untersuchungssch ritte:}

Im ersten Schritt werden all die Sătze gezăht, die strenge SV(O)-Ordnung aufweisen; danach die SV(O)-Sătze mit Einschüben. Diese Sătze werden zusammengefaßt als 'SV(O) ingesamt'. Sodann werden die Folge VS(O) sowie alle anderen Kombinationen wie SOV, VOS usw. aufgefuhrt.

Da SV(O) nur in Sătzen festgestellt werden kann, in denen Subjekt und Prädikat vorhanden sind, können die sog. eingliedrigen Sătze ${ }^{\prime}$, die dadurch gekennzeichnet sind, daß in ihnen die Relation zwischen Subjekt- und Pradikatgruppe feht, nicht auf die Satzordnung SV(O) untersucht werden. Diese Sătze werden unter 'Sonstige' zusammengefaßt; außerdem werden hier auch die Fragesătze subsumiert.

Nachdem die absoluten Zahlen für die verschiedenen Ordnungen angegeben wurden, werden anschließend die prozentualen Anteile von strenger SV(O), SV(O) mit Einschuben, SV(O) insgesamt und VS(O) errechnet.

Schließlich wird noch der gewogene Mittelwert bestimmt; dieser dient im folgenden als Vergleichswert fur das Werk.

\footnotetext{
' Vgl. MULISCH 1993, 292 ff.
} 
Untersuchungsengebnisse:

LOMONOSOV - Geschichtswerk

Text 1 Text $2 \quad$ Text 3

\begin{tabular}{|c|c|c|c|}
\hline strenge SV(O)-Ordnung: & 9 Srtze & 33 Sătze & 54 Sătz \\
\hline SV(O) mit Einschüben: & 5 Sătze & 36 Sătze & $39 \mathrm{Sa}$ \\
\hline SV(O) insgesamt: & 14 Sxtze & 69 Sxtze & $93 \mathrm{Sx}$ \\
\hline VS(O): & 2 Sătze & 6 Satze & $15 \mathrm{Sa}$ \\
\hline Die restlichen & 11 Satze & 31 Sătze & $27 \mathrm{~S}:$ \\
\hline (Summe & 27 & 106 & 135) \\
\hline verteilen sich wie folgt: & $\begin{array}{l}2 \mathrm{SOV} \\
1 \mathrm{OVS} \\
1 \mathrm{OSV}\end{array}$ & $\begin{array}{l}6 \text { SOV } \\
1 \text { OVS } \\
7 \text { OSV } \\
2 \text { VOS }\end{array}$ & $\begin{array}{r}12 \mathrm{SOV} \\
4 \mathrm{OVS} \\
8 \mathrm{OSV}\end{array}$ \\
\hline
\end{tabular}

'gesplittete' Ordnung:

$1 \mathrm{SO}_{1} \mathrm{VO}_{2}$

$1 \mathrm{SV}_{1} \mathrm{OV}_{2}$

$3 \mathrm{O}_{1} \mathrm{SVO}_{2}$

$2 \mathrm{O}_{1 S V O}$

$1 \mathrm{OV}_{1} \mathrm{SV}_{2}$

Sonstige: $\quad 2$ Sătze $\quad 13$ Sătze 2 Sătze

$\begin{array}{llll}\text { prozentual: } & \text { Text } 1 & \text { Text } 2 & \text { Text } 3\end{array}$

strenge SV(O)-Ordnung: $\quad 33 \% \quad 31 \% \quad 30 \% \quad-$ Mittelwert $36 \%$

SV(O) mit Einschüben: $\quad 19 \% \quad 34 \% \quad 29 \% \quad-$ Mittelwert $30 \%$

SV(O) insgessmt: $\quad 52 \% \quad 65 \% \quad 69 \%$ - Mittelwert $66 \%$

$\begin{array}{lllll}\text { VS(O): } & 7 \% & 6 \% & 11 \% & \text { - Mittelwert } 9 \%\end{array}$

Restliche: $\quad 41 \% \quad 29 \% \quad 20 \%$

1) Der Anteil der Sătze mit strenger SV(O) ist relativ konstant: die Streuung betrăgt nur $7 \%$. Der Anteil der SV(O)-Satze insgesamt weist dagegen eine Streuung von $17 \%$ auf.

2) Die anderen Ordnungsschemata sind außerst ungleich uber die einzelnen Abschnitte verteih. Vor allem in der Einleitung (Text 1) zieht Lomonosov alle erdenklichen Ordnungsschemata heran; auffallig ist die Verwendung von 'gesplitteten' Ordnungen. 
KARAMZIN - Geschichtswerk

\begin{tabular}{|c|c|c|c|c|}
\hline & Text 1 & Text 2 & \multicolumn{2}{|c|}{ Text 3} \\
\hline strenge SV(O)-Ordnung: & 60 Sătze & 77 Sătze & \multicolumn{2}{|c|}{68 Sătze } \\
\hline SV(O) mit Einschuben: & 11 Sătze & 45 Sătze & \multicolumn{2}{|c|}{47 Sătze } \\
\hline SV(0) insgesamt: & 71 Sătze & 122 Satze & \multicolumn{2}{|c|}{115 Sătze } \\
\hline VS(O): & 7 Sătze & 7 Sătze & \multicolumn{2}{|c|}{5 Sătze } \\
\hline Die restlichen & 25 Sătze & 18 Sătze & \multicolumn{2}{|c|}{3 Sătze } \\
\hline (Summe & 103 & 147 & \multicolumn{2}{|c|}{ 123) } \\
\hline verteilen sich wie folgt: & $1 \mathrm{SOV}$ & 3 ovs & & - \\
\hline Sonstige: & 24 Sătze & 15 Sătze & \multicolumn{2}{|c|}{3 Sătze } \\
\hline prozentual: & Text 1 & Text 2 & \multicolumn{2}{|c|}{ Text 3} \\
\hline strenge SV(O)-Ordnung: & $58 \%$ & $52 \%$ & $55 \%$ & - Mittelwert 55\% \\
\hline SV(O) mit Einschüben: & $11 \%$ & $31 \%$ & $38 \%$ & - Mittelwert 28\% \\
\hline SV(O) insgesamt: & $69 \%$ & $83 \%$ & $93 \%$ & - Mittehwert $83 \%$ \\
\hline VS(O): & $7 \%$ & $5 \%$ & $4 \%$ & - Mittehwert 5\% \\
\hline Restliche: & $24 \%$ & $12 \%$ & $3 \%$ & \\
\hline
\end{tabular}

1) Der Anteil der Sătze mit strenger SV(O) ist relativ konstant: die Streuung beträgt nur 6\%. Der Anteil der SV(O)-Sătze insgesamt weist dagegen eine Streuung von $25 \%$ auf. 2) Ansonsten stellt nur noch die VS(O)-Ordnung einen nennenswerten Anteil: Mittelwert $5 \%$.

KARAMZIN - Dichterisches Werk (Gesamttext)

strenge SV(O)-Ordnung: $\quad 120$ Sătze $\quad 61 \%$

SV(O) mit Einschüben: $\quad 29$ Sătze $\quad 15 \%$

SV(O) insgesamt: $\quad 149$ Satze $\quad 76 \%$

VS(O): $\quad 31$ Sătze $\quad 16 \%$ 
Die restlichen $\quad \underline{16 \text { Sătze }} \quad 8 \%$

verteilen sich wie folgt: $\quad 1$ SOV

2 OVS

1 OSV

1 Vos

Sonstige:

11 Sătze

Aussagen zur Streuung sind nicht möglich, da das Werk als Ganzes untersucht wurde.

PUSKKIN - Geschichtswerk

$\begin{array}{lll}\text { Text } 1 & \text { Text } 2 & \text { Text } 3\end{array}$

strenge SV(O)-Ordnung: $\quad 55$ Sătze $\quad 99$ Sătze $\quad 187$ Sătze

SV(0) mit Einschaben: $\quad 26$ Sătze $\quad 48$ Sătze $\quad 74$ Sătze

SV(O) insgesamt:

81 Sătze 147 Sătze 261 Sătze

VS(0): $\quad 14$ Sătze $\quad 14$ Sătze $\quad 28$ Sătze

Die restlichen
(Summe $\quad \begin{array}{llll}12 \text { Sătze } & 9 \text { Sătze } & 18 \text { Sătze } \\ 107 & 170 & 307 \text { ) }\end{array}$

$\begin{array}{llll}\text { verteilen sich wie folgt: } & 1 \text { SOV } & 2 \text { SOV } & 3 \text { SOV } \\ & 1 \text { OSV } & & 9 \text { OSV } \\ & 1 \text { OVS } & & 1 \text { OVS } \\ & 1 \text { VOS } & & 1 \mathrm{~V}_{1} \mathrm{SV}_{2}\end{array}$

Sonstige: $\quad 8$ Sătze $\quad 7$ Sătze $\quad 4$ Sătze

$\begin{array}{llll}\text { prozentual: } & \text { Text } 1 & \text { Text } 2 & \text { Text } 3\end{array}$

$\begin{array}{lllll}\text { strenge SV(O)-Ordnung: } & 51 \% & 58 \% & 61 \% & - \text { Mittelwert } 58 \%\end{array}$

SV(O) mit Einschüben: $\quad 24 \% \quad 28 \% \quad 24 \% \quad-$ Mittelwert 25\%

SV(O) insgesamt: $\quad 76 \% \quad 86 \% \quad 85 \% \quad$ - Mittelwert $84 \%$

$\begin{array}{lllll}\text { VS(O): } & 13 \% & 8 \% & 9 \% & - \text { Mittelwert } 10 \%\end{array}$

$\begin{array}{llll}\text { Restliche: } & 11 \% & 5 \% & 6 \%\end{array}$ 
1) Der Anteil der Sătze mit strenger SV(O) weist eine Streuung von $10 \%$ auf. Dies ist die bisher größte Streuung, die innerhalb strenger SV(O) auftrat, doch erscheint sie ausreichend gering, daß immer noch von einer Regelmäßigkeit gesprochen werden kann. Der Anteil der SV(O)-Sătze insgesamt weist eine kaum großßere Streuung auf: $11 \%$.

2) Ansonsten stellt nur noch die VS(O)-Ordnung einen nennenswerten Anteil: Mittelwert $10 \%$.

\section{PUSKIN - Dichterisches Werk}

\begin{tabular}{|c|c|c|c|c|}
\hline & Text 1 & Text 2 & \multicolumn{2}{|c|}{ Text 3} \\
\hline strenge SV(O)-Ordnung: & 69 Sătze & 65 Sătze & \multicolumn{2}{|c|}{94 Sătze } \\
\hline SV(O) mit Einschüben: & 24 Sătze & 21 Sătze & \multicolumn{2}{|c|}{35 Sătze } \\
\hline SV $(0)$ insgesamt: & 93 Sxitze & 86 Sxtze & \multicolumn{2}{|c|}{129 Sxtze } \\
\hline VS(O): & 13 Sătze & 9 Sătze & \multicolumn{2}{|c|}{11 Sătze } \\
\hline Die restlichen & 18 Sătze & 11 Sătze & \multicolumn{2}{|c|}{12 Satze } \\
\hline (Summe & 124 & 106 & \multicolumn{2}{|c|}{ 152) } \\
\hline verteilen sich wie folgt: & $\begin{array}{l}4 \mathrm{SOV} \\
2 \mathrm{VOS} \\
1 \mathrm{~V}_{1} \mathrm{SV}_{2}\end{array}$ & $4 \mathrm{SOV}$ & \multicolumn{2}{|c|}{$\begin{array}{l}3 \text { SOV } \\
6 \text { OSV }\end{array}$} \\
\hline Sonstige: & 11 Sătze & 7 Sătze & \multicolumn{2}{|c|}{3 Sătze } \\
\hline prozentual: & Text 1 & Text 2 & \multicolumn{2}{|c|}{ Text 3} \\
\hline strenge SV(O)-Ordnung: & $56 \%$ & $61 \%$ & $62 \%$ & - Mittehwert $60 \%$ \\
\hline SV(O) mit Einschuben: & $19 \%$ & $20 \%$ & $23 \%$ & - Mittelwert $21 \%$ \\
\hline SV(0) insgesamt: & $75 \%$ & $81 \%$ & $85 \%$ & - Mittelwert $81 \%$ \\
\hline VS(O): & $10 \%$ & $9 \%$ & $7 \%$ & - Mittelwert $9 \%$ \\
\hline Restliche: & $15 \%$ & $10 \%$ & $8 \%$ & \\
\hline
\end{tabular}

1) Der Anteil der Sătze mit strenger SV(O) weist eine Streuung von 6\% auf. Dies ist die bisher geringste Streuung. Der Anteil der SV(O)-Sătze insgesamt weist eine Streuung von $10 \%$ auf.

2) Ansonsten stelt nur noch die VS(O)-Ordnung einen nennenswerten Anteil: Mittelwert $8 \%$. 
Vergleichende Gegenüberstellung der Ergebnisse

strenge SV(O): Geschichtswerke

Lomonosov:

Karamzin:

Puskin:
$36 \%$

$55 \%$

$58 \%$ dichterische Werke

$61 \%$

$60 \%$

Es gibt innerhalb der Geschichtswerke keine Übereinstimmung, vielmehr steigt die Verwendung von strenger $S V(O)$ kontinuierlich an. Auch zeichnen sich die Geschichtswerke nicht etwa durch eine höhere 'logische' Ordnung aus, eher ist das Gegenteil festzustellen, wenngleich die geringen Werte (2\% bei Puskin, $6 \%$ bei Karamzin) nicht überbewertetet werden sollten.

SV(O) insgessmt: Geschichtswerke dichterische Werke

Lomonosov: $\quad 66 \%$

$\begin{array}{lll}\text { Karamzin: } & 83 \% & 76 \%\end{array}$

$\begin{array}{lll}\text { Puskin: } & 84 \% & 81 \%\end{array}$

Es gilt hier das gleiche wie bei der strengen SV(O)-Ordnung (siehe oben).

VS(O):

Lomonosov:

Karamzin:

Pıškin:
Geschichtswerke

$9 \%$

$5 \%$

$10 \%$ dichterische Werke

$16 \%$

$9 \%$

Hinsichtlich der $V S(O)$ Ordnung herrscht großßenordnungsmäßig die gleiche Verteilung: ale Werte liegen in dem Intervall $/ 5-16 /$.

\section{Zisammenfassung:}

De Verwendung der 'logischen' Satzordnung SV(O) erreicht mit Karamzin einen um ca. $26 \%$ hðheren Wert als bei Lomonosov, der auch von Puskin nicht wesentlich übertroffen wrd. Dies zeigt anschaulich, daß Karamzin für die Einführung dieses Prinzips verantw)rthich ist und er es bereits auf eine solche Hohe brachte. daß es von Puskin nicht witer ausgearbeitet zu werden brauchte. 


\section{Bewertung des Parameters c:}

Der Parameter 'logische' Satzordnung weist in allen Werken eine Regelmäigkeit auf. Eine Streuung von $10 \%$ ist u.E. angesichts des Basiswertes von mindestens $30 \%$ bei Lomonosov durchaus vertretbar. Die Grðßenordnung der strengen $\mathrm{SV}(\mathrm{O})$ beträgt bei Lomonosov 30\% - 40\%; bei Karamzin und Puskin 50\% - 60\%. Durch die Anwendung dieses Parameters konnte festgestellt werden, wie konsequent dieses Ordnungsprinzip in den Texten umgesetzt wurde. 


\section{d) Parameter Pradikativităt:}

\section{Definitionen und Untersuchungsechritte:}

Zuerst werden die primären Pradikationen' gezahht. Als primăre Prădikation wird die prădikative Einheit definiert, die unter dem Prădikat rangiert. Ein Prädikat kann demnach aus mehreren Prädikationen bestehen. Im folgenden Satzbeispiel gibt es nur ein Pradikat, aber drei Prădikationen:
Михельсон
завод
прогнал их, oc8o6odun
и через день
пошел далее.

Die Prădikationen werden bei ihrer Erfassung bereits geordnet nach

$V$ (finiten Verbalformen),

$P$ (Prådikativen und prådikativ gebrauchten Partizipien) und

$N$ (nominaken Verbalformen).

Unter $\mathbf{V}$ werden die finiten Verben aufgeführt ${ }^{2}$. Die Prädikative ${ }^{3}$ und die prădikativ gebrauchten Partizipialformen (было уничтожено; уничтожен) werden unter $\mathbf{P}$ zusammengefaßt. Unter $\mathbf{N}$ werden ausschlieBlich die nominalen Prădikationen gezăhlt, deren Prädikatsnomina aus Substantiven. Adjektiven, Numeralien und Adverbien gebildet sind ${ }^{4}$. Beispiele:

Он ... принудил их возвратиться. $1 \mathrm{~V}$

Фрейман далисен был преследовать Путачева; ...

Пугачев сам был ранен ...

Дороги были непроходимы, ... I

Ein Prädikat kann aus mehreren Prädikationen bestehen. Beispiele:

Мятежники бросились
$\begin{gathered}\text { разобрали заплоты } \\ \text { и ворвались. }\end{gathered}$
Крепость была разорена и вылскена, ...
Сие поражение было последним и решительным.

Es gibt also zwei homogene Kategorien: die Kategorie der finiten Verben (V) und die der nominalen Prädikationen ( $\mathbf{N}$ ); die P-Kategorie ist eher eine Mischklasse. Die erste

\footnotetext{
'Es werden in der Untersuchung auch noch die sekundären Prädikationen nach der Definition von ISAČENKO $(1962,334)$ behandelt.

${ }^{2}$ Die finiten Verbalformen kסnnen eindeutig nach morphologischen Merkmalen bestimmt werden. Die Finitheit bezieht sich in erster Linie auf die Person. Auch Infinitive in finalen Nebensătzen werden noch zu den finiten Verbalformen gezăhlt.

${ }^{3}$ Nach der Definition von ISACENKO (1962, $194 \mathrm{ff}$.).

'Partizipien, die als Prádikatsnomina verwendet werden, werden nicht zu den nominaken Prädikatsnomina gezăhh, weil sichergestelt werden soll, da $B$ unter $\mathbf{N}$ ausschlie $B$ lich Prädikationen gezăhlt werden, die Eigenschaften bezeichnen. (Sie werden stattdessen $\mathbf{P}$ zugeteilt.)
} 
Kategorie bezieht sich auf Tătigkeiten' ; die zweite auf Zustände (vgl. auch die Bezeichnung 'Zustandskategorie' für die Prädikative) und die dritte auf Eigenschaften ${ }^{6}$.

\section{Untersuchung:}

Wenn wir die Texte nach den genannten Kriterien auszählen und nach den drei Kategorien $\mathbf{V}, \mathbf{P}, \mathbf{N}$ ordnen, erhalten wir folgende absolute Zahlen sowie die dazu errechneten prozentualen Werte für die Verteilung der primären Prädikationen:

Lomonosov - Geschichtswerk

Text 1: $\quad \begin{array}{llll}58 & 13 & 1\end{array}$

Text 2: $\quad \begin{array}{llll}173 & 33 & 23\end{array}$

Text 3: $\quad 236 \quad 30 \quad 10$

$\begin{array}{rllr} & \mathbf{V} & \mathbf{P} & \mathbf{N} \\ & \mathbf{8 1 \%} & 18 \% & 1 \% \\ & 76 \% & 14 \% & 10 \% \\ & \mathbf{8 5 \%} & 11 \% & 4 \% \\ \text { Mittelwert: } & \mathbf{8 1 \%} & 13 \% & \mathbf{6 \%}\end{array}$

Karamzin - Geschichtswerk

Text 1: $\quad 237 \quad 51 \quad 35$

Text 2: $\quad 294 \quad 40 \quad 26$

Text 3: $\quad 304 \quad 15 \quad 13$

$\begin{array}{rrrr} & \mathbf{7 3} \% & 16 \% & 11 \% \\ & \mathbf{8 2} \% & 11 \% & 7 \% \\ & \mathbf{9 2} \% & 5 \% & 4 \% \\ \text { Mittelwert: } & \mathbf{8 2} \% & 10 \% & \mathbf{7 \%}\end{array}$

Karamzin - Dichterisches Werk

Text gessmt: $494 \quad 15 \quad 21$

$93 \% \quad 3 \% \quad 4 \%$

Puß̌kin - Geschichtswerk

$\begin{array}{lllr}\text { Text 1: } & 152 & 50 & 7 \\ \text { Text 2: } & 261 & 44 & 12 \\ \text { Text 3: } & 475 & 73 & 15\end{array}$

$\begin{array}{cccc} & \mathbf{7 3} \% & 24 \% & 3 \% \\ & \mathbf{8 2} \% & 14 \% & 4 \% \\ & \mathbf{8 4 \%} & 13 \% & 3 \% \\ \text { Mittelwert: } & \mathbf{8 2} \% & 15 \% & \mathbf{3 \%}\end{array}$

Puškin - Dichterisches Werk

Text 1: $\quad 191 \quad 22 \quad 24$

Text 2: $\quad \begin{array}{llll}185 & 18 & 22\end{array}$

Text 3: $\quad 284 \quad 26 \quad 21$

$\begin{array}{rrrr} & \mathbf{8 1 \%} & 9 \% & 10 \% \\ & \mathbf{8 2} \% & 8 \% & 10 \% \\ & \mathbf{8 6 \%} & \mathbf{8 \%} & 6 \% \\ \text { Mittelwert: } & \mathbf{8 3} \% & \mathbf{8 \%} & \mathbf{8 \%}\end{array}$

Der Anteil der finiten Verben liegt in der Größenordnung von 73\% (Karamzin T1; Puskin TI) und 93\% (Karamzins dichterisches Werk).

${ }^{5}$ „Wenn also [...] auch nicht jedes Verb eine Tătigkeit ausdrückt, so kommt doch Tätigkeit primăr und als solche, d.h. an einen Ausführenden gebunden, a 11 e in im Verb zum Ausdruck." (RAECKE 1988, 308)

${ }^{6}$ Natürlich können finite Verben auch Zustände bezeichnen und Partizipien einen Pro$z e ß$, ganz $z u$ schweigen von der Tatsache, daß unter die finiten Verben auch eigentlich infinite gezăhlt werden wie z. B. говорится; doch genügt uns hier eine auf morphologischen Kriterien basierende Klassifizierung, schließlich sollen textuelle Strukturen erkannt werden, und dazu bedarf es eines groben Rasters. 
Wenn man die Mittelwerte des Anteils an finiten Verbalformen (V) betrachtet:

$$
\text { Geschichtswerke dichterische Werke }
$$

Lomonosov: $\quad 81 \%$

$\begin{array}{lll}\text { Karamzin: } & 82 \% & 93 \%\end{array}$

$\begin{array}{lll}\text { Puškin: } & 82 \% & 83 \%\end{array}$

so rücken alle Werke bis auf Karamzins dichterisches Werk sehr eng auf $81-83 \%$ zusammen. Die geringe Streuung der Mittelwerte laßt sich unmittelbar darauf zuruckführen. $\mathrm{da} \beta$ in unserer Untersuchung die grundlegende Diskursform das Erzăhlen ist. Bezüglich der Verteilung unterscheiden sich die Werke nicht wesentlich. Wir kðnnen daraus schließen, daß ein solcher Prozentsatz fur Erzahltexte (gleich ob fiktionaler oder nicht-fiktionaler Art) charakteristisch ist.

Auch P (Prådikative und prådikativ gebrauchte Partizipialformen) kann man unter dem Gesichtspunkt der Streuung betrachten: 3\% (Karamzins dichterisches Werk) bis $24 \%$ (Puskkins Geschichtswerk T1). Der Vergleich der Mittelwerte von P zeigt, daß die Werte in den Geschichtswerken durchweg deutlich höher liegen:

Lomonosov: $\quad 13 \%$

$\begin{array}{lll}\text { Karamzin: } & 10 \% & 3 \%\end{array}$

$\begin{array}{lll}\text { Pułkin: } & 15 \% & 8 \%\end{array}$

das läßt darauf schließen, daß in der Geschichtsschreibung das Beschreiben von Zustănden hăufiger vorkommt als in den dichterischen Werken.

Was die Kategorie der nominalen Prädikationen anbelangt. so zeigt sich. daß die Streuung von $1 \%$ (Lomonosov T1) bis $11 \%$ (Karamzins Geschichtswerk T1) reicht, was einerseits zwar eine große Streuung bedeutet, andererseits doch auch die Großenordnung aufzeigt, nămlich maximal um die $10 \%$, durchschnittlich um die $5 \%$.

Der Vergleich der Mittelwerte von $\mathbf{N}$ zeigt keinen textsortenbedingten Unterschied:

Lomonosov: $\quad 6 \%$

$\begin{array}{lll}\text { Karamzin: } & 7 \% & 4 \%\end{array}$

$\begin{array}{lll}\text { Puskin: } & 3 \% & 8 \%\end{array}$

Was wir bisher betrachtet haben, betraf die primäre Prădikation. Es wăre allerdings völlig unzureichend, wenn nicht auch die sekundäre Prädikation einbezogen werden würde. Festzuhalten ist zunächst. daß wir funktional-syntaktische Kriterien ansetzen und nicht etwa rein morphologische in der Art. daß alle Partizipien unter einer Rubrik zusam- 
mengefaßt werden, wie z.В.: 'бегущая лощадь' und 'Лощадь, бегущая по шоссе, ....' . Denn im ersten Fall erfullt das Partizip eine attributive Funktion (wir ordnen es demnach den Nomina zu); im zweiten Fall wird das Partizip appositionell gebraucht (wir ordnen es den sekundăren Prădikationen zu). Außerdem zăhlen wir das Adverbialpartizip (Gerundium) zur sekundären Prädikation ${ }^{8}$; die sekundäre Prädikation wird demnach nur von Partizipien gebildet ${ }^{9}$.

Die sekundăren Prădikationen treten in folgenden absoluten Zahlen auf:

Lomonosov

$\begin{array}{rrrrr}\text { T 1 } & 14 & 7 & 21 & : 27 \text { Sătze }=0,78 \\ \text { T 2 } & 24 & 9 & 33 & : 106 \text { Sătze }=0,31 \\ \text { T 3 } & 72 & 14 & 86 & : 135 \text { Sătze }=0,64\end{array}$

Karamzin - Geschichtswerk

$\begin{array}{lllrl}\text { T 1 } & 26 & 10 & 36 & : 103 \text { Sătze }=0,35 \\ \text { T } 2 & 29 & 19 & 48 & : 147 \text { Sătze }=0,33 \\ \text { T 3 } & 75 & 41 & 116 & : 123 \text { Sătze }=0,94\end{array}$

Karamzin - Dichterisches Werk

$T$ gesamt: $\quad 4$

Pußkkin - Geschichtswerk

$\begin{array}{lll}\text { T } 1 & 16 & 22\end{array}$

T 255

T $3 \quad 60 \quad 59$

$60: 196$ Sătze $=0,31$

$$
\begin{aligned}
38 & : 107 \text { Sătze }=0,36 \\
83 & : 170 \text { Sătze }=0,49 \\
119: & : 307 \text { Sătze }=0,39
\end{aligned}
$$

\section{Puß̌kin - Dichterisches Werk}

T 1 25

$30: 124$ Sătze $=0,24$

T 2

21

12

T 3

21

Die Anteilszahl liegt in den meisten Texten um 0,3 (in 8 von 13 Texten). Das geringste Aufkommen der sekundären Prädikation ist in Puškins dichterischem Werk Tl mit 0,24 zu verzeichnen; der höchste Wert tritt in Karamzins Geschichtswerk T3 mit 0,94 auf. also durchschnittlich fast in jedem Satz ein Partizip.

\footnotetext{
${ }^{7}$ Beispiele nach ISAČENKO $(1962,334)$.

${ }^{8}$ ISACENKO (1962, 324 und 334).

${ }^{9}$ Der Wortanteil der sekundären Prädikation deckt sich daher in den meisten Texten mit der Anzahl der Partizipien der sekundăren Prädikation; nur in vereinzelten Fălen muß als weitere prădikative Verbalform ein abhängiger Infinitiv mitgezăhlt werden. Beispiel: Михельсон, ..., надеясь соединиться ... = 1 sekundăre Prädikation, 2 prädikative Verbalformen.
} 
Nun sollen

a) die primăren Prădikationen in Verhăltnis zu den sekundăren gebracht und

b) die Summe von primăren und sekundăren Prădikationen auf die Zahl der Sătze bezogen werden; dabei zeigt sich folgendes:

primäre sekundäre

Prädikationen

Summe : Sätze

\begin{tabular}{lcclc}
\multicolumn{4}{l}{ Lomonosov } & Geschichtswerk \\
T 1 & 72 & 21 & Verhăltnis: $3: 1$ & $93: 27=3,4$ \\
T 2 & 229 & 33 & Verhaltnis: $7: 1$ & $262: 106=2,5$ \\
T 3 & 276 & 86 & Verhăltnis: $3: 1$ & $362: 135=2,7$
\end{tabular}

Karamzin - Geschichtswerk

T 1

T $2 \quad 360 \quad 48$

T $3 \quad 332 \quad 116$

Verhăhtnis: $9: 1 \quad 359: 103=3,5$

Verhaltnis: $7: 1 \quad 408: 147=2,8$

Verhăltnis: $3: 1 \quad 448: 123=3,6$

Karamzin - Dichterisches Werk

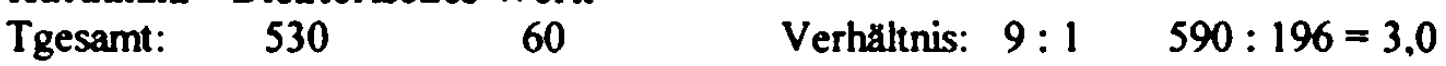

Puškin - Geschichtswerk

$\begin{array}{lrrrr}\text { T 1 } & 209 & 38 & \text { Verhăltnis: } 6: 1 & 247: 107=2,3 \\ \text { T 2 } & 317 & 83 & \text { Verhăltnis: } 4: 1 & 400: 170=2,3 \\ \text { T 3 } & 563 & 119 & \text { Verhăltnis: } 5: 1 & 682: 307=2,2\end{array}$

Pußkkin - Dichterisches Werk

$\begin{array}{lllll}\text { T 1 } & 237 & 30 & \text { Verhăltnis: } 8: 1 & 267: 124=2,2 \\ \text { T } 2 & 225 & 33 & \text { Verhăltnis: } 7: 1 & 258: 106=2,4 \\ \text { T 3 } & 331 & 46 & \text { Verhăltnis: } 7: 1 & 377: 152=2,5\end{array}$

a) Die Streuung ist bei Lomonosov und Karamzin beträchtlich: in Lomonosovs Geschichtswerk beträgt das Verhältnis in Tl und T3 jeweils $3: 1$, springt aber in T2 auf über das Doppelte (7:1). Bei Karamzin erreicht der Spitzemwert in Tl sogar das Dreifache wie in T3. Es ist offensichtlich, daß bei solchen Werten Mittelwerte nicht sinnvoll sind. Bei Puškin dagegen sind Mittelwerte durchaus angebracht, denn er zeichnet sich wieder einmal durch eine hohe Regelmäßigkeit aus. Bei ihm ist das Verhälınis von primären zu sekundären Prädikationen im Geschichtswerk mindestens $4: 1$ (Mittelwert $5: 1$ ); im dichterischen Werk mindestens $7: 1$ (Mittelwert ebenfalls $7: 1$ ). b) Die Werte liegen bei Lomonosov und Karamzin durchweg höher als bei Puskin. Im Schnitt verwendet Puškin pro Satz nur 2 Prädikationen. Lomonosov und Karamzin pro Satz 3 Prädikationen. 


\section{Prådikativitåt als Wortartenverteilung}

Die primăren und sekundăren Prădikationen bezeichneten nur die einzelnen Prädikationen, nicht aber den Gesamtanteil an Wörtern. Um diesen festzustellen, müssen wir die Wörter, die die prödikativen Verbalformen und Prädikativ ausmachen, zăhlen.

Beispiele (für primăre Prădikationen):

Он ... принудил нХ возвратиться Фрейман должен был преследовать Пугачева; ... 1 I $\quad$ - 3 Wörter Пугачев сам был ранен ... Дороги были непроходимы ${ }^{10}, \ldots$

Wortanteil der primären Prädikationen:

Lomonosov - Geschichtswerk

$\begin{array}{lccc}\text { T 1 } & 89 & 12,7 \% & \\ \text { T 2 } & 241 & 10,8 \% & \text { Mittelwert: } 11,7 \% \\ \text { T 3 } & 315 & 12,2 \% & \end{array}$

\begin{tabular}{lccc}
\multicolumn{4}{l}{ Karamzin - Geschichtswerk } \\
T 1 & 338 & $13,0 \%$ & \\
T 2 & 416 & $12,2 \%$ & Mittelwert: $12,9 \%$ \\
T 3 & 389 & $13,4 \%$ &
\end{tabular}

Karamzin - Dichterisches Werk

Tgesamt: $\quad 590 \quad$ Gesamtwert: $17,8 \%$

$\begin{array}{lccc}\text { Puškin - Geschichtswerk } & & \\ \text { T 1 } & 259 & 15,5 \% & \\ \text { T 2 } & 375 & 16,8 \% & \text { Mittelwert: } 16,6 \% \\ \text { T 3 } & 674 & 16,8 \% & \end{array}$

Puškin - Dichterisches Werk

$\begin{array}{llll}\text { T } 1 & 280 & 17,5 \% & \\ \text { T } 2 & 259 & 17,0 \% & \text { Mittelwert: } 17,4 \% \\ \text { T 3 } & 393 & 17,5 \% & \end{array}$

Der Wortanteil der primären Prädikationen hält sich weitgehend konstant. (Die Streuung beträgt bei Lomonosov 1,9\%; bei Karamzin 1,2\% und be: Puskin 1,3\% bzw. 0,5\%.)

\section{Vergleich der Mittełwerte}

Lomonosov: $\quad 11,7 \%$
Karamzin:
$12,9 \%$
$17,8 \%$
Pułkin:
$16,6 \%$
$17,4 \%$

${ }^{10}$ Das als Prådikatsnomen fungierende Adjektiv 'непроходимы' wird zu den Nomina gezăhlt (vgl. S.136). 


\section{Interpretation:}

Es gibt einen klaren Bruch innerhalb von Karamzin: 5\% Unterschied (ein Drittel mehr) zwischen seinem dichterischen Werk und seinem Geschichtswerk und ca. 4\% Unterschied (ein Viertel weniger) zwischen seinem und Puskins Geschichtswerk. Dagegen sind bei Lomonosov und Karamzin die Wortanteile der primăren Prădikation ziemlich gleich hoch. Oberraschend ist die hohe Obereinstimmung der Werte in den dichterischen Werken von Karamzin und Puskin: $17,4 \%$ gegenüber $17,8 \%$.

\section{Wortanteil der prim \ren und sekundăren Pradikation}

Lomonosov - Geschichtswerk

$\begin{array}{llll}\text { T } 1 & 110 & 15,7 \% & \\ \text { T } 2 & 276 & 12,4 \% & \text { Mittelwert: } 14,4 \% \\ \text { T } 3 & 410 & 15.9 \% & \end{array}$

Karamzin - Geschichtswerk

$\begin{array}{llll}\text { T } 1 & 374 & 14.4 \% & \\ \text { T 2 } & 469 & 13,8 \% & \text { Mittelwert: } 15,3 \% \\ \text { T } 3 & 518 & 17,9 \% & \end{array}$

Karamzin - Dichterisches Werk

Tgesamt: $652 \quad$ Gesamtwert: $19,6 \%$

Puškin - Geschichtswerk

$\begin{array}{llll}\text { T } 1 & 300 & 18,0 \% & \\ \text { T } 2 & 467 & 20.9 \% & \text { Mittelwert: } 19,8 \% \\ \text { T 3 } & 797 & 19.9 \% & \end{array}$

Puškin - Dichterisches Werk

$\begin{array}{llll}\text { T } 1 & 311 & 19,5 \% & \\ \text { T } 2 & 294 & 19,3 \% & \text { Mittetwert: } 19,6 \% \\ \text { T } 3 & 444 & 19,8 \% & \end{array}$

Die Sireuung wird großßer (bei Lomonosov 2.3\%; bei Karamzin 4,1\%), was aufgrund der ungleichen Verteilung der sekundären Prädikationen zu erwarten war.

Vergleich der Mittelwerte:

Lomonosov: $\quad 14,4 \%$

$\begin{array}{lll}\text { Karamzin: } & 15,3 \% & 19,6 \%\end{array}$

$\begin{array}{lll}\text { Puskin: } & 19,8 \% & 19,6 \%\end{array}$ 
Der klare Bruch bleibt bestehen. Die Obereinstimmung zwischen den dichterischen Werken erreicht einen identischen Wert, von dem auch der Wert fur Puskins Geschichtswerk nur ăußerst geringfügig abweicht. Letztlich erreicht der Wortanteil der primăren und sekundären Prádikation nahezu 20\% und liegt damit genau in dem Bereich, der durch andere Untersuchungen für das moderne Russisch festgestellt wurde" .

\section{Bewertung des Parameters d:}

Beim Wortanteil der primăren Prădikationen betrăgt die Streuung maximal 1,9\% (Lomonosov) bei einer Basis von ca. $11 \%$. Beim Wortanteil der primären und sekundären Prädikationen betrăgt sie maximal 4,1\% (Karamzin) bei einer Basis von $14 \%$. Trotz der letztgenannten hohen Streuung bei Karamzin verteilt sich dieser Parameter sehr regelmäßig in den verschiedenen Texten der Werke, so daß auch dieser Parameter seine Bedeutung als stilistischer Parameter unter Beweis gestelt hat ${ }^{12}$.

"So z.B. bei MARKOV $(1960,19)$, der in seiner Untersuchung zur Verteilung der Wortarten im modernen Russischen einen Anteil von 19,9\% an Verben, Partizipien und Adverbialpartizipien, die er nach rein morphologischen Kriterien zăhlt, feststelt. Vgl. hierzu KEMPGEN $(1995,37)$.

${ }^{12}$ Die große Bedeutung dieses Parameters für den Nachweis der Literatursprachlichkeit wurde von RAECKE (1997) aufgezeigt. 


\section{BESCHREIBENDE DARSTELLUNG}

Die quantitative Methodik, wie sie bei den vier Parametern angewandt wurde, soll nun durch eine beschreibende Darstellung ergänzt werden (vgl. 5.6). Trotz oder wegen all der Zahlen ergibt sich noch kein anschauliches Bild uber den Stil, da konkretes Textmaterial bisher nicht aufgezeigt wurde. 'Beschreibende Darstellung' bedeutet, daß an den Text selbst herangegangen wird, indem einzelne Sătze in Augenschein genommen werden. Dabei richten wir unser Augenmerk auf

a) wiederholte Satzbaustrukturen

und

b) vereinzelt vorkommende 'rhetorische' Satzbaustrukturen.

zu a):

Es wird versucht, die typischen Satzbauformen in den einzelnen Werken bzw. der Autoren festzumachen. Gleichzeitig sollen diese typischen Satzbauformen an konkreten Beispielen aus den Texten veranschaulicht werden. Das heißt, es geht nicht etwa um das Konstruieren eines abstrakten typischen Satzes (nach dem Vorbild der Generativisten etwa). sondern es soll an konkreten Beispielen die Fakultativităt des Satzbaus gezeigt werden. Letztlich gibt es ja keine zwei identischen Sătze; die einzige 'gleiche Satzbauform' wăre allenfalls in den Kurzsătzen zu finden, und zwar am ehesten bei den Sătzen mit 2 Wörtern, da es bei zwei Elementen $a b$ nur eine weitere Anordnung, nämlich $b a$ gibt.

Weiterhin muß auch bedacht werden, daß die Kategorien 'Einfachsatz', 'Satzreihe' und 'Satzgefüge' oft nur äußerliche Ähnlichkeit oder Gleichheit vortăuschen: z.B. unterscheidet sich ein Satzgefüge bei Lomonosov und Karamzin erheblich, obwohl beide vielleicht gleiche Wortanzahl aufweisen mögen und dadurch beim Parameter Satzkomplexităt durch unser grobes Raster dieselbe Einordnung erfahren. zu b):

Hier sollen diejenigen Satzbaustrukturen aufgefuhrt werden, die zwar vereinzelt auftreten, aber auch 'typisch' für den Autor sind, wenngleich in einem anderen Sinn wie unter a), nămlich insofern. als sich z.B. vor allem Lomonosov durch einige 'charakteristische' (rhetorische) Konstruktionen auszeichnet, die kaum mit dem bisherigen schematischen Inventar beschrieben werden konnten. sondern deren Struktur am besten 
an einzelnen Beispielen veranschaulicht wird. Öberhaupt werden hier vor allem Satzbaubeispiele von Lomonosov zu erwähnen sein, doch sollen (wann immer möglich) die Autoren miteinander verglichen werden, um auf diese Weise auch die Entwicklung der Stile zu exemplifizieren.

\section{a) zu den wiederholten Satzbaustrukturen}

\section{Geschichtswerke}

In den Geschichtswerken dominieren eindeutig die Aussagesătze; lediglich in Karamzins Einleitung treten auch einige Fragesătze auf. Inhaltlich betrachtet werden in den Einleitungen bestimmte Thesen vertreten oder wird gegen bestimmte Thesen argumentiert '.

Es sollen nun die bei der Untersuchung zur Satzkomplexităt gebrauchten Kategorien 'Einfachsatz', 'Satzreihe' und 'Satzgefüge' genauer betrachtet werden, wobei die durch den Parameter Prădikativităt gewonnenen Daten eine wertvolle Hilfestellung leisten.

\section{Einfachsatz:}

Bereits die Lănge des Einfachsatzes varïert bei den Autoren ${ }^{2}$ :

Lomonosov: Mittehwert: 15 Worter; Variationsweite: 3-68 Wörter

Karamzin: Mittehwert: 15 Worter; Variationsweite: 3-49 Worter

Puškin: $\quad$ Mittelwert: 11 Worter; Variationsweite: 2 - 47 Wörter

Bei Pusktin ist der Einfachsatz um 4 Worter, also um fast ein Drittel kürzer als bei den anderen Autoren.

Beispiel $^{3}$ für einen Einfachsatz mit 15 Wortern bei Lomonosov:

История, повсюду распростираясь и обращаясь в руках человеческого рода,

\footnotetext{
' Dies ist kein Argument dafür, daß wir diese Texte, d.h. die Einleitungen, hătten ausklammern sollen, denn sie sind sehr wohl historiographisch, das erzăhlende Moment tritt lediglich in den Hintergrund; wohlgegemerkt nur in den Hintergrund, denn die Auslegung der Thesen nimmt nur einen kleinen Teil der Texte ein und ist umgeben von Erzăhlung.

${ }^{2}$ Die einzelnen Durchschnittswerte sind folgende:

\section{Text 1 Text $2 \quad$ Text 3}

Lomonosov: 19 Wörter 15 Wörter 15 Wörter

Karamzin: 14 Wörter 13 Wörter 17 Wörter

Pư̌kin: 12 Worter 11 Worter 10 Worter

${ }^{3}$ Für dieses und die zwei folgenden Beispielsătze gilt: diese spezifische Satzlănge ist nicht am hăufigsten aufgetreten. Die Sătze wurden nur gewăhlt, weil sie am besten den Mittelwert veranschaulichen.
} 
стихия строгость и грызение древности презирает. (171) - Т $1\left(^{4}\right)$

Beispiel furr einen Einfachsatz mit 15 Wörtern bei Karamzin:

В самый первый век бытия своего

Россия превосходила обширностию едва-ли не все тогдашние государства Европейские. (158) - Т 1

Beispiel für einen Einfachsatz mit 11 Wörtern bei Puskin:

Из Москвы посланы были на Дон и на Яик увещевательные грамоты. (11) - T 1

Einfachsatze und primäre Pradikationen

Lomonosov (Geschichtswerk):

Das Pradikat besteht in Lomonosovs Einfachsătzen zum überwiegenden Teil (Text 1: 100\%: Text 2: 85\%; Text 3: 68\%) aus nur einer Prădikation. Nur in Text 3, der durch seine belebte Schilderung von Handlungen auffallt, gibt es einen größeren Teil an mehrgliedrigen Prådikaten: 21 Einfachsătze weisen hier jeweils 2 primăre Prădikationen auf (Beispiel:)

Держа в руке узду, побежсал по печенежскому стану

и спрашивал их языком о своей лошади. (238) - Т 3

und 5 Einfachsătze weisen in diesem Text sogar 3 primăre Prădikationen auf. Beispiele:

Сим подвигнута,

и святым крещением достигает Констанинова града, открывает свое желание царю и патриарху сочетавается христовой церкви, преименовавшись Еленою. (235 f.) - Т 3

Россияне с великим князем Святославом, услышав переезд греческого войска, соединили подданных себе болгар

и, присовокупив в сообщество печенегов и живших в западной Венгрии турков,

в трехстах осьмидесяти тысячах вошли во Фракию, опустошая все грабежом и пламенем,

и, ополчась станом при андрианопольских стенах, ожсидали к сражению случая. (241) - Т 3

И так Переяславец

и во имя Цимисхиево Иоаннополем 63st, обновлен проименован. (243) - Т 3

\footnotetext{
${ }^{4}$ Die Zahl in Klammer bezeichnet die Seitenzahl der russischen Primärliteratur.
} 


\section{Karamzin (Geschichtswerk):}

Auch bei Karamzin besteht das Prădikat in den Einfachsătzen zum überwiegenden Teil aus nur einer Prådikation (Text 1: 81\%; Text 2: 95\%; in Text 3 allerdings nur noch $51 \%$ ). Wie bei Lomonosov ist die Anzahl der Prädikationen sehr unregelmäßig verteilt und widerspiegelt vor allem den Inhalt der einzelnen Texte. Die Einfachsătze mit 2 primăren Prädikationen verteilen sich folgendermaßen:

$\begin{array}{lcc}\text { Text 1: } & 4 \text { Sătze } & (13 \%)^{3} \\ \text { Text 2: } & 1 \text { Satz } & (2 \%) \\ \text { Text 3: } & 18 \text { Sătze } & (33 \%)\end{array}$

Dagegen verhălt sich der Anteil an Einfachsätzen weitaus konstanter mit $32 \% ; 30 \%$; 45\%. Vor allem in Text 3 năhert sich Karamzin Puškin; dieser Text weist 7 Einfachsătze mit 3 primăren Prădikationen auf (Beispiele:)

Половцы во многих местах рассекли ограду, ворвались в улицы

и зажсли дома. (194) - Т 3

Там Император Мануил принял изгнанников с честию и с любовию; желал их утешить благодеяниями,

и das Васильку, по известию Российских и Греческих Летописцев, область Дунайскую. (197) - Т 3

sowie zwei Einfachsătze mit 5 primăren Prådikationen:

В самое то время

народ вламился во дворец, неволею послал Князя в Ладогу, залер жену в монастырь, разграбил казну, оковал дружину. (193) - Т 3

Имея не только доброе сердце, но и разум превосходный, он видел ясно причину государственных бедствий, и хотел спасти от них по крайней мере свою область:

то есть отменил несчастную Систему Уделов, кнгхсил единовластно, и не давал городов ни братьям, ни сыновьям. (196) - Т3

\footnotetext{
${ }^{3}$ Die Prozentangaben beziehen sich auf die Gesamtzahl der Einfachsätze in den betreffenden Texten.
} 


\section{Pußkin (Geschichtswerk):}

Auch bei Puskin besteht das Prådikat in Einfachsătzen zum überwiegenden Teil aus einer Pradikation (Text 1: 83\%; Text 2: 62\%; Text 3: 72\%). Allerdings liegen auch hier wieder die Werte in Puskins Texten năher beieinander als bei Lomonosov oder Karamzin. Der Anteil an Einfachsătzen mit 2 und 3 primăren Prădikationen entspricht grob dem von Karamzin. Weiter konstruiert Puškin 4 Einfachsătze mit 4 primăren Prädikationen (Text 1: 1 Satz; Text 2: 1 Satz; Text 3: 2 Sătze). Beispiele:

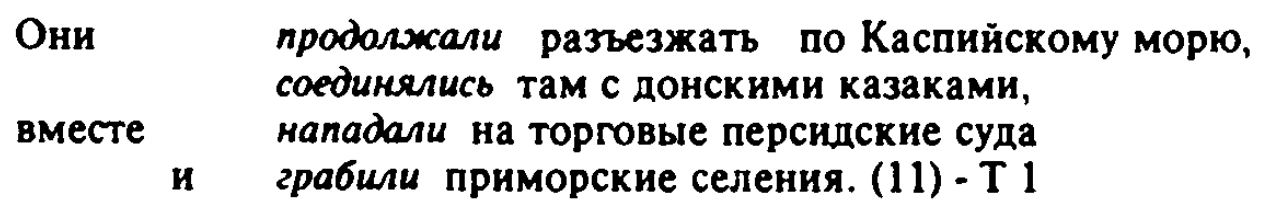

Комендант Верхо-Яицхой крепости, полковник Ступишин, вошел в Башкирию, скег несколько пустых селений

и, захватив одного из бунтовщиков, отрезал ему уши, нос, пальцы правой руки

и oтnycrun ero, грозясь поступить таким же образом со всеми бунтовщиками. (70 f.) - T2

und jeweils einen Einfachsatz mit 5 primären Prădikationen:

OH nошел на Цивильск, ограбил город, повесил воеводу

и, разделив шайку свою на две части, послал одну по Нижегородской дороге,

и а другую по Алатырской пресек таким образом сообщение Нижнего с Казанью. (88) - Т 3

bzw. 6 primären Prädikationen:
Но Михельсон
ударил на мятежников со всею своею конницею, рассеял их в одно мгновение, взял назад свои пушки,
a с ними и последнюю, оставшуюся у Пугачева после его разбития под Троицкой, в плен взял до пятисот и гнал остальных несколько верст. (74) - Т 2

Die erhöhte Prădikativität macht sich folglich bei Karamzin und Puškin bereits in den Einfachsătzen bemerkbar. 
Satzreihe und primäre Praddikationen

Lomonosov, Karamzin und Puškin (Geschichtswerke):

Die Satzreihe spielt bei Lomonosov eine untergeordnete Rolle. Wenn er sie verwendet, dann in einfachster Form, d.h. bei 2 primăren Prädikationen $H S$; $H S$ und allenfalls 3 primăre Prădikationen ${ }^{6}$. Bei Karamzin weisen viele Satzreihen auch noch 4 primăre Prădikationen auf (Text 1: 1 Satz; Text 2: 2 Sătze; Text 3: 5 Sătze). Bei Puškin geht diese Tendenz noch weiter:

$\begin{array}{lccc} & \text { Text 1 } & \text { Text 2 } & \text { Text 3 } \\ 4 \text { primăe Prădikationen } & 1 & 2 & 2 \\ 5 \text { primăre Prădikationen } & 1 & 2 & 1 \\ 6 \text { primăre Prädikationen } & 3 & 0 & 1\end{array}$

Beispiele aus Pư̧kins Geschichtswerk:

/ 4 HS; 4 primăre Prädikationen/

Дороги

люди

бьли непроходимы,

реки

ручьи вязли в бездонной грязи; разливались на несколько верст; становились реками. (71) - Т2

/ 3 HS; 5 primăre Prădikationen/

Kpenoctb

церковь

иконы

/ 3 HS; 6 primăre Prädikationen/

Его течение

мутные воды

берега большею частию но в местах поемных была разорена и вылскиена, разграблена, ободраны и разламаны в щепы. (72) - Т2

быстро, напалнены рыбою всякого рода; глинистые, песчаные и безлесные, удобные для скотоводства. (9) - Т1

$\mathrm{Zu}$ bemerken ist noch, daß bei Karamzin der Konstruktionstyp 'Satzreihe' auch oft in den Satzgefügen anzutreffen ist; nicht selten kommt es vor, daß auf mehrere (>2) parataktische Hauptsătze ein hypotaktischer Nebensatz kommt. Dabei kommt der Satztyp 2HS + INS sehr hăufig vor (Geschichtswerk: Text 1: 15 Sătze; Text 2: 18 Sătze ; Text 3: 13 Sătze).

\footnotetext{
${ }^{6}$ In diesem Falle liegt dann HS; HS; HS zugrunde oder HS; HS, wobei eines der beiden Prädikate 2 Prădikationen aufweist.
} 
Satzgefüge ' :

Lomonosov (Geschichtswerk):

Bei der Betrachtung der Verteilung von Satzgefugen bei Lomonosov ist es von Vorteil, den Charakter der Texte zu beachten:

T 1: Beschreibung; Programm des Geschichtsschreibers

T 2: Beschreibung von Zustănden; Zitienung ălterer Autoren

T 3: (eigenständige) Beschreibung von Handlungen

In Text 1 uberwiegt das Satzgefuge; dies ruhrt unmittelbar vom Inhalt her: Lomonosov spricht pathetisch von den Aufgaben und der Verpflichtung der Historiographie, wobei er sich auch polemisch mit den Meinungen deutscher Gelehrter (v.a. Maller / Normannentheoric) auseinandersetza. Die Einkeitung trăgt an dieser Stelle einen rhetorisch ausgeprăgten Charakter.

In Text 2 wendet sich Lomonosov der eigentlichen Geschichtsschreibung zu: dabei ist der Anteil an Satzgefugen beachtlich (50\%), was teilweise auch von der Tatsache herrührt, daß Lomonosov viele Zitate ăterer Autoren mit Hilfe indirekter Rede als Objektsätze anschließt.

In Text 3 gerăt die Handlung stărker in den Vordergnund (60\% Einfachsătze), wodurch sich Lomonosov auf Puskkin zubewegt: bei Puskin betrăgt der Mittelwert 68\% Einfachsätze im Geschichtswerk bzw. 61\% im dichterischen Werk. Allerdings unterscheiden sich die Einfachsătze Lomonosovs noch gewaltig von denen Puškins (Durchschnittslănge 15 Worter bei Lomonosov T 3 gegenäber dem Mittelwert 11 Worter bei Puskin). In Text 3 sind einige Stilverfahren, die Puskin noch ausbaut und verfeinert. schon bei Lomonosov angelegt: die Verwendung der Einfachsătze und die Mehrfach-Prădikation innerhalb eines einzigen Einfachsatzes.

\section{Karamzin (Geschichtswerk):}

Bei Karamzin zeichnen sich auch die komplexeren Satzgefuge durch einen immerpräsenten parataktischen Grundzug aus. Man kơnnte die Sătze als klotzartig nebeneinandergestelt bezeichnen; die Fuge zwischen den Klotzen wird bei Karamzin durch den Strichpunkt vertreten. Eine weitere Besonderheit des Karamzinschen Satzgefüges besteht

\footnotetext{
${ }^{7}$ Bei den Satzgefugen spielen die Prädikationen eine zweitrangige Bedeutung, sie werden daher hier nicht weiter behandelt.
} 
darin. daß innerhalb eines Satzgebildes mehrere einfache Satzgefuge aneinandergereiht werden, wobei die Komplexităt nicht erhőht wird, d.h. die Nebensătze bleiben ersten Grades ( z.B.: HS: ибо ...; HS, что ...).

Ein wichtiger stilistischer Kunstgriff bei Karamzin besteht in der syntaktischen Verwertung der Interpunktion: viele Doppelpunkte beinhalten einen Kausalităts- oder Finalitătsbezug, ohne daß eine explizite Kennzeichnung stattfindet. Damit verfügt Karamzin über folgende intertextuelle Bezugsmarkierungen:

a) explizite: Konjunktionen -- die Art der Unterordnung wird klar aufgezeigt;

b) implizife: Partizipien -- die Art der Unterordnung wird nicht năher spezifiziert; sie wird nur bei der Übersetzung ins Deutsche expliziert, wenn die Konstruktion mit Hilfe modaler Nebensătze aufgelðst wird;

c) graphische: $\quad$-- die Art der Unterordnung wird nicht năher spezifiziert.

Bei Lomonosov sind weit mehr hochgradige Satzgefüge (bis 4. Grad) anzutreffen. Bei ihm gibt es immer wieder Verschachtelungen, die sich nicht immer zwangsläufig aufgrund der Komplexităt des Sachverhattes ergeben, sondern die einfach den Willen zur Verschnörkelung und Verwebung offenbaren. Karamzin hingegen zeigt, daß Satzgefüge sehr wohl aufgebrochen werden konnen.

\section{Puð̌kin (Geschichtswerk):}

Wie schon unter Parameter b gezeigt, weist Puskin in seinem Geschichtswerk den niedrigsten Anteil an Satzgefugen im Vergleich zu allen anderen untersuchten Werken auf. Alle Satzgefüge sind nur ersten Grades (Beispiele:)

Близ устья оброс он высоким камышом, где кроются кабаны и тигры. (9) - Т1

Поселение казаков на бесхозяином Яике могло казаться завоеванием, коего важность была очевидна. (11) - Т1

oder mehrere Nebensătze, aber alle ersten Grades:

Нижегородский губернатор,

генерал-поручик Ступишин, писал к князю Волконскому, что участь Казани ожсидает и Нижний

и что он не отвечает и за Москву. (88) - Т3

Он

(как мы уже дабы оттуда пресечь дорогу Пугачеву в случае побега его на Иргиз. (91) - Т3 


\section{Dichterische Werke}

Durch den Ausschluß der wortlichen Rede dominieren auch in den untersuchten Texten der dichterischen Werke die Aussagesătze.

Bezuglich der Kategorien 'Einfachsatz', 'Satzreihe' und 'Satzgefuge' ist festzustellen:

Einfachsatz:

Die Lănge des Einfachsatzes variiert folgendermaßen ${ }^{8}$ :

Karamzin: Gesamtwert: 11 Worter; Variationsweite: 2 - 32 Wörter

Puß̌kin: $\quad$ Mittelwert: 9 Wörter; Variationsweite: 2 - 31 Wörter

Es handelt sich hier eindeutig um gleiche Größenordnungen; die Variationsweite ist uberraschend gleich breit.

Beispiel fur cinen Einfachsatz mit $1 /$ Wortem bei Karamzin:

Всякое лето нахому новые приятные места или в старых новые красоты. (23)

Beispiel für einen Einfachsatz mit 9 Wörtern bei Puskin:

Надели на меня заячий тулуп, а сверху лисью шубу. (290) - Т 1

\section{Einfachsätze und primäre Prädikationen:}

\section{Karamzin (Dichterisches Werk):}

Das Prädikat besteht in Karamzins Einfachsätzen zum uberwiegenden Teil (67\%) aus nur einer Prădikation. 14 Einfachsätze weisen 2 primăre Prădikationen auf; 5 Einfachsätze 3 primăre Prädikationen; 4 Einfachsătze 4 primäre Prädikationen und 2 Einfachsätze 5 primăre Prädikationen. Im großen und ganzen entspricht die Struktur des Einfachsatzes im dichterischen Werk der Struktur in den historiographischen Texten, allerdings wird ein höheres Maximum erreicht, nămlich 2 Einfachsătze mit sogar 6 primären Prädikationen. Beispiel:

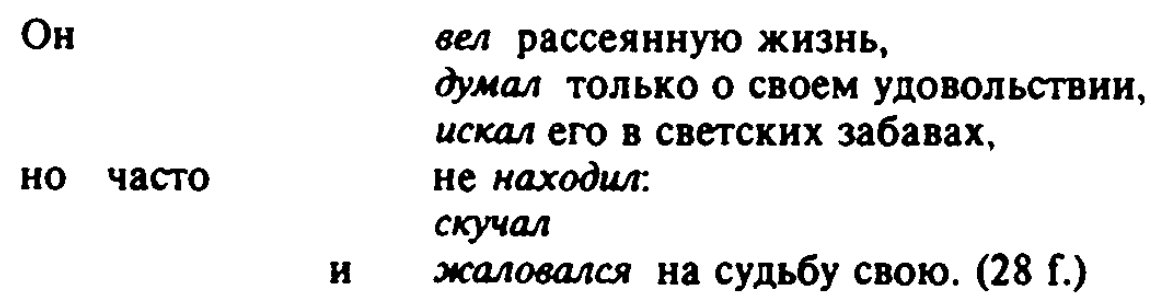

\footnotetext{
${ }^{8}$ Der einzelne Mittelwert betrăgt bei Puskin in allen 3 Texten jeweils 9 Wörter.
} 


\section{Puškin (Dichterisches Werk):}

Wie in seinem Geschichtswerk besteht auch in Puškins dichterischem Werk das Prädikat in den Einfachsătzen zum überwiegenden Teil aus nur einer Prädikation (Text 1: 72\%; Text 2: 72\%; Text 3: 71\%). Überraschend ist wieder einmal bei Puskin die hohe RegelmäBigkeit der Verteilung. Allerdings sind in den dichterischen Texten 4 primăre Prädikationen das Maximum (nur 2 Einfachsätze in Text 1; in Text 2 und Text 3 sind 2 bzw. 3 primäre Prădikationen das Maximum).

Beispiel fur einen Einfachsatz mit 4 primăren Prădikationen:

Увидя мои упряжнения в географии,

\begin{tabular}{|c|c|}
\hline $\begin{array}{l}\text { батюшка } \\
\text { потом }\end{array}$ & $\begin{array}{l}\text { дернул меня за ухо, } \\
\text { подбежсал к Бопре. } \\
\text { разбудил его очень неосторожно } \\
\text { стал осыпать укоризнами. }(288)-\mathrm{T}\end{array}$ \\
\hline
\end{tabular}

Der Satzbau unterscheidet sich in den dichterischen Texten nicht strukturell von dem in den historiographischen Texten; die Kürze wird in erster Linie durch die personelle Finitheit der Verben und die dadurch bedingte Handlungskonzentration verursacht.

\section{Satzreihe und primäre Praddikationen:}

\section{Karamzin (Dichterisches Werk):}

Wie in seinem Geschichtswerk gibt es auch in Karamzins dichterischem Werk Satzreihen mit 4 primăren Prädikationen (insgesamt 4 Satzreihen): Beispiel:

$\mathrm{OH}$

$$
\begin{aligned}
& \text { тамится, } \\
& \text { вянет, } \\
& \text { сохнет - }
\end{aligned}
$$

и унылый звон колокола возвещает мне безвременную смерть его. (25)

Ebenso viele Satzreihen weisen 5 primăre Prădikationen auf. Folgende zwei je nur einmal auftauchenden Erscheinungen stechen ins Auge und stellen gleichzeitig einen dramatischen Hohepunkt in dem Werk dar:

a) eine Satzreihe mit 7 primären Prädikationen:

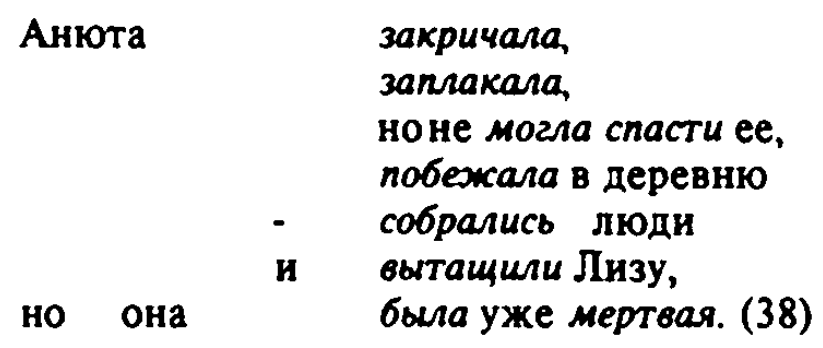


b) eine Satzreihe mit sogar 12 primären Pradikationen:

Она

- и в сей час

Эраст

- никогда Лиза

- никогда ласки ее

- никогда еe поцелуи

- она ничего ничего ничего

- мрак вечера

- ни одной звездочки

- никакой луч бросилась в его обьятия надлежало погибнуть непорочности !чувствовал необыкновенное волнение в крови своей не казалась ему столь прелестною не трогали его так сильно не были столь пламенны не знала, не подозревала, не бorracb питал желания не сияло на небе не мог осветить заблуждения. (33)

In beiden Fallen faßt Karamzin entscheidende Momente der Erzählung anschaulich in einen einzigen Satz und veranschaulicht damit die hohe Dichre des Handlungsablaufs.

\section{Puškin (Dichterisches Werk):}

Puskin dagegen setzt in seinem dichterischen Werk die Satzreihe weniger dramatisierend ein. Gab es in seinen historiographischen Texten noch etliche Satzreihen mit 4 und mehr primären Prădikationen. so stellt in seinen dichterischen Texten nur eine Satzreihe mit 4 primăren Prădikationen (Text 2) das Maximum dar:

\section{В крепости между казаками во всех улицах они Thxo}

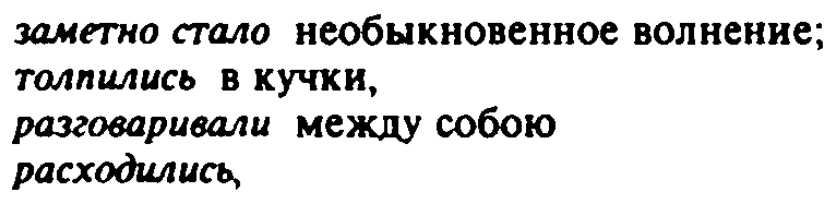

и

увидя драгуна или гарнизонного солдата. (331) - Т 2

\section{Surzgefüge und primäre Prädikationen:}

\section{Karamzin (Dichterisches Werk):}

Wie schon in seinen historiographischen Texten beobachtet, so zeichnen sich auch im dichterischen Werk die Satzgefüge durch einen parataktischen Grundzug aus: das Satzgefüge, das die meisten (nämlich 11) primäre Prädikationen aufweist, gleicht eigentlich weitgehend der oben vorgestellten Satzreihe:

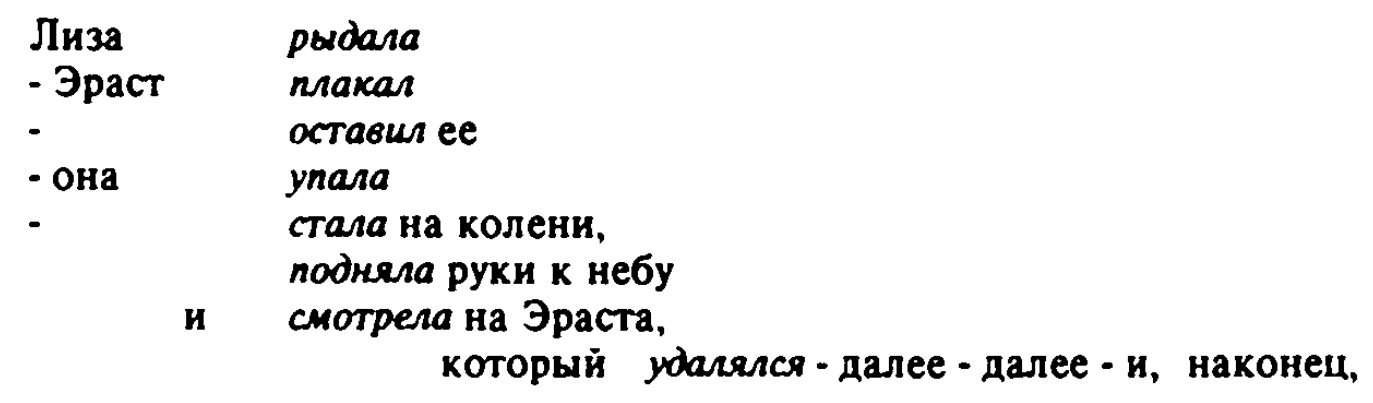


скрылся, воссияло солнце,

и Лиза, оставленная, бедная, лишилась чувств и памяти. (36)

Durch den hohen Anteil an Pradikationen wirkt der Satz aufgelockert; das Satzgefüge (der Nebensatz) kommt kaum zur Geltung.

\section{Pußkin (Dichterisches Werk):}

Wie schon unter dem Parameter Satzkomplexităt beobachtet, treten im dichterischen Werk Puskins die komplexeren Satzgefuge auf. Bemerkenswert ist, daß bei ihm selbst die Satzgefüge noch von der hohen Prädikationsdichte geprăgt werden. Die Prădikationen 'übertonen' damit gewissermaßen die Ordnungshierarchie des Satzgefüges.

\section{Beispiele:}

a) Satzgefüge mit 7 primăren Prädikationen:

\section{Когда ж один из инвалидов \\ и, положив их себе охоло шеи, а Юлай}

- тогда башкирец и, кивая головою, в котором вместо языка 638л его руки

подиял стариха на свои плечи, 63я плеть

и замахнулся, застонал слабым, умоляюшим голосом открыл рот, шевелился короткий обрубок. (334) - Т 2

Puskin vermeidet jegliche Umklammerung, die Hierarchie des Satzgefüges ist linear auflosbar.

b) Satzgefüge mit 9 primären Prädikationen:

Она

В котором часу государыня обыкновенно просыпалась, куишала кофей, прогуливалась;

какие вельможи находились в то время при ней;

что изволила она вчерашний день говорить у себя за столом, коro принимала вечером, - словом, разговор Анны Власьевны стоил нескольких страниц исторических записок и был бы драгоченен для потомства. (396) - Т 3

Dieses Satzgefüge bleibt durchgehend ersten Grades; durch die lineare Anordnung der Nebensätze wird Komplexitä vermieden. 
b) zu den vereinzelt vorkommenden Satzbaustrukturen ('Rhetorische Elemente')

Im folgenden werden stellvertretend Beispiele fur die entsprechenden rhetorischen Konstruktionen angefuhrt. Es soll dabei, im Gegensatz zum statistischen Teil, keine erschð̈pfende Erfassung angestrebt werden, jedoch spiegelt die Zahl der Beispiele ihre Hăufigkeit in den Texten wider.

1) Spannungsbogen:

Lomonosov - Beispiel 1:

Hapod российскuй

от времен,

глубокою древностию сокровенных,

до нынешнего веку

толь многие
в н д е л в счастии своем перемены [...] (169) - Т 1

Man sieht hier deutlich, welchen Spannungsbogen Lomonosov aufmacht: zwischen dem Subjekt und dem P r a d i k a t wird die erste Zeitangabe, eine partizipiale Apposition. eine zweite Zeitangabe und der erste Teil des gesplitteten Objekts untergebracht: Distanz: 10 Wörter.

Lomonosov - Beispiel 2:

Возрастая до толикого величества

Poccus

и восходя чрез сильные и многообразные препятства

коль многие деяния и приключения

да т в могла писателям [...] (170) - Т 1

Das Subjekt wird von zwei Adverbialpartizipien eingerahmt; außerdem steht das Objekt vor dem P r a dik a t (SOV); Distanz: 12 Wørter.

Lomonosov - Beispiel 3:
Ольга,
видя довольные опыты способности своего сына
ко владению Российским государством, с к л о и л а с ь желанием к
покою [...] (235) - Т 3

Sperrung durch ein eingeschobenes Adverbialpartizip; Distanz: 10 Worter.

Lomonosov - Beispiel 4:

Oт сето не токмо многих сел, но рек и городов и целых областей

чудские имена в России, особливо в восточных и северных краях, поныне оста л и с ь . (173) - Т 2

Gemäß Definition (S.129) handelt es sich in beiden Sătzen um SV(O) mit Einschüben. die wegen ihrer Lange als rhetorisches Stilmittel angesehen werden müssen (im modernen Russischen würde die Spannung sofort aufgelöst werden); Distanz: 9 Wōrter. 
Lomonosov - Beispiel 5:

Древние внешние авторы скифов и сармат, на разные поколения разделенных, под разными именованиями в ней п о л а г а ю т . (173) - Т 2

Eingeschoben wurde das Objekt, eine partizipiale Apposition und eine Umstandsbestimmung; Distanz: 12 Worter.

Lomonosov - Beispiel 6:

Мномество и величество городов

хотя тогда не таково было, как ныне, однако же весьма 3 н а т н о . (175) - Т 2

Zwar könnte man den eingeschobenen adversativen Nebensatz auch im modernen Russischen noch antreffen, doch umspannt das Subjeta und das $\mathrm{P}$ r a d i k a $t$ den ganzen Satz; Distanz: 10 Worter.

\section{Lomonosov - Beispiel 7:}

Кроме славян,

особенно именованных, вендов и антов, сверх Сармации,

где в половине шестого веку Лех и Чех державствовали

над многочисленным славенским народом,

балгары [...] (177) - T 2

д о к а 3 ы в а ю т его тогдашнюю великость

Hier wird die Spannung dadurch erzeugt, daß P r ă d i k a und Subjekt am Schluß und umgestellt stehen. Dem $P$ r $a d i k$ a $t$ gehen 22 Worter voran, und erst nach weiteren drei Wortern (dem Objekt) folgt schließlich das Subjekt.

Lomonosov - Beispiel 8:

По сем россияне, по желанию своего князя, для великой удобности мест владение и пребывание свое на Дунае утвердить в намерении п $о$ л $о$ ж и л и . (240 f.) - Т 3

Die Distanz von Subjekt zu P r ă d i k a t betrăgt 17 Worter.

Lomonosov - Beispiel 9:

Свигељ, первый его военачальник

и в Переяславце градодержатель,

отвращая опасность от города, ворота 3 a п е p $[\ldots](242)$ - Т 3

Distanz: 12 Worter; verursacht durch zwei Appositionen, ein Adverbialpartizip und das Objekt.

Karamzin - Beispiel 1:

История, отверзая гробы, поднимая мертвых, влагая им жизнь в сердце и слово в уста, из тления вновь созидая царства,

и представляя воображению ряд веков с их отличными страстями, нравамн, деяниями, р а с ш и р я е т пределы нашего собственного бытия [...] (XVIII) - T 1 
Zwischen Subjekt und P r a d i a t wurden 5 partizipiale Umstandsbestimmungen gezwängt. Allerdings bleibt durch die Wiederholung des Strukturelementes Adverbialpartizip die Konstruktion leicht durchschaubar.

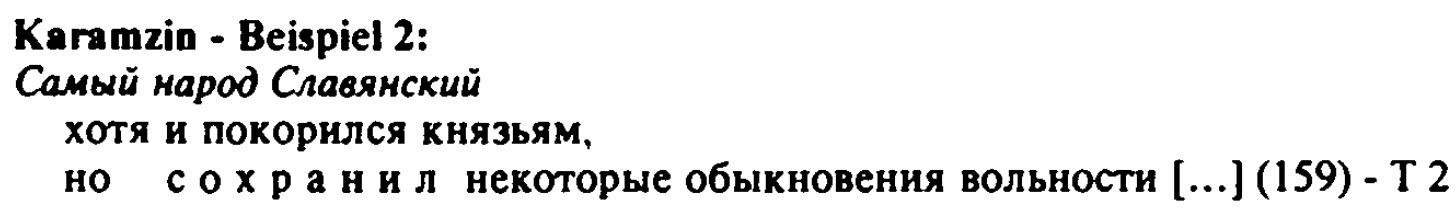

Der adversative Nebensatz verursacht bei Karamzin nur eine Distanz von 6 Wortern. wohingegen die gleiche Konstruktion bei Lomonosov - Beispiel 6 eine Distanz von 10 Wortern aufwies. Man kann daher bei Karamzin kaum mehr von einem Spannungsbogen sprechen.

\section{Zu den Spannungsbogen bei Karamzin und Lomonosov:}

Bei Lomonosov treten bedeutend mehr Spannungsbogen auf als bei Karamzin. Die Spannungsbogen sind bei Lomonosov syntaktisch verwoben. wohingegen bei Karamzin selbst lange Bogen wie in Beispiel 1 immer noch klar und durchsichtig wirken. weil bei ihm die Konstruktion die Syntax unangetastet läßt und in den Satz blockartig eingebaut wird: Meist greift Karamzin zum Parallelismus bzw. zur Satzgliedwiederholung; in Beispiel 1 erhalten die Adverbialpartizipien einen Rhythmus, der es leicht macht, die Umstandsbestimmung getrennt vom Subjekt zu erkennen. Die Einrahmung des Subjekas bei Lomonosov wie in

\section{Lomonosov - Beispiel 2:}

Возрастая до толикого величества

Poccus

и восходя чрез сильные и многообразные препятства [...]

sowie eigentlich sămtliche Spannungsbogen bei ihm scheinen eher auf lautes Deklamieren mit entsprechender Herausarbeitung des Subjektes angewiesen als auf das stille Lesen ausgerichtet zu sein; doch kann dieser Aspekt innerhalb dieser Untersuchung nicht weiter verfolgt werden. Einige Konstruktionen werden von beiden Autoren benutzt, allerdings verst $\varnothing B t$ Karamzin nie gegen die SVO-Ordnung. wohingegen dies offensichtlich von Lomonosov als freie Stilmøglichkeit angesehen wird.

\section{2) Parallelismus:}

Lomonosov - Beispiel 1:

Каждому несчастию последовало каждому упадку

Die Ordnung OSV wird parallel aufgebaut. благополучне большее прежнего, высшее восстановление [...] (169) - Т 1 
Lomonosov - Beispiel 2:

Наконец, она дает

государям примеры правления,

подданным - повиновения,

воинам - мужества,

судиям - правосудия,

младым - старых разум,

престарелым - сутубую твердость в советах

каждому незлобивое увеселение,

с несказанною пользою соединенное. (171) - Т 1

Das Dativ- und Akkusativobjekt der prădikativen Verbalform wird siebenmal variiert.

Karamzin - Beispiel 1:

Всемирная История великими воспоминаниями у к а ш а е т мир для ума, а Российская

ук р а ш а е т отечество [...] $(\mathrm{XIX}) \cdot \mathrm{T} 1$

Karamzin wiederholt sogar die gleiche pradikative Verbalform (у к р а ш а е т).

\section{Karamzin - Beispiel 2: \\ Не удивительно-ли,}

как земли, разделенные вечными преградами естества, нензмеримыми пустынями и лесами непроходимыми, хладными и жаркими климатами;

как Астрахань и Лапландия, Сибирь и Бессарабия, могли составить одну державу с Москвою ? (XIX) - T 1

Die Subjektsglieder sind durch die Partikel (kak) parallel aufgebaut.

Karamzin - Beispiel 3:

Подобно Америке Россия

имеет своих диких;

подобно другим странам Европы являет плоды долговременной гражданской жизни. (XIX) - T 1

Als Hauptsatzeinleitung wird zweimal die Partikel (подобно) verwendet.

Karamzin - Beispiel 4:

С умилением смотрим на Агриппину, несушую пепел Германика;

с жалостию на рассеянные в лесу кости и доспехи Легиона

с ужасом на кровавый пир неистовых Римлян, Bapoвa;

с омерзением освещаемых пламенем Капитолия; на чудовище тиранства, пожирающее остатки Республиканских добродетелей в столице мира [...] (XXI) - T 1

Wie durch die Darstellung sichtbar wird, ist die vierfache Parallelităt dieser Konstruktion ausgewogen angelegt. 
Karamzin - Beispiel 5:

Не дозволяя себе никакого изобретения,

я uскал выражений в уме своем, а мыслей единственно в памятниках;

искал духа и жизни в тлеющих хартиях;

желал преданное нам веками соединить в систему, ясную стройным

изображал не только бедствия и славу войны, но и все, сближением частей;

что входит в состав гражданского бытия людей:

успехи разума, искусства, обычаи, законы, промышленвость;

не боялся с важностию говорить о том, что уважалось предками;

хотел, не изменяя своему веку, без гордости и насмешек описывать века душевного младенчества, легковерия, баснословия;

хотел представить и харахтер времени и характер летописцев:

ибо одно казалось мне нужным для друтого. (XXVI) - T 1

Die jeweils zweimal gebrauchten Verben des Suchens (uckan) bzw. des Wünschens (xoren) erzeugen eine Parallelităt sowohl auf formaler als auch auf inhalticher Ebene. Die 7 Hauptsătze werden eingerahmt von einer adverbialen Partizipialkonstruktion und einem kausalen ибо-Satz.

Karamzin - Beispiel 6:

Мы одно любим,

одного желаем:

любим отечество;

желаем ему благоденствия еще более, нежели славы;

желаем,

$d a$ не изменится никогда твердое основание нашего величия;

da правила мудрого самодержавия и святой веры более и более

да цветет Россия [...] (XXVIII) - T 1

укрепляют союз частей;

Karamzin benutzt zweimal die gleiche pradikative Verbalform (любим), dreimal die gleiche prădikative Verbalform (желаем) und dreimal die gleiche Nebensatz-Einleitung (da).

Karamzin - Beispiel 7 (Dichterisches Werk):

Она

- н в сей час

бросилась в его обьятия

Эраст

- никогда Лиза

надлежало погибнуть непорочности !-

чувствовал необыкновенное волнение в крови своей

не казалась ему столь прелестною

- никогda ласки ее

не трогали его так сильно

- никогда ее поцелуи

- она ничего

ничего

ничего

не были столь пламенны

не знала,

не подозревала,

не боялась

- мрак вечера

- ни одной звездочки

- никакой луч

питал желания

не сияло на небе

не мог осветить заблуждення. (33)

Die parallelen Konstruktionen sind in diesem Satz symmetrisch um die zwei Dreiergruppen ( $3 \mathrm{mal}$ нuкогdx; $3 \mathrm{mal}$ нuчеzo) angelegt. 
Zum Parallelismus bei Lomonosov und Karamzin:

Karamzin konstruiert weitaus mehr Sătze parallel als Lomonosov. Dabei ist zu bemerken, daß diese Konstruktionen aufgrund der ihnen eigenen Symmetrie selbst bei großer Extension immer noch durchschaubar bleiben. Aus diesem Grunde schadet es auch nicht dem dramatischen Handlungsfluß in Karamzins dichterischem Werk, wenn er hier ebenfalls den Parallelismus anwendet.

3) Häufung (Satzgliedreihe):

\section{Lomonosov - Beispiel 1:}

Ни многие обозы с запасами или с орудиями, к приутотовлению пищи нужными,

ни шатры,

ни постели к упокоению тягостию не препятствовали быстрым походам.

Das Satzglied Subjekt wird dreimal spezifiziert.

Karamzin - Beispiel 1:

Знание всех прав на свете, ученость немецкая, остроумие Вольтерово, ни самое глубокомыслие Макиавелево в историке не заменяют таланта изображать действия. (XXIV) - T 1

Vier Subjektsglieder werden aneinandergereiht.

\section{Karamzin - Beispiel 2:}

Дела их были подсудны одним епископам:

также весы и мерила городские, распри и неверность супругов, браки незаконные, волшебство, отравы, идолопоклонство, непристойная брань, злодейства детей в отношении к отцу и матери, тяжбы родных, оскверение храмов, церковная татьба, снятие одежды с мертвеца, и проч. и проч. (161) - Т 2

Das Subjekt (Дела) wird mit zwölf Nominalgliedem expliziert, allerdings erst nachdem das Prădikat genannt wurde, wodurch ein Spannungsbogen vermieden wird.

\section{Zur Haufung bei Lomonosov und Karamzin:}

Die Hăufung wird von beiden Autoren verwendet; auch diese Satzkonstruktion laßt den Satzbau durchsichtig bleiben. 
4) Rhetorische Konstruktionen bei Lomonosov:

Subjekt ganz am Schlu B:

В отсутствие великого князя Святослава на Дунае

печенеги. (238) - Т 3

пришли на Россию

\section{Chiasmus:}

Н а ч и н а ют с я народы, когда другие р а с сы п а ют ся $[\ldots](170) \cdot$ Т 1

$\mathrm{Zu}$ den rhetorischen Konstruktionen wären auch alle gesplitteten Ordnungen (siehe Parameter c) und etliche komplexe Satzgefuge (siehe Parameter b) zu zathlen. wobei aber nicht immer eine übermaßig verwobene Satzkonstruktion durch den Begriff 'rhetorische Konstruktion erklart werden kann.

(Es wurden bisher keine Satzbeispiele von Puskin aufgezeigt. Dies hat seinen Grund darin. daß sich bei ihm kaum rhetorische Konstruktionen finden lassen; weder solche, die eine großßere Komplexităt und Unübersichtlichkeit aufweisen, noch solche, die wie die Parallelismen durchsichtig bleiben, aber dennoch einen gewissen rhetorischen Glanz verbreiten. Es kommt hier offensichtlich das Ideal Puskins zum Tragen, einen einfachen Stil zu schreiben und jeglichen Schnorrkel zu vermeiden.)

\section{5) Langster Satz:}

Die überlangen Sătze (über $\mathbf{4 0}$ Worter) stellen je nach Autor und Text einen Anteil von $1 \%$ (Puškin) bis $16 \%$ (Karamzin) dar. Es würde zu weit führen. jeden dieser Sătze aufzuführen. exemplarisch aber soll jeweils der längste Satz, der in den untersuchten Texten der einzelnen Werke auftrat, aufgezeigt und beschrieben werden.

Långster Satz in den untersuchten Texten von Lomonosovs Geschichtswerk: 94 Wörter

Толикие перемены в деяниях российских: соединение разных племен под самодержавством первых князей варяжских, внутренние потом несогласия, ослабившие наше отечество, наконец, новое совокупление под единоначальство и приобщение сильных народов на востоке и на западе рассужсдая, порядок оных подобен течению великой реки п ред с т а в я ю,

которая, от источников своих по широким полям распростираясь иногда в малые потоки разделяется и между многими островами теряет глубину и стремление; но, паки соединясь в одни береги, 


$\begin{array}{cl}\text { вящую быстрину и великость } & \text { приобретает; } \\ \text { потом присовокупив в себя иные великие от сторон реки, } \\ \text { чем далее } & \text { протекает, } \\ \text { тем обильнейшими водами } & \begin{array}{l}\text { разливается } \\ \text { умножает свои силы. (169) - Т } 1\end{array}\end{array}$

Die ersten 33 Worter stellen das Objekt zu dem Adverbialpartizip (paccyscdas) dar; die Nennung des Objekts an erster Stelle bzw. die Finalstellung des Partizips sorgen dafur, daß ein sehr großer Spannungsbogen aufgetan wird. Auch das Objekt zu (n p e д c т aв л я ю) geht diesem voraus. Der durch (которая) eingeleitete Relativsatz umfaßt 55 Worter. Allerdings wird er durch 9 Prädikationen aufgeteilt, so daß Lomonosov im zweiten Teil des Satzes eine gewisse Auflockerung erzieit. Im Grunde genommen wechselt der Rhythmus des ersten Teils des Satzes zum zweiten Teil. Es ist aber gerade dieser Rhythmuswechsel um die Verbalform ( seinen rhetorischen Glanz. verleiht.

$\mathrm{Zu}$ beachten ist, daß der Satz beim lauten Vorlesen schneller verständlich ist, weil dann durch die Intonation die Umkehrungen (Objekt vor Adverbialpartizip bzw. finitem Verb) besser klar gemacht werden konnen. Im Grunde wird damit erneut deutlich, wie bei Lomonosov die Prosa noch auf der Schwelle von lautem Vortrag, der von der Deklamation der Versdichtung als alleiniger Vertreter der schøngeistigen Literatur herrihrte, und stillem Lesen steht.

\section{Langster Satz in den untersuchten Texten von Karamzins Geschichtswerk:}

\section{Worter}

Не дозволяя себе никакого изобретения,

я искал выражений в уме своем, а мыслей единственно в памятниках;

искал духа и жизни в тлеющих хартиях;

желал преданное нам веками соединить в систему, ясную стройным

изображал не тольхо бедствия и славу войны, но и все, сближением частей;

что входит в состав гражданского бытия людей:

успехи разума, искусства, обычаи, законы, промышленностъ;

не боялся с важностию говорить о том, что уважалось предками;

xотељ, не изменяя своему веку, без гордости и насмешек описывать века душевного младенчества, легковерия, баснословия;

хотел представить и характер времени и характер летописцев:

и6о одно хазалось мне нужным для друтого. (XXVI) - T 1

(Auch unter Parallelismus als Karamzin - Beispiel 5 auf S.160 aufgefuhrt.)

Obwohl der lăngste Satz bei Karamzin sogar 3 Worter mehr als Lomonosovs längster Satz aufweist, ist er entscheidend ubersichtlicher gebaut. Die bereits beschriebenen Parallelismen gliedem den Satz in uberschaubare Einheiten und machen dadurch das gesamte Satzgebilde leicht linear verstandlich und damit lesefreundlich. 
Langster Satz in den untersuchten Texten von Pußkkins Geschichtswerk:

56 Worter

Яик, по указу Екатерины II переименованный в Урал,

выходит из гор, давших ему нынешнее его названне;

течет $к$ югу вдоль их цепи, до того места,

где некогда положено было основание Оренбургу

и где теперь находится Орская крепость;

тут, разделив каменистый хребет их, поворачивает на запад и,

протекши более двух тысяч пятисот верст,

впадает в Кастийское море. (9) - T 1

Trotz der partizipialen Einschabe (переименованный, давших, разделив, протекии) und der zwei Relativsătze bleibt der Satz abersichtlich.

Langster Satz in Karamzins dichterischem Werk:

\section{Worter}

Она

- и в сей час

Эраст

- никогda Лиза

- нuкоzda ласки еe

- нuкоzda еe поцелуи

- она ничего

ничего

ничего

бросилась в его обьятия

надлежало погибнуть непорочности !-

чувствовал необыкновенное волнение в крови своей

не казалась ему столь прелестною

не трогали его так сильно

не были столь пламенны

не знала,

не подозревала,

не боялась

- мрак вечера

питал желания

- ни одной звездочки

не сияло на небе

- никакой луч

не мог осветить заблуждения. (33)

(Auch unter Parallelismus als Karamzin - Beispiel 7 auf S.160 aufgeführt.)

Die Überschaubarkeit dieses Satzes wird bereits durch die Darstellung deutlich gemach. Der Gedankenstrich sorgt für Zasuren, die den Satz in klare Handlungsschritte und damit Verstăndniseinheiten unterteilen.

\section{Lxingster Satz in den untersuchten Texten von Puškins dichterischem Werk:}

\section{Worter}

я

имя Марьн Ивановны

оттого ли,

что самолюбие его страдало при мысли о той, которая отвергла его с презрением;

оттого ли,

что в сердце его таилась искра того же чувства, которое и меня заставляло молчать, -

как бы то ни было,

имя дочери белогорского коменданта не было произнесено в присутствин комиссии. (393) - Т 3 
Zwar weist der Satz zweimal zweifache Hypotaxe auf, doch erstens ist diese in beiden Fallen symmetrisch gebaut (mit denselben Konjunktionen und fast den gleichen Nebensatzlängen, nămlich 8:5 und 9:5 Worter), und zweitens ist die Hypotaxe linear angeordnet und nicht etwa eingeschachtelt. Auf diese Weise bleibt selbst dieser für Puskin untypisch hochkomplexe Satz viel durchsichtiger, als es ein Satz vergleichbarer Komplexitătsstufe bei Lomonosov wäre.

\section{6) Kürzester Satz:}

Nachdem die lăngsten Sătze betrachtet wurden, seien nun auch noch die kürzesten angefuhrt: bei Lomonosov bestand der kürzeste Satz aus 3 Wortern: Coгласовался Курций, Солин. (179) - T2 : er stellt aber eine Ausnahme dar. Ähnlich verhălt es sich in Karamzins Geschichtswerk. Dabei ist allerdings ein historiographischer Lakonismus zu erwăhnen, wenn es um die Beschreibung von Schlachten geht, und der zwar bei Lomonosov und Karamzin nur einmal auftaucht, aber von Puskin weiter entwickelt wird:

Сразились обои войска жестоко.

Тут началось сражение.

Сражение было некзбежимо.

Произошло сражение.

Ночь прекратила сражение.

Сражение завязалось.

Сражение продолжалось недолго.
(242) Lomonosov - T 3
(194) Karamzin - T 3
(76) Puskin - T 2
(78) Puskin - T 2
(94) Puskin - T 3
(95) Puškin - T 3
(96) Puskkin - T 3

Überhaupt wird diese Art von Lakonismus von Puðkin oft verwendet. So entstehen auch andere Kurzsatze in dieser Art:
Казаки волновались.
(14) - T 1
Мятежники торжествовали.
(15) - T 1
Недостовало предводителя.
(15) - T 1
Предводитель сыскался.
(16) - T 1
Диц был убит.
(95) - T 3
Остальные рассеялись.
(96) - T 3

Die kürzesten Sătze in den dichterischen Werken sind folgende:
Хижина опустела.
Karamzin (39)
Савельич заплакал.
Puskin
(293) - T 1
Урядник усмехнулся.
Puskin
(329) - T 2
Начался допрос.
Puskin
(391) - T 3 
1 s.

1) = P. 5.

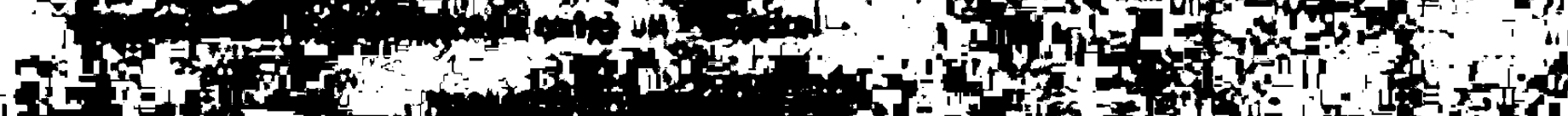
10

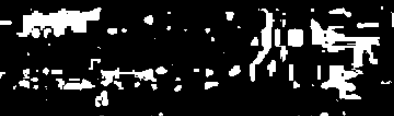
(N)

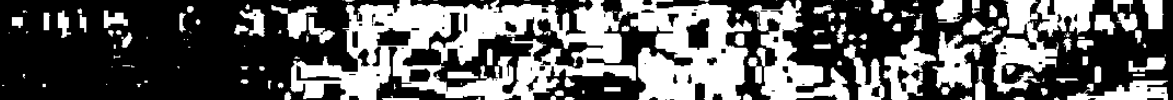

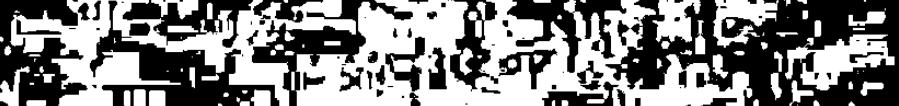
inting

$40+4$

$=0$

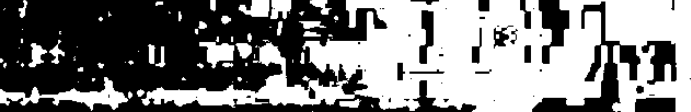

17

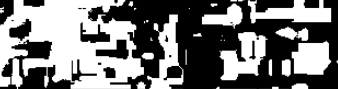

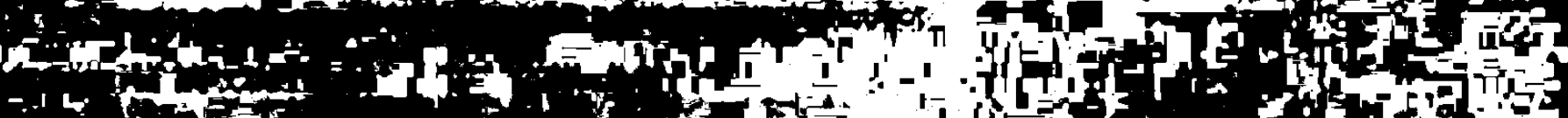

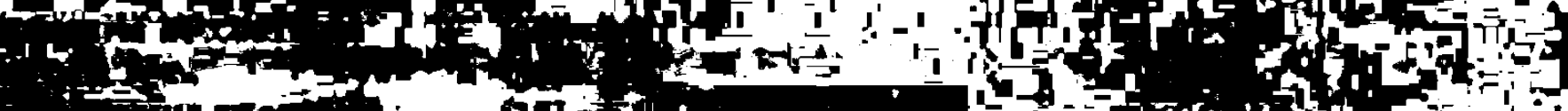

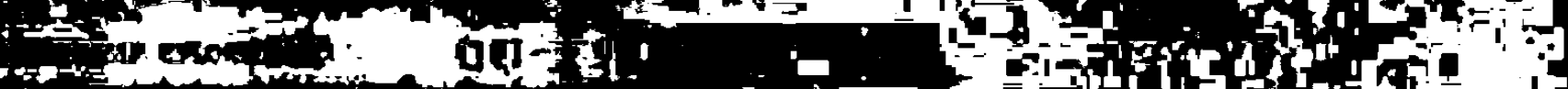
mat H=tar

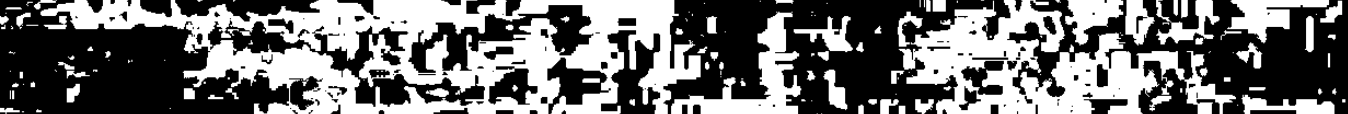
3 Thes Wor 4 I

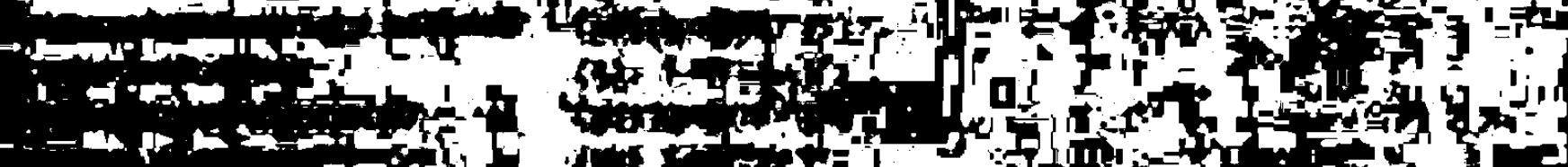

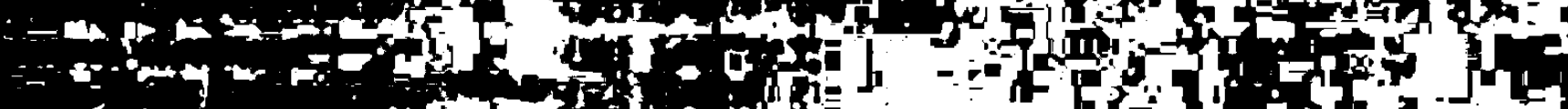

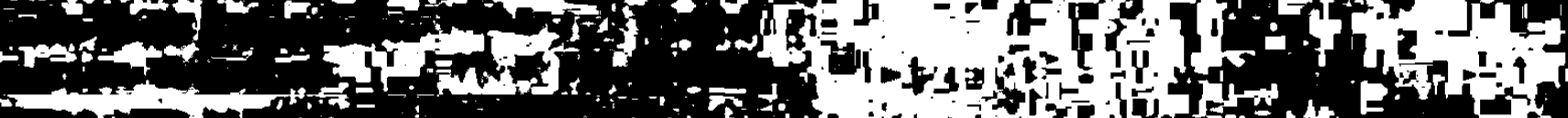
-

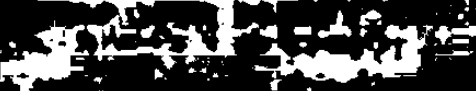

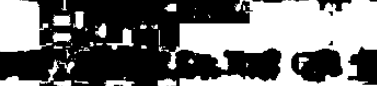

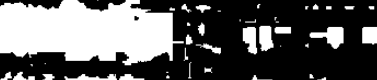

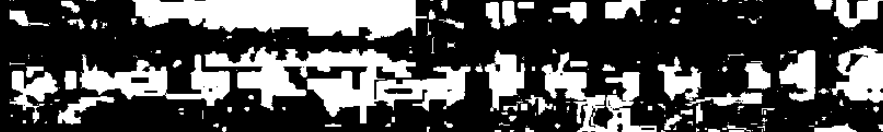
100 and

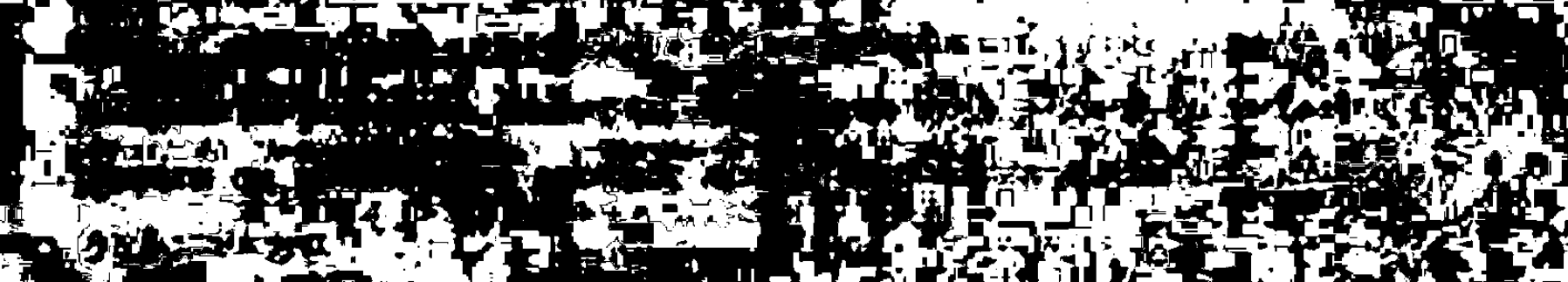
(10)

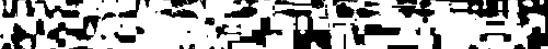

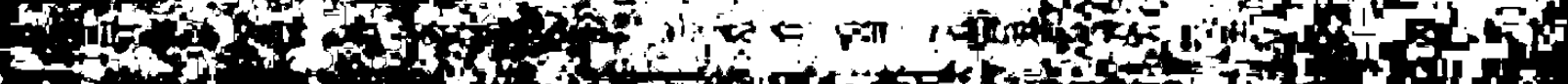

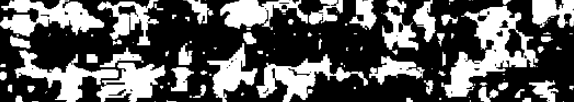
ming 15

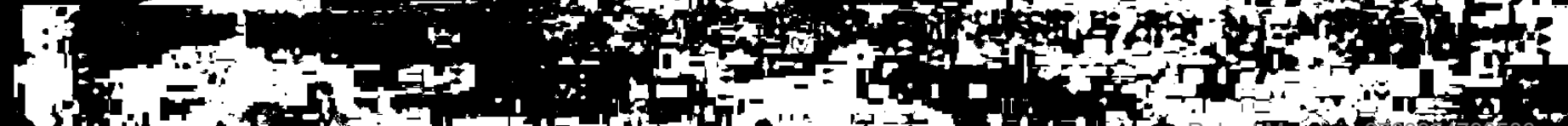

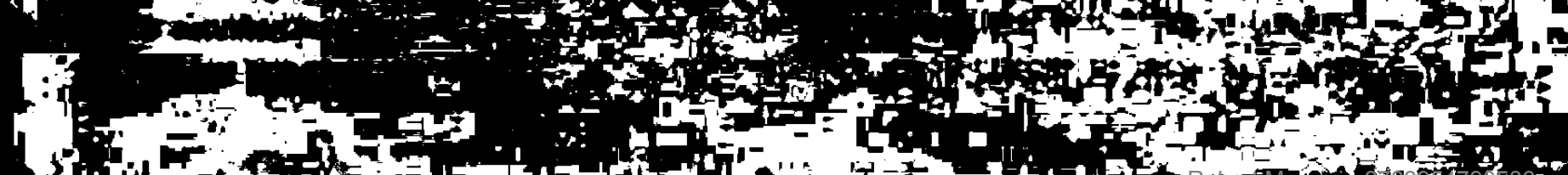
15 3i.

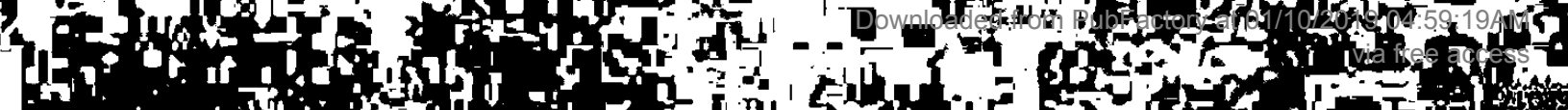




\section{Teil C:}

\section{Ergebnisse und Interpretation}




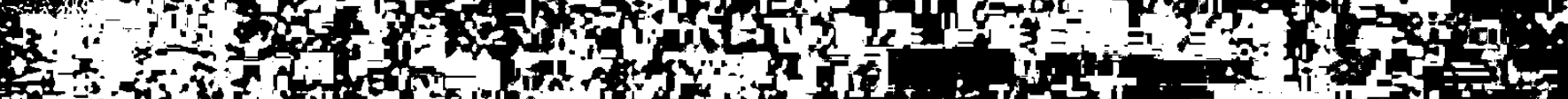
(2)

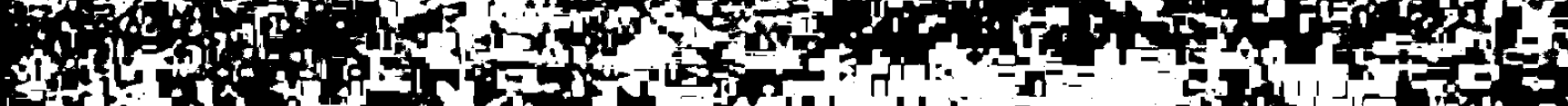

Hy

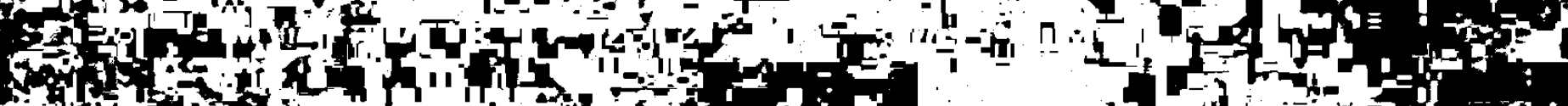

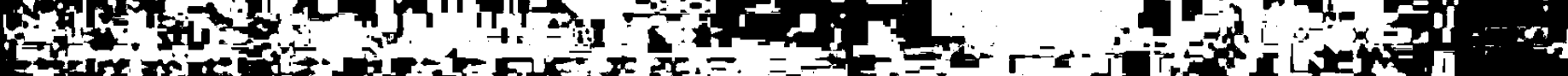

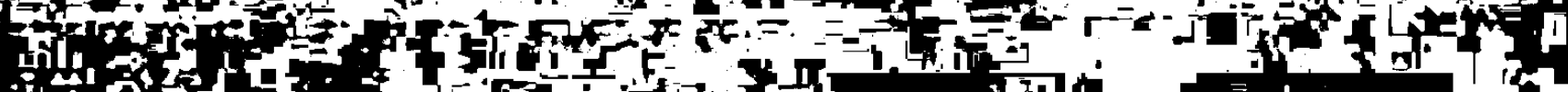
The

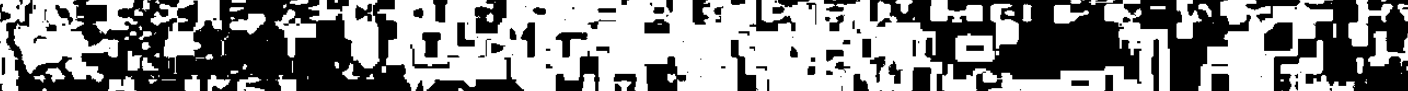
-

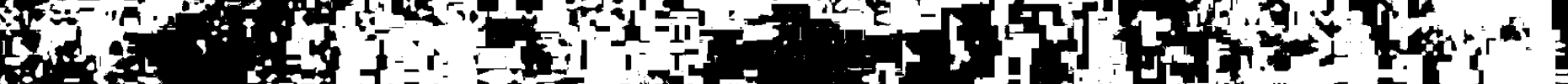
there

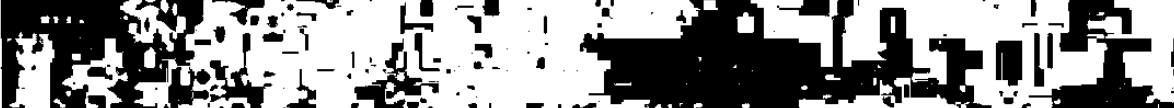
we

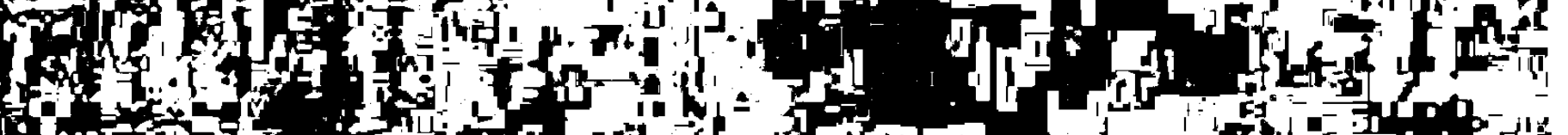
Lin

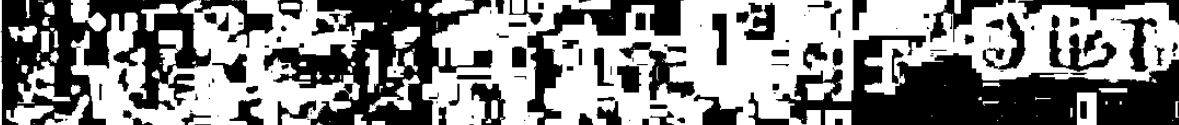

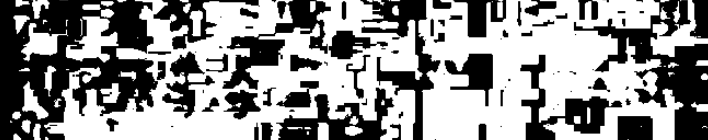
Pats Pand

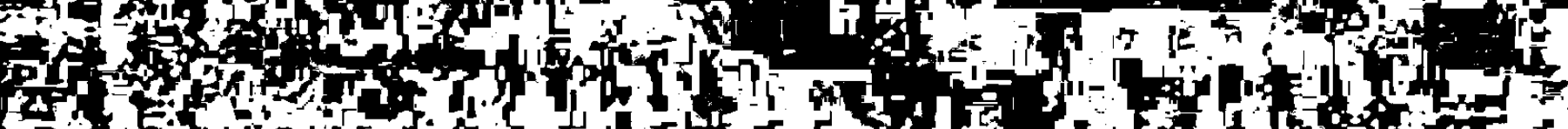
F

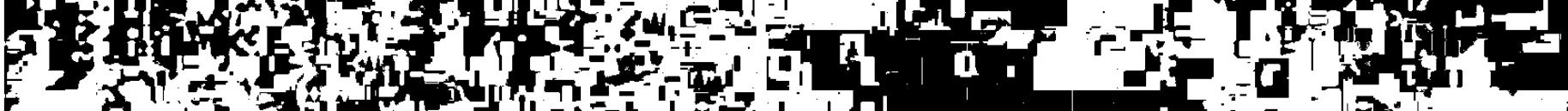

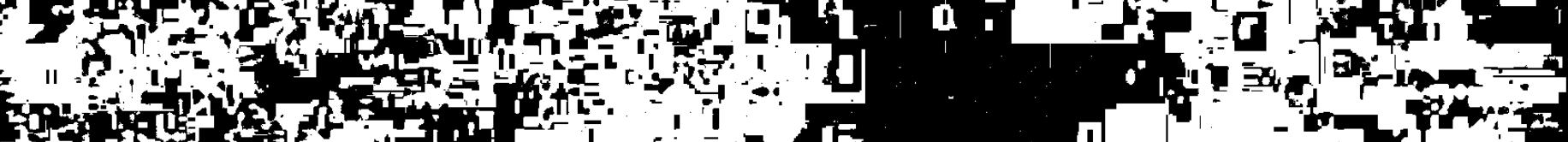

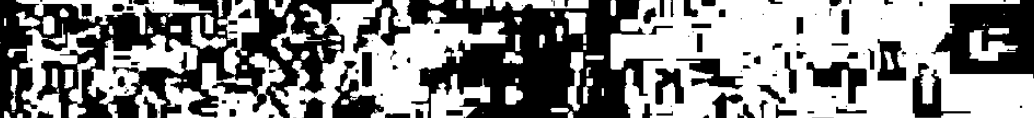

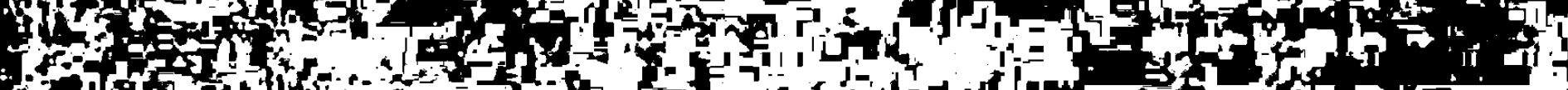

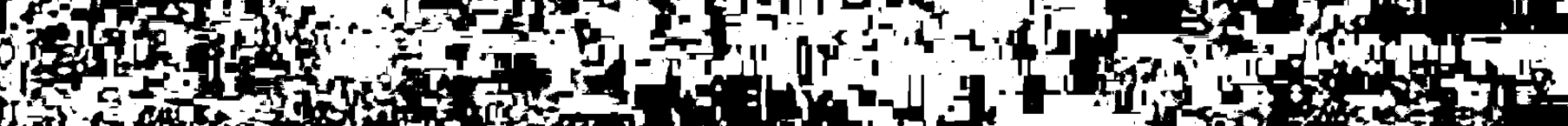

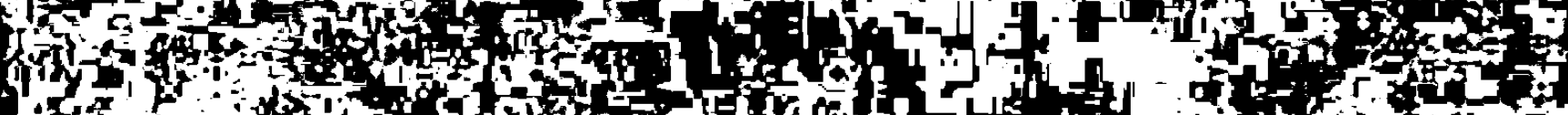

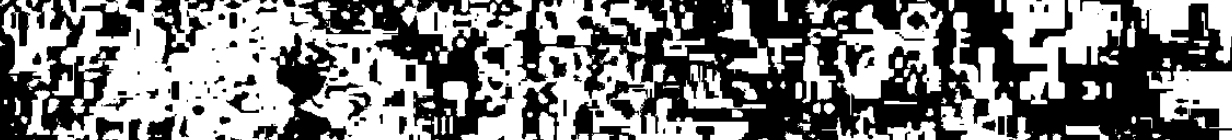

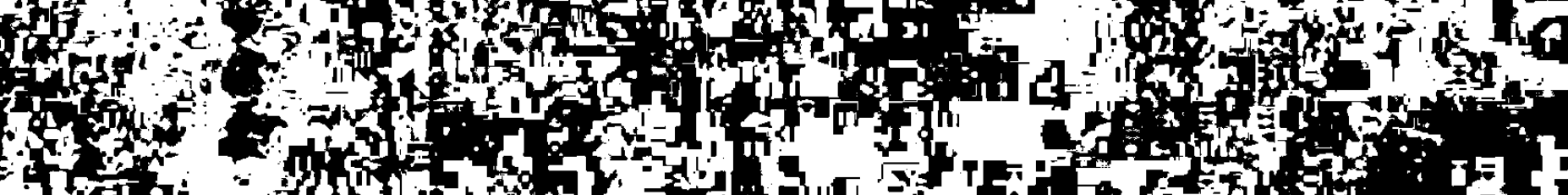
ato

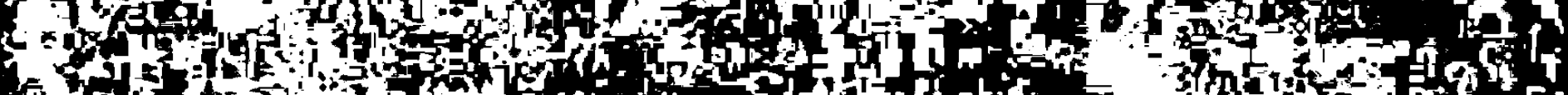

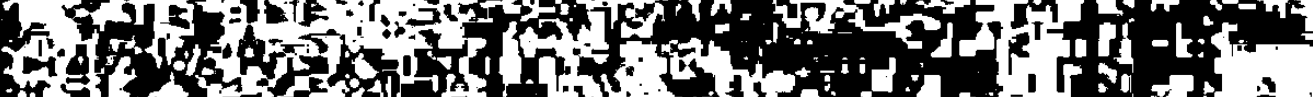

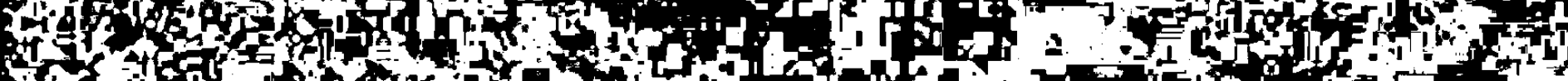

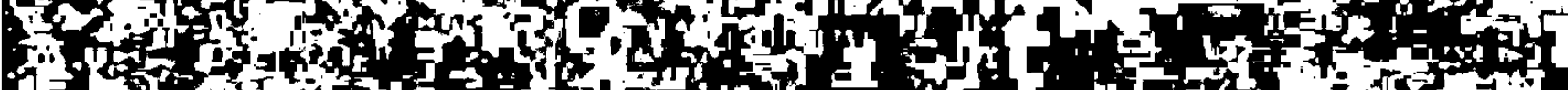
and of 
SYNOPSEN der Mittelwerte

Parameter a:

Satzlinge:

Lomonosov

Karamzin

Puskin
Geschichtswerke

21 Worter

24 Worter

14 Worter dichterische Werke

17 Worter

14 Worter

\section{Satzlongenprofile:}

Lomonosov:

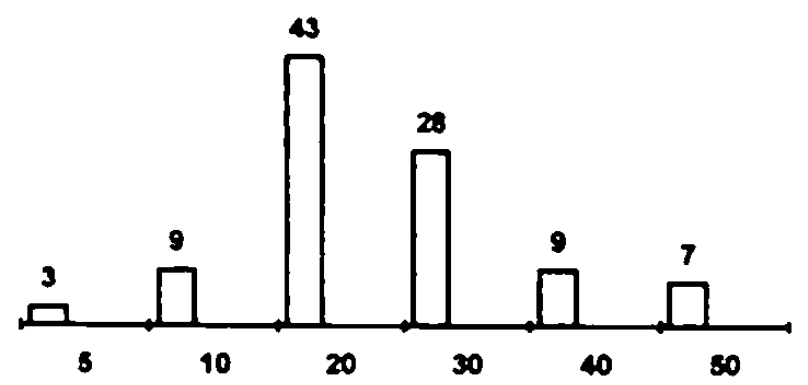

Karamzin:
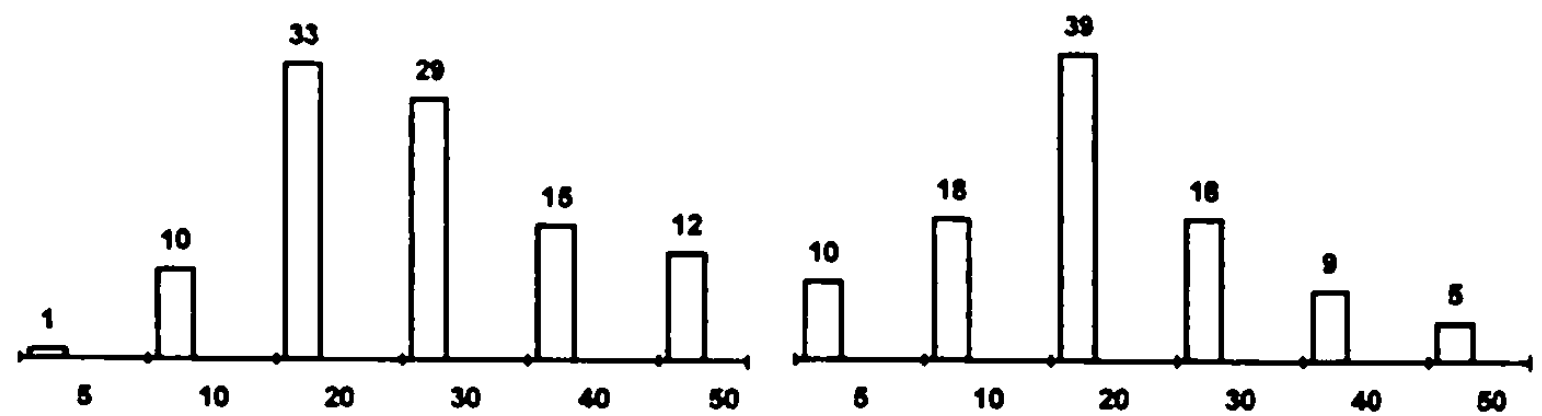

Puskkin:
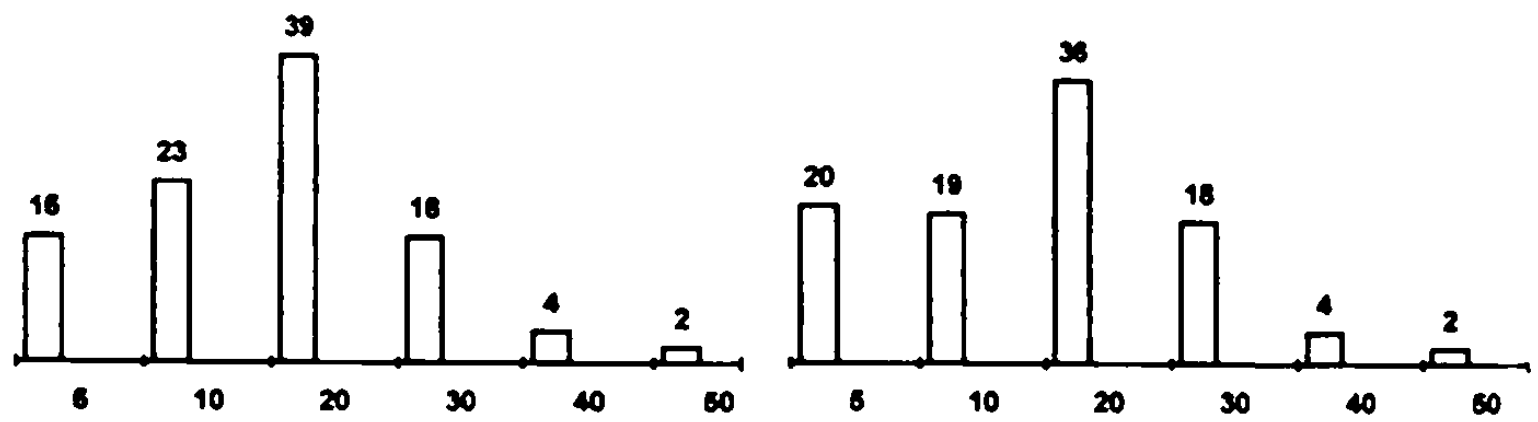

Zwischen Karamzins historiographischem und dichterischem Stil verlăuft ein Bruch. 
Parameter b: $\quad$ Satzkomplexitåt

$\begin{array}{lcc}\text { Einfachsătze: } & \text { Geschichtswerke } & \text { dichterische Werke } \\ \text { Lomonosov: } & 48 \% & \\ \text { Karamzin: } & 35 \% & 42 \% \\ \text { Puskin: } & 68 \% & 61 \%\end{array}$

Satzreihen:

Lomonosov: $\quad 10 \%$

Karamzin: $\quad 21 \% \quad 19 \%$

$\begin{array}{lll}\text { Puskin: } & 17 \% & 10 \%\end{array}$

Satzgefige:

Lomonosov: $\quad 42 \% *$

Karamzin: $\quad 44 \% \quad 39 \%$

$\begin{array}{lll}\text { Puskin: } & 15 \% & 30 \%\end{array}$

Dieser Parameter zeigt keinen Bruch auf; zwischen Karamzins historischem und literarischem Stil herrschen sogar gleiche Großenordnungen vor. (Vgl. jedoch die Bewertung dieses Parameters auf S.128)

Parameter c: 'logische' Satzordnung

strenge SV(O): Geschichtswerke dichterische Werke

Lomonosov: $\quad 36 \%$

$\begin{array}{llll}\text { Karamzin: } & 55 \% & / 1 & 61 \%\end{array}$

$\begin{array}{lll}\text { Puskin: } & 58 \% & 60 \%\end{array}$

Bei strenger SV(O) ist der Bruch innerhalb Karamzin ebenfalls erkennbar. 
Parameter d: $\quad$ Prădikativităt

Wortanteil (prim§̊re Prädikation): Geschichtswerke dichterische Werke Lomonosov: $11,7 \%$

Karamzin:

$12,9 \%$

11

$17,8 \%$

Puskin:

$16,6 \%$

$17,4 \%$

Wortanteil (primăre und sekundăre Prädikation):

Lomonosov:

$14,4 \%$

Karamzin:

$15,3 \%$

II

$19,6 \%$

Puskin:

$19,8 \%$

$19,6 \%$

Sowohl beim Wortanteil der primăren Prädikationen als auch bei dem Wortanteil der primären und sekundăren Prädikationen ist der Bruch innerhalb Karamzin klar erkennbar.

\section{Fazit:}

Die Gegenthese, daß bereits Karamzin Sachprosa und dichterische Prosa mit einem gemeinsamen Stil bewăltigt, wird nur von dem Parameter Satzkomplexităt gestützt, der ohnehin als sehr unzuverlässiger Parameter bewertet werden mußte. Dagegen wird die These, daB Puß̌kin Sachprosa und dichterische Prosa in den untersuchten Texten mit einem gemeinsamen Stil behandelt, von drei Parametern gestützt. Damit kann die These als bewiesen getten. 


\section{BEANTWORTUNG DER FRAGESTELLUNGEN UND INTERPRETATION}

\section{Zur Fragestellung I : Entwicklung des historiographischen Stils}

a) Die Sătze werden immer kürzer: von durchschnittlich 21 Wortern bei Lomonosov bzw. 24 Wőrtem bei Karamzin zu 14 Wörtern bei Puškin. Das Satzlăngenprofil verschiebt sich zu den Kurzsätzen.

b) Auch die Hypotaxe erreicht bei Puskin ein Minimum von 14\%; bei Lomonosov ist noch eine große Streuung festzustellen, bei Karamzin und Puškin wird dieser Parameter konstant.

c) Die Mittelwerte für den SV(O)-Anteil erhöhen sich von Lomonosov zu Karamzin und Puskin um ca. 20\%: der VS(O)-Anteil scheint dagegen eher konstant, doch muß dieser um die 10\%-Marke streuende Wert eher auf die einzelsprachliche Gegebenheit zurückgefuhrt werden.

d) Die Mittelwerte der primären Prădikationen liegen bei Lomonosov und Karamzin in der gleichen Großenordnung: 12\%-13\%; bei Puskin erhø̋ht sich der Anteil um fast ein Viertel (4\%) auf rund 17\%. Gleiches gilt für die Summe der primăren und sekundären Prädikationen: bei Lomonosov und Karamzin liegt der Mittelwert um 14\%-15\%; bei Puskin erhöht er sich um ein Drittel (5\%) auf rund 20\%.

\section{Zusammen fassung:}

Die Sătze in Karamzins Geschichtswerk sind zwar oft noch so lang wie in Lomonosovs, doch vereinfacht er bereits intern: die Länge seiner Sătze rührt oft nur von der Parataxe her: die Hypotaxe und sonstige rhetorische Stilmittel, die den Lesefluß nur aufhalten würden. reduziert er auf ein Minimum. Puskin erreicht die großte Vereinfachung: sein historiographischer Stil ist nur noch ein Medium für die Vermittlung von Fakten und Ereignissen.

\section{Funktionen des historiographischen Stils}

In Lomonosovs Geschichtswerk sind die Sătze ausschweifend und komplex. Rhetorische Stilmittel spielen eine wesentliche Rolle. Wenn wir nach SCHLIEBEN-LANGE als grundlegende Funktion der Geschichtsschreibung die gedächtnisbewahrende Funktion annehmen. so kommt bei Lomonosov als weitere die identitätsstiftende und rühmende 
Funtaion hinzu. Da unmittelbar vor Lomonosov die Geschichte RuBlands von einigen ausländischen Gelehrten nicht besonders vorteilhaft geschildert worden war, sollte sein Geschichtswerk gewissermaßen als Ehrenrettung der russischen Geschichte dienen. Dargestellt werden soltte die Geschichte eines großen Volkes und großen Reiches, dementsprechend mußte auch der Stil prunkhaft und erhaben sein. Außerdem wollte Lomonosov nicht breite Massen aufklären, denn dazu fehlte ohnehin der entsprechende Bildungsstand, sondern er richtete sein Werk an den einheimischen (und ausländischen) Adel und Gelehrtenstand. Die Verwendung der Prosa war für diese Funktion neu, in Versform (Ode) konnte aber Lomonosov nicht schreiben. weil er ein wissenschaftliches Werk vorstellen wollte. Für ihn war der historiographische Stil durchaus dem wissenschaftlichen Funktionalstil zugehorig. Die Verwendung der rhetorischen Mittel ist daher bei ihm nur Ausdruck einer spezifischen Funktion, die die Geschichtsschreibung zu seiner Zeit erfüllen solte.

Bei Karamzin ist der historiographische Stil weit einheitlicher als bei Lomonosov. Auch bei ihm läßt sich als zusătzliche Funktion die Erhöhung der Nation / des Volkes erkennen. Allein die Emennung zum Hofhistoriker zeigt, daß eine solch wichtige Aufgabe am liebsten einem renommierten Schriftsteller zugesprochen wurde. Des weiteren spricht die rasche Obersetzung und Verbreitung seines Werkes im Westen fur den Erfolg des Werkes. Die Funktion der Identitätsstiftung ist daher auch bei Karamzin vorhanden; im Vergleich zu Lomonosov sind die rhetorischen Elemente allerdings weniger vertreten, die rühmende Funktion tritt in den Hintergrund. Karamzin verwendet kaum die rhetorischen Elemente von Lomonosov; sein Stil ist uberwiegend parataktisch. und wenn er die Hypotaxe verwendet, so vorwiegend ersten Grades.

Karamzin war überzeugter Anhänger der Aufklărung. In der Sprache strebte er Prăgnanz und Durchsichtigkeit (clarete) an. Deshalb blieb aber nicht die Wissenschaftlichkeit auf der Strecke. Man kann sogar sagen, daß Karamzin noch genauer arbeitete als Lomonosov: die Kritiken sowohl der Zeitgenossen als auch der spăteren Wissenschaftler sind außerst positiv. Das sprachliche Ideal der Aufklarung schlägt sich am deutlichsten nieder in dem um rund $20 \%$ höheren Anteil der SV(O)-Ordnung. Öberhaupt zeichnet sich Karamzins historiographischer Stil durch eine grőßere Regelmaßigkeit gegenüber Lomonosov aus. Er schreibt sein Geschichtswerk klarer als Lomonosov, sein Werk wird dadurch leserfreundlicher und kann breitere Schichten erreichen. 
Mag bei Karamzin das Ideal der Wissenschaftichkeit vielleicht noch stärker als das Ideal der Aufklărung gewesen sein (man denke an den ungeheuren Apparat der Anmerkungen), so ist es bei Puskkin umgekehrt: Aufklärung geht vor Wissenschaftlichkeit. Das Ideal der Aufklărung machte sich bei Puskin vor allem inhaltlich bemerkbar: im Gegensatz zu Lomonosov und Karamzin, deren Thematik auf das Interesse des Hofes stieß und die sich des Wohlwollens des Zaren erfreuten, verhieht es sich bei Puskin anders. Bereits die Art und Weise, wie er sich den Zugang zu den Akten uber Pugacev verschaffen mußte, zeigt deutlich, wie sehr dieses Thema auf Mißtrauen und Abneigung stieß. Die Funktion der Aufklarung wird bei Puskin auf zweifache Art erreicht:

1) durch die Schaffung einer leicht zugănglichen (Sach)Prosa, welche letztlich auch das Volk als Adressaten im Auge hatte, zumindest war nicht nur der Adel als Leserkreis intendiert: und

2) durch die Thematik und die Behandlung der historischen Begebenheit: Puskin zeigt Pugarev nicht als einen allein durch Grausamkeit und Raserei motivierten Radelsfuhrer, sondern er beleuchtet die gesellschaftlichen und geschichtlichen Hintergrinde. Dadurch bekommt das Werk auch inhaltlich eine aufklärerische Funktion.

Zusammenfassend können folgende Funktionen des historiographischen Stils eruiert werden: als Grundfunktion die gedächtnisbewahrende und als Nebenfunktionen die rühmende. die identitätsstiftende und die aufklärerische Funktion.

\section{Fachsprache und Funktionalstil}

Die Scheidung von Fachsprache zu nicht-Fachsprache bzw. vom historiographischen zum literarischen Stil ist beim Anteil der Wortarten offensichtlich: die Geschichtswerke zeichnen sich durchweg durch einen deutlich höheren Anteil an nominalen Wortern aus. In bezug auf die drei satzbaubezogenen Parameter aber sieht man keine Obereinstimmung innerhalb der Geschichtswerke, womit eine hypothetische Fachsprache für die Historiographie nicht mit weiteren konkreten Fakten belegt werden kann. Es ist daher doch nötig. auf das Konzept des Funktionalstils zurückzugreifen, um den historiographischen Stil als Ganzes fassen zu können.

Dem wissenschaftlichen Funktionalstil liegt die theoretisch-fachliche Mitteihungsfunktion zugrunde: diese wird in allen Geschichtswerken sicher erfullt. Gleichwohl ist sie sehr breit formulien, weshalb u.E. diese sehr allgemein gehahtene Funktion für die einzeinen 
wissenschaftichen Disziplinen konkreter spezifiziert werden soltte, wobei die grundlegende Funktion im Falle des historiographischen Stils zweifellos die gedächtnisbewahrende darstellt. An konkreten Funktionen lassen sich (wie oben gezeigt) noch andere Funktionen festmachen; diese manifestieren sich nicht nur auf der semantischen also inhaltlichen Ebene: z.B. schlägt sich die aufklärerische Funktion, die ja wesentlich mit der Lesefreundlichkeit zusammenhängt, deutlich nieder in der Abnahme der Satzkomplexităt. einer stringenten 'logischen' Satzordnung und nicht zuletzt in der Kürze der Sătze.

\section{Zur Fragestellung II : Entwicklung des literarischen Stik}

a) Die Sătze werden bei Puškin nur noch geringfügig kürzer: 17 Worter bei Karamzin gegenüber 14 Wörtem bei Puškin. Der Anteil der Kurzsătze ( $\leq 5$ Wörter) erhöht sich allerdings um das Doppette: $10 \%$ bei Karamzin; $20 \%$ bei Puskin.

b) Die Hypotaxe ist bei Karamzin um $9 \%$ mehr vertreten als bei Puskin; die Großenordnung ist bei beiden etwa dieselbe: $30 \%$ bei Puskin; $39 \%$ bei Karamzin.

c) Die strenge SV(O)-Ordnung ist bei beiden Autoren praktisch gleich oft vertreten: $61 \%$ bei Karamzin gegenüber $60 \%$ bei Puskin.

d) Die Wortanteile der primăren Pradikationen weichen sehr gering voneinander ab: $17,8 \%$ bei Karamzin; $17,4 \%$ bei Puskin. Der Wortanteil an primären und sekundăren Prådikationen ist bei beiden identisch: $19,6 \%$.

\section{Zusammenfassung:}

Die Übereinstimmung ist innerhalb des literarischen Stils von Karamzin zu Puškin derart gleich hoch, daß es sich nach unserer Parameter-Stildefinition um einen gleichen Stil handelt !

Zur These: Erst Pusktin war imstande, die Sachprosa und die dichterische Prosa mit einem gemeinsamen Stil zu bewältigen.

Wie bei der synoptischen Gegenüberstellung der Mittelwerte der Parameter (S.169-171) bereits festgestelt, sind die Werte der Parameter im historiographischen und literarischen Stil Puskins in drei von vier Parametern so sehr einheitlich daß hier letztendlich von einem Stil gesprochen werden kann. Dagegen ist Karamzins historiographischer Stil 
deutlich verschieden von (a) seinem eigenen literarischen Stil und (b) dem historiographischen und literarischen Stil Puskins. Im historiographischen Stil Karamzins weist kein einziger Parameter gleiche Werte wie bei Puskin auf, außer dem Parameter SV(O) liegen sie nicht einmal in derselben quantitativen Größenordnung. Dabei ist zu bedenken. daß Karamzin das historiographische Werk 20 (!) Jahre nach dem literarischen Werk schrieb, und nicht etwa umgekehrt. Dies weist darauf hin, daß Karamzin davor zurückschreckte. seinen neuen literarischen Stil auf die Sachprosa anzuwenden und daB es erst der Weitsicht und des Mutes eines Puskins bedurfte, sich endgultig von der alten Stilauffassung Lomonosovs zu losen. die einen 'erhabenen' Stil für die Historiographie im besonderen und fur die Wissenschaft im allgemeinen forderte. Wenn die These besagt. daß erst Puskin dazu imstande war. so bezieht sich das "imstande sein' eher auf den Komplex des Wollens und Wagens als auf den des intellektuellen und sprachlichen Konnens. Schließlich ließ sich der literarische Stil Karamzins leicht etablieren, weil er gleichzeitig mit der Gattung der Novelle neu entwickeh wurde. Und in diesem Fall war es nicht zu schwierig, einen neuen Stil zu schaffen. denn es gab ja keine Tradition. die man bewahren oder gegen die man anschreiben mußte. Karamzin fullte den neuen Wein in neue Schläuche. In dieser Hinsicht spiehte sich die entscheidende 'Schlacht' um einen neuen Stil vor allem auf dem Feld der Sachprosa ab, schließlich war die Sachprosa auch das Feld der Sprache, wo sich die atten schriftsprachlichen Traditionen des Kirchenslavischen am zähesten hielten.

Wenn aus dieser Perspektive die Sachprosa Karamzins betrachtet wird. so sieht man eine Tendenz: der historiographische Stil bewegt sich bei Karamzin schon klar auf seinen literarischen Stil zu. Aber der Abstand ist eben doch spürbar (und größenordnungsmäßig offenkundig), so daß eines feststeht: Karamzin behandelt bewr $\beta t$ die beiden Stile unterschiedlich. wohingegen Puškin Sachprosa und dichterische Prosa ebenbürtig behandeh. Von der ebenbürtigen Behandlung profitiert bei Puškin die Sachprosa und damit auch der Rezipient derselben. Praktisch gesehen heißt das folgendes: die dichterische Prosa Puskins kann leicht gelesen werden: seine Sachprosa, die ebenso fließend und abwechslungsreich (hohe Prådikativităt !) geschrieben ist, liest sich genauso leicht. Der leichte Zugang wiederum optimiert das Vermitteln des Inhalts; die Sprache wird zum reinen Instrument. Wohl mag das Omament, wie es bei Lomonosov stark ausgeprăgt ist, in manchen Bereichen durchaus vertretbar sein, aber es ist eben eher elităr als aufklärerisch 
und eher brillant als didaktisch. Genau einen didaktischen Grundzug mußte aber, hier sah Puskin absolut richtig, die Sprache erhalten, wenn sie in den metaphysischen, d.h. in den humanwissenschaftlichen Bereichen das leisten soltte, was sie im 19. Jahrhundert immer mehr leisten mußte. Dabei bestand die Neuerung darin daß er dieselben sprachlichen Mittel verwendete, die sich in der dichterischen Literatur bewăhrt und dort sowohl für leichtes Verstăndnis als auch für Flexibilität im Aus- druck gesorgt hatten.

Die hohe Regelmåßigkeit und Rigidităt des Puškinschen Stils in den untersuchten Werken kann vollstăndig nur ermessen werden, wenn man sie in Zahlen gefaßt sieht. Letztlich bedeutet die hochgradige Ubereinstimmung des historiographischen Stils mit dem literarischen bei Puskin folgendes: mit einem gemeinsamen Stil werden zwei verschiedene sprachliche Bereiche bewaltigt, was eine ungeheure Steigerung des Ausdruckspotentials und eine universale Anwendbarkeit dieses Stils nach sich zieht. Tatsăchlich ist es gerade diese Universalităt, die den (literarischen bzw. historiographischen) Stil Puskins so nachahmenswert machte, denn dadurch konnte dieser Stil in mehreren sprachlichen Funktionsbereichen eingesetzt werden. Wichtig furr die Vorbildwirkung war auch, daß er gerade aufgrund seiner Einfachheit so leicht erlernt und nachgeahmt werden konnte. Im Gegensatz zu dem rhetorisch anspruchsvollen historiographischen Stil eines Lomonosov konnten sich auch leicht weniger geschulte Schreiber diesen Stil angeeignen. was den Erfordernissen des 19. Jahrhunderts entgegenkam.

Eine Einschränkung bezüglich der Interpretation der Ergebnisse gitt es noch einmal deutlich zu wiederholen: die Untersuchung hatte nur fün konkrete Werke zur Grundlage, was streng genommen nur Aussagen aber den Stil in den betreffenden Werken zulaßt. Jede weitergehende Verallgemeinerung auf 'Lomonosovs Stil', 'Karamzins Stil' oder 'Puskins Stil' ist zwar teilweise zulässig, bringt aber all die 'impressionistischen' Ungenauigkeiten mit sich, welche wir in dieser Untersuchung weitgehend auszuschließen versuchten. 


\section{LITERATURVERZEICHNIS}

Primårliteratur (Untersuchungstexte):

KARAMZIN, N.M. История государства Российского. Sankt-Peterburg 1892. Slavistic Printings and Reprintings: edited by C.H.Schooneveld. Indiana University. The Hague/ Paris 1969. Bd. 1 und 2.

KARAMZIN, N.M. Бедная Лиза - повести. Leningrad 1970.

I.OMONOSOV, M.V. Полное собрание сочинений в 10 томах. Изд. Акад. наук CCCP. Moskau / Leningrad 1952. Том шестой.

PUSKIN, A.S. Собрание сочинений в 10 томах. Moskau 1962. Том пятый / Том седьмой.

\section{Sekundxriteratur:}

AKIMOVA, G.N. (1973) "Размер предложения как фактор стилистики и грамматики (На матернале русского литературного языка XVIII в.)", in: ВЯ, 1973. Nr. 2, 67-79.

AVRASIN, V.M. (1973) "Некоторые лингвистическне аспекты интерпретации явлений, сопутствуюших научно-технической революции", in: VOPROSY 1973.

BAILEY. R.W. (1969) „Statistics and Style: A Historical Survey”, in: DOLEŽEL 1969, 217-236.

BAUMGARTNER. H.M. (1975) „Narrative Struktur und Objektivităt. Wahrheitskriterien im historischen Wissen.", in: RUSEN 1975, 48-67.

BENES. E. (1966) ..Syntaktische Besonderheiten der deutschen wissenschaftlichen Fachsprache", in: Deutsch als Fremdsprache 3 (1966), 26-36.

BIRŽAKOVA, E.Э./ Vojnova. L.A./ Kutina, L.L. (1972) Очерки по исторической лексикологии русского языка XVIIl века. Leningrad.

BLACK. J. L. (1975) „The Primexanija: Karamzin as a 'Scientific' Historian of Russia“, in: BLACK, J. L.(ed.) Essays on Karamzin: Russian man-of-letters, Political thinker, Historian, 1766-1826, The Hague, 127-147.

BODAMMER. Th. (1987) Philosophie der Geisteswissenschaften. München.

BORKOVSKJJ, V.I./ KUZNECOV, P.S. (1963) Историческая грамматика русского языка. Moskau. 
BUDAGOV, R.A. (1954) "K вопросу о языковых стилях", in: BЯ, 1954, Nr.3, 5467.

BUDAGOV, R.A. (1965) Введение в науку о языке. Moskau.

BUDAGOV, R.A. (1967) Литературные языки и языковые стили. Moskau.

BUNGARTEN, Th. (Hsg.) (1986) Wissenschaftssprache und Gesellschaft - Aspekte der wissenschaftlichen Kommunikation und des Wissenstransfers in der heutigen Zeit. Hamburg.

BUNGARTEN, Th. (Hsg.) (1992) Beiträge zur Fachsprachenforschung. Tostedt.

CLAUS, G./ EBNER, H. (1974) Grundlagen der Statistik für Psychologen, Pådagogen und Soziologen. Berlin.

COMRIE, B. (1981) Language Universals and Linguistic Typology. Chicago.

COMRIE, B. (ed.) (1987) The World's Major Languages. London.

COSERIU, E. (1988) Sprachkompetenz. Tübingen.

CROCE. (1984) Die Geschichte auf den allgemeinen Begriff der Kunst gebracht. Hamburg.

DEBRECZENY, P. (1983) The Other Pushkin - A Study of Alexander Pushkin's Prose Fiction. Stanford.

DESCARTES. (1637) Discours de la méthode. Leiden.

DILTHEY. Gesammette Schriften. VII. Band: Der Aufbau der geschichtlichen Welt in den Geisteswissenschften. Stuttgart 1958. (zitiert allein nach Bandzahl und Seitenangabe)

DIMTER, M. (1981) Textklassenkonzepte heutiger Altagssprache. Tübingen.

DOLEŽEL, L./ BAILEY, R.W. (eds.) (1969) Statistics and Style. New York.

ECKERT, R./ CROME, E./ FLECKENSTEIN, Ch. (1983) Geschichte der russischen Sprache. Leipzig.

EFIMOV, A.I. (1969) Стилистика pyсcкого языка. Moskau.

EGGERS, H. (1961) „Wandlungen im deutschen Satzbau“, in: DU 13, 1961, H.5, 47-61.

FACHSPRACHEN (1981): Fachsprachen: Wege der Forschung, Bd. 498 (Hsg.: W.v. Hahn). Darmstadt. 
FRICKE, H. (1986), Zur gesellschaftichen Funktion humanwissenschaftlicher Fachsprachen", in: BUNGARTEN 1986, 62-75.

FRUMKNNA, R.M. (1973) „Die Anwendung statistischer Methoden in der Sprachforschung", in: HOFFMANN (1973), 272-288.

FUCKS, W. (1968) Nach allen Regeln der Kunst. Stuttgart.

FUNKCIO- (1974) Функциональный стиль общенаучното языка и методы его исследования. Moskau.

GALILEI. (1632) Dialogo di Galileo Galilei sopra i due massimi sistemi del mondo tolemaico e copernicano. Florenz.

GLÄSER. R. (1983) „Das Verhältnis von Texttypologie und Stiltypologie in der Fachsprache", in: Wissenschäfliche Zeitschrift der Wilhelm-Pieck-Universität Rostock 32 (1983), Heft 2, 7-11.

GOGOL', N.V. Полное собрание сочинений. Изд. Акад. наук CCCP. Moskau 1952. Том 7.

GOLUBZOWA, L. (1991) Adverb und Sprachstil - Untersuchungen zur stilistischen Differenziertheit, insbesondere im lexikalischen Bereich. München.

GRUNDLAGEN der Sprachkultur. Beitrăge der Prager Linguistik zur Sprachtheorie und Sprachpflege. Teil 1. Berlin 1976.

HABERMAS. J. (1968) Erkenntnis und Interesse. Frankfurt/M.

HAHN, W. v. (1983) Fachkommunikation. Berlin.

HANDBUCH des Russisten. (Hsg.: Jachnow, H.) Wiesbaden 1984.

HARDTWIG, W. (1979) „Theorie oder Erzählung - eine falsche Alternative“, in: KOCKA (1979) , 290-299.

HARTMANN, K.-H. (1979) Wiederholungen im Erzählen - Zur Literarităt narrativer Texte. Stuttgart.

HAVRÁNEK. B. (1976) „Die Aufgaben der Literatursprache und die Sprachkultur“, in: GRUNDLAGEN der Sprachkultur. Teil 1, 103-141.

HENTSCHEL, G. (1992) ,Zum Einfluß der Konstituentenfolge auf die Kasuswahl im Russischen“, in: Lingua 87 (1992), 231-255.

HOFFMANN, L. (Hsg.) (1973) Sprachstatistik. Berlin.

HOFFMANN. L. (1976) Kommunikationsmittel Fachsprache: Eine Einfuhrung. Berlin. 
HUTTL-FOLTER, G. (1996) Syntaktische Studien zur neueren russischen Literatursprache. Wien.

HUTTL-WORTH, G. (1956) Die Bereicherung des russischen Wortschatzes im XVIII. Jahrhundert. Wien.

ISAČENKO, A.V. (1958) "Кахова специфика литературного двуязычия в истории славянских народов ?", in: $B Я, 1958$, Nr.3, 42-45.

ISAČENKO, A.V. (1962) Die russische Sprache der Gegenwart. Teil I: Formenlehre. München.

ISAČENKO, A.V. [Issatschenko] (1983) Geschichte der russischen Sprache. 2.Bd. Das 17. und 18. Jahrhundert. Heidelberg.

JUMPELT, R.W. (1960) „Fachsprachen: Fachworte als Problem der Dokumentation und Ubersetzung", in: FACHSPRACHEN 1981, 67-85.

KALVERKÄMPFER, H. (1979) „Der Begriff der Fachlichkeit in der FachsprachenLinguistik-Tradition", in: Fachsprache, Sonderheft 1, 53-71.

KALVERKÄMPFER, H. (1981) Orientierung zur Textlinguistik. Tabingen.

KAMPRAD, W. (1975) „Über die Struktur von Absătzen gesellschaftswissenschaftlicher Texte und $\mathrm{zu}$ Modellen für die Textarbeit", in: Deutsch als Fremdsprache 4 (1975), 223-234.

KAYE, A.S. (1987) „Arabic“, in: COMRIE (1987), 664-685.

KEIPERT, H. (1984) „Geschichte der russischen Literatursprache“, in: HANDBUCH des Russisten, 444-481.

KEMPGEN, S. (1995) Russische Sprachstatistik. München.

KIPARSKY, V. (1975) Russische historische Grammatik. Bd. III: Entwicklung des Wortschatzes. Heidelberg.

KOCKA, J./ NIPPERDEY, T. (1979) Theorie und Erzăhlung in der Geschichte. Müchen.

KOŻNA. M.N. (1972) О речевой системности научного стиля сравнительно с иекоторыми другими. Perm'.

KOVTUNOVA, I.I. (1969) Порядок слов в русском литературном языке XVIII первой трети XIX в. Moskau.

KRETZENBACHER, H. L. (1994) „Wie durchsichtig ist die Sprache der Wissenschaften ?", in: Linguistik der Wissenschaftssprache. Hrsg.: KRETZENBACHER, H.L. und WEINRICH, H., Berlin, 15-40. 
KREYE. H. (1989) Satzform und Stil. Heidelberg.

KUHN, T.S. (1967) Die Struktur wissenschaftlicher Revolutionen. Frankfurt M.

KUTINA, L.L. (1964) Формирование языка русской науки. Moskau.

KUTINA, L.L. (1966) Формирование терминологии физики в России. Moskau.

KUTSCHMANN, W. (1986) „Von der Natursprache zur Warensprache. Die Sprache der Naturwissenschaften zwischen Objektivităt und sinnlicher Verlockung", in: BUNGARTEN 1986. 94-112.

LESSKIS, G.A. (1962) "О размерах предложений в русской научной и художественной прозе 60-х годов XIX в.", in: BЯ, 1962, Nr. 2, 78-95.

LESSKIS, G.A. (1963a) "О зависимости между размером предложения и характером текста", in: BЯ, 1963, Nr. 3, 92-112.

LESSKIS, G.A. (1963b) "O некоторых различиях простого предложения в научной и художественной прозе", in: Вусский язык в национальной uкале, 1963, Nr. 6, 7-15.

LESSKIS, G.A. (1964) "О зависимости между размером предложения и его структурой в разных видах текста", in: BЯ, 1964, Nr. 3, 99-123.

LESSKIS, G.A. (1968) "Некоторые статистические характеристики простого и сложного предложения в русской научной и художественной прозе XVIII - XX вв.", in: Русский язык в национальной шкале, Nr. 2, 1968. 67-81.

LICHAČEV, D.S. (1986) Исследования по древнерусской литературе. Leningrad.

LINGVO- (1979): Лингво-стилистические исследования научной речи. Moskau.

LOMONOSOV, M.V. Полное собрание сочинений в 10 томах. Изд. Акад. наук CCCP. Moskau / Leningrad 1952. Том 6.

MAIRET, G. (1974) Le discours et l'historique. Paris.

MARKOV, Ju. (1960) "K вопросу о частности грамматических категорий", in: Русский язык в национальной шкале 4, Moskau, 19-20.

MARTEL. A. (1933) Michel Lomonosov et la langue littéraire russe. Paris.

MARZARI, R. (1998) .Zur Problematik statistischer Prufverfahren in stilistischen Untersuchungen", in: Beitrăge der Europäischen Slavistischen Linguistik (Polyslav), Bd. 1 (Hsg.: Giger, M. / Wiemer, B.). München. 125-130.

MŐHN. D./ PELKA, R. (1984) Fachsprachen: eine Einführung. Tübingen. 
MULISCH, H. (1993) Handbuch der russischen Gegenwartssprache. Berlin.

MURAT, V.P. (1957) Об основных проблемах стилистики. Moskau.

OEVERMANN, U. (1972) Sprache und soziale Herkunft. Frankfurt.

OLSCHKI, L. (1922) Geschichte der neusprachlichen wissenschaftichen Literatur. Bd.II: Bildung und Wissenschaft im Zeitalter der Renaissance in Italien. Vaduz 1967 (Reprint der Ausgabe von 1922).

ONG, W.J. (1987) Oralităt und Literalităt. Opladen.

OTTEN, F. (1985) Untersuchungen zu den Fremd- und Lehnwortem bei Peter dem Großen. Koln.

PAVLOVA, G.E./ FEDOROV, A.S. (1986) Михаил Васильевич Ломоносов 17111765. Moskau.

PIOTROVSKIJ, R.G. (1954) "O некоторых стилистических хатегориях", in: BЯ, 1954, Nr.1, 55-68.

PONOMAREV, S. (1883) Материалы для бнблиографии литературы о H.M Карамзине. Санктпетербург 1883. (Fotomechanischer Neudruck der Originalausgabe. Leipzig 1974.)

PUŠKIN, A.S. Полное собрание сочинений. Изд. Ахад. наук CCCP. Moskau 1949. Tom 11.

RAECKE, J. (1988) „Der Grass'sche 'Butt' als 'Lumbur' und 'List' auf kroatische und slowenische Art oder Wie beim Obersetzen Sinn verloren geht", in: Slavistische Linguistik 1987, München 1988, 297-347.

RAECKE, J. (1989) „Gesprochene Sprache - Dialekt - Dialektales Sprechen“, in: Gesprochene Sprache - Język mówiony. Bochumer Slavistische Beitrage Bd. 14. Bochum 1989, 130-161.

RAECKE, J. (1990) „'und den selbigen auf das maul sehen, wie sie reden'. Anmerkungen zum Prostore`ie bei Cechov und Suksin", in: Anton P. Cechov: Werk und Wirkung. Hrsg. R.-D. Kluge. Wiesbaden 1990, Teil II, 890-938.

RAECKE, J. (1992) „Grundfragen und Fragestellungen zur Geschichte der russischen Literatursprache (bei ISACENKO und USPENSKIJ)“, in: Slavistische Linguistik 1991, Müchen 1992, 251-264.

RAECKE, J. (1993) „Zu den moglichen Quellen einer Geschichte der (modernen) russischen iteratursprache", in: Slavistische Linguistik 1992, München 1993, 197-224. 
RAECKE, J. (1994) „Das 18. Jahrhundert im polnischen Satzbau", in: Slavistische Linguistik 1993, München 1994, 225-249.

RAECKE, J. (1997) „Zwischen Avvakum und Puß̌kin - oder: Ab wann könnte es eine Geschichte der russischen Literatursprache geben ?", in: Forschungen zur Linguistik und Poetik: Zum Andenken an Grigorij O. Vinokur. Hrsg. R. Belenschikow. Berlin 1997, 219-239.

REHDER, P. (1995) „Standardsprache. Versuch eines dreistufigen Modells“, in: Welt der Slawen 40 (1995), 352-366.

ROTHERMUND, D. (1994) Geschichte als Prozeß und Aussage. München.

ROZENTAL', D./ TELENKOVA. M. (1976) Практическая стилистика русското языка. Moskau.

RÜSEN, J. (Hsg.) (1975) Historische Objektivităt. Gơttingen.

RÜSEN, J. (1976) Für eine erneuerte Historik: Studien zur Theorie der Geschichtswissenschaft. Stuttgart.

SACHS, L. (1993) Statistische Methoden. Berlin.

SANDERS, W. (1973) Linguistische Stiltheorie. Göttingen.

SČRBA. L.V. (1957) Избранные работы по русскому языку. Moskau.

SCHEFE, P. (1975) Statistische syntaktische Analyse von Fachsprachen mit Hilfe elektronischer Rechenanlagen am Beispiel der medizinischen. betriebswirtschaftlichen und literaturwissenschaflichen Fachsprache im Deutschen. Göppingen.

SCHILLING. I. (1973) „Sachverhalte und Syntax beim Erwerb fachorientierter Fremdsprachenkenntnisse“. in: Deutsch als Fremdsprache 3 (1973), 176-182.

SCHLIEBEN-LANGE, B. (1983) Traditionen des Sprechens. Stuttgart.

SCHMID. W. / STÄHLIN, O. (1959) Geschichte der griechischen Literatur. Erster Teil: Die klassische Periode der griechischen Literatur. Erster Band: Die griechische Literatur vor der attischen Hegemonie. München.

SCHRÖDER. H. (1987) Aspekte sozialwissenschaftlicher Fachtexte. Hamburg.

SEITZ, E. (1998) Primus Truber - Schőpfer der slovenischen Schriftsprache ? München.

SENKEVIC. M.P. (1976) Стилистика научной речи и литературное редактирование научных произведений. Moskau. 
SOROKIN, Ju.S. (1966) "O задачах изучения лексики русского языка XVIII в.", in: Процессы формирования лексики русского литературного языка. Moskau, 7-34.

STIERLE, K. (1979) „Erfahrung und narrative Form - Bemerkungen zu ihrem Zusammenhang in Fiktion und Historiographie", in: KOCKA 1979, 85-118.

TERRAS, V. (1991) A History of Russian Literature. New York.

TOPOROV, V.N. (1995) "Бедная Лиза" Карамзина: Опьт прочтения. Moskau.

USPENSKIJ, В.A. (1985) Из истории русского литературного языка XVIII начала XIX века. Moskau.

VEYNE, P. (1990) Geschichtsschreibung - Und was sie nicht ist. Frankfurt/M.

VINOGRADOV, V.V. (1941) Стиль Пушкина. (Slavica-Reprint Nr. 26). Unverănderter fotomechanischer Nachdruck der Originalausgabe von 1941. Vaduz 1969.

VINOGRADOV, V.V. (1946) "Русская науха о руссхом литературном языхе", in: Ученые запискв МГУ, вып. 106, т. III, кв. 1.

VINOGRADOV, V.V. (1963) Стилистиха: теория поэтическиой речи поэтика. Moskau.

VOGT, J. (1990) Aspekte erzahlender Prosa: eine Einfuhrung in Erzahltechnik und Romantheorie. Opladen.

VOMPERSKIJ, V.P. (1970) Стилистическое учение М. В. Ломоносова и теория трех стилей. Moskau.

VOPROSY (1973): Вопросы романо-германского языхознания, вып. 4. Celjabinsk.

WEISS, D. (1989) „Parataxe und Hypotaxe: Versuch einer Skalarisierung“, in: Slavistische Linguistik 1988, Müchen 1989, 287-322.

WHITE, H. (1990) Die Bedeutung der Form: Erzahlstrukturen in der Geschichtsschreibung. Frankfurt/M. 


\section{ANHANG}

zu Parameter a: Verteilung der Satzlăngen nach geschlossenen und gleich großen Klassen

n = absolute Hăufigkeit der Sătze

$\%=$ prozentuale Hăufigkeit det Sătze

Lomonosov: Geschichtswerk

\begin{tabular}{|l|l|c|c|c|c|c|c|}
\hline $\begin{array}{l}\text { Nr. } \\
\text { der } \\
\text { Klasse }\end{array}$ & Klasse & $\begin{array}{c}\text { Text 1 } \\
\mathbf{n}\end{array}$ & $\begin{array}{c}\text { Text 1 } \\
\%\end{array}$ & $\begin{array}{c}\text { Text 2 } \\
\mathbf{n}\end{array}$ & $\begin{array}{c}\text { Text 2 } \\
\%\end{array}$ & $\begin{array}{c}\text { Text 3 } \\
\mathbf{n}\end{array}$ & $\begin{array}{c}\text { Text 3 } \\
\%\end{array}$ \\
\hline 1 & $0<\mathrm{x}<10$ & 1 & 4 & 15 & 14 & 17 & 13 \\
\hline 2 & $10<\mathrm{x}<20$ & 10 & 37 & 45 & 42 & 61 & 45 \\
\hline 3 & $20<\mathrm{x}<30$ & 10 & 37 & 24 & 23 & 40 & 30 \\
\hline 4 & $30<\mathrm{x}<40$ & 2 & 7 & 14 & 13 & 9 & 7 \\
\hline 5 & $40<\mathrm{x}<50$ & 1 & 4 & 4 & 4 & 5 & 4 \\
\hline 6 & $50<\mathrm{x}<60$ & 2 & 7 & 2 & 2 & 3 & 2 \\
\hline 7 & $60<\mathrm{x}<70$ & 0 & 0 & 1 & 1 & 0 & 0 \\
\hline 8 & $70<\mathrm{x}<80$ & 0 & 0 & 1 & 1 & 0 & 0 \\
\hline 9 & $80<\mathrm{x}<90$ & 0 & 0 & 0 & 0 & 0 & 0 \\
\hline 10 & $90<\mathrm{x}<100$ & 1 & 4 & 0 & 0 & 0 & 0 \\
\hline & Insgesamt & 27 & 100 & 106 & 100 & 135 & 101 \\
\hline
\end{tabular}

Karamzin: Geschichtswerk

Dichterisches

Werk

\begin{tabular}{|l|l|c|c|c|c|c|c||c|c|}
\hline $\begin{array}{l}\text { Nr. } \\
\text { der } \\
\text { Klasse }\end{array}$ & Klasse & $\begin{array}{c}\text { Text 1 } \\
\text { n }\end{array}$ & $\begin{array}{c}\text { Text 1 } \\
\%\end{array}$ & $\begin{array}{c}\text { Text 2 } \\
n\end{array}$ & $\begin{array}{c}\text { Text 2 } \\
\%\end{array}$ & $\begin{array}{c}\text { Text 3 } \\
n\end{array}$ & $\begin{array}{c}\text { Text 3 } \\
\%\end{array}$ & $\begin{array}{c}\text { Gesamt } \\
\text { n }\end{array}$ & $\begin{array}{l}\text { text } \\
\%\end{array}$ \\
\hline 1 & $0<x<10$ & 13 & 13 & 18 & 12 & 10 & 9 & 56 & 28 \\
\hline 2 & $10<x<20$ & 33 & 32 & 49 & 33 & 42 & 34 & 76 & 39 \\
\hline 3 & $20<x<30$ & 29 & 28 & 45 & 31 & 35 & 28 & 36 & 18 \\
\hline 4 & $30<x<40$ & 11 & 11 & 21 & 14 & 23 & 19 & 18 & 9 \\
\hline 5 & $40<x<50$ & 8 & 8 & 7 & 5 & 11 & 9 & 8 & 4 \\
\hline 6 & $50<x<60$ & 5 & 5 & 3 & 2 & 0 & 0 & 1 & 1 \\
\hline 7 & $60<x<70$ & 3 & 3 & 1 & 1 & 2 & 2 & 1 & 1 \\
\hline 8 & $70<x<80$ & 0 & 0 & 3 & 2 & 0 & 0 & 0 & 0 \\
\hline 9 & $80<x<90$ & 0 & 0 & 0 & 0 & 0 & 0 & 0 & 0 \\
\hline 10 & $90<x<100$ & 1 & 1 & 0 & 0 & 0 & 0 & 0 & 0 \\
\hline & Insgesamt & 103 & 101 & 147 & 100 & 123 & 101 & 196 & 100 \\
\hline
\end{tabular}




\section{Puškin : Geschichtswerk}

\begin{tabular}{|l|l|r|r|r|r|r|r|}
\hline $\begin{array}{l}\text { Nr. } \\
\text { der } \\
\text { Klasse }\end{array}$ & Klasse & $\begin{array}{c}\text { Text 1 } \\
\text { n }\end{array}$ & $\begin{array}{c}\text { Text 1 } \\
\%\end{array}$ & $\begin{array}{c}\text { Text 2 } \\
\text { n }\end{array}$ & $\begin{array}{c}\text { Text 2 } \\
\%\end{array}$ & $\begin{array}{c}\text { Text 3 } \\
\text { n }\end{array}$ & $\begin{array}{c}\text { Text 3 } \\
\%\end{array}$ \\
\hline 1 & $0<x<10$ & 35 & 33 & 66 & 39 & 128 & 41 \\
\hline 2 & $10<x<20$ & 38 & 36 & 75 & 44 & 116 & 38 \\
\hline 3 & $20<x<30$ & 24 & 22 & 20 & 12 & 48 & 16 \\
\hline 4 & $30<x<40$ & 5 & 5 & 7 & 4 & 11 & 4 \\
\hline 5 & $40<x<50$ & 4 & 4 & 2 & 1 & 3 & 1 \\
\hline 6 & $50<x<60$ & 1 & 1 & 0 & 0 & 1 & $0 !$ \\
\hline & Insgesamt & 107 & 101 & 170 & 100 & 307 & 100 \\
\hline
\end{tabular}

Pußkkin: Dichterisches Werk

\begin{tabular}{|l|l|r|r|r|r|r|r|}
\hline $\begin{array}{l}\text { Nr. } \\
\text { der } \\
\text { Klasse }\end{array}$ & Klasse & $\begin{array}{c}\text { Text 1 } \\
\text { n }\end{array}$ & $\begin{array}{c}\text { Text 1 } \\
\%\end{array}$ & $\begin{array}{c}\text { Text 2 } \\
\text { n }\end{array}$ & $\begin{array}{c}\text { Text 2 } \\
\%\end{array}$ & $\begin{array}{c}\text { Text 3 } \\
\text { n }\end{array}$ & $\begin{array}{c}\text { Text 3 } \\
\%\end{array}$ \\
\hline 1 & $0<x<10$ & 53 & 43 & 38 & 36 & 60 & 39 \\
\hline 2 & $10<x<20$ & 43 & 35 & 41 & 39 & 54 & 36 \\
\hline 3 & $20<x<30$ & 21 & 17 & 22 & 21 & 26 & 17 \\
\hline 4 & $30<x<40$ & 6 & 5 & 3 & 3 & 6 & 4 \\
\hline 5 & $40<x<50$ & 1 & 1 & 2 & 2 & 3 & 2 \\
\hline 6 & $50<x<60$ & 0 & 0 & 0 & 0 & 2 & 1 \\
\hline 7 & $60<x<70$ & 0 & 0 & 0 & 0 & 1 & 1 \\
\hline & Insgesam & 124 & 101 & 106 & 101 & 152 & 100 \\
\hline
\end{tabular}




\section{ANHANG}

zu Parameter b: Art der Nebensătze

Lomonosov - Geschichtswerk

Relativsatze:

$\begin{array}{lll}\text { Text } 1 & \text { Text } 2 & \text { Text } 3\end{array}$

\begin{tabular}{lccc} 
который & 5 & 15 & 13 \\
кто & 1 & 0 & 1 \\
какой & 2 & 0 & 0 \\
тот & 1 & 0 & 0 \\
что & 1 & 2 & 1 \\
кое & 1 & 3 & 2 \\
\hline & 11 & 20 & 17 \\
rде & 2 & 2 & 3
\end{tabular}

unterordnende Konjuntationen:

Objekt-/ Subjektsiltze:

\begin{tabular}{lrrr} 
что & 3 & 21 & 15 \\
чтобы & 0 & 6 & 1 \\
дабы & 0 & 1 & 0 \\
\hline & 3 & 28 & 16
\end{tabular}

Adverbialastze:

\begin{tabular}{|c|c|c|c|}
\hline final: & $\begin{array}{l}\text { дабы } \\
\text { чтобы }\end{array}$ & $\begin{array}{l}1 \\
0\end{array}$ & $\begin{array}{l}1 \\
0\end{array}$ \\
\hline kausal: & $\begin{array}{l}\text { ибо } \\
\text { почему } \\
\text { что }\end{array}$ & $\begin{array}{l}0 \\
0 \\
0\end{array}$ & $\begin{array}{l}1 \\
1 \\
1\end{array}$ \\
\hline konditional: & $\begin{array}{l}\text { ехели } \\
\text { если } \\
\text { когда } \\
\text { буде }\end{array}$ & $\begin{array}{l}1 \\
0 \\
1 \\
0\end{array}$ & $\begin{array}{l}0 \\
1 \\
3 \\
0\end{array}$ \\
\hline konsekutiv: & $\begin{array}{l}\text { что } \\
\text { чтобW }\end{array}$ & $\begin{array}{l}2 \\
1\end{array}$ & $\begin{array}{l}1 \\
0\end{array}$ \\
\hline konzessiv: & xотя & 0 & 8 \\
\hline modal: & $\begin{array}{l}\text { как } \\
\text { коль } \\
\text { нехели }\end{array}$ & $\begin{array}{l}1 \\
1 \\
0\end{array}$ & $\begin{array}{l}1 \\
1 \\
1\end{array}$ \\
\hline temporal: & $\begin{array}{l}\text { когда } \\
\text { xax }\end{array}$ & $\begin{array}{l}1 \\
0\end{array}$ & $\begin{array}{l}2 \\
0\end{array}$ \\
\hline
\end{tabular}


Karamzin - Geschichtswerk

\section{$\begin{array}{lll}\text { Text } 1 & \text { Text } 2 & \text { Text } 3\end{array}$}

Relativsitze:

\begin{tabular}{lrrr} 
который & 10 & 11 & 9 \\
кое & 4 & 10 & 1 \\
чтО & 8 & 1 & 0 \\
\hline & 22 & 22 & 10
\end{tabular}

$\begin{array}{llll}\text { где } & 8 & 3 & 7 \\ \text { куда } & 0 & 1 & 0\end{array}$

unterordnende Konjunktionen:

Objektsătze:

$\begin{array}{lrrr}\text { 4TO } & 14 & 36 & 20 \\ \text { 4TO6b } & 0 & 2 & 0 \\ & 14 & 38 & 20\end{array}$

Adverbiaksatze:

final

$\begin{array}{llll}\text { дабы } & 1 & 0 & 0 \\ \text { чтобы } & 4 & 2 & 7\end{array}$

kausal:

$\begin{array}{ll}\text { ибо } & 5 \\ \text { почему } & 0 \\ \text { что } & 0 \\ \text { для того, что } & 0\end{array}$

$\begin{array}{ll}8 & 5 \\ 1 & 0 \\ 0 & 1 \\ 1 & 0\end{array}$

konditional:

$\begin{array}{lrll}\text { ежели } & 0 & 2 & 0 \\ \text { если } & 10 & 1 & 1 \\ \text { когда } & 3 & 0 & 0\end{array}$

konsekutiv: $\quad$..., что $\quad 1 \quad 2$

konzessiv: $\quad$ xoтr $\quad 0 \quad 2 \quad 3$

$\begin{array}{lllll}\text { modal: } & \text { как } & 2 & 3 & 3 \\ & \text { сколь } & 1 & 0 & 0\end{array}$

temporal: $\quad$ когда $\quad 2 \quad 3 \quad 3$

Karamzin - Dichterisches Werk

Relativsatze:

который

кахой

पTQ

33
Objekt-/ Subjektsătze:

\begin{tabular}{lr} 
что & 20 \\
чтобы & 1 \\
rge & 1 \\
\hline
\end{tabular}


Adverbistaxtze:

\begin{tabular}{|c|c|c|c|c|}
\hline final: & чтобы & 4 & konsekutiv: & पTO \\
\hline \multirow[t]{3}{*}{ kausal: } & и6о & 3 & modal: & Kak \\
\hline & $\begin{array}{l}\text { потому что } \\
\text { для того, что }\end{array}$ & $\begin{array}{l}2 \\
2\end{array}$ & & схоль \\
\hline & & & temporal: & когда \\
\hline konditional: & если & 1 & & $\begin{array}{l}\text { ках } \\
\text { прежде нехели }\end{array}$ \\
\hline
\end{tabular}

Puskin - Geschichtswerk

\section{Relativsitze:}

$\begin{array}{lllr}\text { который } & 1 & 1 & 7 \\ \text { кое } & 1 & 1 & 3 \\ \text { КTе } & 0 & 1 & 0 \\ & 2 & 3 & 10\end{array}$

$\begin{array}{lllr}\text { где } & 7 & 2 & 12 \\ \text { (от)куда } & 0 & 0 & 3\end{array}$

unterordnende Konjunktionen:

Objekt-/ Subjektsintze:

\begin{tabular}{lrrr} 
что & 2 & 10 & 19 \\
чтобы & 0 & 1 & 3 \\
где & 0 & 1 & 0 \\
как & 0 & 0 & 1 \\
который & 0 & 0 & 1 \\
кте & 0 & 0 & 1 \\
\hline & 2 & 12 & 25
\end{tabular}

Adverbialsatze:

$\begin{array}{lllll}\text { final: } & \begin{array}{l}\text { дабы } \\ \text { чтоб(ы) }\end{array} & 2 & 2 & 5 \\ & & 2 & 0 & 1 \\ \text { modal: } & \text { как } & 0 & 0 & 1 \\ \text { temporal: } & \text { когда } & 0 & 0 & 1 \\ & \text { как } & 0 & 0 & 1 \\ & \text { пока } & 0 & 0 & 1\end{array}$


Pu§kin - Dichterisches Werk

\begin{tabular}{|c|c|c|c|}
\hline \multirow{2}{*}{$\begin{array}{l}\text { Relativsătze: } \\
\text { который }\end{array}$} & Text 1 & Text 2 & Text 3 \\
\hline & 9 & 11 & 12 \\
\hline xoe & 0 & 1 & 1 \\
\hline 4T0 & 3 & 2 & 4 \\
\hline & 12 & 14 & 17 \\
\hline где & 2 & 0 & 1 \\
\hline
\end{tabular}

unterordnende Konjuntaionen:

Objekt-/ Subjektsatze:

\begin{tabular}{lcrr} 
что & 12 & 14 & 34 \\
чтобы & 0 & 0 & 4 \\
будто & 0 & 1 & 1 \\
который & 0 & 0 & 1 \\
Какой & 0 & 0 & 1 \\
КтО & 0 & 0 & 1 \\
\hline
\end{tabular}

Adverbiaksitze:

$\begin{array}{lllll}\text { final: } & \text { дабы } & 0 & 2 & 2 \\ & \text { чтоб } & 1 & 2 & 0 \\ \text { kausal: } & & & & \\ & \text { пбо } & 0 & 0 & 1 \\ & \text { потому что } & 0 & 2 & 1 \\ & \text { оттого что } & 0 & 0 & 2 \\ & \text { как } & 1 & 1 & 0\end{array}$

\begin{tabular}{|c|c|c|c|}
\hline konditional: & если & 3 & 2 \\
\hline & когда & 0 & 0 \\
\hline konsekutiv: & что & 2 & 1 \\
\hline konzessiv: & xотя & 1 & 1 \\
\hline modal: & Kax & 3 & 1 \\
\hline temporal: & $\begin{array}{l}\text { когда } \\
\text { как } \\
\text { пока } \\
\text { прежде чем }\end{array}$ & $\begin{array}{l}2 \\
1 \\
1 \\
0\end{array}$ & $\begin{array}{l}2 \\
1 \\
0 \\
1\end{array}$ \\
\hline
\end{tabular}


Zusammenfassung: Verteilung der Nebensătze in den Geschichtswerken

\section{Lomonosov}

T1 $\quad$ T2 $\quad$ T3
Karamzin

$\begin{array}{lll}\text { T1 } & \text { T2 } & \text { T3 }\end{array}$

Relativantze:

lokale RS:

2

sonstige RS:

$11 \quad 20 \quad 17$

Objekt-/ Subjektsutze:

$8 \quad 4 \quad 7$

$\begin{array}{lll}22 & 22 & 10\end{array}$

$14 \quad 38 \quad 20$

Pułkin

$\begin{array}{lll}\text { T1 } & \text { T2 } & \text { T3 }\end{array}$

$7 \quad 2 \quad 15$

2310

$\begin{array}{lll}14 & 38 & 20\end{array}$

$2 \quad 12$

25

Adverbiakntze:

tinal:

kausal:

$\begin{array}{lllllllll}1 & 1 & 10 & 5 & 2 & 7 & 4 & 2 & 6\end{array}$

konditional:

$\begin{array}{llllll}5 & 10 & 6 & 0 & 0 & 0\end{array}$

konsekutiv:

$\begin{array}{llllll}13 & 3 & 1 & 0 & 0 & 0\end{array}$

konzessiv:

$\begin{array}{llllll}1 & 2 & 1 & 0 & 0 & 0\end{array}$

modal:

$\begin{array}{lllllllll}0 & 8 & 4 & 0 & 2 & 3 & 0 & 0 & 0\end{array}$

temporal:

\begin{tabular}{ccccccccc}
1 & 2 & 1 & 2 & 3 & 3 & 0 & 0 & 3 \\
\hline 24 & 72 & 62 & 73 & 89 & 61 & 15 & 19 & 60
\end{tabular}

Bei der Verteilung der Adverbialsatze zeichnet sich keinerlei Regelmäßigkeit oder Tendenz ab. Jedoch laßt sich bei Puskkin ein starkes Zunücktreten der Adverbialsätze feststellen.

Bezogen auf die Gesamtzahl der Nebensătze ergeben sich folgende Anteile:

Relativsintze:

lokale RS:

$$
\begin{array}{lllllllll}
8 \% & 3 \% & 5 \% & 11 \% & 4 \% & 11 \% & 47 \% & 11 \% & 25 \%
\end{array}
$$

sonstige RS:

$$
\begin{array}{llllllllll}
46 \% & 28 \% & 27 \% & 30 \% & 25 \% & 16 \% & 13 \% & 16 \% & 17 \%
\end{array}
$$

Objekt-/ Subjektantoe:

$$
\begin{array}{lllllllll}
13 \% & 39 \% & 26 \% & 19 \% & 43 \% & 33 \% & 13 \% & 63 \% & 42 \%
\end{array}
$$

Adverbiakstac:

$\begin{array}{llllllllll}33 \% & 31 \% & 42 \% & 40 \% & 28 \% & 39 \% & 27 \% & 11 \% & 17 \%\end{array}$ 
Lediglich die lokalen Relativsatze bei Lomonosov sowie die sonstigen Relativsätze bei Puskin bleiben in einem 5\%-Intervall. Bei allen anderen Nebensatzarten liegen die einzelnen Werte zu weit auseinander, als daß eine Regelmäßigkeit erkennbar wäre.

\section{Semantische Auswertung:}

Die verschiedenen Nebensatzarten sind ăußerst unregelmaßig verteilt. Der historiographische Stil zeigt in dieser Hinsicht keine Einheitlichkeit. Was die lokalen Relativsătze anbelangt, so kann man immerhin noch einwenden, daß die Bestimmung der Lokalităt auch durch andere explizite Ortsangaben erfolgt; das gleiche gilt fur die Angaben zu den Personen. Ähnlich laß̉ sich auch die geringe Anzahl an temporalen Nebensătzen erklăren. Auch hier würde man in einem Geschichtswerk doch einen höheren Anteil erwarten; $z u$ beobachten sind aber nur Einsprengsel. Die fehlenden Kausalsătze verwundern hingegen doch einigermaßen. Wohl wurde (unter 2.6.1) auf die satzübergreifenden Kausalitătsbezüge hingewiesen, aber wir erwarteten doch einen höheren Anteil an expliziten Kausalbezügen. Da aber Puskin in seinen Texten keinen einzigen Kausalsatz verwendet, wird klar, welche bedeutende Rolle die nicht-explizite Kausalbeziehung in der Geschichtsschreibung spiett. Wie ROTHERMUND $(1994,44)$ bemerkte, bedarf der Leser gar nicht des expliziten Hinweises auf die Kausalbeziehung, da die 'lineare Kausalitắtsvermutung' hier eingreift. Auch die zahlreiche Verwendung der adverbialen Partizipialsătze beweist, daß es gar nicht nötig ist, syntaktisch explizit auf die Art der Beziehung zwischen Partizip und Hauptprádikat hinzuweisen, da in der Regel dem Leser die Beziehung ausreichend klar wird.

Die Parataxe des historiographischen Stiles oder anders betrachtet die Erzählung ist demnach nichts anderes als die Anreihung von Ursache - Folge = neue Ursache Folge, d.h. die Parataxe der Geschichtsschreibung stelt die Anreihung von Kausalketten dar; das zugrunde liegende Ordnungsprinzip ist nahezu ausschlieBiich die Kausalităi. 


\section{ANHANG}

zu Parameter d: Wortartenanteil der Nomina

Es werden die Nomina (Substantive und Adjektive) gezahht; dabei werden rein morphologische Kriterien zugrundegelegt, d.h. diese Zahlen kơnnen unmittelbar mit den Werten aus anderen Untersuchungen verglichen werden.

Absolut ergeben sich folgende Verteilungen:

$$
\text { Substantive : Adjektive Substantive : Adjektive }
$$

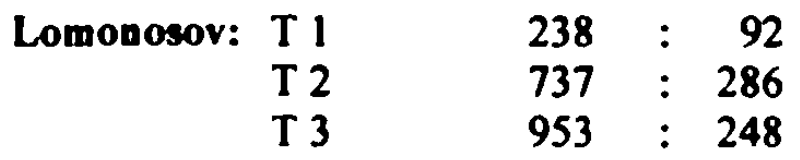

$\begin{array}{lrrrrrr}\text { Karamzin: } & \text { T 1 } & 908 & : 290 & \text { T ges } 877 & : 284 \\ & \text { T 2 } & 1158 & : 453 & & & \\ & \text { T 3 } & 1079 & : 291 & & & \\ \text { Pułkin: } & & & & & & \\ & \text { T 1 } & 577 & : 184 & 436 & : 91 \\ & \text { T 2 } & 724 & : 141 & 468 & : 102 \\ & \text { T 3 } & 1379 & : 259 & 640 & : 165\end{array}$

Daraus folgt das prozentuale Verhaltnis von Substantiv zu Adjektiv:

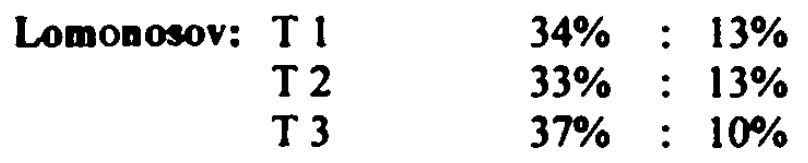

\begin{tabular}{|c|c|c|c|c|c|c|}
\hline Karamzin: & $\begin{array}{ll}\text { T } & 1 \\
\text { T } 2 \\
\text { T } 3\end{array}$ & $\begin{array}{l}35 \% \\
34 \% \\
37 \%\end{array}$ & $\begin{array}{l}: 11 \% \\
: 13 \% \\
: 10 \%\end{array}$ & Tges & $26 \%$ & \\
\hline Pułkin: & $\begin{array}{ll}\text { T } & 1 \\
\text { T } 2 \\
\text { T } 3\end{array}$ & $\begin{array}{l}35 \% \\
32 \% \\
34 \%\end{array}$ & $\begin{array}{r}: \quad 11 \% \\
: \quad 6 \% \\
: \quad 7 \%\end{array}$ & & $\begin{array}{l}27 \% \\
31 \% \\
29 \%\end{array}$ & \\
\hline
\end{tabular}


Summe der Nomina (absolut):

Geschichtswerk Dichterisches Werk

Lomonosov: T 1330

T 21023

T 31201

Karamzin: T $11198 \quad$ Tges 1161

T $2 \quad 1611$

T 31370

Pußkin: $\quad$ T $1 \quad 761 \quad 527$

T $2865 \quad 570$

$\begin{array}{lll}\text { T } 3 & 1638 & 805\end{array}$

Summe det Nomina (prozentual):

Lomonosov: T $147 \%$

T $246 \%$

T $347 \%$

Karamzin: $\quad$ T $1 \quad 46 \% \quad$ Tges $35 \%$

T $247 \%$

T $347 \%$

$\begin{array}{llll}\text { Puskin: } & \text { T } 1 & 46 \% & 33 \%\end{array}$

$\begin{array}{lll}\text { T } 2 & 39 \% & 38 \%\end{array}$

T $341 \% \quad 36 \%$

Mittehwerte:

Lomonosov: $\quad 46 \%$

Karamzin: $\quad 47 \% \quad 35 \%$

$\begin{array}{lll}\text { Pułkin: } & 41 \% & 35 \%\end{array}$ 